EDUARDO VICTOR DOS SANTOS POUZADA

\title{
ESTUDO DA APLICAÇÃO DO MÉTODO DOS ELEMENTOS DE CONTORNO À ANÁLISE DE PROPAGAÇÃO EM ESTRUTURAS GUIANTES
}

Documento baseado na Tese apresentada à Escola Politécnica da Universidade de São Paulo para obtenção do título de Doutor em Engenharia. 
EDUARDO VICTOR DOS SANTOS POUZADA

\section{ESTUDO DA APLICAÇÃO DO MÉTODO DOS ELEMENTOS DE CONTORNO À ANÁLISE DE PROPAGAÇÃO EM ESTRUTURAS GUIANTES}

Documento baseado na Tese apresentada à Escola Politécnica da Universidade de São Paulo para obtenção do título de Doutor em Engenharia.

Área de Concentração:

Engenharia Elétrica

Orientador:

Prof. Dr. Jorge Mieczyslaw Janiszewski 
A.M.D.G. 


\section{N O T A}

Esta edição contempla a correção de pequenos erros e as alterações sugeridas pela Banca Examinadora que aprovou este trabalho, constituída pelos senhores:

- Prof. Dr. José Roberto Cardoso, L.D.;

- Prof. Dr. Amílcar Careli César, L.D.;

- Prof ${ }^{\mathrm{a}}$. Dra. Denise Consonni;

- Prof. Dr. Jorge Mieczyslaw Janiszewski, L.D., (Presidente);

- Prof. Dr. Rui Fragassi Souza. 


\section{A G R A D E C I M E N T OS}

Ao Prof. Dr. Jorge Mieczyslaw Janiszewski, amigo e orientador, pelo incansável apoio e disponibilidade sempre dispensados.

À Escola de Engenharia Mauá do Instituto Mauá de Tecnologia, pelo apoio ao longo de vários anos.

À minha esposa, Olinda, pelo amor, paciência e ajuda.

A meus pais e sogros, pelo amor, compreensão e incentivo.

Ao Sr. Artur Selmikaitis, Sra. Paulina F. L. Cardoso e Srta. Sandra M. Timotheo, do Departamento de Engenharia Elétrica da Escola de Engenharia Mauá pela ajuda.

A todos aqueles que direta ou indiretamente colaboraram na execução deste trabalho. 


\section{SUMÁRIO}

Lista de tabelas

Lista de figuras

Resumo

"Abstract"

1 INTRODUÇÃO

2 REVISÃO BIBLIOGRÁFICA

3 FORMULAÇÃO INTEGRAL DE CONTORNO

3.1 Generalidades

3.2 Método dos Resíduos Ponderados

3.3 Formulação Fraca

3.4 Classificação de Soluções

3.5 A Solução Fundamental

3.6 A Equação Integral de Contorno

3.7 Equação de Helmholtz: solução fundamental

3.8 Equação de Helmholtz: equação integral de contorno

3.9 Perdas em meios materiais

\section{O MÉTODO DOS ELEMENTOS DE CONTORNO}

4.1 Generalidades

4.2 Discretização do Contorno

4.3 Obtenção do sistema de equações algébricas

4.4 Formulação com elementos constantes

4.5 Formulação com elementos lineares

4.6 Tratamento de cantos da geometria

\section{IMPLEMENTAÇÃO}

5.1 Metodologia básica 


\section{APLICAÇÃO}

6.1 Linha de transmissão bifilar $\quad 6.1$

$\begin{array}{ll}6.2 \text { Stripline } & 6.10\end{array}$

6.3 Guia de onda homogêneo $\quad 6.16$

$\begin{array}{ll}\text { 6.3.1 Guia retangular } & 6.16\end{array}$

$\begin{array}{ll}\text { 6.3.2 Guia circular } & 6.23\end{array}$

$\begin{array}{ll}6.4 \text { Perdas } & 6.25\end{array}$

6.5 Guia de onda com ressalto (Ridged Waveguide) 6.28

$\begin{array}{ll}6.6 \text { Guia de onda parcialmente carregado } & 6.32\end{array}$

$\begin{array}{ll}\text { 7. CONCLUSÕES } & 7.1\end{array}$ 


\section{LISTA DE FIGURAS}

3.1 Aplicação da função impulsiva sobre o contorno $\Gamma$

3.2 Condução do ponto $i$ ao contorno por um processo de limite 3.17

3.3 Ponto de aplicação sobre região suave do contorno 3.18

3.4 Ponto de aplicação sobre região de contorno descontínuo 3.19

3.5 Medição do ângulo interno em região de contorno descontínuo 3.20

4.1 Elementos constantes $\quad 4.4$

4.2 Elementos lineares 4.4

4.3 Elementos quadráticos $\quad 4.5$

4.4 Elementos constantes. Relação entre o sistema de coordenadas global, local e o valor nodal $\quad 4.7$

4.5 Elementos lineares. Relação entre o sistema de coordenadas global, local e o valor nodal

4.6 Elementos quadráticos. Relação entre o sistema de coordenadas global, $\begin{array}{ll}\text { local e o valor nodal } & 4.8\end{array}$

4.7 O ponto $i$ não pertence ao elemento sobre o qual se efetua a integração 4.12

4.8 O ponto $i$ pertence ao elemento sobre o qual se efetua a integração 4.13

4.9 Integração ao longo do elemento no qual é aplicada a excitação 4.14

4.10 Coordenadas locais aplicadas ao elemento $i$ de comprimento $l \quad 4.15$

4.11 Ilustração do conceito de variação linear do potencial 4.19

4.12 Ilustração do conceito de variação linear da derivada normal $\begin{array}{ll}\text { do potencial e sua descontinuidade } & 4.19\end{array}$

4.13 (a) ponto de aplicação no início do elemento; (b) ponto de aplicação no fim do elemento

4.14 Ponto de aplicação no ínicio do elemento $\quad 4.24$

4.15 Ponto de aplicação no fim do elemento 4.25

4.16 Arredondamento de canto de contorno 4.26

4.17 Elemento descontínuo linear $\quad 4.27$

4.18 O valor da função ao longo do elemento é obtido por interpolação ou extrapolação $\left(-1 \leq \xi<\xi_{\mathrm{a}}\right.$ ou $\left.\xi_{\mathrm{b}}<\xi \leq+1\right)$ 
5.1 Diagrama de fluxo básico $\quad 5.2$

5.2 Secção transversal de guia de onda retangular $\quad 5.3$

5.3 Domínio $\Omega_{1}$ fechado, simplesmente conexo $\quad 5.5$

5.4 Geometria de domínio fechado, não simplesmente conexo 5.6

$\begin{array}{ll}5.5 \text { Discretização geométrica } & 5.7\end{array}$

$\begin{array}{ll}5.6 \text { Geometria com três domínios } & 5.7\end{array}$

5.7 Geometria com buraco; quatro elementos no contorno interno e quatro $\begin{array}{ll}\text { elementos no contorno externo } & 5.8\end{array}$

5.8 Fragmento do arquivo de entrada para a geometria da figura 5.7 5.9

5.9 Geometria com interface $\quad 5.9$

5.10 Fragmento do arquivo de entrada para a geometria da figura 5.9 5.10

$\begin{array}{ll}5.11 \text { Problema de eletrodinâmica; valores no contorno } & 5.12\end{array}$

5.12 Descrição dos seis primeiros nós (e seis primeiros elementos) da figura 5.11 (geometria e condições de contorno) 5.12

5.13 Designação genérica dos dados de entrada 5.13

5.14 Fragmento de descrição para formulação linear $\quad 5.14$

5.15 Caracterização da descrição dos vários domínios $\quad 5.16$

5.16 Detalhamento das ações referidas naa figura 5.15 5.17

$\begin{array}{ll}5.17 \text { Indexação de elementos de fronteira } & 5.18\end{array}$

5.18 Montagem de vetores de código e de valor $\quad 5.20$

$\begin{array}{ll}5.19 \text { Sub-tarefas ligadas às interfaces } & 5.21\end{array}$

5.20 Geometria com três meios materiais distintos $\quad 5.22$

5.21 Representação genérica de quatro submatrizes relacionadas às interfaces $\quad 5.28$

5.22 Diagrama para montagem de $\left[\mathrm{H}_{\text {auto }}\right]$ e $\left[\mathrm{G}_{\text {auto }}\right] \quad 5.29$

5.23 Diagrama para montagem de $\left[\mathrm{H}_{\text {interfc }}\right] \quad 5.30$

5.24 Contagem do número de intersecções para localizar $\mathrm{P}_{\text {aplic }}$

$\begin{array}{ll}5.25 \text { Situação patológica a ser evitada } & 5.33\end{array}$

5.26 Detecção de ocorrências de intersecções válidas $\quad 5.35$

5.27 Cálculo do ângulo interno $\quad 5.38$

$\begin{array}{ll}\text { 5.28 Localização de } \mathrm{P}_{\text {aplic }} & 5.39\end{array}$ 
5.30 Cálculo do potencial devido ao modo de ressonância excitado 5.46

6.1 Linha bifilar infinita, mergulhada num meio homogêneo 6.2

6.2 Discretização da linha bifilar. $\mathrm{D}=2 \mathrm{~h}=10 \mathrm{~mm} ; \mathrm{d}=2 \mathrm{r}=1,6308 \mathrm{~mm}$

6.3 Variação do potencial ao longo de segmento paralelo ao eixo $\mathrm{x}(\mathrm{y}=1,5$ $\mathrm{mm}$ ) para a geometria da figura 6.2; oito elementos por condutor

6.4 Variação do potencial ao longo de segmento paralelo ao eixo $\mathrm{x}(\mathrm{y}=1,5$ $\mathrm{mm}$ ) para a geometria da figura 6.2; dezesseis elementos por condutor

6.5 Distribuição do potencial próximo ao condutor $(3 \mathrm{~mm} \leq \mathrm{x} \leq 7 \mathrm{~mm}$; $-2 \mathrm{~mm} \leq \mathrm{y} \leq 2 \mathrm{~mm})$

6.6 Distribuição do potencial $(0 \leq \mathrm{x} \leq 4 \mathrm{~mm} ;-4 \mathrm{~mm} \leq \mathrm{y} \leq 4 \mathrm{~mm})$

6.7 Linhas equipotenciais $(-7 \mathrm{~mm} \leq \mathrm{x} \leq 7 \mathrm{~mm} ;-3 \mathrm{~mm} \leq \mathrm{y} \leq 3 \mathrm{~mm})$

$\begin{array}{ll}\text { 6.8 Configuração de linha stripline } & 6.11\end{array}$

$\begin{array}{ll}6.9 \text { Stripline discretizada } & 6.12\end{array}$

6.10 Capacitância total normalizada; $t / b=0,1 ; b=1 \mathrm{~m}$

6.11 Capacitância total normalizada; $w=1 \mathrm{~m} ; b=1 \mathrm{~m}$. 6.15

6.12 Valores de $q$ nos nós de função $\quad 6.16$

$\begin{array}{ll}6.13 \text { Secção transversal de guia retangular } & 6.17\end{array}$

6.14 Comportamento do determinante na discretizacão 1

6.15 Comportamento do determinante na discretizacão 2

6.16 Comportamento do determinante na discretizacão 3

6.17 Configuração de campo magnético para o modo $\mathrm{TE}_{10}$

6.18 Configuração de campo magnético para o modo $\mathrm{TE}_{20}$

6.19 Configuração de campo magnético para o modo $\mathrm{TE}_{21}$

6.20 Incidência de campo em região com perdas $(x \geq 0)$

$\begin{array}{ll}6.21 \text { Geometria do meio dissipativo } & 6.26\end{array}$

6.22 Valores do fasor de campo em meio dissipativo $\quad 6.27$

6.23 Geometria de um guia com ressalto duplo $\quad 6.28$

$\begin{array}{ll}6.24 \text { Geometria discretizada típica } & 6.29\end{array}$

6.25 Guias de onda com ressalto duplo; $a=2 b \quad 6.30$

6.26 Comprimento de onda de corte para guias com ressalto duplo; $a=2 b \quad 6.30$ 
6.27 Comprimento de onda de corte do primeiro modo para guias com ressalto duplo, obtido pelo MEC; $a=2 b$

6.28 Largura de faixa de guias de onda com ressalto duplo

6.29 Largura de faixa de guias com ressalto duplo, referenciado em (BALANIS,1989)

6.30 Guia parcialmente preenchido

6.31 Discretização do guia

6.33

6.32 Varredura no guia parcialmente preenchido

6.34

6.33 Freqüência de corte em função da constante dielétrica

6.35 


\section{LISTA DE TABELAS}

5.1 Atributos de nós geométricos usados no arquivo de entrada

5.2 Fixação de condições de contorno nos eletrodos

6.1 Resultados nos elementos da geometria da figura 6.2

6.4

6.2 Resultado em estrutura stripline com variação da largura da fita

6.3 Resultado em estrutura stripline com variação da espessura da fita

6.4 Frequiências de corte de guia retangular ( $\mathrm{a}=30 \mathrm{~mm} ; \mathrm{b}=10 \mathrm{~mm})$

6.17

6.5 Discretizações realizadas

6.18

6.6 Resultados de $\mathrm{f}_{\mathrm{c}}$ com três discretizações

6.20

6.7 Resultados com três discretizações (formulação linear)

6.8 Frequiência de corte do modo $\mathrm{TM}_{21}$

6.23

6.9 Freqüência de corte de guia circular $(\mathrm{a}=2 \mathrm{~cm})$

6.10 Freqüências de corte obtidas com formulação constante

6.11 Frequiências de corte obtidas com formulação linear

6.25

6.12 Alguns valores obtidos do gráfico da figura 6.25 


\section{R E S U M O}

O presente trabalho objetiva um estudo de aplicação do Método dos Elementos de Contorno à análise de problemas de propagação de ondas eletromagnéticas. O Método baseia-se numa formulação integral que elimina todas as operações de integração em domínio, restando apenas as de contorno.

Inicialmente faz-se um estudo dos fundamentos teóricos do método, apresentando-o de forma genérica e encaminhando sua aplicação à equação de Helmholtz.

Os procedimentos computacionais desenvolvidos para a implementação do método viabilizam a solução eficiente de problemas de interesse, envolvendo diferentes meios com ou sem perdas.

São apresentados resultados de simulações realizadas que confirmam a aplicabilidade do método, permitindo também uma análise de seu desempenho através da variação de parâmetros, como, por exemplo, número de elementos na discretização e função de interpolação. 


\begin{abstract}
A B S T R A C T
This work deals with a study of application of the Boundary Element Method (BEM) directed to electromagnetic guided wave propagation. This method relies on an integral formulation that does not need any domain integration. Only boundary integrations have to be performed.
\end{abstract}

The work begins with a study of the theoretical foundations of the method, presenting its general formulation and then directing it to Helmholtz's equation solution.

Developed computational procedures allow efficient application of the method to real problems with more than one medium, with or without losses.

Simulations results are presented which confirm the applicability of the method and allow the analysis of its performance through parameters variation as, for example, the number of discretized elements and interpolation function. 


\section{Introdução}

Este trabalho tem por objetivo um estudo de aplicação do Método dos Elementos de Contorno à análise de problemas de propagação de ondas eletromagnéticas guiadas.

Para este fim foram desenvolvidas ferramentas computacionais, baseadas no método, que permitiram sua aplicação a problemas bidimensionais.

No mundo atual e desde que se iniciou a Revolução Industrial, a Engenharia sempre foi desafiada a apresentar soluções cada vez mais rápidas, com qualidade, de problemas, por sua vez, também cada vez mais complexos. Esta constatação nunca fez distinção entre os ramos da Engenharia, atingindo a todos. A solução analítica desses problemas complexos nem sempre é possível, sendo, então, exigida a aplicação de métodos numéricos. A popularização e difusão do uso de computadores, associada, evidentemente, aos avanços das técnicas numéricas, se estabeleceu como grande auxiliar neste aspecto; ficava mais barato e rápido analisar um modelo do que construir vários protótipos.

Na Engenharia Elétrica, alguns dos principais métodos numéricos utilizados são:

- Método das Diferenças Finitas (FD) e o Método das Diferenças Finitas no Domínio do Tempo (FDTD);

- Método dos Elementos Finitos (FEM);

- Método dos Elementos de Contorno (BEM);

- Método Matricial das Linhas de Transmissão (TLM). 
Todas estas técnicas podem ser vistas como versões particularizadas de uma abordagem bem mais geral - o Método dos Resíduos Ponderados - ou ainda o Método dos Momentos (MoM).

Cada método foi aplicado inicialmente em diferentes campos da Engenharia: FDTD e TLM 'nasceram' na Engenharia Elétrica; FEM e BEM 'nasceram' na Engenharia Mecânica e Civil. As distinções entre eles consistem na utilização de diferentes funções de ponderação e no número de integrações por partes efetuadas na equação que rege o problema.

Os métodos têm suas particularidades, porém, atualmente, todos apresentam extensões que dificultam a sua rigorosa classificação. Estas extensões apresentam-se como métodos híbridos que fazem uso das características vantajosas de cada um deles, nos aspectos em que se sobressaem. Suas particularidades podem tornar um certo método mais conveniente que outro para uma determinada situação.

Uma outra maneira de categorizá-los diz respeito à abordagem que pode ser: diferencial ou integral. Isto influi diretamente no tipo de discretização que é feita. Métodos diferenciais necessitam fazê-la em toda a região estudada. Outro parâmetro de classificação é o domínio relacionado à formulação do problema. Ele pode ser o domínio do tempo ou o domínio de freqüência.

O Método dos Elementos de Contorno (BEM), a partir daqui chamado pela sua sigla em português, MEC, é um método de formulação integral. Quando aplicado ao estudo de ondas eletromagnéticas é, em princípio, tomado no domínio de frequiência. 
$\mathrm{Na}$ Engenharia Elétrica, as estruturas de guiamento de ondas apresentam-se cada vez mais elaboradas, sendo comum a utilização de vários dielétricos. Sua análise é feita, às vezes, de modo simplificado devido à complexidade matemática ou à falta de soluções analíticas. Assuntos relacionados à otimização de projetos, como, por exemplo, excitação de um único modo numa estrutura, melhoria no acoplamento de sinais, interferência entre modos não podem ser equacionados plenamente pelo uso de aproximação quase-estática, o que ainda é comum. A melhoria da análise é sempre desejável e pode ser obtida por intermédio de métodos numéricos. O MEC é ainda pouco explorado neste campo, o que justifica o presente trabalho.

O Capítulo 2 apresenta uma pequena revisão bibliográfica relacionada ao desenvolvimento do Método dos Elementos de Contorno (MEC).

No Capítulo 3 são abordados os principais conceitos utilizados pelo método e apresentada sua formulação teórica. Segue-se o desenvolvimento de resultados que serão aplicados à solução da equação de Laplace e da equação de Helmholtz.

O Capítulo 4 mostra o desenvolvimento da aplicação do método em suas formulações com elementos constantes e elementos lineares.

O Capítulo 5 apresenta o desenvolvimento dos procedimentos computacionais correspondentes. 
No Capítulo 6 apresentam-se exemplos de aplicação visando validar o método e estudar seu desempenho.

No Capítulo 7 são apresentadas conclusões e propostas de trabalhos futuros. 


\section{Revisão bibliográfica}

O Método dos Elementos de Contorno com aplicações à Engenharia teve divulgação inicial bem definida em 1978, com a publicação de um livro (BREBBIA, 1978) alguns meses após o aparecimento dos dois primeiros artigos que sugeriam o esforço de desenvolvimento do método. Antes disso, o MEC, ainda não conhecido por este nome, era de domínio quase exclusivo de matemáticos e físicos.

A acolhida do método ocorreu principalmente nas áreas da Engenharia Civil e da Engenharia Mecânica. De certa forma isto permanece até hoje. É também interessante observar que, apesar do MEC apresentar-se como formulação alternativa ao Método dos Elementos Finitos, principalmente por causa do forte apelo que tem de necessitar discretizar apenas o contorno da região estudada, e, com isto abaixar a ordem da dimensão do problema, ele ainda não é tão utilizado quanto o FEM, mesmo decorridos aproximadamente duas décadas de sua "apresentação". O MEC conta há muitos anos com um centro de pesquisas, o Wessex Institute of Technology, fundado e até hoje dirigido pelo autor do livro acima mencionado, localizado em Southampton, Inglaterra, que atua como forte divulgador e patrocinador do assunto.

Até o presente, pesquisa bibliográfica relacionada ao assunto indica apenas uma Dissertação de Mestrado apresentada nesta Escola Politécnica (FRANCO, 1993) no Departamento de Engenharia de Estruturas e Fundações.

KAGAMI; FUKAI (1984) apresentaram um dos primeiros artigos dirigidos à comunidade de microondas a respeito do MEC, aplicado à equação de Helmholtz, 
exemplificando-o com um guia de planos paralelos. Os autores sugerem um modo estruturado de usar o MEC em regiões que apresentem interfaces (problema de multimeios) e mostram, finalmente, a possibilidade de cálculo de espalhamento de onda por um objeto dielétrico, iluminado por uma onda plana.

CHANG; TAN (1990) utilizaram o MEC para verificar a influência da espessura de metalização em linhas de microfita blindadas, usando a equação de Laplace e, portanto, analisando o problema na situação quase estática. A partir da formulação tradicional do MEC, obtiveram a distribuição de carga na microfita e calcularam os parâmetros globais impedância característica e permissividade efetiva.

Considerando que, em estruturas de microfita blindadas, a quantidade de elementos que discretizam a fita propriamente dita é muito menor que a quantidade que discretiza a porção restante da estrutura, CHANG; LIN (1993) propuseram alterar a solução fundamental da equação de Laplace no espaço livre, trocando-a por duas funções de Green, aplicadas separadamente nas regiões preenchidas com dielétrico e com ar. Estas novas funções satisfazem identicamente o potencial nulo na blindagem e, assim, o método permite que se discretize, para cada região, apenas a interface, com grande redução na dimensão das matrizes resultantes, se comparada ao método tradicional. Este tipo de abordagem foi generalizado em CHANG; SZE (1994) para permitir estudar estruturas de multi-camadas. Isto pôde ser obtido por usarem funções de Green que forçavam a continuidade do componente tangencial do campo elétrico nas interfaces. $\mathrm{O}$ método pode, então, ser aplicado também às linhas suspensas e a guias de onda coplanares. 
SWAMINATHAN (1990) et al. publicaram artigo referente ao cálculo do número de onda no corte para guias de onda metálicos sem perdas e secção transversal arbitrária; sua análise separava os modos TE e TM e se baseava na avaliação do campo espalhado pelo guia ao ser iluminado por uma onda incidente. A formulação aplicada utilizou o potencial vetorial magnético, e também o escalar (para os modos TE). A solução numérica foi obtida pelo Método dos Momentos, livre de soluções espúrias; seus resultados serviram de referência a outros trabalhos que se seguiram, talvez pelo fato de que tenha utilizado uma formulação integral, sendo necessária apenas a discretização do contorno.

COLLIN (1991) previa o crescente interesse no MEC na solução de problemas de autovalores, especialmente em guias nos quais a permissividade elétrica não varie longitudinalmente.

WANG et al. (1995) apresentaram o primeiro trabalho a associar o MEC a investigações do comportamento de microfitas com o uso de expansões em wavelets. Esta última abordagem isolada impunha severidade na forma dos condutores (infinitesimamente delgados); o MEC permitiu que fossem estudados condutores de secção transversal arbitrária inseridos em multi-camadas. Os resultados permitiam obter parâmetros globais, especificamente as matrizes de capacitância e indutância da estrutura.

Para estruturas em microfita, ATSUKI; LI (1995) propuseram algo mais abrangente que o trabalho inicial de CHANG; TAN (1990) ao utilizarem funções de Green específicas que satisfaziam as condições de contorno de uma parte relevante, mas não de toda a 
geometria estudada; isto permitia o cálculo do potencial em cada ponto da estrutura original circulando-se apenas a região subtraída desta última. No percurso associado é necessário o conhecimento da densidade de cargas sobre ele. Este procedimento de cálculo é, muito resumidamente, uma situação especial da formulação indireta do MEC. Os autores deram-lhe a denominação de Método Parcial dos Elementos de Contorno. O número de equações na discretização é reduzido consideravelmente, o que contribui para diminuir o tempo de CPU. Há, também, a vantagem de que as interfaces já estão automaticamente contempladas, o que é um ponto fraco na formulação tradicional, principalmente se comparado ao Método dos Elementos Finitos.

Um trabalho bastante complexo e inovador foi desenvolvido por DI NALLO et al. (1995) que apresentaram análise modal completa para guias dielétricos cilíndricos. Três pontos importantes são destacados: 1) Um pesado esforço analítico para contornar singularidades e obter as equações integrais (para campo elétrico e magnético) sob uma forma que não cause problemas numéricos quando implementada; 2) obter as equações integrais mantendo as operações de derivação apenas nas funções de Green, sem transferí-las para as incógnitas, o que, na solução numérica 3) permitiu abandonar o MEC tradicional (entendido como caso particular do Método dos Momentos) e efetuar as integrações por um método direto de quadratura, conhecido como método de Nystrom. A abordagem destes pesquisadores não pode ser aplicada diretamente às formulações tradicionais anteriores, mas seus resultados são encorajadores.

KAGAWA et al. (1996) estudaram a equação escalar de Helmholtz pelo MEC a partir de formulação variacional. Para evitar singularidades nas integrações, a solução 
fundamental é aplicada em pontos externos ao domínio em processo semelhante ao do método de simulação de cargas. O trabalho não trata da distribuição de campos nos guias, mas calcula os números de onda associados ao corte, usando a técnica de busca do determinante. Os modos espúrios são eliminados forçando-se a continuidade dos componentes tangenciais dos campos elétricos e magnéticos. Este artigo ampliou propostas de trabalho anterior de SONG; FU (1994) que procuravam diminuir ainda mais a quantidade de elementos usados na discretização, como conseqüência das fontes fictícias serem colocadas fora do domínio, eliminando, assim, as singularidades nas integrações.

O artigo de ABDULNOUR; MARCHILDON (1994) é um exemplo da utilização de métodos híbridos na análise de junções planares em guias de onda; ele aplica o MEC nas paredes metálicas, expansões modais nos guias e representações analíticas nas amostras dielétricas existentes na junção.

SAUVIAC et al. (1994) utilizaram o MEC no cálculo das frequiências de ressonâncias de cavidades metálicas retangulares e cilíndricas carregadas por ressoadores dielétricos. Os campos tangenciais na interface ar-dielétrico foram calculados a partir de funções diádicas de Green e da imposição das condições de contorno.

CHAO et al. (1995) obtiveram uma formulação integral de contorno visando o cálculo de espalhamento eletromagnético causado por formas geométricas arbitrárias. O estudo 
apresentado é significativamente complexo em relação ao tratamento das integrações e singularidades, mas tem como fruto o fato de que as geometrias podem deixar de ser discretizadas por elementos planares, melhorando a acuidade dos resultados.

O primeiro artigo a utilizar o MEC com análise de onda completa em estruturas de microfita, simples e acopladas, foi o de LIN; LEE (1996). Serviu para comparar os resultados obtidos com outros métodos: Diferenças Finitas, Domínio Espectral, Elementos Finitos (com formulações diversas), o que sinalizou a viabilidade do MEC. O trabalho estendeu-se também ao estudo de modos evanescentes. Foram obtidos valores da permissividade efetiva em função de freqüência e também da distribuição longitudinal e transversal de corrente. No entanto, permaneceram as hipóteses de meios sem perdas e dielétrico único. As estruturas multicamadas ainda estão sendo analisadas pela aproximação quase-TEM.

ARCIONI et al. (1997) discutem minimização do tempo de cálculo de integrais de superfície utilizadas por métodos integrais em três dimensões que utilizem funções de Green para os potenciais auxiliares escalar e vetorial, em formulações constantes e lineares. Em algumas situações, puderam chegar a resultados analíticos destas integrais.

Dois artigos recentes abordam analiticamente problemas relativos à determinação de autovalores em guias de onda não homogêneos (ROZZI et al., 1997) e à análise modal em transição de guias circulares para retangulares (WANG et al., 1997). 
EIBERT, HANSEN (1997) aplicaram um método híbrido (Elementos Finitos e Elementos de Contorno) para analisar volumes anisotrópicos imersos em estruturas planares multi-camadas utilizando o princípio de Huygens. A análise apresentada é complicada; os resultados numéricos referem-se a ressoadores dielétricos acoplados a circuitos em microfita.

Recentemente, FONTGALLAND et al. (1997) estudaram a questão do cálculo do número de onda em guias com ressalto (ridged waveguides), usando o MEC. A distinção de sua abordagem reside na função de Green que utilizaram, expressa em termos das autofunções relacionadas a guias retangulares e circulares vazios, ainda sem contemplar perdas.

Também recentemente, BALAGANGADHAR et al. (1998) publicaram um trabalho de solução da equação de Helmholtz cuja formulação, pela primeira vez, deixa de lado as funções de Hankel normalmente utilizadas, e usa apenas função de Green estática, o que é conseguido reduzindo-se a equação de Helmholtz à equação de Poisson que, então, é resolvida por superposição da equação de Laplace com uma solução particular. Para esta última última é necessária integração de domínio. A vantagem é que o parâmetro freqüência aparece apenas como fator de escala; a desvantagem é a integração de domínio e, ainda, a impossibilidade de estudar guias não-homogêneos. 
SHEN, STERZ (1998) propõem melhoria nos problemas numéricos devidos aos cantos geométricos; a rigor eles não existem na prática, mas para evitar aumento exagerado do número de elementos, propõem uma combinação do método de Galerkin e do método de colocação na abordagem numérica por resíduos ponderados. A primeira passa a ser aplicada aos cantos; a segunda permanece utilizada nos demais nós. Os resultados, aplicados a problemas magnetostáticos, tem tempo de CPU intermediário entre as duas situações, se mantido o número de nós. O método proposto passa a ser o mais rápido quando se considera a necessidade de melhorar a discretização na abordagem por colocação.

Apesar da crescente utilização do MEC nos problemas de ondas eletromagnéticas guiadas, os artigos a ele referentes constituem fração pequena da busca em banco de dados eletrônicos. O serviço do IEEE revelou aproximadamente $0,02 \%$ das citações ocorridas após 1994. A maioria delas ( 90\%) encontram-se na área de Magnetismo. 


\section{Formulação Integral de Contorno}

O Método dos Elementos de Contorno (MEC) ou Método dos Elementos de Fronteira é o nome geral dado a um método numérico de solução de equações diferenciais (parciais) cuja formulação as transforma em equações integrais sobre o contorno/fronteira da região particular em estudo, às vezes chamada de domínio. Estas equações integrais são resolvidas numericamente; a integração se dá ao longo do contorno e, para isto, ele é dividido em segmentos, normalmente retos, - os elementos de contorno - nos quais as condições de contorno do problema são aplicadas.

\subsection{Generalidades}

Existem procedimentos diversos para a formulação do Método dos Elementos de Contorno. Um deles faz extensivo uso de integração por partes do produto interno de duas funções $u$ e $v$ definidas no domínio $\Omega$ em estudo, como

$$
\langle u, v\rangle=\int_{\Omega} u v d \Omega
$$

Considerando-se uma equação diferencial genérica, pode-se representá-la com o auxílio de um operador L:

$$
\mathrm{L}(\mathrm{u})=\mathrm{b}
$$

no domínio $\Omega$. O símbolo $b$ representa uma função associada ao termo não homogêneo da equação. Assim, por exemplo, o operador associado à equação de Laplace em três dimensões pode ser escrito como 


$$
L(\cdot)=\frac{\partial^{2}(\cdot)}{\partial x^{2}}+\frac{\partial^{2}(\cdot)}{\partial y^{2}}+\frac{\partial^{2}(\cdot)}{\partial z^{2}}=\nabla^{2}(.)
$$

Considerando, então, o produto interno $\langle L(u), w\rangle$ dado por

$$
\int_{\Omega} L(u) w d \Omega
$$

em que $w$ é uma função definida em $\Omega$ e conhecida e supondo ser L(.) um operador diferencial, a integração por partes da equação (3.4) fornece a expressão geral

$$
\int_{\Omega} L(u) w d \Omega=\int_{\Omega} u L^{*}(w) d \Omega+\int_{\Gamma} S^{*}(w) G(u) d \Gamma-\int_{\Gamma} G^{*}(w) S(u) d \Gamma
$$

em que: $\quad \Gamma$ é a superfície exterior do domínio $\Omega$;

$$
\begin{aligned}
& \text { S(.) e G(.) são operadores diferenciais; } \\
& \text { o asterisco * indica operador adjunto. }
\end{aligned}
$$

Então, fixados um operador L(.) e uma função $w$, a integração por partes de (3.4), quando comparada ao membro direito da equação (3.5), permite determinar todos os operadores envolvidos. Se resultar $L^{*}()=.L($.$) , então o operador L($.) será chamado auto-adjunto e, neste caso, pode-se demonstrar que S(.) e G(.) também o serão.

A equação (3.5) mostra também os diferentes tipos de condição de contorno. Fixar valores de S(u), na terceira parcela do membro direito da equação, equivale a estabelecer as condições de contorno essenciais, também conhecidas por condições de contorno de Dirichlet. Fixar valores de G(u), na segunda parcela do membro direito da equação, equivale a estabelecer as condições de contorno naturais, também conhecidas por condições de contorno de Neumann.

Na maioria dos problemas de Engenharia, a solução exata de suas equações não pode ser conhecida devido à sua complexidade. A solução se dá apenas de forma aproximada; as 
várias técnicas numéricas aplicadas com auxílio de computador - e entre elas o MEC - obtêm apenas soluções próximas da situação exata.

Chamando de $\mathrm{u}_{0}$ a solução exata da equação (3.2), pode-se expressar uma solução aproximada de $\mathrm{u}_{0}$ por

$$
u \cong u_{0}
$$

com

$$
u=\sum_{k=1}^{N} \alpha_{k} \varphi_{k}
$$

em que: $\quad \alpha_{\mathrm{k}}$ são coeficientes a determinar;

$\varphi_{\mathrm{k}}$ são funções linearmente independentes, definidas no domínio $\Omega$.

Quando necessário, pode-se somar ao membro direito da equação (3.7) uma parcela constante $\alpha_{0}$ a fim de acomodar a porção não homogênea da equação diferencial em estudo. Rescrevendo a equação (3.2) como

$$
\mathrm{L}\left(\mathrm{u}_{0}\right)=\mathrm{b}
$$

a substituição da aproximação, representada pelas equações (3.6) e (3.7), na equação (3.8) resultará em

$$
\mathrm{L}(\mathrm{u}) \neq \mathrm{b}
$$

Haverá o aparecimento de um erro, aqui chamado de função residual ou simplesmente resíduo

$$
\mathrm{R}=\mathrm{L}(\mathrm{u})-\mathrm{b} \neq 0
$$

Considerando agora as condições de contorno

$$
\begin{array}{ll}
\mathrm{S}\left(\mathrm{u}_{0}\right)=\mathrm{s} & \text { sobre } \Gamma_{1} \\
\mathrm{G}\left(\mathrm{u}_{0}\right)=\mathrm{g} & \text { sobre } \Gamma_{2}
\end{array}
$$


sendo $\Gamma_{1}+\Gamma_{2}=\Gamma$, e admitindo que a aproximação $u$ não as satisfaça, isto é não atenda às condições de contorno, haverá também mais duas funções residuais

$$
\begin{array}{ll}
\mathrm{R}_{1}=\mathrm{S}(\mathrm{u})-\mathrm{s} \neq 0 & \text { sobre } \Gamma_{1} \mathrm{e} \\
\mathrm{R}_{2}=\mathrm{G}(\mathrm{u})-\mathrm{g} \neq 0 & \text { sobre } \Gamma_{2}
\end{array}
$$

O objetivo dos métodos numéricos é forçar todos os resíduos a um valor mínimo. A maneira como isto é realizado é que dá origem aos vários métodos, servindo também para distinguilos.

\subsection{Método dos Resíduos Ponderados}

Numa situação genérica as funções residuais são dadas pelas equações (3.10), (3.13) e (3.14). Pode-se propor que estes resíduos sejam distribuídos de forma a se tornarem nulos num sentido médio, isto é, global. Seja um conjunto de funções $\psi_{\mathrm{k}}$, linearmente independentes, definidas no domínio $\Omega$. Estas funções podem ser distintas das funções $\varphi_{\mathrm{k}}$ da equação (3.7).

Com a idéia já mencionada de procurar diminuir o resíduo tanto quanto possível, pode-se definir vários produtos internos e impor a cada um deles resultado nulo. Admitindo que as funções de aproximação $\varphi_{\mathrm{k}}$ satisfaçam a todas as condições de contorno, tem-se $\mathrm{R} \neq 0, \mathrm{R}_{1} \equiv 0$ e $\mathrm{R}_{2} \equiv 0$. Então

$$
\left\langle R, \Psi_{k}\right\rangle=\int_{\Omega} R \psi_{k} d \Omega=0 \text { para } \mathrm{k}=1,2, \ldots, \mathrm{N}
$$

ou definindo uma nova função $w$ tal que

$$
w=\beta_{1} \psi_{1}+\beta_{2} \psi_{2}+\ldots+\beta_{N} \psi_{N}=\sum_{k=1}^{N} \beta_{k} \psi_{k}
$$


com os coeficientes $\beta_{\mathrm{k}}$ arbitrários, resulta

$$
\langle R, w\rangle=\int_{\Omega} R w d \Omega=0
$$

Como mencionado no fim da seção anterior, proposições diferentes para as funções $\psi_{\mathrm{k}}(\mathrm{e}$, portanto, também para a função $w$ ) é que diferenciam os métodos aproximados de resolução da equação diferencial em estudo.

Note-se que a equação (3.15) corresponde a um sistema de equações algébricas que, resolvido, fornecerá os coeficientes $\alpha_{\mathrm{k}}$ da equação (3.7). A solução aproximada está, então, completada.

\subsection{Formulação Fraca}

$\mathrm{Na}$ seção anterior considerou-se apenas o produto interno $<\mathrm{R}, \mathrm{w}\rangle$, ao admitir que as funções de aproximação satisfaziam todas as condições de contorno. Pode-se relaxar estas condições, permitindo que os resíduos possam ser todos diferentes de zero e refazer o cálculo do produto interno $<\mathrm{R}, \mathrm{w}\rangle$, no qual $w$ continua, por ora, a ser uma função qualquer, porém conhecida. Seja, então, um problema descrito pela equação de Poisson; pode-se escrever a proposição de resíduos ponderados

$$
\int_{\Omega}\left[\nabla^{2}(u)-b\right] w d \Omega=0
$$

No raciocínio que se seguirá, haverá, por duas vezes, a integração por partes da equação (3.18). Por isto, é necessário impor-se a restrição da função $w$ ser contínua, pelo menos por trechos, até a sua segunda derivada. Isto também significa que a ordem de continuidade da função $u$ pode ser relaxada; daí a designação de formulação fraca. Observe-se que esta 
mesma imposição já estava, pela natureza do problema (e da equação diferencial que o rege), aplicada à função $u$ pelo operador laplaciano. Admitindo-se por simplicidade, mas sem perda de generalidade, que o domínio $\Omega$ seja bidimensional e utilizando coordenadas cartesianas retangulares, pode-se integrar por partes duas vezes, resultando

$$
\int_{\Omega}\left(\frac{\partial^{2} w}{\partial x^{2}} u+\frac{\partial^{2} w}{\partial y^{2}} u-b w\right) d \Omega+\int_{\Gamma} w \frac{\partial u}{\partial n} d \Gamma-\int_{\Gamma} u \frac{\partial w}{\partial n} d \Gamma=0
$$

sendo $n$ a direção do vetor normal a $\Gamma$. Reconhece-se, imediatamente, na integral de domínio acima, a presença do operador laplaciano atuando sobre a função $w$. Na equação (3.18) ele atua sobre a função de aproximação $u$. Como estas expressões são iguais, pode-se escrever

$$
\int_{\Omega}\left(\nabla^{2} u-b\right) w d \Omega=\int_{\Omega}\left[\left(\nabla^{2} w\right) u-b w\right] d \Omega+\int_{\Gamma} w \frac{\partial u}{\partial n} d \Gamma-\int_{\Gamma} u \frac{\partial w}{\partial n} d \Gamma=0
$$

A parcela - $b w$ apresenta-se nos dois membros da equação e pode ser cancelada. Resulta

$$
\int_{\Omega}\left(\nabla^{2} u\right) w d \Omega=\int_{\Omega}\left(\nabla^{2} w\right) u d \Omega+\int_{\Gamma} w \frac{\partial u}{\partial n} d \Gamma-\int_{\Gamma} u \frac{\partial w}{\partial n} d \Gamma=0
$$

que representa o teorema de Green, isto é,

$$
\int_{\Omega}\left[\left(\nabla^{2} u\right) w-\left(\nabla^{2} w\right) u\right] d \Omega=\int_{\Gamma}\left(w \frac{\partial u}{\partial n}-u \frac{\partial w}{\partial n}\right) d \Gamma
$$

Então, verifica-se que a proposição de resíduos ponderados da equação (3.18) traz embutida a tentativa de também procurar aproximar as condições de contorno essenciais e naturais. Esta colocação ficará mais clara ao se procurar, a partir da equação (3.19), retornar à proposição inicial, isto é, o operador voltando a atuar sobre a função de aproximação. Reescrevendo a equação citada tem-se

$$
\int_{\Omega}\left[\left(\nabla^{2} w\right) u-b w\right] d \Omega+\int_{\Gamma} w \frac{\partial u}{\partial n} d \Gamma-\int_{\Gamma} u \frac{\partial w}{\partial n} d \Gamma=0
$$


Esta equação costuma ser tomada como proposição inicial para o MEC e é conhecida como proposição inversa pois o operador da equação diferencial em estudo não mais atua sobre a função de aproximação mas sim sobre a função $w$ (isto é, a função de ponderação). Introduzindo a definição

$$
q \equiv \frac{\partial u}{\partial n}
$$

e lembrando que em parte do contorno $\left(\Gamma_{1}\right)$ a condição essencial está fixada e na parte complementar do mesmo contorno $\left(\Gamma_{2}\right)$ fixa-se a condição natural, tem-se

$$
\begin{aligned}
& u=\bar{u} \text { sobre } \Gamma_{1} \\
& q=\bar{q} \text { sobre } \Gamma_{2}
\end{aligned}
$$

Nas duas últimas equações a barra indica que o valor da função está fixado (portanto, conhecido); observe-se que estas equações equivalem às equações (3.11) e (3.12), a menos da mudança de notação.

$\mathrm{Na}$ equação (3.23) pode-se separar cada integração sobre o contorno nas porções complementares $\Gamma_{1}$ e $\Gamma_{2}$. Então,

$$
\int_{\Omega}\left[\left(\nabla^{2} w\right) u-b w\right] d \Omega+\int_{\Gamma_{1}} q w d \Gamma+\int_{\Gamma_{2}} \bar{q} w d \Gamma-\int_{\Gamma_{1}} \bar{u} \frac{\partial w}{\partial n} d \Gamma-\int_{\Gamma_{2}} u \frac{\partial w}{\partial n} d \Gamma=0
$$

Integrando por partes, segue-se

$$
\begin{aligned}
& \int_{\Omega}\left[-\frac{\partial w}{\partial x} \frac{\partial u}{\partial x}-\frac{\partial w}{\partial y} \frac{\partial u}{\partial y}-b w\right] d \Omega+\int_{\Gamma} u \frac{\partial w}{\partial n} d \Gamma+ \\
& \int_{\Gamma_{1}} q w d \Gamma+\int_{\Gamma_{2}} \bar{q} w d \Gamma-\int_{\Gamma_{1}} \bar{u} \frac{\partial w}{\partial n} d \Gamma-\int_{\Gamma_{2}} u \frac{\partial w}{\partial n} d \Gamma=0
\end{aligned}
$$

Separando a primeira integral de contorno nas suas duas porções $\left(\Gamma_{1}\right.$ e $\left.\Gamma_{2}\right)$ e simplificando, tem-se 


$$
\int_{\Omega}\left[-\frac{\partial w}{\partial x} \frac{\partial u}{\partial x}-\frac{\partial w}{\partial y} \frac{\partial u}{\partial y}-b w\right] d \Omega+\int_{\Gamma_{1}} u \frac{\partial w}{\partial n} d \Gamma+\int_{\Gamma_{1}} q w d \Gamma+\int_{\Gamma_{2}} \bar{q} w d \Gamma-\int_{\Gamma_{1}} \bar{u} \frac{\partial w}{\partial n} d \Gamma=0
$$

Integrando por partes uma segunda e última vez, escreve-se

$$
\int_{\Omega}\left[\left(\nabla^{2} u\right) w-b w\right] d \Omega-\int_{\Gamma} w q d \Gamma+\int_{\Gamma_{1}} u \frac{\partial w}{\partial n} d \Gamma+\int_{\Gamma_{1}} q w d \Gamma+\int_{\Gamma_{2}} \bar{q} w d \Gamma-\int_{\Gamma_{1}} \bar{u} \frac{\partial w}{\partial n} d \Gamma=0
$$

Utilizando novamente a separação da primeira integral de contorno e simplificando, resulta

$$
\int_{\Omega}\left[\left(\nabla^{2} u\right) w-b w\right] d \Omega-\int_{\Gamma_{2}} w q d \Gamma+\int_{\Gamma_{1}} u \frac{\partial w}{\partial n} d \Gamma+\int_{\Gamma_{2}} \bar{q} w d \Gamma-\int_{\Gamma_{1}} \bar{u} \frac{\partial w}{\partial n} d \Gamma=0
$$

Agrupando as integrais nas porções $\Gamma_{1}$ e $\Gamma_{2}$, resulta finalmente

$$
\int_{\Omega}\left[\left(\nabla^{2} u-b\right) w\right] d \Omega-\int_{\Gamma_{2}}(q-\bar{q}) w d \Gamma+\int_{\Gamma_{1}}(u-\bar{u}) \frac{\partial w}{\partial n} d \Gamma=0
$$

Em todos os integrandos acima reconhece-se um fator devido aos resíduos dados por (3.10), (3.13) e (3.14), isto é

$$
\int_{\Omega} R w d \Omega-\int_{\Gamma_{2}} R_{2} w d \Gamma+\int_{\Gamma_{1}} R_{1} \frac{\partial w}{\partial n} d \Gamma=0
$$

A equação (3.32) comprova a afirmação de que a formulação com resíduos ponderados embute as aproximações das condições de contorno essenciais e naturais.

De forma equivalente, pode-se retornar às equações (3.23) e (3.27), referentes à proposição inversa, a partir da formulação com os três resíduos ponderados, expressos em (3.32), bastando integrá-la por partes duas vezes. A identidade

$$
\int_{\Omega} \alpha(\operatorname{div} \vec{F}) d \Omega=\int_{\Gamma} \alpha \vec{F} \cdot \hat{n} d \Gamma-\int_{\Omega}(\operatorname{grad} \alpha) \cdot \vec{F} d \Omega
$$

serve a este propósito; nela $\vec{F}$ é uma quantidade vetorial, $\alpha$ uma quantidade escalar com derivadas contínuas até, pelo menos, a segunda ordem e $\widehat{n}$ é o versor normal ao contorno $\Gamma$ que envolve o domínio $\Omega$. 
Na primeira integração, operada em (3.32), pode-se identificar $\vec{F} \operatorname{com} \operatorname{grad}(\mathrm{u})$ e $\alpha \operatorname{com} w$; na segunda integração as identidades são trocadas. Finalmente, a aplicação das condições de contorno $\bar{u}$ em $\Gamma_{1}$ e $\bar{q}$ em $\Gamma_{2}$ resulta na proposição inversa (equação 3.23 ou 3.27); este é o ponto de partida para o Método do Elementos de Contorno.

\subsection{Classificação de soluções}

As soluções aproximadas de problemas de contorno, como as discutidas anteriormente, podem ser obtidas por três métodos:

Métodos de domínio: quando a solução aproximada satisfaz identicamente a todas as condições de contorno porém deve ser ajustada à equação em estudo;

Métodos de contorno: é a situação complementar da acima. A solução aproximada satisfaz identicamente a equação em estudo mas deve ser ajustada às condições de contorno. As incógnitas permanecem exclusivamente na fronteira;

Métodos híbridos ou mistos: a aproximação escolhida deve ser ajustada às condições de contorno e à equação em estudo.

Evidentemente, o Método dos Elementos de Contorno enquadra-se na segunda classificação, mas com uma importante observação. Durante o procedimento de dupla integração por partes da seção anterior, o operador associado à equação em estudo foi transferido e passou a atuar sobre a função de ponderação $w$. Um método de contorno poderá, então, ser 
aplicado escolhendo-se uma função $w$ que satisfaça identicamente a equação em estudo $e$ não suas condições de contorno.

Explicando de outra forma: a equação (3.27) poderá ser resolvida apenas com as integrações de contorno, desde que a integração sobre o domínio $\Omega$ possa ser:

- reduzida a zero, ou

- calculada "facilmente".

Em ambas as situações o termo não homogêneo, relacionado à excitação da equação diferencial, compromete significativamente a atraente característica inicial que o MEC possui de resolver um problema apenas com integrações de contorno. Formulações recentes e mais sofisticadas do MEC atacam diretamente estas questões.

Considerando, por simplicidade, apenas a equação homogênea (isto é, b $\equiv 0$ ), a integração de domínio, em (3.23) ou (3.27), fica reduzida a

$$
\int_{\Omega}\left(u \nabla^{2} w\right) d \Omega
$$

Esta integral poderá ser anulada se for escolhida adequadamente uma certa função $w$ que satisfaça a porção homogênea da equação em estudo.

De outra forma, pode-se calcular facilmente a integral (3.35) se forem usadas funções especiais para $w$ a fim de que o problema ainda possa ser remetido apenas ao seu contorno. Por exemplo: é possível utilizar-se, para $w$, a função de Green (ou solução fundamental) da equação em estudo, isto é

$$
\nabla^{2} w=-\delta\left(\vec{r}-\vec{r}^{\prime}\right)
$$


A função $\delta($.) é a função (impulsiva) de Dirac no espaço de dimensão do problema estudado, $\vec{r}$ é o vetor de posição associado ao ponto de observação e $\vec{r}^{\prime}$ o vetor de posição associado ao ponto de aplicação da função impulsiva. Na equação (3.36) tem-se necessariamente que

$$
w=G\left(\vec{r}, \vec{r}^{\prime}\right)=u^{*}\left(\vec{r}, \vec{r}^{\prime}\right)
$$

sendo daqui em diante a terminologia u* usada para a solução fundamental.

Então, usando a solução fundamental como função de ponderação $w$, a expressão (3.35) torna-se

$$
\int_{\Omega}\left(u \nabla^{2} u^{*}\right) d \Omega=-u\left(\vec{r}^{\prime}\right)=-u_{i}
$$

em virtude das propriedades da função impulsiva. O índice $i$ está associado ao ponto de aplicação desta última.

\subsection{A solução fundamental}

As expressões da seção anterior foram desenvolvidas considerando-se a equação de Laplace como sendo a equação que governa o problema em estudo. No entanto, estas expressões e todo o raciocínio anterior poderão ser aplicados a outras equações. As suas respectivas soluções fundamentais (funções de Green) são bem conhecidas da Física Matemática.

Da teoria relacionada às funções de Green, entende-se que elas equivalem à resposta do sistema, governado pela equação em estudo, a uma excitação impulsiva de amplitude unitária, localizada no ponto " $i$ ” definido pelo vetor de posição $\vec{r}^{\prime}$. Em todos os demais pontos do domínio há ausência de fontes. Usando a notação estabelecida, se 


$$
\mathrm{L}(\mathrm{u})=\mathrm{b}
$$

então

$$
\mathrm{L}\left(\mathrm{u}^{*}\right)=-\delta\left(\vec{r}-\vec{r}^{\prime}\right)
$$

Particularizando para o operador de Laplace, deve-se ter

$$
\nabla^{2} u^{*}=-\delta\left(\vec{r}-\vec{r}^{\prime}\right)
$$

Na seção de formulações fracas apresentou-se a limitação de que a função de ponderação $w$, agora aplicada como solução fundamental, devia ter derivadas contínuas até a segunda ordem. Pelas propriedades da função impulsiva, escreve-se

$$
\int_{\Omega} \nabla^{2} u^{*} d \Omega=-1
$$

Utilizando integração por partes na equação (3.42), ou equivalentemente aplicando a equação (3.34) $\operatorname{com} \vec{F}=\operatorname{grad} u^{*}$ e $\alpha=1$, tem-se

$$
\int_{\Gamma} \frac{\partial u^{*}}{\partial n} d \Gamma=-1
$$

que mostra ser constante (igual a -1) o fluxo total que atravessa o contorno $\Gamma$.

Considere-se o domínio $\Omega$ como sendo representado por uma esfera $\Omega_{\mathrm{e}}$ centrada no ponto de aplicação da função impulsiva; tem-se, neste caso, que a direção radial e a direção normal à superfície da esfera são as mesmas. Também, deve-se ter, por simetria, que a derivada de u* na direção radial seja constante, isto é

$$
\int_{\Gamma_{e}} \frac{\partial u^{*}}{\partial n} d \Gamma=-1=\int_{\Gamma_{e}} \frac{\partial u^{*}}{\partial r} d \Gamma=C \int_{\Gamma_{e}} d \Gamma
$$

$\Gamma_{\mathrm{e}}$ é o contorno de $\Omega_{\mathrm{e}}$. $C$ é uma constante de cálculo imediato, $C=\frac{-1}{4 \pi r^{2}}$ pois $\int_{\Gamma_{e}} d \Gamma$ é a área da superfície esférica $\Gamma_{\mathrm{e}} ; r=\left|\vec{r}-\vec{r}^{\prime}\right|$ é a distância entre o ponto de aplicação da função 
impulsiva e o ponto de observação. Pela natureza do problema, é evidente que a solução fundamental terá simetria radial a partir de seu ponto de aplicação.

Numa situação bidimensional, $\Omega_{\mathrm{e}}$ equivale a um círculo centrado no ponto de aplicação da função impulsiva, $\Gamma_{\mathrm{e}}$ é o perímetro (contorno) desse círculo e $\int_{\Gamma_{e}} d \Gamma$ vale $2 \pi$ r. Conclui-se que, neste caso, $C=\frac{-1}{2 \pi r}$.

A solução fundamental é obtida por integração.

Na situação tridimensional,

$$
\frac{\partial u^{*}}{\partial r}=-\frac{1}{4 \pi r^{2}}
$$

e

$$
u^{*}=\frac{1}{4 \pi r}+C_{1}
$$

Na situação bidimensional,

$$
\frac{\partial u^{*}}{\partial r}=-\frac{1}{2 \pi r}
$$

$\mathrm{e}$

$$
u^{*}=\frac{1}{2 \pi} \ln \left(\frac{1}{r}\right)+C_{2}
$$

As constantes $\mathrm{C}_{1}$ e $\mathrm{C}_{2}$ são arbitrárias; por simplicidade, pode-se tomá-las iguais a zero.

Prosseguindo, constata-se que, para $r \neq 0$, as soluções fundamentais (3.46) e (3.48) satisfazem a (3.41). 
No caso tridimensional, considerando que $\mathrm{u}^{*}$ é apenas função de $r$, pode-se utilizar o sistema de coordenadas esféricas $(r, \theta, \phi)$ e impor $\partial / \partial \theta \equiv 0$ e $\partial / \partial \phi \equiv 0$. Nestas condições, a expressão do laplaciano fica particularizada a

$$
\begin{aligned}
\nabla^{2} u^{*} & =\frac{1}{r^{2}} \frac{\partial}{\partial r}\left(r^{2} \frac{\partial u^{*}}{\partial r}\right) \\
& =\frac{\partial^{2} u^{*}}{\partial r^{2}}+\frac{2}{r} \frac{\partial u^{*}}{\partial r}
\end{aligned}
$$

A partir da equação (3.45), calcula-se

$$
\frac{\partial^{2} u^{*}}{\partial r^{2}}=\frac{1}{2 \pi} \frac{1}{r^{3}}
$$

Aplicando-se as equações (3.45) e (3.50) na expressão (3.49), resulta

$$
\nabla^{2} u^{*}=\frac{1}{2 \pi r^{3}}+\frac{2}{r}\left(\frac{-1}{4 \pi r^{2}}\right) \equiv 0, \mathrm{r} \neq 0
$$

De maneira análoga, no caso bidimensional, tratado com coordenadas cilíndricas $(\mathrm{r}, \phi, \mathrm{z}), \mathrm{z}$ arbitrário, mas com $\partial / \partial \phi \equiv 0$ e $\partial / \partial z \equiv 0$, tem-se

$$
\begin{aligned}
\nabla^{2} u^{*} & =\frac{1}{r} \frac{\partial}{\partial r}\left(r \frac{\partial u^{*}}{\partial r}\right) \\
& =\frac{\partial^{2} u^{*}}{\partial r^{2}}+\frac{1}{r} \frac{\partial u^{*}}{\partial r}
\end{aligned}
$$

A partir da equação (3.47), calcula-se

$$
\frac{\partial^{2} u^{*}}{\partial r^{2}}=\frac{1}{2 \pi} \frac{1}{r^{2}}
$$

Finalmente, aplicando-se as equações (3.47) e (3.53) na expressão (3.52), vem 


$$
\nabla^{2} u^{*}=\frac{1}{2 \pi r^{2}}+\frac{1}{r}\left(\frac{-1}{2 \pi r}\right) \equiv 0, \mathrm{r} \neq 0
$$

As equações (3.51) ou (3.54), juntamente com a equação (3.42), confirmam as equações (3.46) ou (3.48) como sendo a solução fundamental da equação de Laplace, nos casos bi e tridimensionais, respectivamente.

Uma vez constatada a validade da solução fundamental $\mathrm{u}^{*}$, usada como função de ponderação, calcula-se facilmente o valor $\partial w / \partial n$. Faz-se, então,

$$
\frac{\partial w}{\partial n}=\frac{\partial u^{*}}{\partial n}=q^{*}
$$

ou seja,

$$
q^{*}\left(\vec{r}, \vec{r}^{\prime}\right)=\operatorname{grad} u^{*} \cdot \hat{n}
$$

é a projeção do gradiente da solução fundamental sobre a normal ao contorno, no ponto (associado ao vetor de posição $\vec{r}$ ) calculado.

Devido à simetria radial da solução fundamental tem-se

$$
q^{*}\left(\vec{r}, \vec{r}^{\prime}\right)=\hat{r} \frac{\partial u^{*}}{\partial r} \cdot \hat{n}
$$

$\hat{r}$ é o versor radial aplicado a partir da localização da função impulsiva, isto é $\vec{r}-\vec{r}^{\prime}=r \hat{r}, \mathrm{r} \geq 0$

O resultado para a situação tridimensional é

$$
q^{*}\left(\vec{r}, \vec{r}^{\prime}\right)=-\frac{1}{4 \pi r^{2}} \cos (\hat{r}, \hat{n})=-\frac{1}{4 \pi r^{2}} \cos \alpha
$$

$\alpha$ é o ângulo formado entre os versores radial e normal no ponto de observação.

No caso bidimensional vale 


$$
q^{*}\left(\vec{r}, \vec{r}^{\prime}\right)=-\frac{1}{2 \pi r} \cos (\hat{r}, \hat{n})=-\frac{1}{2 \pi r} \cos \alpha
$$




\subsection{A equação integral de contorno}

O desenvolvimento apresentado nas seções anteriores permite reescrever a equação (3.27) ponto de partida para aplicação do MEC - como

$$
u_{i}+\int_{\Omega} b u^{*} d \Omega+\int_{\Gamma_{1}} \bar{u} q^{*} d \Gamma+\int_{\Gamma_{2}} u q^{*} d \Gamma=\int_{\Gamma_{1}} u^{*} q d \Gamma+\int_{\Gamma_{2}} u^{*} \bar{q} d \Gamma
$$

ou, de forma compacta, sem a aplicação das condições de contorno,

$$
u_{i}+\int_{\Omega} b u^{*} d \Omega+\int_{\Gamma} u q^{*} d \Gamma=\int_{\Gamma} u^{*} q d \Gamma
$$

Para a determinação dos valores de $u$ e $q$, ainda desconhecidos em parte do contorno, tornase primeiramente necessário aplicar a função impulsiva sobre o contorno. Ocorrerá, então, o aparecimento de singularidades nos integrandos das expressões, como conseqüência da situação $\vec{r}=\vec{r}^{\prime} \Leftrightarrow r=0$. Estas singularidades precisam ser contornadas.

Considere-se, por simplicidade, o caso bidimensional. Pode-se tomar o ponto $i$ como interno a $\Omega$ e aproximá-lo do contorno $\Gamma$ por um processo de limite. (Figuras 3.1 e 3.2).

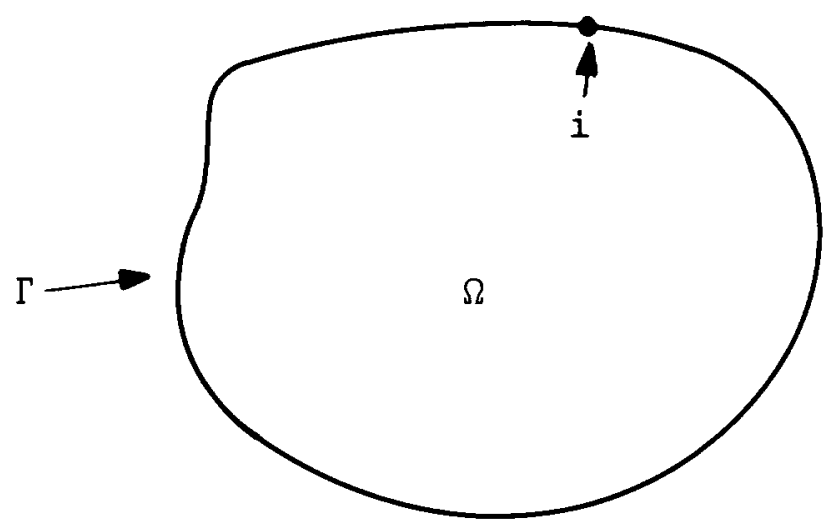

Figura 3.1: Aplicação da função impulsiva sobre o contorno $\Gamma$. 
Para representar os integrandos das integrais de contorno acima como função da distância $r$, isto é, $f(r)$, considere-se uma pequena seção de círculo de raio $\varepsilon$ (ou, equivalentemente, uma seção de cilindro com eixo normal ao plano do papel, $\mathrm{z}$ qualquer, $\partial / \partial \mathrm{z} \equiv 0$ ) centrado no ponto $i ; \Gamma_{\varepsilon}$ é o contorno da seção de círculo e $\Gamma_{-\varepsilon}$ a porção restante do contorno do problema original. $\Omega_{\varepsilon}$ é o domínio associado a $\Gamma_{\varepsilon}$.

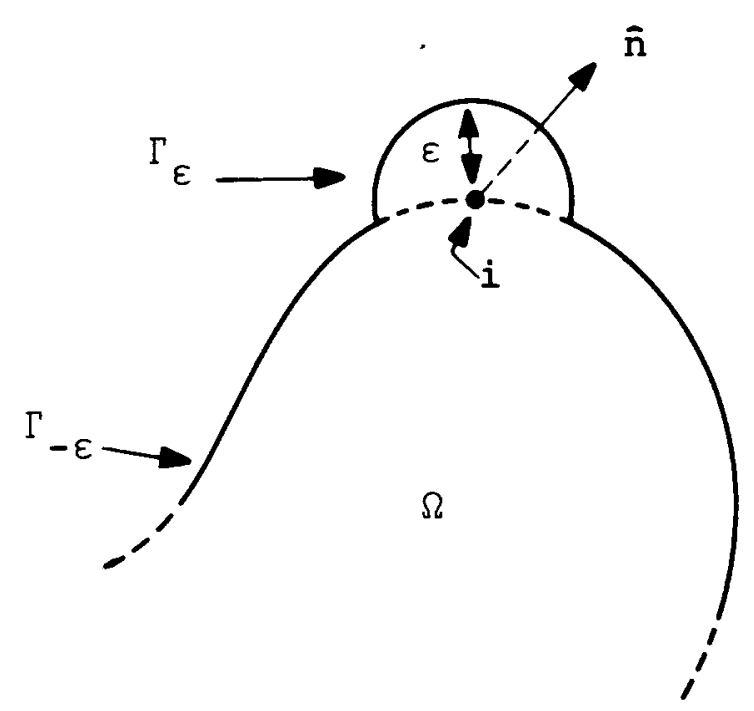

Figura 3.2: Condução do ponto $i$ ao contorno por um processo de limite.

Então vale

$$
\begin{aligned}
\int_{\Gamma} f(r) d \Gamma & =\lim _{\varepsilon \rightarrow 0}\left\{\int_{\Gamma_{-\varepsilon}} f(r) d \Gamma+\int_{\Gamma_{\varepsilon}} f(r) d \Gamma\right\} \\
& =\int_{\Gamma} f(r) d \Gamma+\lim _{\varepsilon \rightarrow 0} \int_{\Gamma_{\varepsilon}} f(r) d \Gamma
\end{aligned}
$$

A primeira integral do membro direito não mais apresenta singularidade. Este artifício será utilizado na equação (3.61). 
Aplicando o processo de limite na integral do membro direito da equação (3.61) tem-se, considerando as figuras 3.2 e 3.3 ,

$$
\begin{aligned}
\lim _{\varepsilon \rightarrow 0} \int_{\Gamma_{\varepsilon}} u^{*} q d \Gamma & =\lim _{\varepsilon \rightarrow 0} \int_{\Gamma_{\varepsilon}} \frac{1}{2 \pi} \ln \left(\frac{1}{\varepsilon}\right) q d \Gamma \\
& =\lim _{\varepsilon \rightarrow 0} \int_{\theta_{1}}^{\theta_{2}} \frac{1}{2 \pi} \ln \left(\frac{1}{\varepsilon}\right) q \varepsilon d \theta \\
& =\lim _{\varepsilon \rightarrow 0} \frac{1}{2 \pi} \ln \left(\frac{1}{\varepsilon}\right) q_{i} \varepsilon\left(\theta_{2}-\theta_{1}\right)=0
\end{aligned}
$$

que mostra não haver alteração no lado direito de (3.61) quando o ponto $i$ é deslocado para o contorno. $\mathrm{q}_{\mathrm{i}}$ é o valor da derivada normal de u tomada no ponto $i$. $\theta_{1}$ e $\theta_{2}$ são, respectivamente, os ângulos formados entre uma referência arbitrária e o versor tangente ao contorno antes e depois do ponto $i$, respeitado seu sentido de percurso.

Quanto à integral de contorno do membro esquerdo da equação (3.61) e lembrando que, nesta situação, as direções radial e normal são idênticas, tem-se

$$
\begin{aligned}
\lim _{\varepsilon \rightarrow 0} \int_{\Gamma_{\varepsilon}} u q^{*} d \Gamma & =\lim _{\varepsilon \rightarrow 0} \int_{\Gamma_{\varepsilon}} u \frac{\partial u^{*}}{\partial n} d \Gamma \\
& =\lim _{\varepsilon \rightarrow 0} \int_{\theta_{1}}^{\theta_{2}} u\left(-\frac{1}{2 \pi \varepsilon}\right) \varepsilon d \theta=-\frac{1}{2 \pi} u_{i}\left(\theta_{2}-\theta_{1}\right)
\end{aligned}
$$

Na figura 3.3, o ponto $i$ está localizado numa porção suave do contorno; portanto $\theta_{2}-\theta_{1}=\pi$ radianos.

Na figura 3.4, o ponto $i$ está localizado sobre uma ponta do contorno (um canto vivo) e, consequentemente, $\theta_{2}-\theta_{1} \neq \pi$ radianos. 


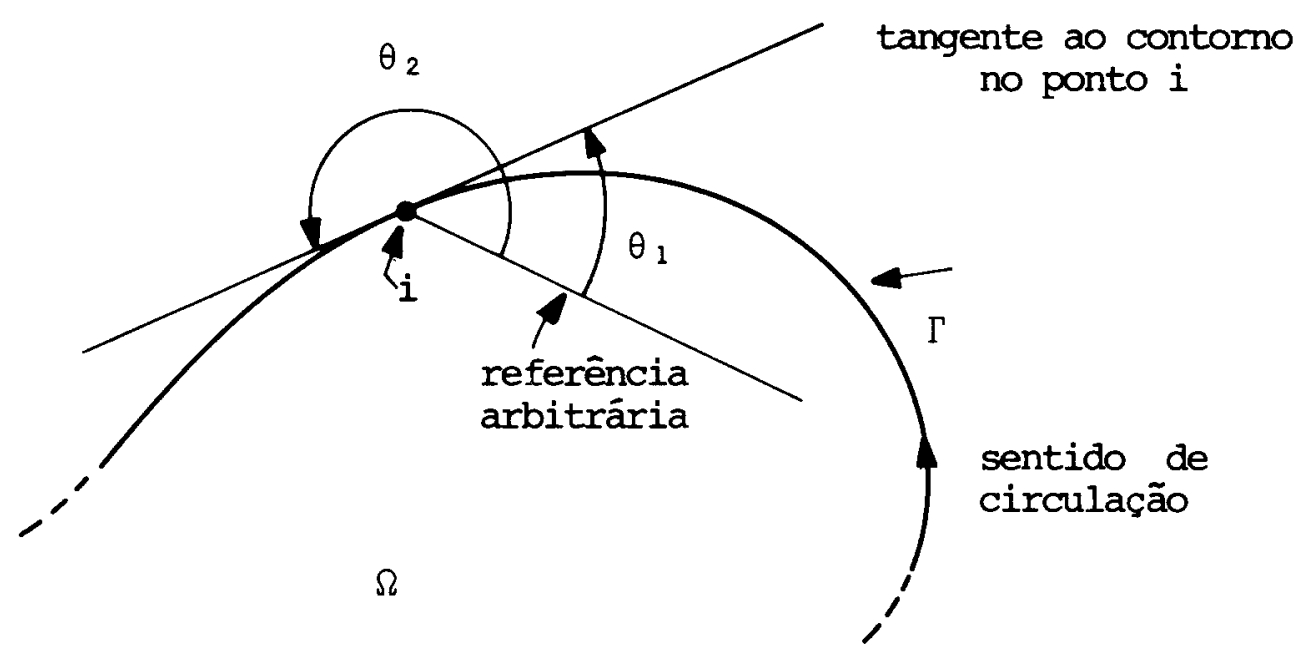

Figura 3.3: Ponto de aplicação sobre região suave do contorno.

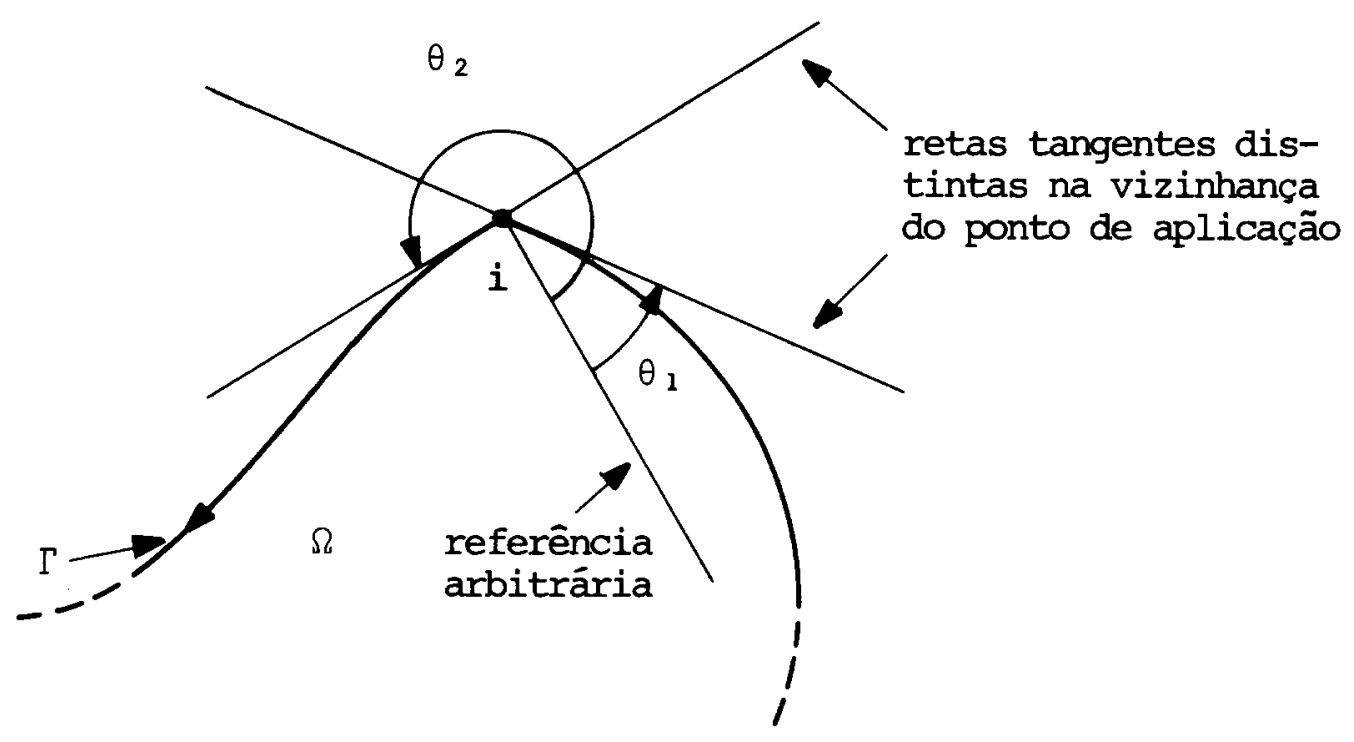

Figura 3.4: Ponto de aplicação sobre região de contorno descontínuo. 
Por raciocínio semelhante ao utilizado para a equação (3.63), a integral de domínio em (3.61) leva a

$$
\lim _{\varepsilon \rightarrow 0} \int_{\Omega_{\varepsilon}} b u^{*} d \Omega=\lim _{\varepsilon \rightarrow 0} \int_{\theta_{1}}^{\theta_{2}} \int_{0}^{\varepsilon} b \frac{1}{2 \pi} \ln \left(\frac{1}{\varepsilon}\right) \varepsilon d \varepsilon d \theta=0
$$

Os resultados acima permitem generalizar a equação (3.61) à luz da equação (3.62). Então, vale

$$
u_{i}+\int_{\Omega} b u^{*} d \Omega+\int_{\Gamma} u q^{*} d \Gamma-\frac{1}{2 \pi} u_{i}\left(\theta_{2}-\theta_{1}\right)=\int_{\Gamma} u^{*} q d \Gamma
$$

que pode ser reescrita

$$
c_{i} u_{i}+\int_{\Omega} b u^{*} d \Omega+\int_{\Gamma} u q^{*} d \Gamma=\int_{\Gamma} u^{*} q d \Gamma
$$

O fator $\mathrm{c}_{\mathrm{i}}$ atua como um coeficiente dependente da localização do ponto $i$, com

$$
\mathrm{c}_{\mathrm{i}}=1-\frac{\theta_{2}-\theta_{1}}{2 \pi}=\frac{2 \pi-\theta_{2}+\theta_{1}}{2 \pi}=\frac{\theta_{\text {int }}}{2 \pi}
$$

estando o ponto $i$ sobre a fronteira, $\mathrm{i} \in \Gamma$.

$\theta_{\text {int }}$ é o ângulo interno ao contorno, medido entre as retas tangentes antes e depois do ponto i, conforme a figura 3.5 .

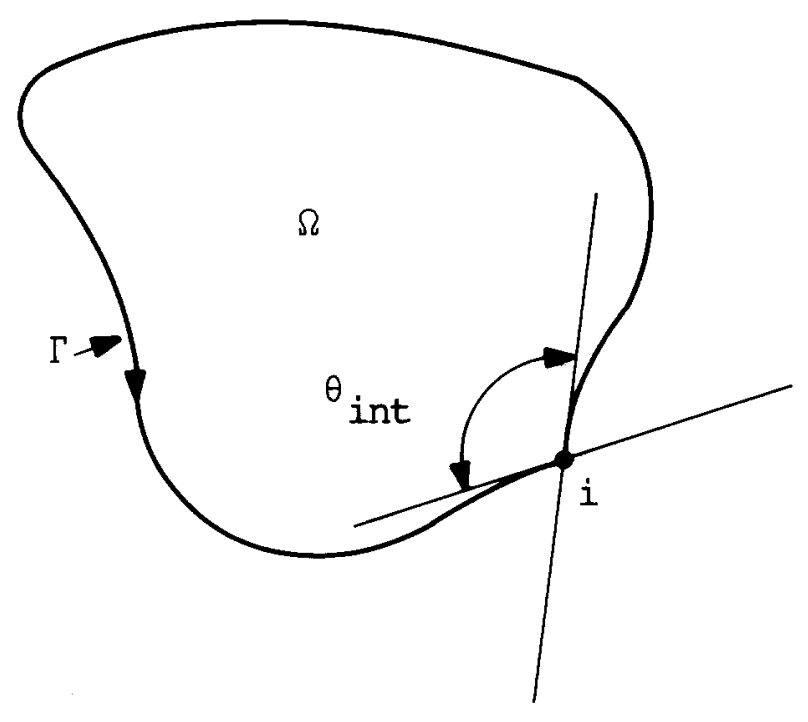


Figura 3.5: Medição do ângulo interno em região de contorno descontínuo.

Não havendo fontes (excitações), $\mathrm{b} \equiv 0$ e a equação (3.67) é a equação integral de contorno associada ao problema estudado (equação de Poisson reduzida à equação de Laplace). No caso geral, com $b \neq 0$, a integral de domínio em (3.67) pode ser reescrita também como integral de contorno utilizando formulações mais avançadas do MEC como, por exemplo, o Método de Reciprocidade Dupla (MRD), o Método de Reciprocidade Múltipla (MRM) ou simplesmente calculando-a numericamente, mas agora perdendo a grande atração do MEC que é a de equacionar todo o problema exclusivamente com valores de contorno.

O mesmo raciocínio apresentado para o caso bidimensional pode ser estendido à situação tridimensional com os mesmos resultados.

Uma vez conhecidos todos os valores de $u$ e $q$ no contorno, a equação (3.61) pode ser utilizada para o cálculo de $\mathrm{u}_{\mathrm{i}}$ interno ao domínio $\Omega$. Neste caso, o fator $\mathrm{c}_{\mathrm{i}}$ terá os valores

$$
\mathrm{c}_{\mathrm{i}}=1
$$

se o ponto $i$ for interno ao domínio, $\mathrm{i} \in \Omega \mathrm{e}$

$$
\mathrm{c}_{\mathrm{i}}=0
$$

se o ponto $i$ for externo ao domínio, $\mathrm{i} \notin \Omega$.

\subsection{Equação de Helmholtz: solução fundamental}

Esta equação, freqüentemente associada a fenômenos ondulatórios, também pode ser resolvida numericamente pelo MEC. Em Eletromagnetismo, a equação de onda em um meio sem perdas e sem fontes de campo é escrita 


$$
\nabla^{2} \vec{F}=\mu \varepsilon \frac{\partial^{2} \vec{F}}{\partial t^{2}}
$$

$\vec{F}$ pode representar o vetor intensidade de campo elétrico ou o vetor campo magnético; $\mu$ e $\varepsilon$ representam respectivamente a permeabilidade e a permissividade do meio material; $t$ representa o tempo. Supondo a condição de regime permanente senoidal, pode-se utilizar notação fasorial e escrever para o vetor intensidade de campo elétrico $\vec{E}$ que

$$
\nabla^{2} \vec{E}+k^{2} \vec{E}=0
$$

$\mathrm{O}$ parâmetro $\mathrm{k}$ depende do meio material e da freqüência de oscilação, e é chamado comumente por número de onda ou constante de fase, medido em radianos por metro. A equação (3.72) é uma das formas da equação de Helmholtz, de muito interesse em Engenharia; utilizando-se coordenadas retangulares, pode-se reduzi-la a três equações escalares semelhantes, representadas genericamente por

$$
\nabla^{2} u+k^{2} u=0
$$

A fim de poder aplicar o MEC na solução de equações desta natureza é necessária a obtenção de uma solução fundamental u*, tal qual a aplicada à equação de Laplace. Neste caso

$$
\nabla^{2} u^{*}+k^{2} u^{*}=-\delta\left(\vec{r}-\vec{r}^{\prime}\right)
$$

e a solução fundamental é dada, em duas dimensões, por

$$
u^{*}=\frac{j}{4} H_{0}^{(1)}(k r)
$$

$r$ tem o mesmo significado das seções anteriores e $H_{0}^{(1)}(x)$ é a função de Hankel de primeira espécie, ordem zero e argumento $\mathrm{x}$, dada por $J_{0}(x)+j Y_{0}(x)$. As partes real $\mathrm{J}_{0}$ e imaginária 
$\mathrm{Y}_{0}$ são, respectivamente, a função de Bessel de primeira espécie e segunda espécie, ambas de ordem zero.

A solução fundamental apresenta novamente simetria radial. $\partial \mathrm{u}^{*} / \partial \mathrm{n}=\mathrm{q}^{*}$ pode ser obtida pela equação (3.57); a derivada na direção radial é calculada com o auxílio de identidades das funções de Bessel. Vale a equação

$$
\frac{\partial u^{*}}{\partial r}=-j \frac{k}{4} H_{1}^{(1)}(k r)
$$

$H_{1}^{(1)}(\mathrm{x})$ representa a função de Hankel de primeira espécie, ordem um, dada por

$J_{1}(x)+j Y_{1}(x)$

A partir da identidade

$$
\frac{\partial}{\partial x}\left(H_{v}^{(1)}(x)\right)=\frac{v}{x} H_{v}^{(1)}(x)-H_{v+1}^{(1)}(x)
$$

obtém-se a derivada segunda da solução fundamental,

$$
\frac{\partial^{2} u^{*}}{\partial r^{2}}=-j \frac{k}{4}\left\{\frac{1}{k R} H_{1}^{(1)}(k r)-H_{2}^{(1)}(k r)\right\} k
$$

Utilizando-se a equação (3.52), a equação de Helmholtz fica

$$
\nabla^{2} u^{*}+k^{2} u^{*}=\frac{\partial^{2} u^{*}}{\partial r^{2}}+\frac{1}{r} \frac{\partial u^{*}}{\partial r}+k^{2} u^{*}
$$

Aplicando-se, a cada parcela acima, as equações (3.78), (3.76) e (3.75), o resultado é identicamente nulo para $r \neq 0$, o que prova ser válida a solução fundamental. Tendo em vista a equação (3.57), escreve-se finalmente

$$
\begin{aligned}
q^{*} & =\hat{r} \frac{\partial u^{*}}{\partial r} \cdot \hat{n} \\
& =-j \frac{k}{4} H_{1}^{(1)}(k r) \hat{r} \cdot \hat{n}
\end{aligned}
$$




\subsection{Equação de Helmholtz: equação integral de contorno}

A obtenção da Equação Integral de Contorno, tal como abordada anteriormente, foi efetuada por um processo de limite. Refazendo o procedimento, pode-se escrever a partir da equação (3.61), tendo em vista a solução fundamental $u^{*}$ e sua derivada $q^{*}$, dadas por (3.75) e (3.80),

$$
u_{i}+\int_{\Gamma} u q^{*} d \Gamma=\int_{\Gamma} u^{*} q d \Gamma
$$

Por causa do processo de limite tem-se (figura 3.2)

$$
u_{i}+\lim _{\varepsilon \rightarrow 0} \int_{\Gamma_{-\varepsilon}} u q^{*} d \Gamma+\lim _{\varepsilon \rightarrow 0} \int_{\Gamma_{\varepsilon}} u q^{*} d \Gamma=\lim _{\varepsilon \rightarrow 0} \int_{\Gamma_{-\varepsilon}} u^{*} q d \Gamma+\lim _{\varepsilon \rightarrow 0} \int_{\Gamma_{\varepsilon}} u^{*} q d \Gamma
$$

As integrações em $\Gamma_{\varepsilon}$ podem ser obtidas como segue:

a) Integral em $\Gamma_{\varepsilon}$ do membro direito resultará nula pois

$$
\begin{aligned}
A & =\lim _{\varepsilon \rightarrow 0} \int_{\Gamma_{\varepsilon}} q \frac{j}{4} H_{0}^{(1)}(k \varepsilon) d \Gamma= \\
& =\lim _{\varepsilon \rightarrow 0} \int_{\theta_{1}}^{\theta_{2}} q \frac{j}{4} H_{0}^{(1)}(k \varepsilon) \varepsilon d \theta \\
& =\lim _{\varepsilon \rightarrow 0} q \frac{j}{4} H_{0}^{(1)}(k \varepsilon) \varepsilon\left(\theta_{2}-\theta_{1}\right)
\end{aligned}
$$

Os ângulos $\theta_{1}$ e $\theta_{2}$ estão referenciados nas figuras 3.3 e 3.4. O desmembramento da função de Hankel nas suas partes real e imaginária (funções de Bessel) e o processo de limite permitem tomar apenas a primeira parcela do desenvolvimento em série das funções de Bessel. Assim, escreve-se

$$
A=\lim _{\varepsilon \rightarrow 0} q \frac{j}{4} \varepsilon\left(\theta_{2}-\theta_{1}\right)\left\{1+j\left[\frac{2}{\pi}\right]\left(\ln \frac{k \varepsilon}{2}+\gamma\right)\right\}=0
$$


em que $\gamma$ é a constante de Euler.

b) Integral em $\Gamma_{\varepsilon}$ do membro esquerdo resultará num termo livre a ser combinado com a parcela $u_{i}$ da equação (3.81). Considerando que na geometria da figura 3.2 os versores $\hat{r}$ e $\hat{n}$ estão alinhados, escreve-se

$$
\begin{aligned}
B & =\lim _{\varepsilon \rightarrow 0} \int u\left(-j \frac{k}{4} H_{1}^{(1)}(k \varepsilon)\right) d \Gamma \\
& =-\lim _{\varepsilon \rightarrow 0} u j \frac{k}{4} H_{1}^{(1)}(k \varepsilon) \varepsilon\left(\theta_{2}-\theta_{1}\right) \\
& =-u j \frac{k}{4}\left(\theta_{2}-\theta_{1}\right) \lim _{\varepsilon \rightarrow 0} H_{1}^{(1)}(k \varepsilon) \varepsilon
\end{aligned}
$$

Este último limite pode ser resolvido escrevendo-se as aproximações das funções de Bessel para pequenos argumentos, resultando

$$
B=-u j \frac{k}{4}\left(\theta_{2}-\theta_{1}\right) \lim _{\varepsilon \rightarrow 0}\left\{\left[\frac{k \varepsilon}{2}+j\left(\frac{-2}{k \pi \varepsilon}\right)\right] \varepsilon\right\}=-u \frac{\left(\theta_{2}-\theta_{1}\right)}{2 \pi}
$$

Reunindo-se os resultados das expressões (3.84) e (3.86), a Equação Integral de Contorno toma forma semelhante à da equação (3.67), aqui repetida:

$$
c_{i} u_{i}+\int_{\Gamma} u q^{*} d \Gamma=\int_{\Gamma} u^{*} q d \Gamma
$$

\subsection{Perdas em meios materiais}

Nas aplicações práticas do Eletromagnetismo é comum efetuarem-se aproximações em função de fatores tais como: valores de parâmetros constitutivos, comportamento das fontes excitadoras, freqüência do sinal, etc. Estas aproximações tem o efeito de particularizar as equações de Maxwell, simplificando o modelo de Engenharia do problema em questão. 
Da mesma forma, o procedimento geral resumido acima pode ser aplicado à equação de onda na sua forma mais genérica; tem-se assim a vantagem de poder desacoplar as equações que relacionam campo elétrico e campo magnético. Em um meio material homogêneo, a forma genérica da equação de onda para o campo elétrico $\vec{E}$ é

$$
\nabla^{2} \vec{E}=\mu \frac{\partial \vec{J}}{\partial t}+\frac{1}{\varepsilon} \operatorname{div}(\rho)+\mu \sigma \frac{\partial \vec{E}}{\partial t}+\mu \varepsilon \frac{\partial^{2} \vec{E}}{\partial t^{2}}
$$

equação semelhante vale também para o campo magnético $\vec{H}$. Nelas, $\mu, \varepsilon$ e $\sigma$ representam os parâmetros constitutivos do meio material, $\rho$ representa a densidade volumétrica de cargas elétricas e $\vec{J}$ a densidade de corrente elétrica.

Numa região sem fontes de campo $(\vec{J}=0$ e $\rho=0)$, a equação (3.88) particulariza-se a

$$
\nabla^{2} \vec{E}=\mu \sigma \frac{\partial \vec{E}}{\partial t}+\mu \varepsilon \frac{\partial^{2} \vec{E}}{\partial t^{2}}
$$

Admitindo que os campos tenham variação temporal harmônica, pode-se empregar representação fasorial e reescrever a equação (3.89) como

$$
\nabla^{2} \vec{E}=j \omega \mu \sigma \vec{E}-\omega^{2} \mu \varepsilon \vec{E}
$$

$\omega$ é a freqüência angular de oscilação.

A equação (3.90) pode ser reescrita na forma

$$
\nabla^{2} \vec{E}+\omega^{2} \mu\left(\varepsilon-j \frac{\sigma}{\omega}\right) \vec{E}=0
$$

Nela reconhece-se o fator relacionado à permissividade complexa do meio material, isto é,

$$
\dot{\varepsilon}=\varepsilon-j \frac{\sigma}{\omega}
$$

muitas vezes escrita também como

$$
\dot{\varepsilon}=\varepsilon^{\prime}-j \varepsilon^{\prime \prime}=\varepsilon_{0}\left(\varepsilon_{r}^{\prime}-j \varepsilon_{r}^{\prime \prime}\right)
$$


A partir da equação (3.91) pode-se introduzir o número de onda, agora complexo, resultando na equação de Helmholtz

$$
\nabla^{2} \vec{E}+\dot{k}^{2} \vec{E}=0
$$

desde que

$$
\dot{k}=\omega \sqrt{\mu \dot{\varepsilon}}
$$

Esta equações que contemplam os efeitos de perdas nos meios materiais não apresentam complicações adicionais, exceto pelo fato de que, do ponto de vista algébrico e computacional, introduzem maior quantidade de cálculos em aritmética complexa.

À equação de Helmholtz (3.94) pode-se aplicar a formulação do MEC, como mencionada nas duas seções anteriores. A solução fundamental (equação 3.75) e sua derivada normal (equação 3.80) apresentam agora argumentos complexos para as funções de Hankel, como implicação da generalização empregada. 


\section{O Método dos Elementos de Contorno}

O capítulo anterior apresentou a formulação do MEC. Ocorre que para a sua aplicação prática é necessário passar ao procedimento numérico de solução de um problema de contorno, que pode ser resumido nos seguintes passos, ao tratar da solução de um problema descrito pela equação de Poisson/Laplace:

1. Formulação: já realizada. Consistiu na obtenção da equação integral de contorno a partir da equação diferencial do problema com o auxílio do Método dos Resíduos Ponderados;

2. discretização do contorno;

3. montagem das matrizes;

4. solução do sistema de equações;

5. cálculo de variáveis em pontos internos do domínio.

Para o estudo da aplicação a problemas de propagação, o procedimento desenvolvido (analisado no Capítulo 5), propõe três variantes: 1) Determinação de autovalores;

2) Varredura em freqüência e 3) Excitação localizada.

\subsection{Generalidades}

No processo de discretização do contorno utiliza-se uma série de elementos de geometria bem definida. Em cada elemento impõe-se uma lei de variação para a função u (solução do problema); a mesma lei é aplicada à sua derivada normal q. O comportamento destas funções está baseado nas chamadas funções de forma e nos nós que definem a geometria do elemento. Quanto à esta última, costuma-se, nos casos bidimensionais, usar 
segmentos de reta ou segmentos curvos e nos casos tridimensionais elementos triangulares ou elementos poligonais planos, preferencialmente paralelepípedos. $\mathrm{O}$ maior ou menor refinamento da discretização do contorno influirá na precisão dos resultados finais. A lei de variação de $u$ e de $q$ também.

Na montagem das matrizes são necessárias integrações (equação 3.67); para tanto é comum aplicar-se três procedimentos, suplementares entre si, a saber:

1. Integrações analíticas;

2. Integrações numéricas;

3. Integrações numéricas com tratamento especial.

Sempre que for viável é preferível lançar-se mão de integrações analíticas; nas demais situações a única opção é a integração numérica. Neste caso o conhecimento do comportamento do integrando pode dar caminho, por exemplo, às formulas de quadratura de Gauss (para integrais não singulares), que são as mais utilizadas ou à métodos especiais para o caso de haver singularidades. A literatura registra grande atividade neste tópico matemático. O sistema de equações cuja solução fornecerá os valores desconhecidos ainda restantes no contorno (isto é, valores de $u$ em $\Gamma_{2}$ e valores de $q$ em $\Gamma_{1}$ ) é obtido aplicando-se sucessivamente a equação (3.67) a todos os nós dos elementos. Este procedimento efetuará a montagem das matrizes, cujos elementos são calculados pelas integrações mencionadas acima. Supondo que o operador da equação em estudo seja linear e que haja $\mathrm{N}$ nós na geometria discretizada, haverá ,então, $\mathrm{N}$ equações lineares a $\mathrm{N}$ incógnitas, cuja solução pode, em princípio, ser encaminhada por qualquer método adequado (por exemplo, solução direta ou solução iterativa). 
Uma vez obtidos os valores (de $u$ e $q$ ) em todos os nós, e conseqüientemente, os valores ao longo do contorno, pode-se aplicar novamente a versão discretizada da equação (3.67) para resolvê-la em qualquer ponto interno do domínio $\Omega$. Note-se que, agora, os integrandos da referida equação são todos conhecidos e não apresentam singularidade, pois a distância entre o ponto de aplicação e o caminho de integração é sempre diferente de zero.

Volta-se a salientar que, nesta seção, não estão sendo contemplados os efeitos de fontes; não há então necessidade de calcular-se a integral de domínio da equação (3.67).

\subsection{Discretização do contorno}

A idéia básica de todos os métodos numéricos é aplicar alguma forma de discretização a fim de reduzir o problema original a um problema numericamente equivalente, a ser resolvido algebricamente. No caso do MEC, faz-se uso de elementos. Admite-se que, em cada um destes elementos, a função solução (ainda por conhecer) seja aproximada com a ajuda de funções de interpolação (também chamadas funções de forma). Estas, por sua vez, estão associadas aos valores da função solução em pontos específicos sobre o elemento, chamados de valores nodais do elemento.

Particularizando para o MEC em duas dimensões, as discretizações mais comuns estão representadas nas figuras 4.1 a 4.3, correspondendo, respectivamente, às utilizações de elementos constantes, elementos lineares e elementos quadráticos. O sentido de circulação do contorno está indicado nas mesmas figuras. Nos dois primeiros casos cada elemento de contorno é representado por um segmento de reta; no último os elementos de contorno são curvilíneos. 

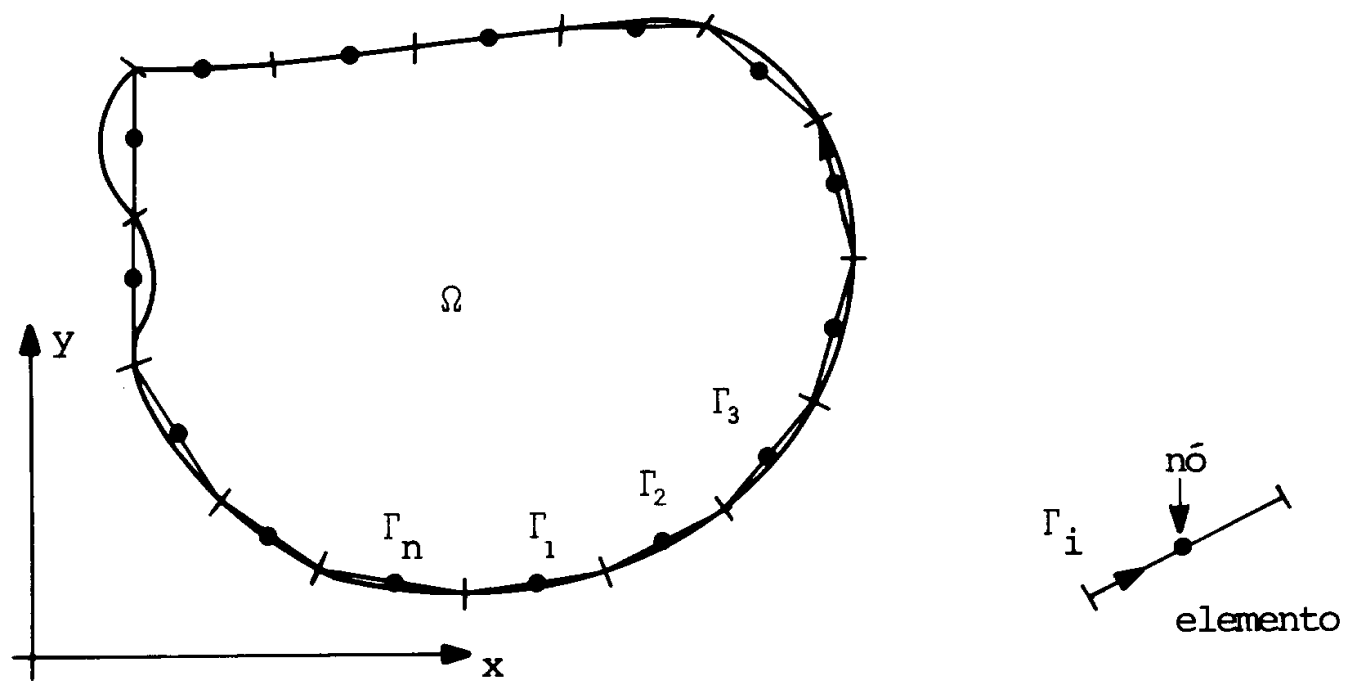

Figura 4.1: Elementos constantes.

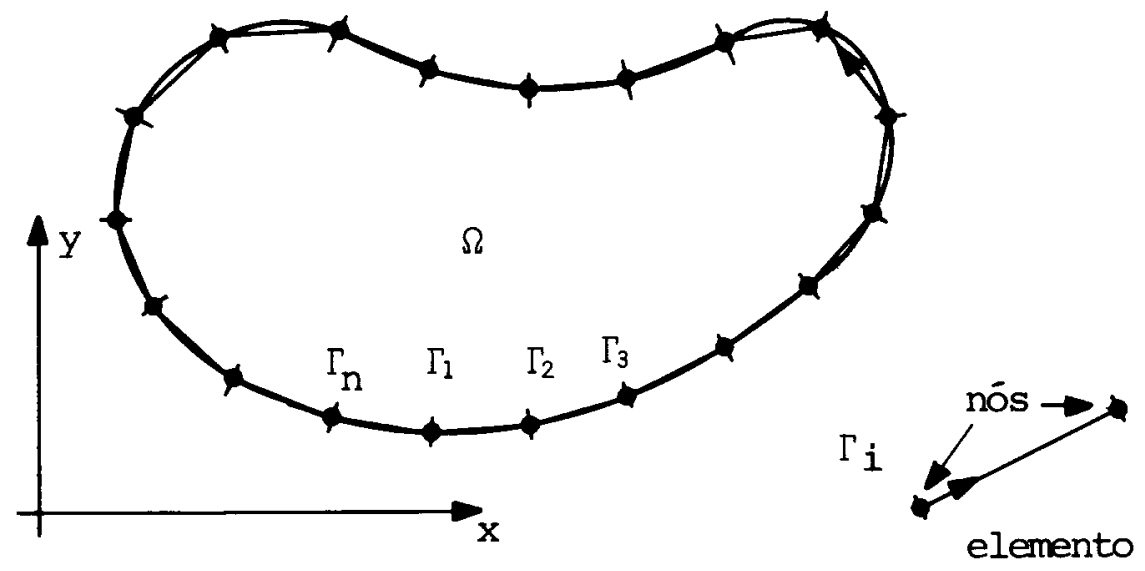

Figura 4.2: Elementos lineares. 

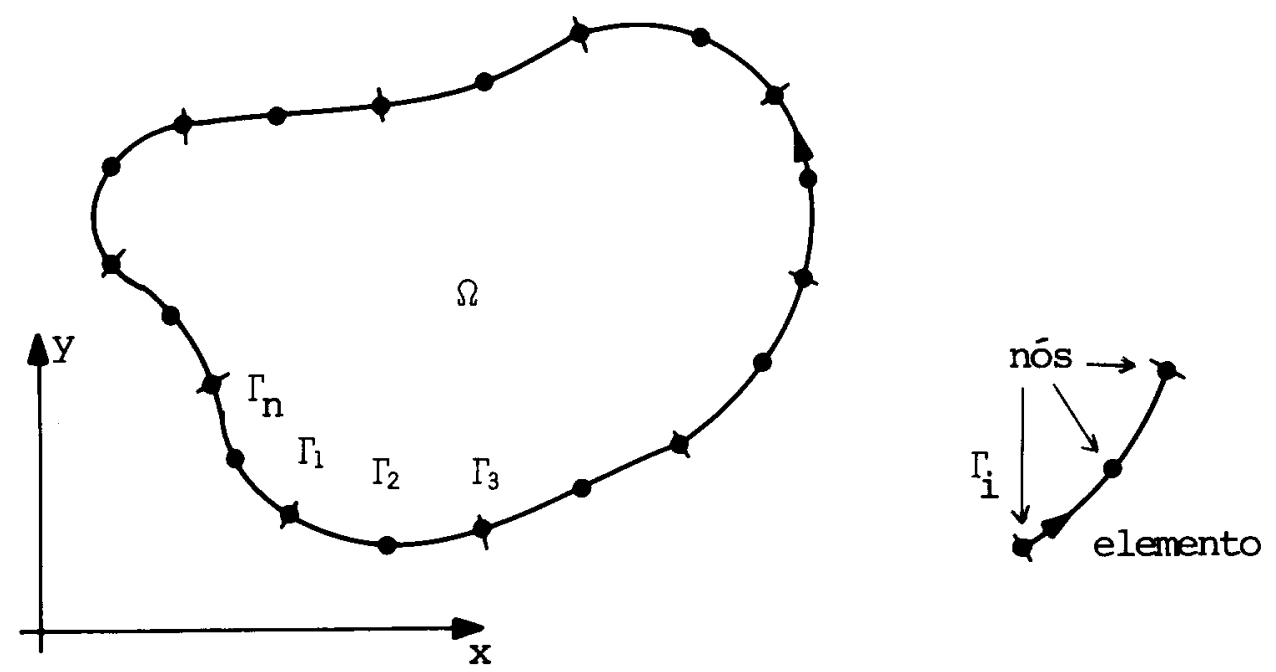

Figura 4.3: Elementos quadráticos.

Uma vez discretizado o contorno pode-se equacionar sua geometria e também as variáveis u e $\mathrm{q}=\partial \mathrm{u} / \partial \mathrm{n}$. Os métodos numéricos costumam fazer uso de uma coordenada local adimensional em cada elemento, representada por $\xi(-1 \leq \xi \leq+1)$ (ou, nos problemas tridimensionais, por um sistema de coordenadas locais adimensionais). Dependendo do tipo de formulação pode-se ter nos casos bidimensionais:

\section{- Elementos constantes}

geometria: $\quad x(\xi)=\frac{1}{2}(1-\xi) x_{1}+\frac{1}{2}(1+\xi) x_{2}$

$$
y(\xi)=\frac{1}{2}(1-\xi) y_{1}+\frac{1}{2}(1+\xi) y_{2}
$$

funções: $\quad u(\xi)=u_{1}=u_{2}$

$$
\mathrm{q}(\xi)=\mathrm{q}_{1}=\mathrm{q}_{2}
$$

Como os valores $u$ e $q$ são constantes ao longo de um elemento, é comum, sem perda de generalidade, associá-los a um ponto situado na metade do elemento. 
- Elementos lineares

geometria: a mesma dos elementos constantes

$$
\text { funções: } \quad \begin{aligned}
u(\xi) & =\frac{1}{2}(1-\xi) u_{1}+\frac{1}{2}(1+\xi) u_{2} \\
q(\xi) & =\frac{1}{2}(1-\xi) q_{1}+\frac{1}{2}(1+\xi) q_{2}
\end{aligned}
$$

- Elementos quadráticos

$$
\begin{aligned}
& \text { geometria: } \quad \begin{aligned}
x(\xi) & =\frac{1}{2} \xi(\xi-1) x_{1}+(1+\xi)(1-\xi) x_{3}+\frac{1}{2} \xi(\xi+1) x_{2} \\
y(\xi) & =\frac{1}{2} \xi(\xi-1) y_{1}+(1+\xi)(1-\xi) y_{3}+\frac{1}{2} \xi(\xi+1) y_{2} \\
\text { funções: } \quad u(\xi) & =\frac{1}{2} \xi(\xi-1) u_{1}+(1+\xi)(1-\xi) u_{3}+\frac{1}{2} \xi(\xi+1) u_{2} \\
q(\xi) & =\frac{1}{2} \xi(\xi-1) q_{1}+(1+\xi)(1-\xi) q_{3}+\frac{1}{2} \xi(\xi+1) q_{2}
\end{aligned}
\end{aligned}
$$

Nas equações acima, $x_{i}$ e $y_{i}$ são coordenadas de pontos associados ao elemento. A variação da coordenada local adimensional $\xi$ provoca a varredura de todo o elemento considerado enquanto $-1 \leq \xi \leq+1$. As figuras 4.4 a 4.6 sugerem a dependência entre o sistema de coordenadas global e local. $\mathrm{u}_{\mathrm{i}}$ e $\mathrm{q}_{\mathrm{i}}$ são os valores nodais.

No caso de elementos constantes o nó é tomado no centro do elemento; trata-se de elementos subparamétricos, pois a ordem de aproximação das funções é inferior à ordem de sua geometria. 


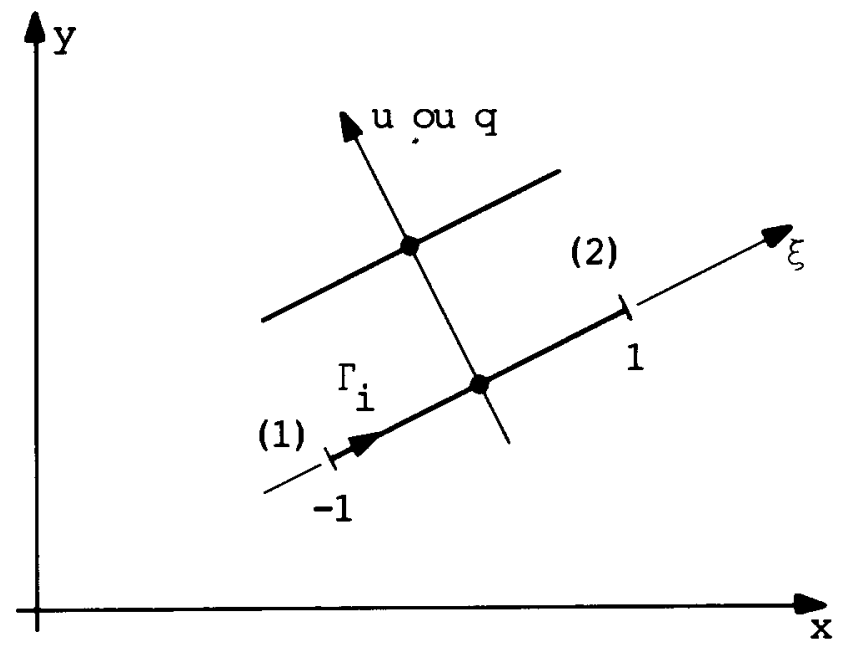

Figura 4.4: Elementos constantes. Relação entre o sistema de coordenadas global, local e o valor nodal.

Nas aproximações lineares e quadráticas tem-se a utilização de elementos isoparamétricos, isto é, que possuem a mesma ordem para a geometria e para as funções $u$ e $q$.

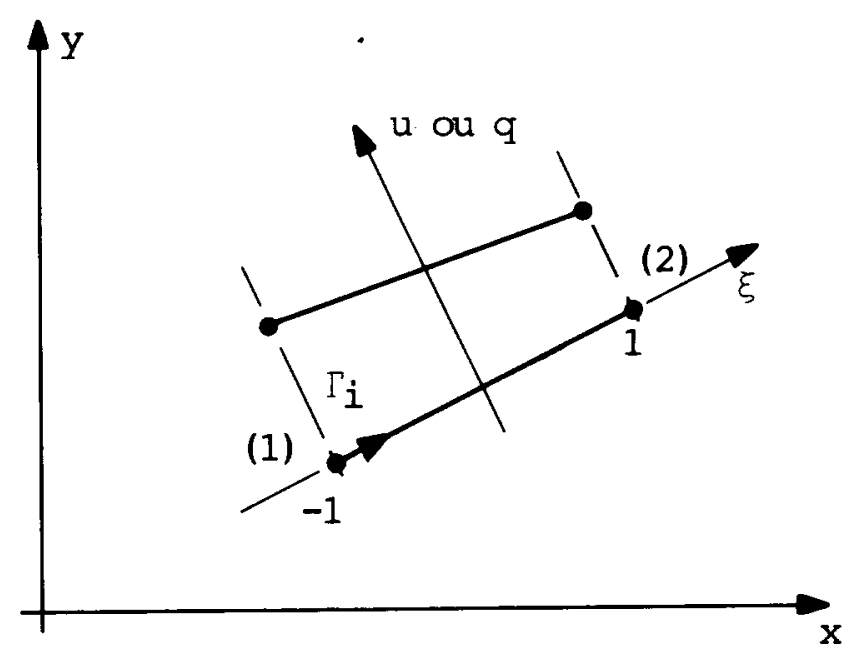

Figura 4.5: Elementos lineares. Relação entre o sistema de coordenadas global, local e os valores nodais. 


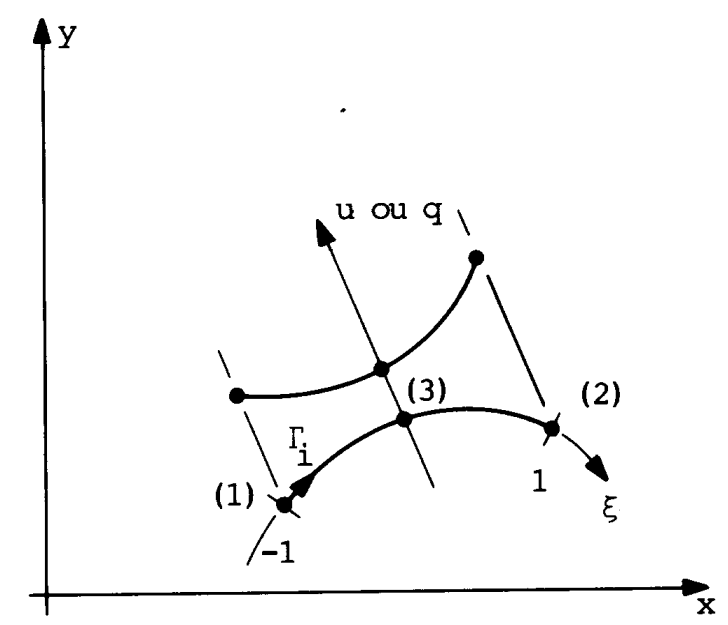

Figura 4.6: Elementos quadráticos. Relação entre o sistema de coordenadas global, local e os valores nodais.

As equações (4.2), (4.3) e (4.5) podem ser compactadas e reescritas de uma forma geral como

$$
\begin{aligned}
& u(\xi)=\sum_{i=1}^{N N} \varphi_{i}(\xi) u_{i}=\{\varphi\}^{T}\{u\} \\
& q(\xi)=\sum_{i=1}^{N N} \varphi_{i}(\xi) q_{i}=\{\varphi\}^{T}\{q\}
\end{aligned}
$$

$\varphi_{\mathrm{i}}(\xi)$ são as funções de forma e NN o número total de nós na descrição de cada elemento. $\{u\}$ e $\{q\}$ são vetores coluna contendo os valores nodais e $\{\varphi\}^{T}$ é um vetor linha contendo as funções de forma.

\subsection{Obtenção do sistema de equações algébricas}

Conforme mencionado anteriormente, a obtenção de um sistema de $\mathrm{N}$ equações lineares a $\mathrm{N}$ incógnitas é feita aplicando-se a excitação impulsiva sucessivamente em cada um dos $\mathrm{N}$ nós que constituem o contorno discretizado. 
Considerando um problema sem fontes $(b \equiv 0)$, a aplicação da equação (3.67) ao contorno discretizado fornecerá

$$
c_{i} u_{i}+\sum_{j=1}^{N} \int_{\Gamma_{j}} u q^{*} d \Gamma=\sum_{j=1}^{N} \int_{\Gamma_{j}} u^{*} q d \Gamma
$$

que, com o auxílio das funções de forma, é reescrito

$$
c_{i} u_{i}+\sum_{j=1}^{N} \int_{\Gamma_{j}}\{\varphi\}^{T} q^{*} d \Gamma\{u\}_{j}=\sum_{j=1}^{N} \int_{\Gamma_{j}} u^{*}\{\varphi\}^{T} d \Gamma\{q\}_{j}
$$

$\{.\}_{\mathrm{j}}$ representa o vetor que contém os valores nodais, da respectiva grandeza (u ou q), associados ao elemento $\mathrm{j}$.

Cada integral ao longo de $\Gamma_{\mathrm{j}}$ é resolvida numericamente e fornece um vetor linha de dimensão $\mathrm{NN}$, isto é

$$
\begin{aligned}
& \{h\}^{T}=\int_{\Gamma_{j}}\{\varphi\}^{T} q^{*} d \Gamma \\
& \{g\}^{T}=\int_{\Gamma_{j}} u^{*}\{\varphi\}^{T} d \Gamma .
\end{aligned}
$$

A equação (4.8) vale

$$
c_{i} u_{i}+\sum_{j=1}^{N}\{h\}^{T}\{u\}_{j}=\sum_{j=1}^{N}\{g\}^{T}\{q\}_{j}
$$

Aplicando-a a todos os $\mathrm{N}$ nós do contorno, pode-se montar um sistema de equações referenciadas às grandezas nodais de todo o contorno. É evidente que a montagem do sistema dependerá da escolha da modelagem das incógnitas nos elementos. Como $\mathrm{u}_{\mathrm{i}}$, neste caso, representará também uma grandeza nodal, então a parcela $c_{i} u_{i}$ poderá ser incorporada convenientemente ao somatório do membro esquerdo se o ponto i pertencer ao elemento j. Constrói-se, então, a equação matricial 


$$
[\mathrm{H}]\{\mathrm{u}\}=[\mathrm{G}]\{\mathrm{q}\}
$$

Esta equação pode ser considerada como uma versão discretizada da equação integral do problema. $\{\mathrm{u}\}$ é o vetor coluna dos potenciais nodais; $\{\mathrm{q}\}$ o vetor coluna dos valores nodais da derivada normal do potencial. As matrizes $[\mathrm{H}]$ e $[\mathrm{G}]$ são conhecidas genericamente como matrizes de influência, pois de certa forma contemplam a influência (ou acoplamento) de cada ponto de aplicação do impulso sobre as variáveis nodais. No cálculo dos elementos destas matrizes estão em jogo os aspectos geométricos e a natureza do problema em estudo.

$\mathrm{O}$ vetor coluna $\{\mathrm{u}\}$ contém os potenciais desconhecidos de alguns nós; os demais elementos deste vetor contém os valores de potencial fixados como condição de contorno de Dirichlet na porção do contorno agora chamada por $\Gamma_{\mathrm{D}}$. Suponha-se que existam $\mathrm{N}_{\mathrm{b}}$ nós nesta condição. Situação análoga ocorre com o vetor coluna $\{q\}$. Alguns elementos de $\{q\}$ estão por determinar; os demais contém os valores da derivada normal fixados como condição de contorno de Neumann na porção $\Gamma_{N}$ do contorno no qual, por hipótese, tem-se $\mathrm{N}_{\mathrm{N}}$ nós. Como $\mathrm{N}_{\mathrm{N}}+\mathrm{N}_{\mathrm{D}}=\mathrm{N}$, então a equação (4.11) terá solução única obtida a partir de seu rearranjo como

$$
[\mathrm{A}]\{\mathrm{x}\}=\{\mathrm{d}\}
$$

$\mathrm{O}$ vetor coluna $\{\mathrm{x}\}$ contém as $\mathrm{N}$ incógnitas dos nós, agora misturadas quanto a sua natureza, num único vetor, ou seja, $\{\mathrm{x}\}$ abriga valores de $\mathrm{u}_{\mathrm{i}}\left(\mathrm{ou} \mathrm{q}_{\mathrm{i}}\right)$ dependendo se $\mathrm{q}_{\mathrm{i}}\left(\mathrm{ou} \mathrm{u}_{\mathrm{i}}\right)$ tiver sido fixado como condição de contorno. 


\subsection{Formulação com elementos constantes}

A análise de propagação de ondas eletromagnéticas em estruturas guiadas faz uso extenso da equação de Helmholtz. Esta seção abordará o cálculo dos elementos de matriz para formulação constante.

No caso de elementos constantes há apenas um nó por elemento e as funções de forma resumem-se à função constante (igual a um), isto é

$$
\begin{aligned}
& \mathrm{u}(\xi)=\mathrm{u}_{1} \\
& \mathrm{q}(\xi)=\mathrm{q}_{1} .
\end{aligned}
$$

$\mathrm{u}_{1}$ e $\mathrm{q}_{1}$ são os valores associados ao elemento considerado. A equação (4.8) fica particularizada a

$$
\frac{1}{2} u_{i}+\sum_{j=1}^{N} u_{j} \int_{\Gamma_{j}} q^{*} d \Gamma=\sum_{j=1}^{N} q_{j} \int_{\Gamma_{j}} u^{*} d \Gamma
$$

Note-se que pelo fato dos valores $u_{j}$ e $q_{j}$ serem definidos no meio do elemento, então o contorno é obrigatoriamente suave nos pontos de aplicação da função impulsiva e, portanto, $c_{i}=1 / 2$. Reescrevendo a equação (4.14) tem-se

$$
\frac{1}{2} u_{i}+\sum_{j=1}^{N} \bar{h}_{i j} u_{j}=\sum_{j=1}^{N} g_{i j} q_{j}
$$

A montagem da equação (4.11) é feita como explicado anteriormente, fornecendo matrizes $[H]$ e $[\mathrm{G}]$ de dimensão N x N. Os elementos de [H] são calculados por

$$
h_{i j}=\bar{h}_{i j}+\frac{1}{2} \delta_{i j}
$$

$\delta_{\mathrm{ij}}$ representa a função delta de Kronecker. 
O cálculo das matrizes $[\mathrm{H}]$ e $[\mathrm{G}]$ precisa considerar duas situações: $\mathrm{i} \neq \mathrm{j}$ e $\mathrm{i}=\mathrm{j}$. Isto deve-se ao fato da solução fundamental (equação (3.46) ou (3.48)) depender da distância $r=|\vec{R}|=\left|\vec{r}-\vec{r}^{\prime}\right|$ entre o ponto de aplicação da função impulsiva e o ponto de observação. Nos casos em que $\mathrm{i} \neq \mathrm{j}$, a distância $r$ nunca será nula. $\mathrm{O}$ caso $\mathrm{i}=\mathrm{j}$ ocorre quando o ponto de aplicação estiver no elemento sobre o qual efetua-se a integração; pela natureza da solução fundamental, seja nas situações bi ou tridimensionais, o integrando apresenta singularidade que precisa ser levantada a fim de se montar a equação matricial. As Figuras 4.7 e 4.8 exemplificam casos bidimensionais; os vetores $\vec{r}$ e $\vec{r}^{\prime}$ estão contidos no plano xy. Para a situação da figura $4.7(i \neq j)$ as integrações podem ser feitas numericamente, obtendo-se os elementos de matriz $h_{\mathrm{ij}}$ e $\mathrm{g}_{\mathrm{ij}}$; o método utilizado pode ser o da quadratura de Gauss, em virtude de sua simplicidade.

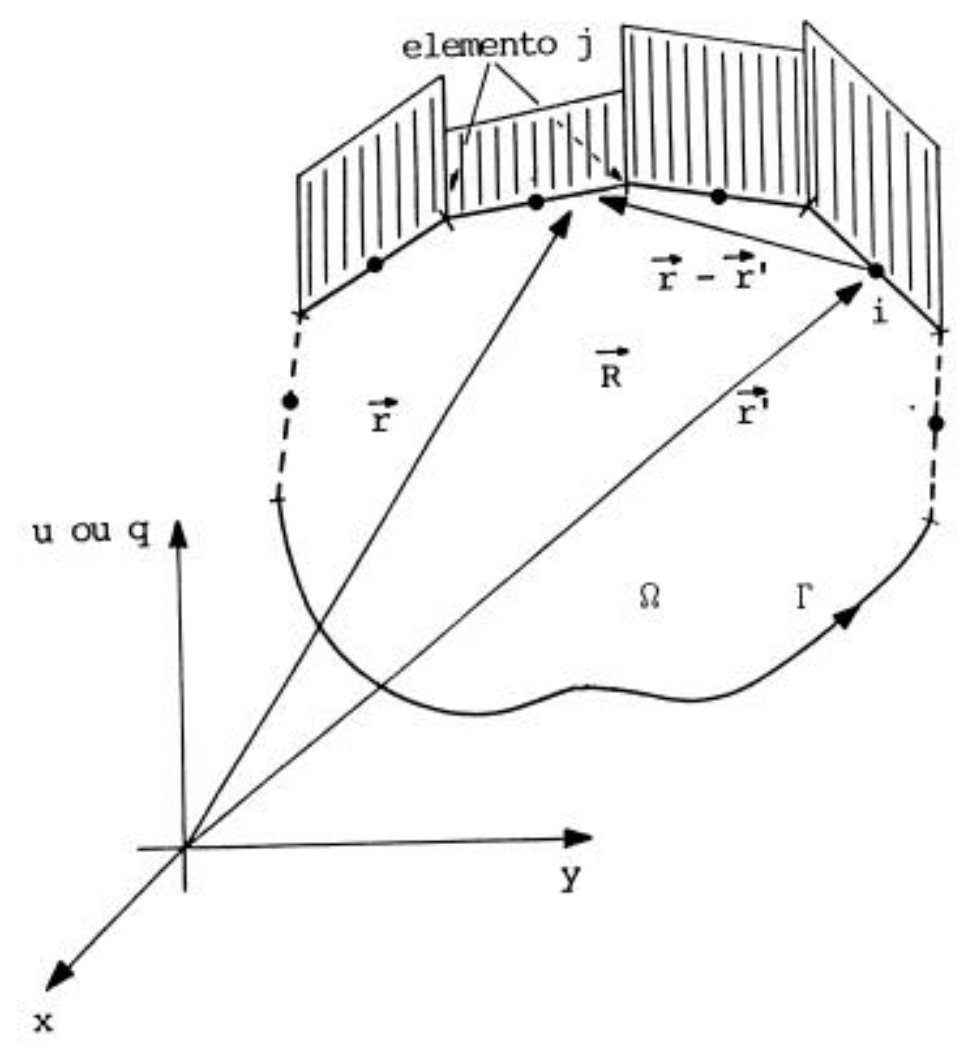

Figura 4.7: O ponto $i$ não pertence ao elemento sobre o qual se efetua a integração. 
No caso de elementos com formulação constante, se $\mathrm{i}=\mathrm{j}$ (figura 4.8), então os elementos das matrizes poderão ser calculados analiticamente; isto evitará perturbações numéricas decorrentes da singularidade da solução fundamental. Na matriz $[\mathrm{H}]$ tem-se

$$
\bar{h}_{i i}=\int_{\Gamma_{i}} q^{*} d \Gamma=\int_{\Gamma_{i}} \frac{\partial u^{*}}{\partial n} d \Gamma=\int_{\Gamma_{i}} \frac{\partial u^{*}}{\partial r} \frac{\partial r}{\partial n} d \Gamma \equiv 0
$$

pois $\partial \mathrm{r} / \partial \mathrm{n} \equiv 0$ pela ortogonalidade existente entre a direção normal ao elemento e a direção radial, medida ao longo do caminho $\Gamma_{\mathrm{i}}$ a partir do ponto de aplicação da excitação impulsiva, conforme esquematizado na figura 4.9.

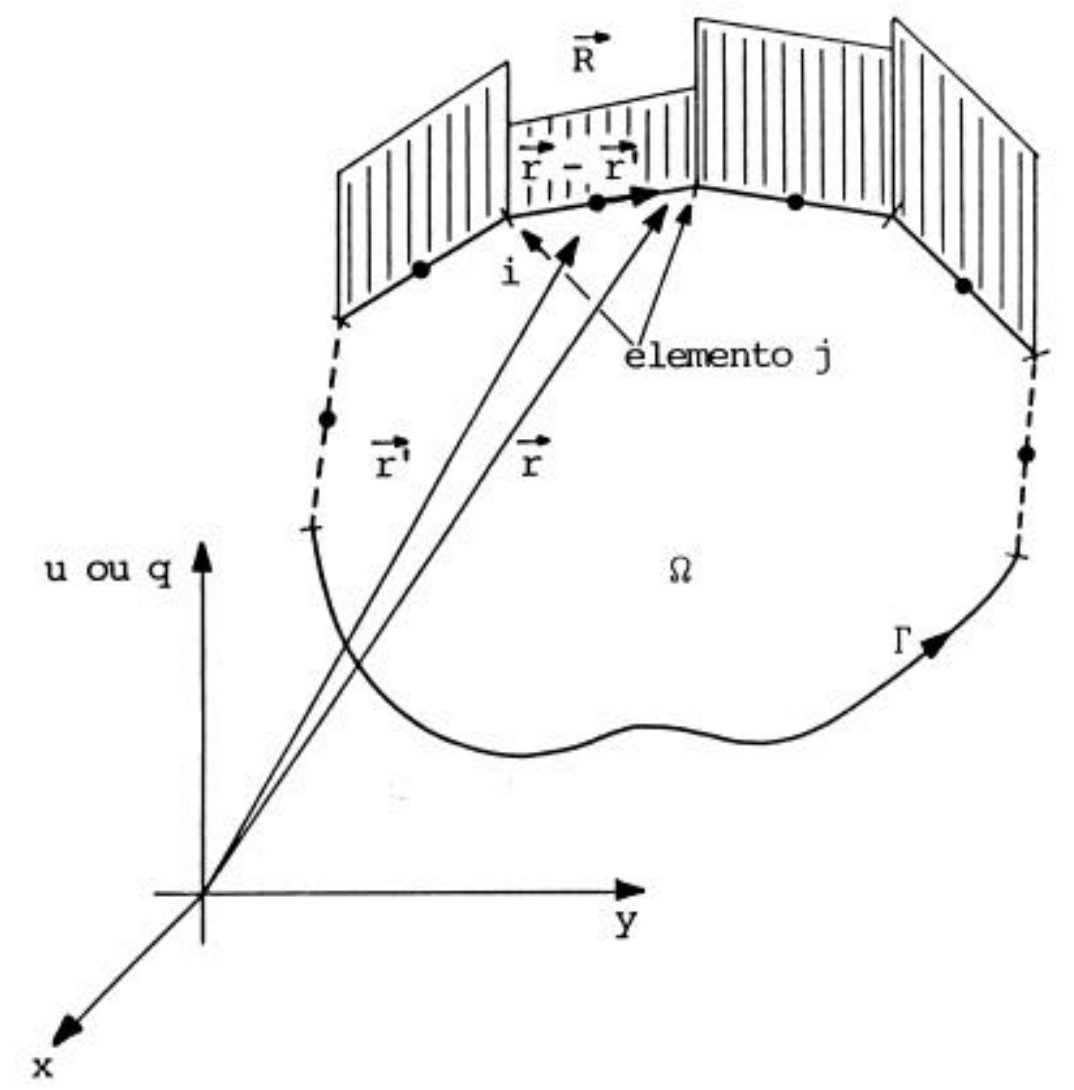

Figura 4.8: O ponto $i$ pertence ao elemento sobre o qual se efetua a integração. 


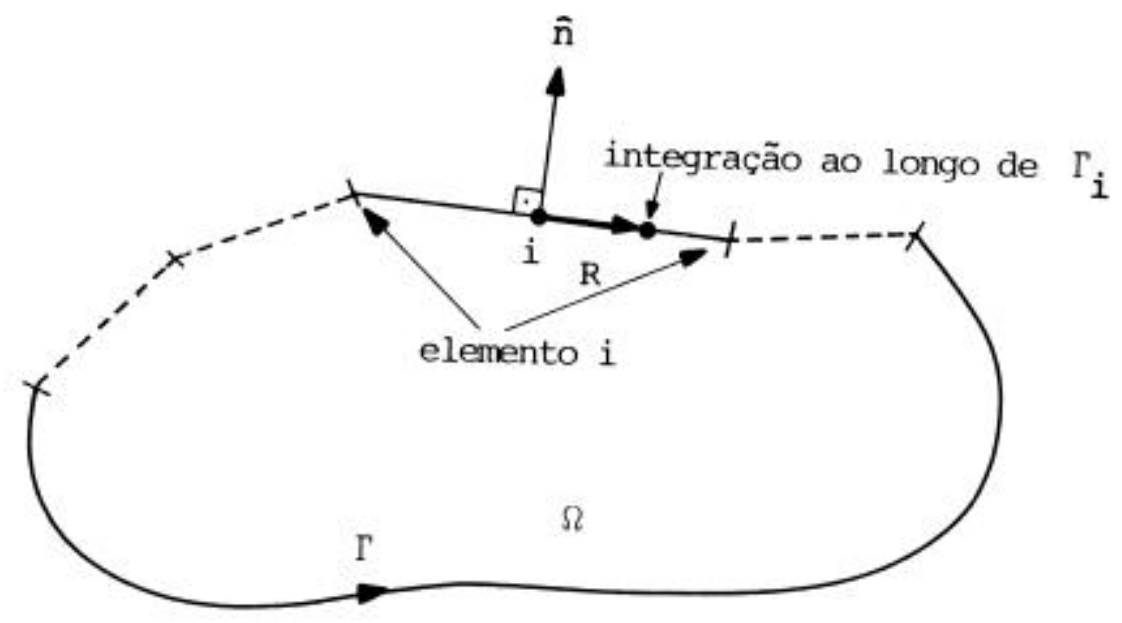

Figura 4.9: Integração ao longo do elemento no qual é aplicada a excitação.

Então, por força de (4.16), escreve-se

$$
h_{i ~ i ~}=1 / 2
$$

Na matriz $[\mathrm{G}]$ tem-se

$$
g_{i i}=\int_{\Gamma_{i}} u^{*} d \Gamma=\frac{j}{4} \int_{\Gamma_{i}} H_{0}^{(1)}(k r) d \Gamma
$$

Esta integração não pode ser efetuada analiticamente. O desenvolvimento a seguir dá atenção especial à singularidade existente se o argumento da função de Hankel tender a zero. A distância $r$ medida a partir do nó de função situado no meio do elemento de contorno sugere o emprego da mudança de variável (figura 4.10), tal que

$$
r=\left|\frac{l}{2} \xi\right|
$$

$l$ representa o comprimento do elemento considerado. 


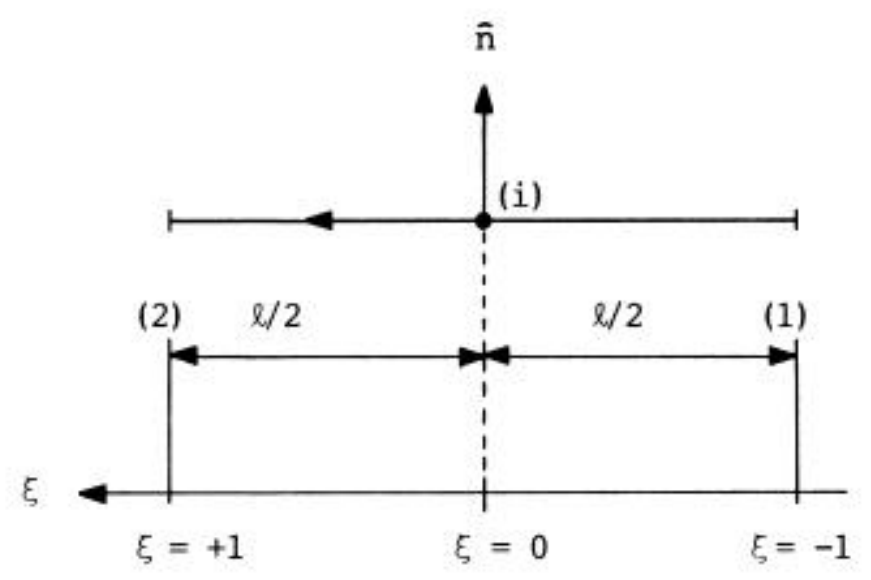

Figura 4.10: Coordenadas locais aplicadas ao elemento $i$ de comprimento $l$.

Procurando-se avaliar a integral pelo seu valor principal de Cauchy, escreve-se

$$
\begin{aligned}
g_{i i} & =\frac{j}{4} \frac{l}{2} \lim _{\varepsilon \rightarrow 0}\left\{\int_{-1}^{-\varepsilon} H_{0}^{(1)}\left(k \frac{l}{2}|\xi|\right) d \xi+\int_{\varepsilon}^{1} H_{0}^{(1)}\left(k \frac{l}{2}|\xi|\right) d \xi\right\} \\
& =\frac{j}{4} l \lim _{\varepsilon \rightarrow 0}\left\{\int_{\varepsilon}^{1} H_{0}^{(1)}\left(k \frac{l}{2} \xi\right) d \xi\right\} \\
& =\frac{j}{4} l\left[\int_{0}^{1} J_{0}\left(k \frac{l}{2} \xi\right) d \xi+j \lim _{\varepsilon \rightarrow 0} \int_{\varepsilon}^{1} Y_{0}\left(k \frac{l}{2} \xi\right) d \xi\right] \\
& =\frac{j}{4} l[L+j I]
\end{aligned}
$$

se o limite existir.

A primeira integral não tem solução analítica mas também não apresenta dificuldade de avaliação numérica. Reescrevendo-a em formato adequado para a aplicação das fórmulas de quadratura de Gauss, a partir da nova mudança de variável

$$
\xi=\frac{1+\eta}{2}
$$


resulta

$$
L=\frac{1}{2} \int_{-1}^{1} J_{0}\left(k \frac{l}{2} \frac{\eta+1}{2}\right) d \eta
$$

Na segunda integral, I, é necessário levantar-se a singularidade do integrando. Supondo que uma certa função $f(x)$ tenha singularidade em $x=c$, e que $a \leq x \leq b$, pode-se escrever

$$
I=\int_{a}^{b} f(x) d x=\int_{a}^{b}[f(x)-g(x)] d x+\int_{a}^{b} g(x) d x
$$

Se $g(x)$ tiver o mesmo tipo de singularidade de $f(x)$ e a última integral em (4.24) puder ser calculada analitica ou numericamente, então o membro direito desta equação é uma alternativa para o cálculo de I. Este procedimento é conhecido como Método de Subtração de Singularidade (MSS).

O integrando de I em (4.21) pode ser colocado sob a forma

$$
Y_{0}(x)=\frac{2}{\pi}\{\ln (x / 2)+\gamma\} J_{0}(x)+h(x)
$$

A função $h(x)$ representa uma série infinita convergente de potências de $x^{2}$ e, portanto, não apresenta singularidade. Aplicando a equação (4.25) ao integrando de I, vem

$$
\begin{aligned}
Y_{0}\left(k \frac{l}{2} \xi\right) & =Y_{0}(k r) \\
& =\frac{2}{\pi} J_{0}(k r) \ln r+\frac{2}{\pi} J_{0}(k r)[\ln k-\ln 2+\gamma]+h(k r) \\
& =\frac{2}{\pi} J_{0}(k r) \ln r+g(k r)
\end{aligned}
$$

sendo que $\mathrm{g}(\mathrm{kr})$ também não apresenta singularidade.

Aplicando-se o MSS à última equação, tem-se 


$$
\begin{aligned}
I & =\int_{0}^{1}\left[Y_{0}(k r)-\frac{2}{\pi} J_{0}(k r) \ln r\right] d \xi+\int_{0}^{1} \frac{2}{\pi} J_{0}(k r) \ln r d \xi \\
& =I 1+I 2
\end{aligned}
$$

nesta ordem.

A integral I1 pode agora ser resolvida numericamente. A integral I2, equivalente à última parcela de (4.24), ainda precisa ser colocada sob forma apropriada para integração numérica. Como os limites da integração em $\xi$ são zero e 1, pode-se escrever

$$
r=\frac{l}{2} \xi
$$

Resulta então

$$
I 2=\frac{2}{\pi} \ln \left(\frac{l}{2}\right) \int_{0}^{1} J_{0}\left(k \frac{l}{2} \xi\right) d \xi-\frac{2}{\pi} \int_{0}^{1} J_{0}\left(k \frac{l}{2} \xi\right) \ln \left(\frac{1}{\xi}\right) d \xi
$$

A integral na primeira parcela do membro direito de (4.29) tem o mesmo valor da equação (4.23). A segunda parcela já está sob forma adequada para integração numérica.

Reunindo-se os resultados de (4.21), (4.23) e (4.29) escreve-se a expressão de $g_{\text {ii }}$ tal como será aproximada para a futura avaliação numérico-computacional, isto é

$$
\begin{aligned}
g_{i i}= & {\left[-\frac{(l / 2)}{2} \frac{1}{2}\right]_{-1}^{1} \int\left[Y_{0}\left(k \frac{l}{2} \frac{1+\eta}{2}\right)-\frac{2}{\pi} J_{0}\left(k \frac{l}{2} \frac{1+\eta}{2}\right) \ln \left(\frac{l}{2} \frac{1+\eta}{2}\right)\right] d \eta } \\
& +\frac{(l / 2)}{2} \frac{1}{2}\left[j-\frac{2}{\pi} \ln \left(\frac{l}{2}\right)\right]_{-1}^{1} \int_{0} J_{0}\left(k \frac{l}{2} \frac{1+\eta}{2}\right) d \eta \\
& +\frac{(l / 2)}{2}\left(\frac{2}{\pi}\right) \int_{0}^{1} J_{0}\left(k \frac{l}{2} \xi\right) \ln \left(\frac{1}{\xi}\right) d \xi
\end{aligned}
$$

que, por conveniência futura e simplicidade, é identificada com

$$
g_{i i}=\left[-\frac{(l / 2)}{2} \frac{1}{2}\right] A+\frac{(l / 2)}{2} \frac{1}{2}\left[j-\frac{2}{\pi} \ln \left(\frac{l}{2}\right)\right] B+\frac{(l / 2)}{2}\left(\frac{2}{\pi}\right) C
$$




\subsection{Formulação com elementos lineares}

Como se trata de uma formulação isoparamétrica, são iguais os números de nós geométricos e de nós da variável. Neste caso, por simplicidade, cada nó é colocado na extremidade do elemento; assim cada elemento tem dois nós a ele associados. As expressões de descrição da geometria (equação (4.1)) e das variáveis (funções) (equação (4.3)) estabelecem os elementos isoparamétricos. A equação (3.87) fica particularizada a

$$
c_{i} u_{i}+\sum_{j=1}^{N} \int_{\Gamma_{j}}\left[\varphi_{1} \varphi_{2}\right] q^{*} d \Gamma\left[\begin{array}{l}
u_{1} \\
u_{2}
\end{array}\right]_{j}=\sum_{j=1}^{N} \int_{\Gamma_{j}}\left[\varphi_{1} \varphi_{2}\right] u^{*} d \Gamma\left[\begin{array}{l}
q_{1} \\
q_{2}
\end{array}\right]_{j}
$$

Reescrevendo-a, tem-se

$$
c_{i} u_{i}+\sum_{j=1}^{N}\left[\begin{array}{ll}
h 1_{i j} & h 2_{i j}
\end{array}\right]\left[\begin{array}{l}
u_{1} \\
u_{2}
\end{array}\right]_{j}=\sum_{j=1}^{N}\left[\begin{array}{ll}
g 1_{i j} & g 2_{i j}
\end{array}\right]\left[\begin{array}{l}
q_{1} \\
q_{2}
\end{array}\right]_{j}
$$

As integrais $h_{\mathrm{ij}}$ e gk $\mathrm{ij}_{\mathrm{ij}}$ atuam como coeficientes de influência entre o ponto $i$ de aplicação e o k-ésimo nó do elemento j.

A montagem da equação (4.11) é feita ordinariamente como na seção anterior, mas tendo atenção ao tratamento de "cantos" na fronteira. Conforme indicado nas Figuras 4.11 e 4.12 a formulação linear pode permitir que se especifiquem derivadas normais distintas na intersecção de elementos adjacentes a fim de contemplar mudanças na direção normal aos elementos ao longo de um percurso. O mesmo já não ocorre para o potencial pois ele é único em cada ponto do contorno e, assim, não oferece maiores dificuldades, podendo-se agrupar seus valores, dois a dois. 


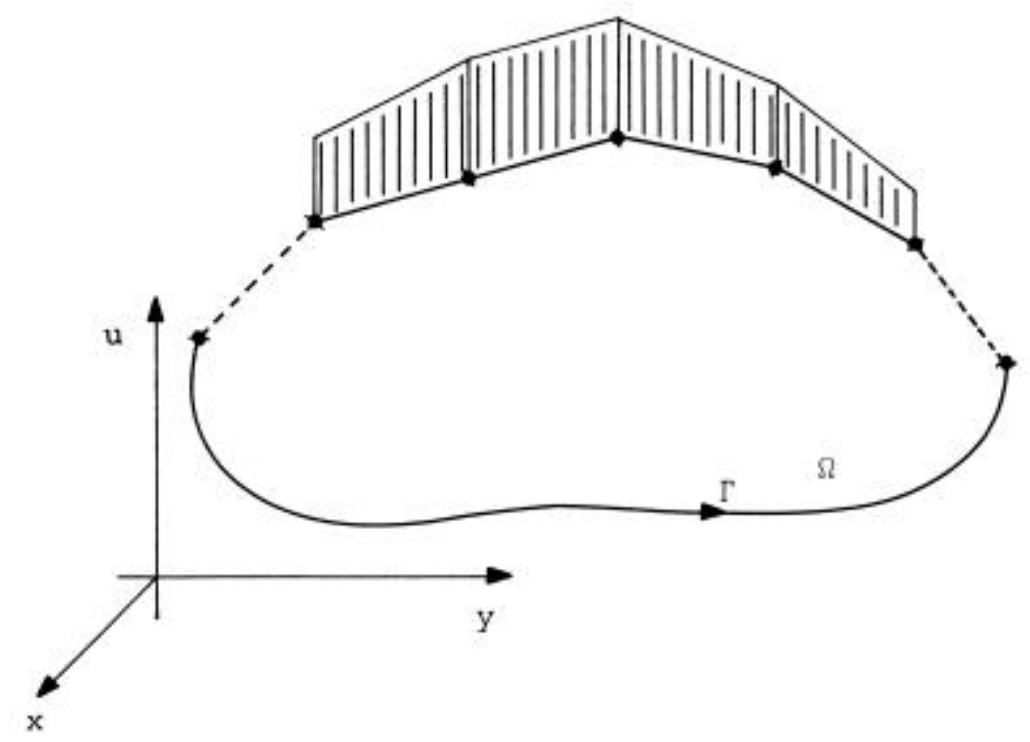

Figura 4.11: Ilustração do conceito de variação linear do potencial.

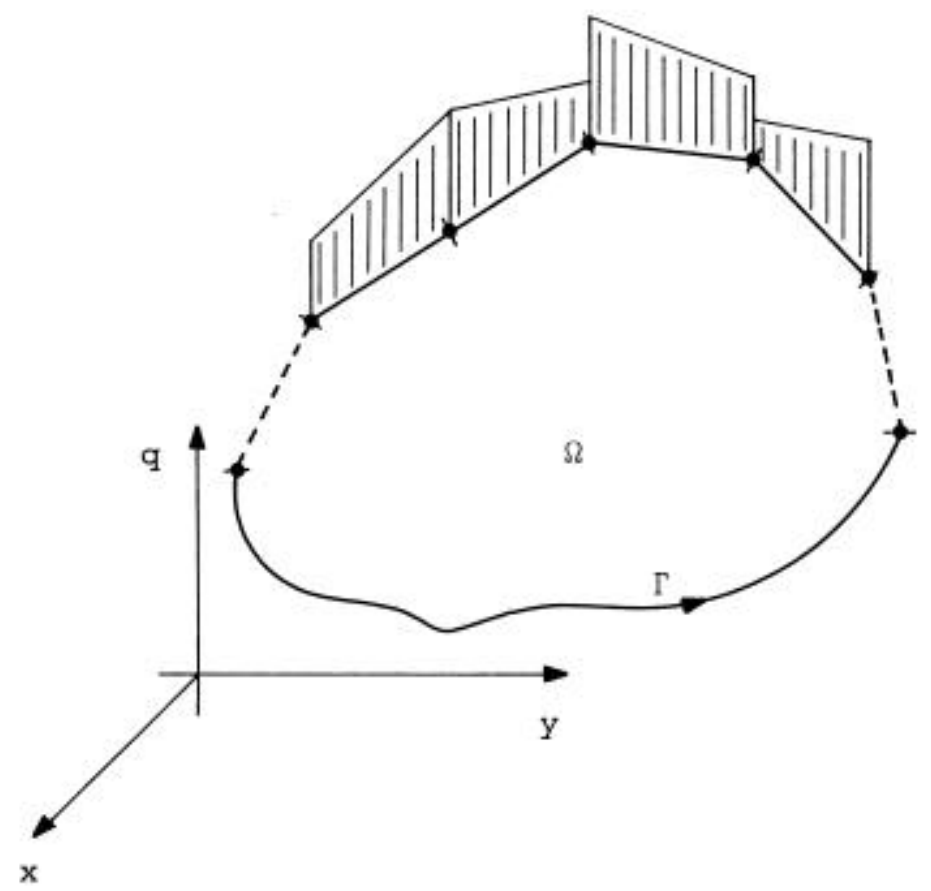

Figura 4.12: Ilustração do conceito de variação linear da derivada normal do potencial e sua descontinuidade. 
Como o segundo nó de um elemento j corresponde ao mesmo ponto associado ao primeiro nó do elemento j+1 é desejável que se coloquem os valores nodais da derivada normal em um vetor coluna de dimensão $2 \mathrm{~N}$. Varrendo-se todos os $\mathrm{N}$ elementos do contorno reescreve-se a equação (4.33) usando numeração global para os nós,

$$
c_{i} u_{i}+\left[\bar{h}_{i 1} \bar{h}_{i 2} \ldots \bar{h}_{i N}\right]\left[\begin{array}{c}
u_{1} \\
u_{2} \\
\vdots \\
u_{N}
\end{array}\right]=\left[\begin{array}{lll}
g_{i 1} g_{i 2} \ldots g_{i 2 N}
\end{array}\right]\left[\begin{array}{c}
q_{1} \\
q_{2} \\
\vdots \\
q_{2 N}
\end{array}\right]
$$

Cada elemento $\bar{h}_{i k}$ do vetor é formado pela soma das parcelas h1 do elemento k e h2 do elemento k-1, ou seja:

$$
\begin{aligned}
& \bar{h}_{i 1}=h 2_{i N}+h 1_{i 1} \\
& \vdots \\
& \bar{h}_{i k}=h 2_{i k-1}+h 1_{i k} \\
& \vdots \\
& \bar{h}_{i N}=h 2_{i N-1}+h 1_{i N}
\end{aligned}
$$

Da equação (4.34) vem

$$
c_{i} u_{i}+\sum_{j=1}^{N} \bar{h}_{i j} u_{j}=\sum_{j=1}^{2 N} g_{i j} q_{j},
$$

que pode ser compactada com a ajuda da equação

$$
h_{i j}=\bar{h}_{i j}+c_{i} \delta_{i j}
$$

fornecendo

$$
\sum_{j=1}^{N} h_{i j} u_{j}=\sum_{j=1}^{2 N} g_{i j} q_{j}
$$


As equações (4.34), (4.36) e (4.38), equivalentes entre si, representam a equação relacionada ao nó i. O estabelecimento de $[\mathrm{H}]\{\mathrm{u}\}=[\mathrm{G}]\{\mathrm{q}\}$, com $\mathrm{N}$ incógnitas, é, como antes, obtido aplicando-se a excitação impulsiva a todos os nós do contorno. A matriz [H] mantém sua dimensão $\mathrm{N}$ x N; a matriz [G] deixa de ser quadrada e passa a ter dimensão $\mathrm{N}$ x $2 \mathrm{~N}$ por atender descontinuidades de $\partial \mathrm{u} / \partial \mathrm{n}$.

De forma análoga à situação de elementos constantes as integrais

$$
\begin{aligned}
& h 1_{i j}=\int_{\Gamma_{j}} \varphi_{1} q^{*} d \Gamma=\int_{\Gamma_{j}} \frac{1}{2}(1-\xi) q^{*} d \Gamma \\
& h 2_{i j}=\int_{\Gamma_{j}} \varphi_{2} q^{*} d \Gamma=\int_{\Gamma_{j}} \frac{1}{2}(1+\xi) q^{*} d \Gamma \\
& g 1_{i j}=\int_{\Gamma_{j}} \varphi_{1} u^{*} d \Gamma=\int_{\Gamma_{j}} \frac{1}{2}(1-\xi) u^{*} d \Gamma
\end{aligned}
$$

$\mathrm{e}$

$$
g 2_{i j}=\int_{\Gamma_{j}} \varphi_{2} u^{*} d \Gamma=\int_{\Gamma_{j}} \frac{1}{2}(1+\xi) u^{*} d \Gamma
$$

são calculadas numericamente sempre que $i$ não pertencer ao elemento $\mathrm{j}$.

Quando o nó i pertencer ao elemento j algumas integrações resultarão nulas; outras ainda poderão ser avaliadas numericamente. Assim, utilizando indexação global relativa aos nós (figura 4.13), tem-se

$$
\begin{aligned}
& h 1_{i j}=\int_{\Gamma_{j}} \varphi_{1} q^{*} d \Gamma=\int_{\Gamma_{j}} \varphi_{1} \frac{\partial u^{*}}{\partial r} \frac{\partial r}{\partial n} d \Gamma \equiv 0 \\
& h 2_{i j}=\int_{\Gamma_{j}} \varphi_{2} q^{*} d \Gamma=\int_{\Gamma_{j}} \varphi_{2} \frac{\partial u^{*}}{\partial r} \frac{\partial r}{\partial n} d \Gamma \equiv 0
\end{aligned}
$$


sempre que $\mathrm{i}=\mathrm{j}$ e $\mathrm{i}=\mathrm{j}+1$, ou seja se $i$ estiver em um dos nós que definem o elemento $\mathrm{j}$. Estes resultados são justificados pelas mesmas razões mencionadas na avaliação da equação (4.17).
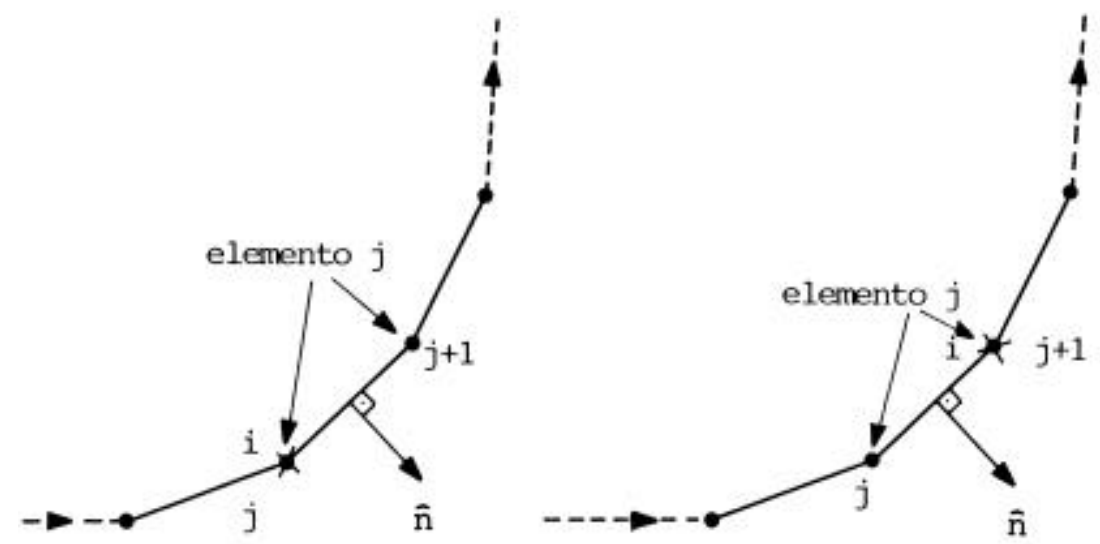

Fig. 4.13: (a) ponto de aplicação no início do elemento; (b) ponto de aplicação no fim do elemento.

Tendo em vista as relações (4.35) e a equação (4.37) pode-se escrever

$$
\mathrm{h}_{\mathrm{i} \mathrm{i}}=\mathrm{c}_{\mathrm{i}}
$$

Conclui-se ser necessário o conhecimento do ângulo interno do vértice associado a cada nó.

Há uma outra forma, computacionalmente mais vantajosa, para se determinar $h_{i i}$; ela será mencionada mais adiante, ainda nesta seção.

As integrações relativas à matriz $[\mathrm{G}]$ precisam considerar se o ponto (de aplicação) $i$ está no início $(i=j)$ do elemento $j$, ou no fim dele $(i=j+1)$.Iniciando com a condição $i=j$ e chamando compactamente as funções de forma por

$$
\varphi_{m}(\xi)=\left\{\begin{array}{l}
\varphi_{1} \\
\varphi_{2}
\end{array}\right\}=\frac{1}{2}\left\{\begin{array}{l}
1-\xi \\
1+\xi
\end{array}\right\}=\frac{1}{2}(1 \mp \xi), \quad \mathrm{m}=1,2
$$

tem-se 


$$
\begin{aligned}
g m_{i j} & =g m_{i i}=\int_{(1)}^{(2)} \varphi_{m} u^{*} d \Gamma=\frac{l}{2} \int_{-1}^{1} \varphi_{m} u^{*} d \xi \\
& =j \frac{l}{8} \int_{-1}^{1} \varphi_{m} H_{0}^{(1)}(k r) d \xi \\
& =j \frac{l}{8}\left\{\int_{-1}^{1} \varphi_{m} J_{0}(k r) d \xi+j \int_{-1}^{1} \varphi_{m} Y_{0}(k r) d \xi\right\}
\end{aligned}
$$

A integral da primeira parcela, como na seção anterior, não apresenta singularidade, mas a da segunda parcela, agora dividida em duas por causa da função de forma, fará com que uma delas deixe de ter singularidade.

Aplicando o método de subtração de singularidade,

$$
\begin{aligned}
\int_{-1}^{1} \varphi_{m} Y_{0}(k r) d \xi & =\int_{-1}^{1} \varphi_{m}\left\{Y_{0}(k r)-\frac{2}{\pi} J_{0}(k r) \ln r\right\} d \xi \\
& +\frac{2}{\pi} \ln l \int_{-1}^{1} \varphi_{m} J_{0}(k r) d \xi-\frac{4}{\pi} \int_{0}^{1} \varphi_{m} J_{0}(k \eta l) \ln \left(\frac{1}{\eta}\right) d \eta
\end{aligned}
$$

$\eta$ é uma nova variável adimensional introduzida para adequar os limites de integração às aproximações numéricas necessárias para a aplicação das fórmulas de quadratura (figura 4.14).

Vale

$$
\eta=\frac{1+\xi}{2}
$$

e, portanto,

$$
\varphi_{m}(\eta)=\left\{\begin{array}{c}
1-\eta \\
\eta
\end{array}\right\}, \quad \mathrm{m}=1,2
$$




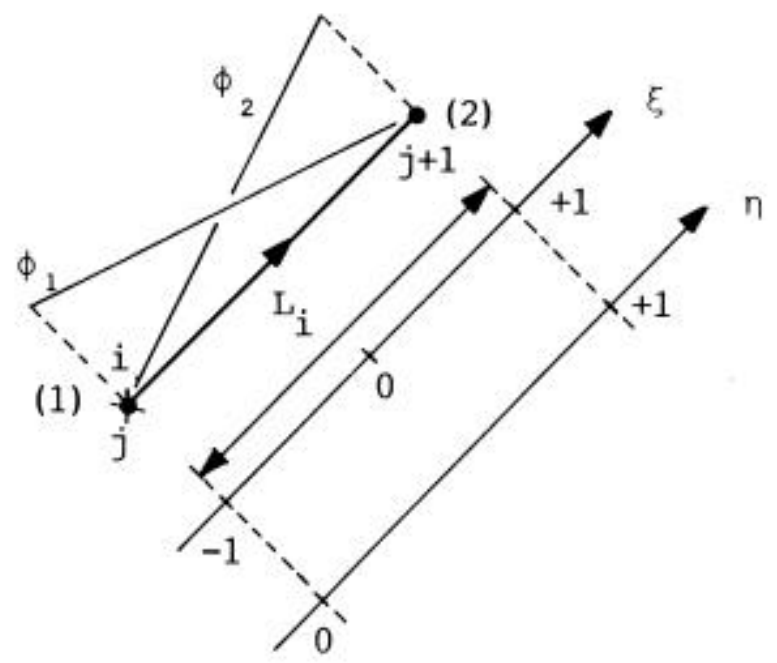

Figura 4.14: Ponto de aplicação no ínicio do elemento.

Aplicando os resultados de (4.44) em (4.43) pode-se escrever

$$
\begin{aligned}
g m_{i i}= & -\frac{(l / 2)}{8} \int_{-1}^{1}(1 \mp \xi)\left\{Y_{0}\left(k \frac{l}{2}(1+\xi)\right)-\frac{2}{\pi} J_{0}\left(k \frac{l}{2}(1+\xi)\right) \ln \left(\frac{l}{2}(1+\xi)\right)\right\} d \xi \\
& +\left[\frac{(l / 2)}{8}\left(j-\frac{2}{\pi} \ln l\right)\right] \int_{-1}^{1}(1 \mp \xi) J_{0}\left(k \frac{l}{2}(1+\xi)\right) d \xi \\
& +\frac{(l / 2)}{\pi} \int_{0}^{1}\left\{\begin{array}{c}
1-\eta \\
\eta
\end{array}\right\} J_{0}(k \eta l) \ln \left(\frac{1}{\eta}\right) d \eta, \quad \mathrm{m}=1,2
\end{aligned}
$$

que, na avaliação computacional, será identificada com

$$
g m_{i i}=-\frac{(l / 2)}{8}\left\{\begin{array}{l}
a 1 \\
a 2
\end{array}\right\}+\frac{(l / 2)}{8}\left[j-\frac{2}{\pi} \ln l\right]\left\{\begin{array}{l}
b 1 \\
b 2
\end{array}\right\}+\frac{(l / 2)}{\pi}\left\{\begin{array}{l}
c 1 \\
c 2
\end{array}\right\}
$$

Quando a fonte impulsiva estiver no fim do elemento sobre o qual é feita a integração $(i=j+1)$, situação representada na figura 4.15, os valores resultantes para

$$
\mathrm{g} 1_{\mathrm{ij}}=\mathrm{g} 1_{\mathrm{i}, \mathrm{i}-1}
$$

$\mathrm{e}$

$$
\mathrm{g} 2_{\mathrm{ij}}=\mathrm{g} 2_{\mathrm{i}, \mathrm{i}-1}
$$


devem ser intercambiados com os da equação (4.47).

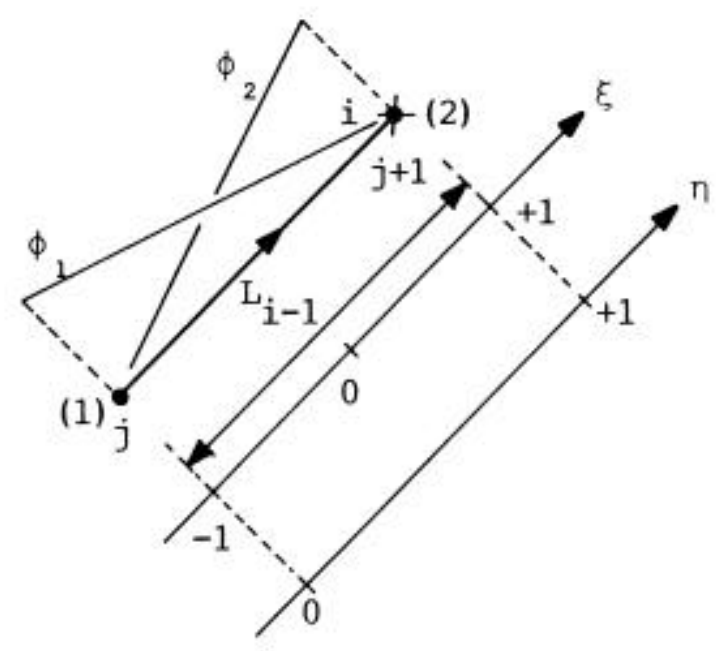

Figura 4.15: Ponto de aplicação no fim do elemento.

\subsection{Tratamento de cantos da geometria}

Uma questão importante que se apresenta está relacionada ao encaminhamento da solução da equação $[H]\{u\}=[G]\{q\}$. Algumas situações podem ocorrer:

- nó situado em porção suave do contorno $\left(c_{i}=0,5\right)$ :

considerando o sentido de circulação do contorno, não há razão física para que o valor da derivada na normal, $q$, no elemento anterior ao nó e na sua vizinhança seja diferente do valor no elemento posterior ao mesmo nó e na sua vizinhança. Chamando estas derivadas de "anterior" e "posterior", então no nó considerado pode-se

a) conhecer o potencial $u$ e desconhecer a derivada na normal $q$ ou

b) vice-versa.

Em ambos os casos tem-se uma incógnita por nó. 
- nó situado em "canto” do contorno $\left(c_{i} \neq 0,5\right)$ :

a derivada "anterior" pode ser diferente da derivada "posterior". Seis possibilidades existem.

a) $q$ "anterior" e "posterior" conhecidos; potencial $u$ desconhecido;

b) potencial $u$ e $q$ "anterior" conhecidos; $q$ "posterior" desconhecido;

c) potencial $u$ e $q$ "posterior" conhecidos; $q$ "anterior" desconhecido;

d) potencial $u$ conhecido; valores de $q$ desconhecidos;

e) $q$ "anterior" conhecido; $q$ "posterior" e potencial $u$ desconhecidos;

f) $q$ "posterior" conhecido; $q$ "anterior" e potencial $u$ desconhecidos.

Nos casos $a, b$ e $c$ existe apenas uma incógnita por nó. O sistema de equações terá solução única pois consiste em $\mathrm{N}$ equações lineares a $\mathrm{N}$ incógnitas.

Os casos $d$, e e $f$ apresentam duas incógnitas e precisam ser considerados. No sistema de equações lineares não homogêneas, é necessário obter-se mais uma equação para o nó. Historicamente algumas abordagens foram feitas.

1) Arredondamento do canto: propõe a substituição do nó por outros dois novos nós, próximos a ele (figura 4.16). O inconveniente desta abordagem é que a proximidade entre $\mathrm{P}_{1}$ e $\mathrm{P}_{2}$ piora o condicionamento das matrizes, com conseqüente degradação de precisão.
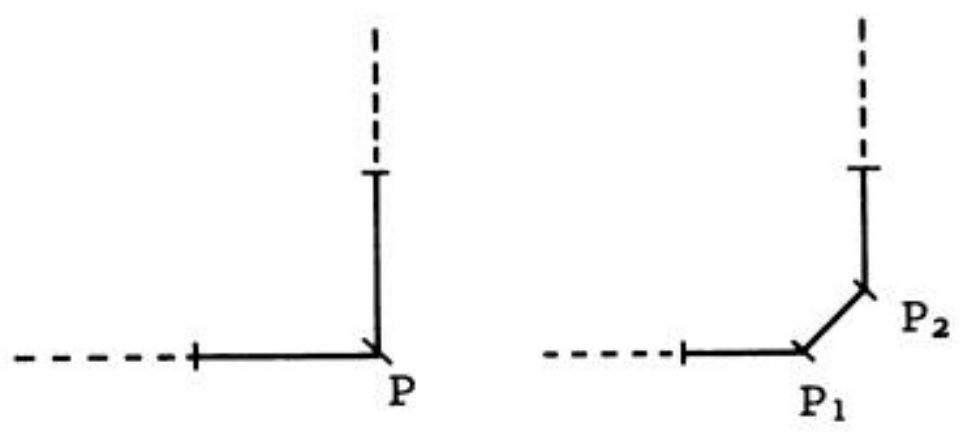

Figura 4.16: Arredondamento de canto do contorno. 
2) Uso de elementos descontínuos: a idéia parte do princípio de que o "problema" acima existe porque nos elementos de fronteira ordinários os valores nodais utilizados na interpolação das variáveis são definidos nos

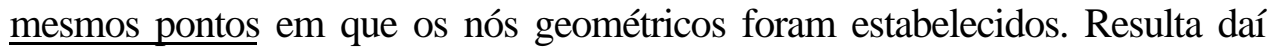
que o fluxo é indeterminado já que a direção normal em um canto de geometria não tem definição única. A figura 4.17 sugere a idéia dos elementos descontínuos aplicada a um elemento linear.

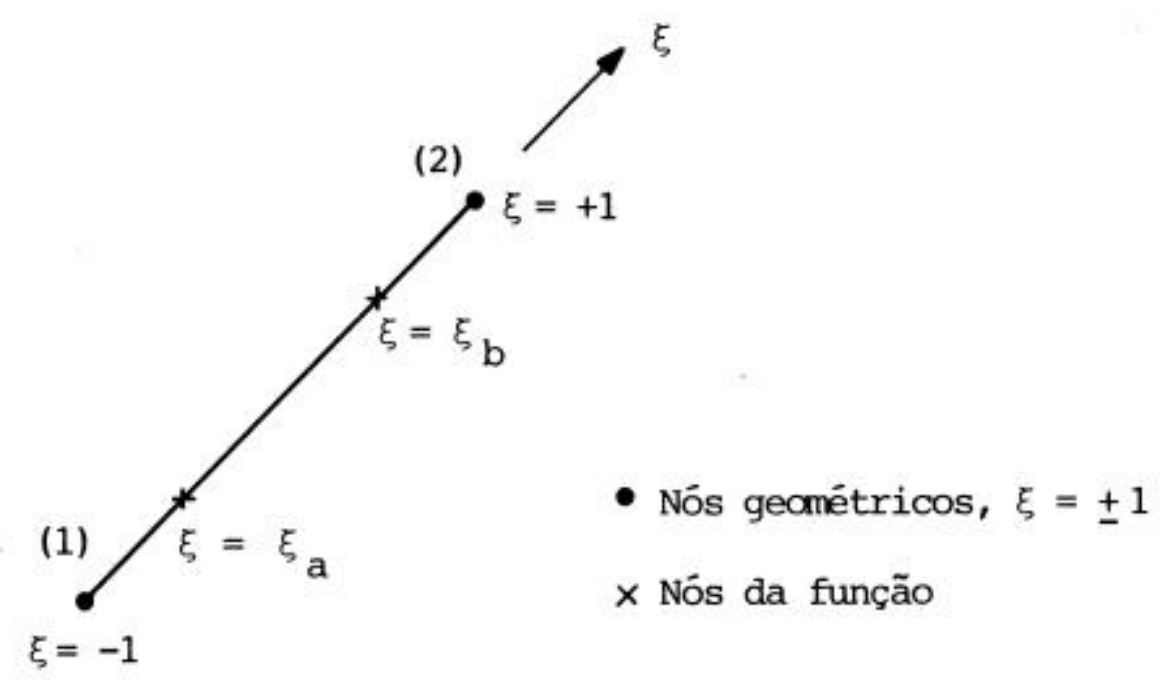

Figura 4.17: Elemento descontínuo linear.

Supondo que o elemento esteja num canto da geometria, os nós da função podem ser arbitrariamente deslocados de seus extremos (figura 4.18). 


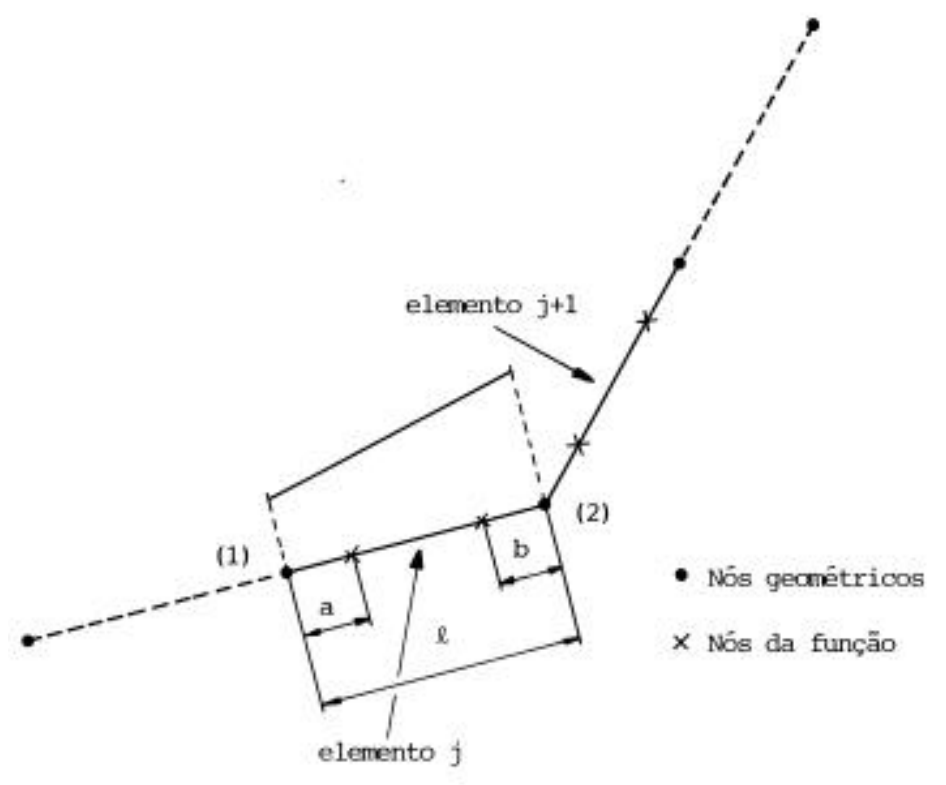

Figura 4.18: O valor da função ao longo do elemento é obtido por interpolação ou extrapolação $\left(-1 \leq \xi<\xi_{\mathrm{a}}\right.$ ou $\left.\xi_{\mathrm{b}}<\xi \leq+1\right)$.

Tendo em vista as funções de forma utilizadas na equação (4.3), pode-se escrever

$$
u(\xi)=\left[\varphi_{1} \varphi_{2}\right]\left[\begin{array}{l}
u_{1} \\
u_{2}
\end{array}\right]_{j}=\left[\varphi_{1} \varphi_{2}\right][Q]\left[\begin{array}{l}
u_{a} \\
u_{b}
\end{array}\right]_{j}
$$

onde a matriz [Q] serve para transladar o ponto em que se avalia o potencial e é dada por

$$
[Q]=\frac{1}{l-a-b}\left[\begin{array}{cc}
l-b & -a \\
-b & l-a
\end{array}\right] .
$$

Equação semelhante a (4.51) pode ser escrita para a derivada normal do potencial; este procedimento equivale a efetuar uma interpolação para obter os valores nos nós da função. 
A equação integral de contorno é de novo reeescrita após a discretização do contorno (equação (4.7)); a única diferença é que, sendo o elemento j um elemento descontínuo, as integrações ao longo dele são expressas por

$$
\int_{\Gamma_{j}} u q^{*} d \Gamma=\int_{\Gamma_{j}}\left[\varphi_{1} \varphi_{2}\right][Q] q^{*} d \Gamma\left[\begin{array}{l}
u_{a} \\
u_{b}
\end{array}\right]_{j}=\left[h a_{i j} h b_{i j}\right]\left[\begin{array}{l}
u_{a} \\
u_{b}
\end{array}\right]_{j}
$$

e

$$
\int_{\Gamma_{j}} q u^{*} d \Gamma=\int_{\Gamma_{j}}\left[\varphi_{1} \varphi_{2}\right][Q] u^{*} d \Gamma\left[\begin{array}{c}
q_{a} \\
q_{b}
\end{array}\right]_{j}=\left[g a_{i j} g b_{i j}\right]\left[\begin{array}{c}
q_{a} \\
q_{b}
\end{array}\right]_{j}
$$

ambas calculadas numericamente.

Mesmo se tratando de elementos lineares, pode-se aplicar $c_{i}=1 / 2$ na equação integral de contorno quando o ponto de aplicação estiver sobre o nó da função de elemento descontínuo, pois neste ponto o contorno é suave por construção; ainda neste caso as integrações podem ser efetuadas analiticamente.

3) Uso de elementos parcialmente descontínuos: os elementos descontínuos podem introduzir descontinuidades desnecessárias em porções regulares da geometria (nó (1) da figura 4.18). Nestes casos é mais vantajosa a utilização de elementos parcialmente descontínuos. Eles permitem a descontinuidade da função apenas em pontos selecionados como, por exemplo, os cantos da geometria. Um dos nós da função é mantido em $\xi=+1$ ou $\xi=-1$, conforme a necessidade de garantir a continuidade (figura 4.19). 


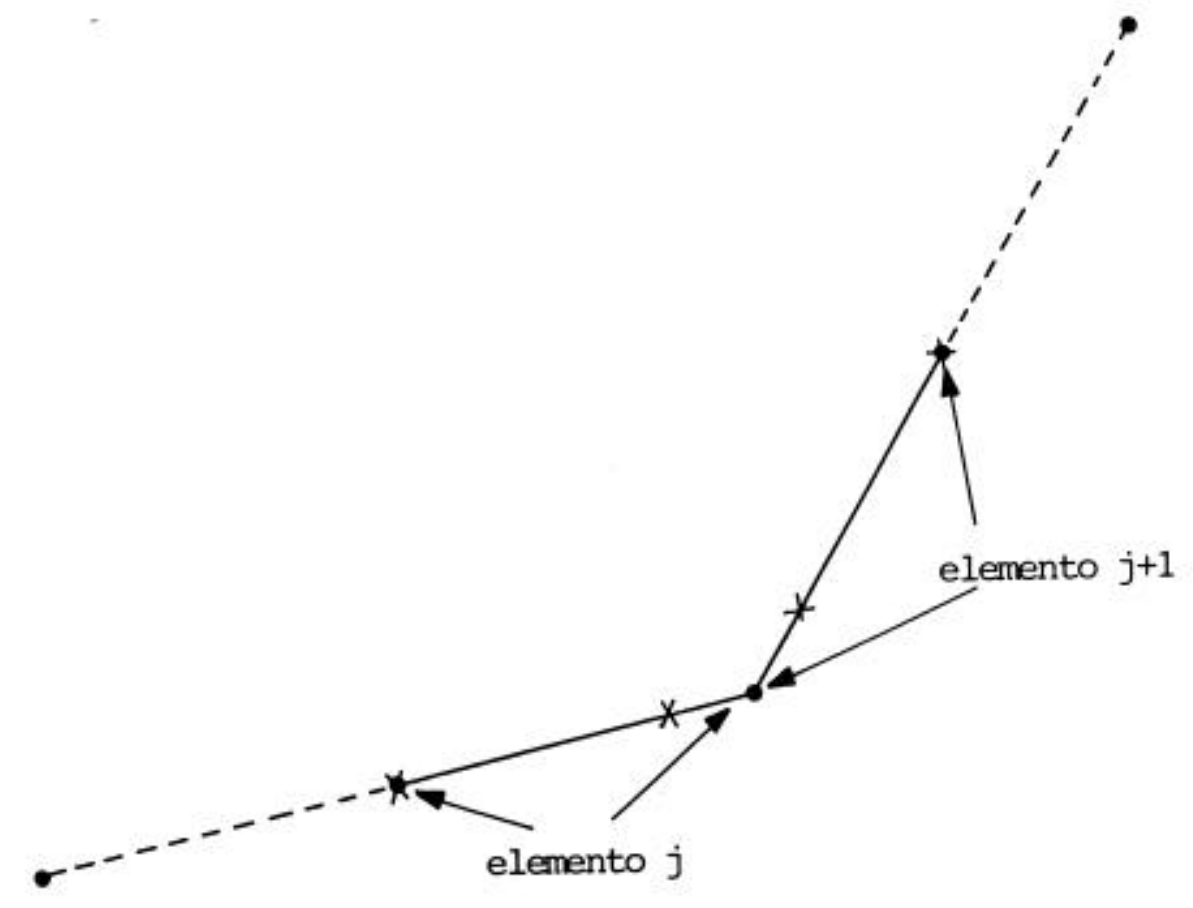

Figura 4.19: Elemento parcialmente descontínuo. 


\section{Implementação}

Os tópicos vistos nos capítulos anteriores constituem o cerne de qualquer aplicação que utilize o Método dos Elementos de Contorno (MEC). Como nos demais métodos numéricos, é necessário considerar vários aspectos para uma adequada implementação, independentemente de sua maior ou menor sofisticação. Isto será abordado neste capítulo e está relacionado ao desenvolvimento de ferramentas computacionais dedicadas ao estudo de propagação de ondas guiadas. Os códigos desenvolvidos atendem unicamente casos bidimensionais.

Conforme mencionado, o trabalho objetiva a aplicação do método a problemas de propagação, que exigem procedimentos específicos. Há, entretanto, pontos em comum entre a aplicação básica do método à equação de Poisson/Laplace e o problema proposto, como será visto. Por este motivo, inicia-se pela apresentação da metodologia básica desenvolvida e, a seguir, são detalhados procedimentos específicos relativos à equação de Helmholtz.

\subsection{Metodologia básica}

Ela é utilizada nas aplicações do MEC a problemas regidos pela equação de Poisson/Laplace e, em casos simples, também pela equação de Helmholtz; pode ser resumida como sendo uma aplicação direta do método, ou seja:

- conhecendo-se $\bar{u}$ em $\Gamma_{1}$ e $\bar{q}$ em $\Gamma_{2}$, então

- a resolução do sistema de equações torna conhecidos os valores de $u$ em $\Gamma_{2} \mathrm{e}$ $q$ em $\Gamma_{1}, \mathrm{e}$ 
- a partir dos itens anteriores, a aplicação numérica da formulação integral de contorno permite o cálculo da variável da equação em estudo em qualquer ponto interno ao domínio.

O diagrama de fluxo da figura 5.1 apresenta os procedimentos envolvidos.

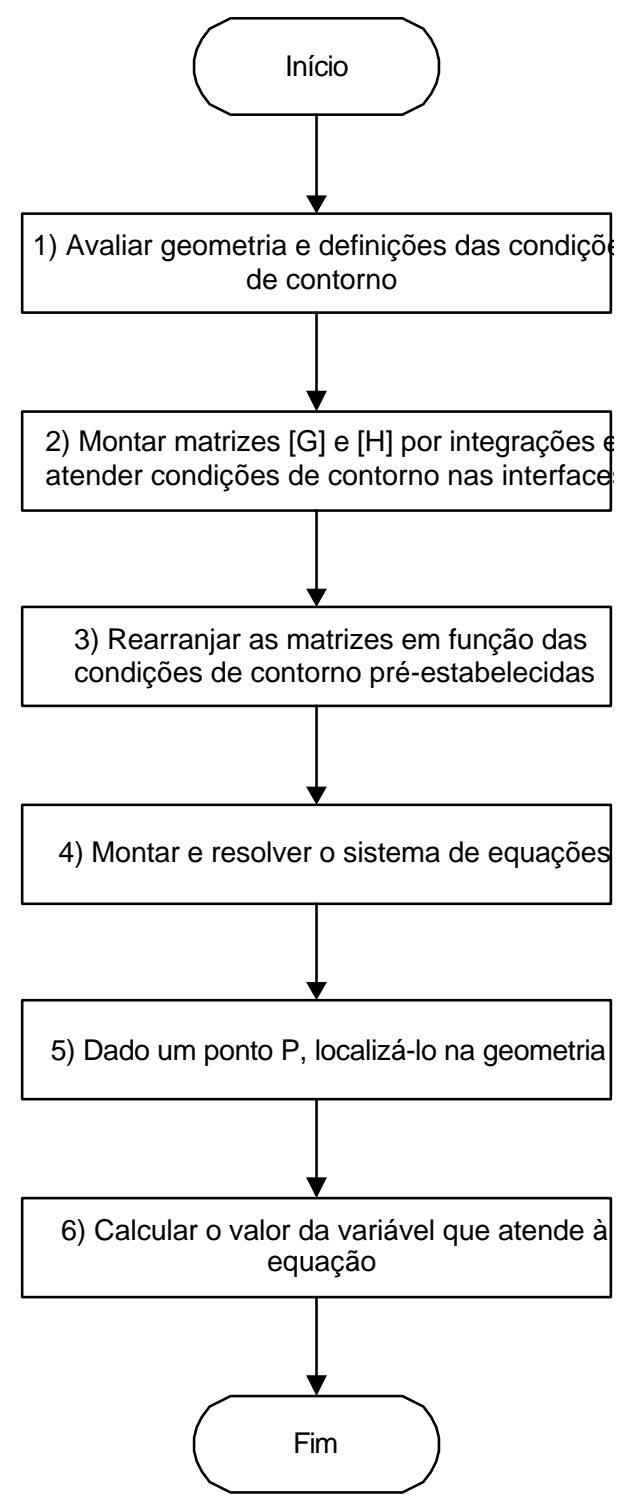

Figura 5.1: Diagrama de fluxo básico 
Nos programas desenvolvidos para aplicação de metodologia básica, os procedimentos indicados na figura 5.1 foram agrupados em subrotinas, exceção feita às de número 5 e 6 , reunidas em subrotina única.

É fácil perceber que a seqüência apresentada não é a mais apropriada para a resolução da equação de Helmholtz quando aplicada a estruturas práticas porque o primeiro item não pode ser admitido a priori.

Como exemplo da limitação desta metodologia, quando aplicada à equação de Helmholtz, considere-se a geometria (bidimensional) de um guia de ondas retangular cuja secção transversal está na figura 5.2.

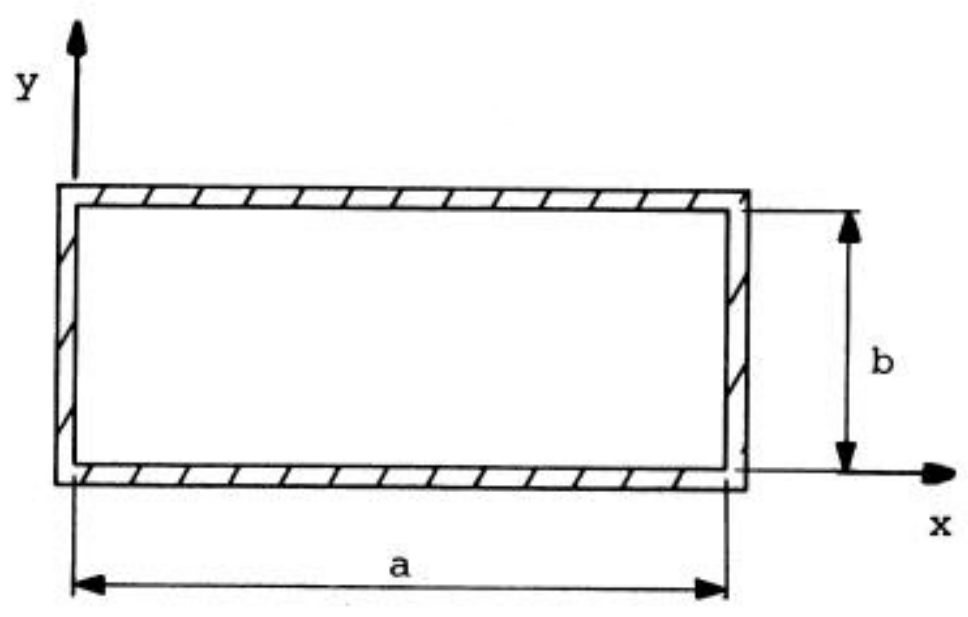

Figura 5.2: Secção transversal de guia de onda retangular.

Supondo arbitrariamente o estabelecimento do modo $\mathrm{TE}_{11}$, pode-se avaliar a distribuição de $\mathrm{E}_{\mathrm{y}}(\mathrm{x}, \mathrm{y})$ em todo o interior do guia, desde que

- se aplique nos elementos de contorno valores de potencial $u$ que correspondam a Ey para $\mathrm{TE}_{11}$;

- o número de onda seja o do modo considerado. 
Isto, então, equivale a resolver a equação

$$
\nabla^{2} E_{y}+k^{2} E_{y}=0
$$

sujeita às condições de contorno adequadas.

O mesmo procedimento pode ser efetuado para obter-se $E_{x}(x, y)$, ou seja resolver

$$
\nabla^{2} E_{x}+k^{2} E_{x}=0
$$

Trata-se da resolução da equação vetorial de Helmholtz separando-a em equações escalares. Verificada a necessidade de uma extensão do método, a seguir serão tratados inicialmente os procedimentos básicos. Assim, o procedimento 1 (figura 5.1) será descrito nos itens 5.2 a 5.4, o procedimento 2 no item 5.5, os procedimentos 3 e 4 no item 5.6 e os procedimentos 5 e 6 no item 5.7.

\subsection{Avaliação da geometria do problema}

Mencionando de forma muito simplificada, a aplicação do MEC aos problemas de ondas guiadas com modelamento bidimensional resume-se a solucionar a equação de Helmholtz em domínios sujeitos a certas condições de contorno. Obviamente, a geometria do problema tem que ser conhecida e a elaboração de um algoritmo que a interprete implica tarefas mais elaboradas do que a simples leitura de uma sequiência de pares coordenados que definem os elementos de contorno que discretizam a geometria. As figuras 5.3, 5.4 e 5.6 exemplificam situações básicas, a partir das quais podem ser consideradas quaisquer outras. 
a) Geometria de domínio fechado, simplesmente conexo

Na figura 5.3, equivalente à figura 3.1, mostra-se a situação mais simples possível, cuja discretização, dependendo da formulação, pode ser vista nas figuras 4.1 a 4.3.

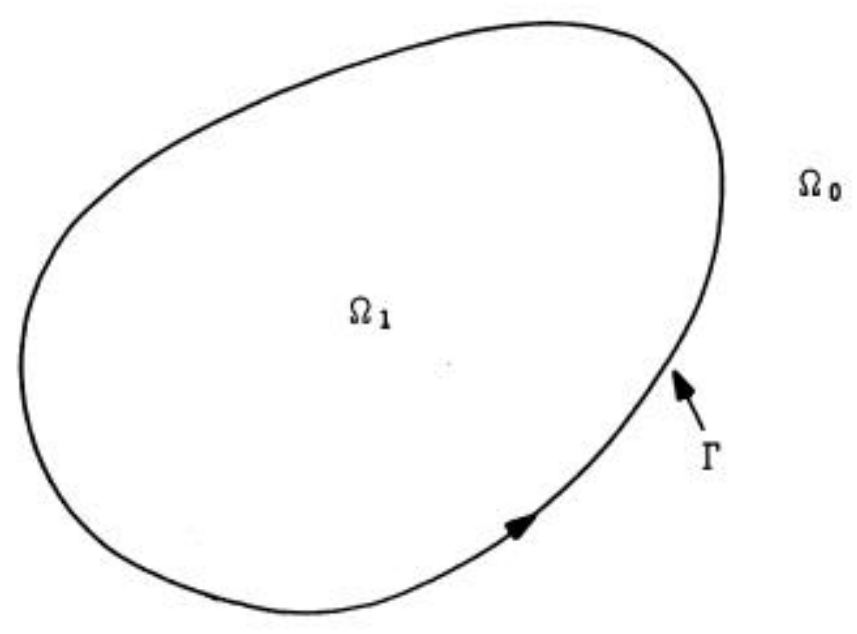

Figura 5.3: Domínio $\Omega_{1}$ fechado, simplesmente conexo.

A figura 5.3 salienta apenas que o domínio $\Omega_{1}$ é a região em estudo; o domínio (aberto) $\Omega_{0}$ é, por definição, uma região sem interesse de estudo.

Uma simples inversão no sentido de circulação do contorno ocasiona troca de papel dos domínios $\Omega_{1}$ e $\Omega_{0}$, tendo-se, assim, uma geometria de domínio aberto, onde $\Omega_{0}$ é a região de interesse.

b) Geometria de domínio fechado

Por não ser mais geometria simplesmente conexa, existe descontinuidade em sua descrição seqüencial (figura 5.4). 


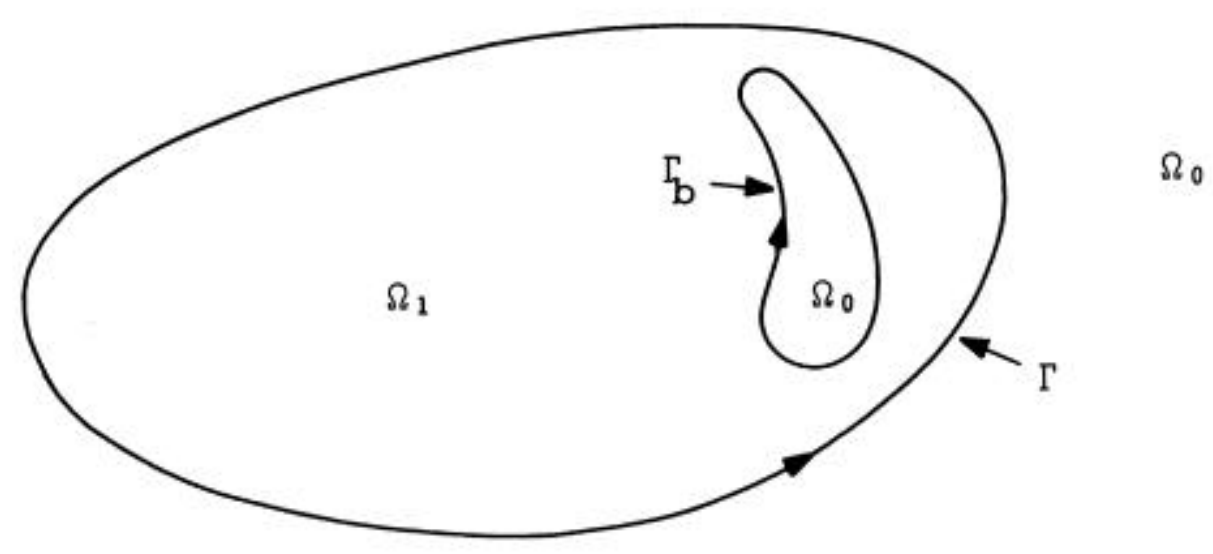

Figura 5.4: Geometria de domínio fechado, não simplesmente conexo.

A região de interesse é $\Omega_{1}$. Há também uma região vazia, envolvida por $\Omega_{1}$, onde, por hipótese, não há interesse de estudo. A fronteira $\Gamma_{\mathrm{b}}$ que a delimita não constitui uma interface propriamente dita; neste sentido, condições de contorno adequadas devem ser a ela aplicadas. Esta região pode ser indicada simplesmente como sendo um "buraco" de $\Omega_{1}$. Deve-se notar que, mesmo pertencendo a $\Omega_{1}$, a circulação do contorno $\Gamma_{\mathrm{b}}$ tem sentido contrário a $\Gamma$. Se necessário, vários "buracos" podem ser aplicados ao domínio $\Omega$ pelo mesmo processo. A figura 5.5 ilustra uma sequiência de descrição de nós na discretização de uma geometria com buracos.

A seqüência de descrição do domínio $\Omega_{1}$ pode ser tomada como

$$
\left\{\begin{array}{lllllll}
\mathrm{P}_{1} & \mathrm{P}_{2} & \ldots & \mathrm{P}_{\mathrm{N}} & \mathrm{P}_{\mathrm{N}+1} & \ldots & \mathrm{P}_{\mathrm{M}}
\end{array}\right\}
$$

O reconhecimento do início da descrição do buraco é feito simplesmente sinalizando $\mathrm{P}_{\mathrm{N}}$ com um atributo específico para isso. 


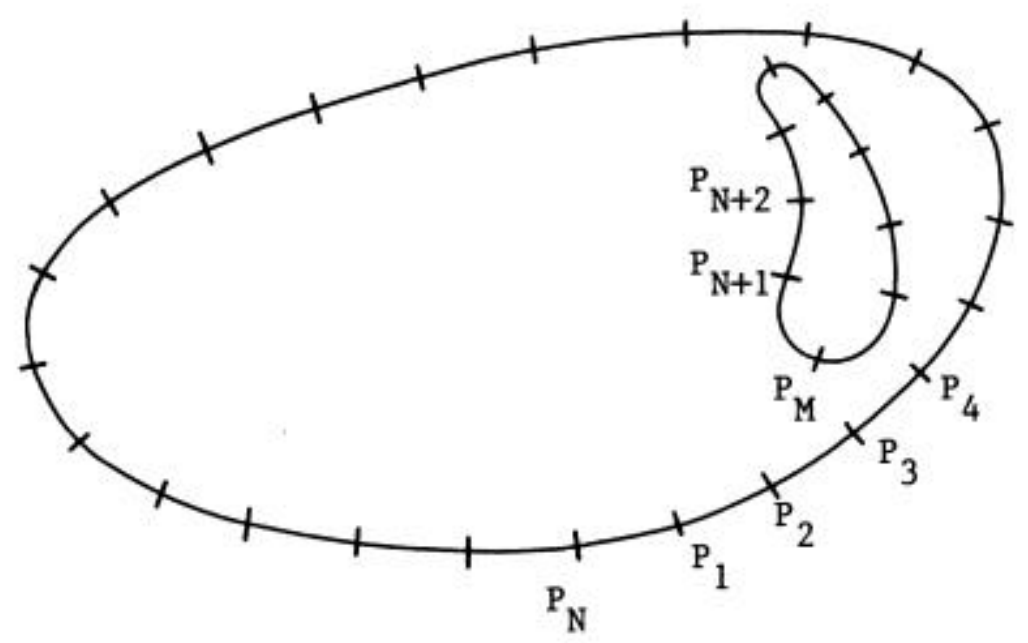

Figura 5.5: Discretização geométrica.

c) Geometria com interfaces

Trata-se de um trecho de contorno que é comum a dois, e somente dois, domínios.

A figura 5.6 exemplifica um caso.

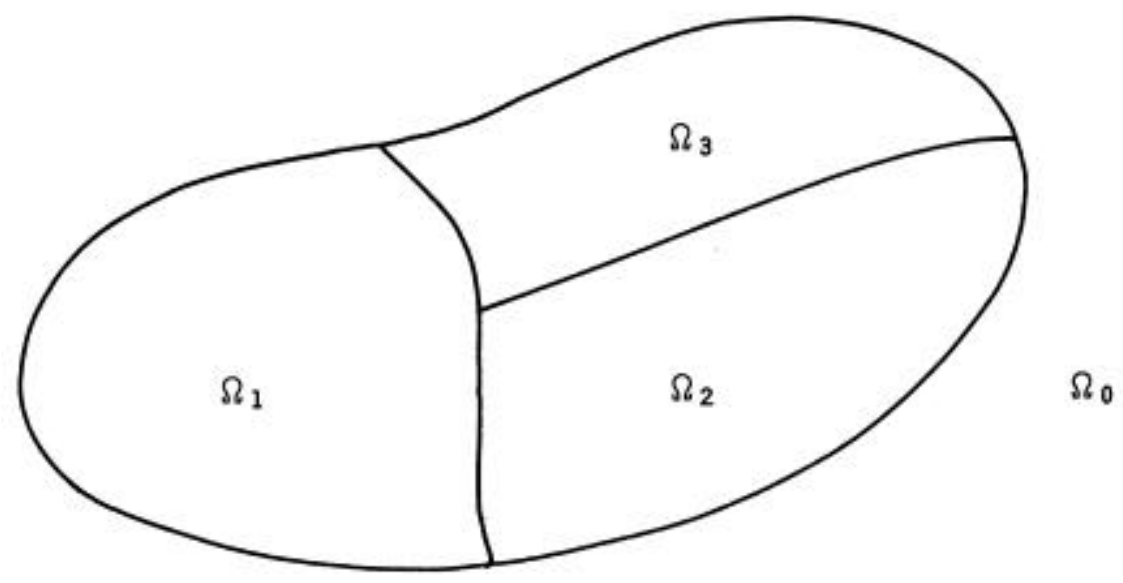

Figura 5.6: Geometria com três domínios.

Os elementos de contorno na interface entre os domínios $\Omega_{\mathrm{j}}$ e $\Omega_{\mathrm{k}}$, com j $\neq \mathrm{k}$, serão percorridos em sentidos contrários, dependendo da integração ser efetuada em $\Gamma_{\mathrm{jk}}$ 
$=\Gamma_{\mathrm{j}} \cap \Gamma_{\mathrm{k}}$ referenciada primeiramente a $\Omega_{\mathrm{j}}$ e, depois, a $\Omega_{\mathrm{k}}$. Isto significa que os elementos fora da interface serão percorridos uma única vez e os elementos da interface serão percorridos duas vezes.

Geometrias reais mais elaboradas podem ser descritas por combinações dos casos citados.

Com o objetivo de semi-automatizar a entrada de dados para a família de programas desenvolvidos, foi elaborado um outro programa que cria o principal arquivo de descrição da geometria. Este arquivo tem apenas duas seções:

- Descrição sequiencial das coordenadas dos nós e atributos de sinalização, a ser mencionados adiante.

- Valores das características físicas de cada domínio.

Um exemplo de geometria, propositalmente simplificada, com um buraco, está mostrada na figura 5.7.

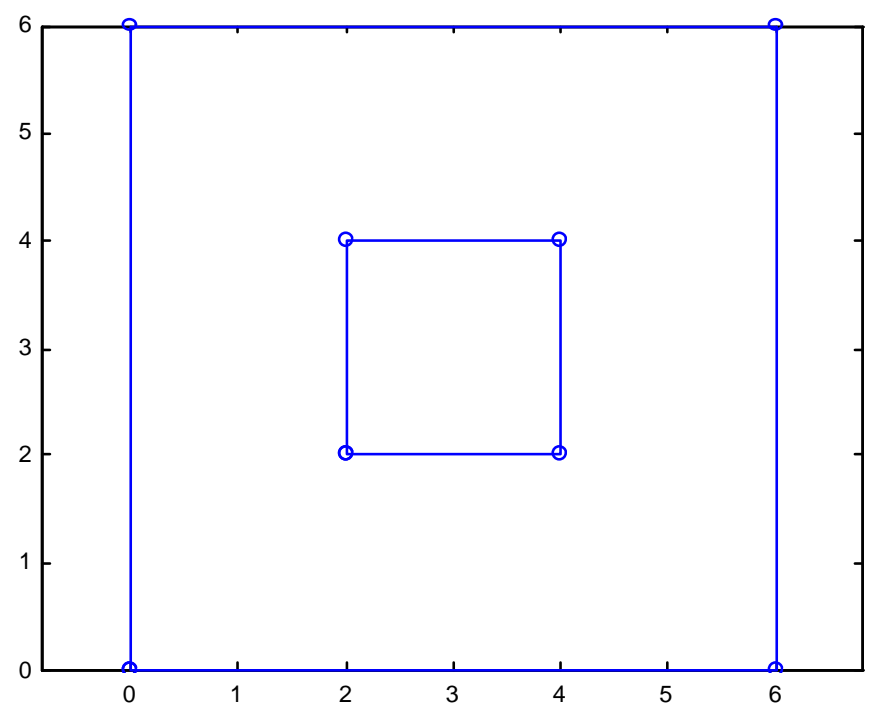

Figura 5.7: Geometria com buraco; quatro elementos no contorno interno e quatro elementos no contorno externo. 
Sua descrição no arquivo de entrada encontra-se na figura 5.8, com símbolos definidos na tabela 5.1, adiante.

\begin{tabular}{|c|c|c|}
\hline .00000 & .00000 & ' $x$ ' \\
\hline 6.0000 & .00000 & ' $x$ ' \\
\hline 6.0000 & 6.0000 & $' x^{\prime}$ \\
\hline $\begin{array}{l}.00000 \\
\text { ' } x \text { ' }\end{array}$ & 6.0000 & 'BAVS ' \\
\hline 2.0000 & 2.0000 & \\
\hline 2.0000 & 4.0000 & \\
\hline 4.0000 & 4.0000 & ' $x$ ' \\
\hline 4.0000 & 2.0000 & 'FDOM' \\
\hline END' & & \\
\hline
\end{tabular}

Figura 5.8: Fragmento do arquivo de entrada para a geometria da figura 5.7.

A situação de mais de um domínio pode ser observada nas figuras 5.9 e 5.10 .

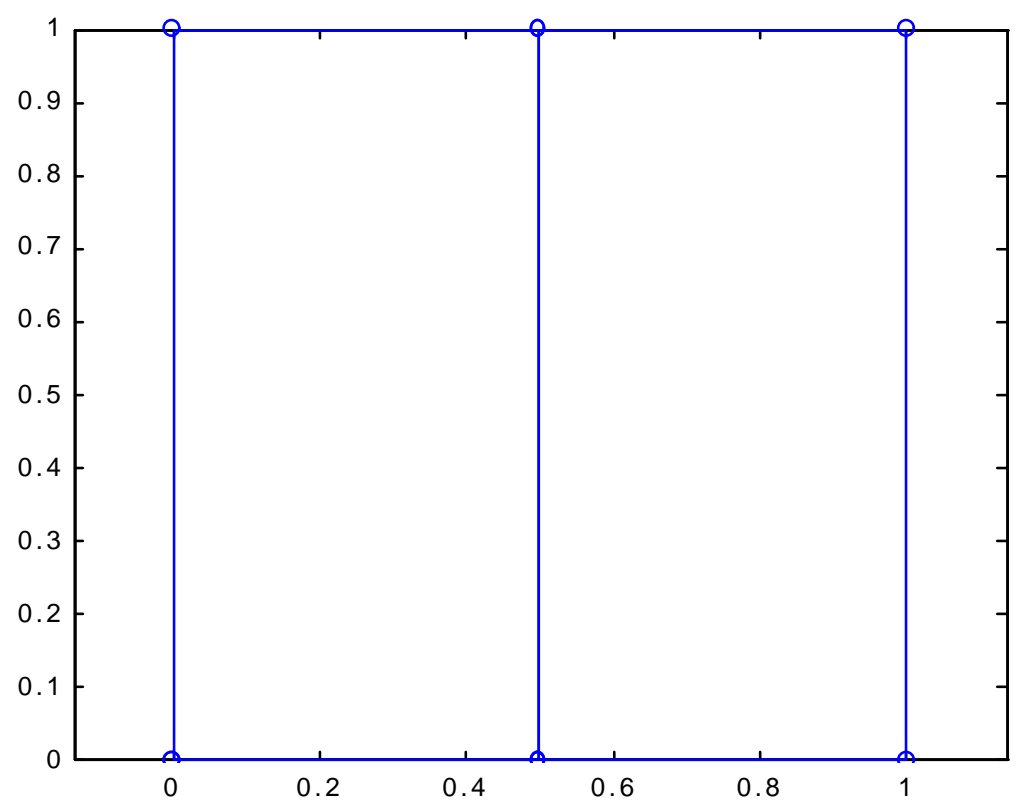

Figura 5.9: Geometria com interface. 


$\begin{array}{lrr}.00000 & .00000 & ' x^{\prime} \\ .50000 & .00000 & ' f{ }^{\prime} \\ .50000 & 1.0000 & ' f^{\prime} \\ .00000 & 1.0000 & ' F D O M ' \\ ' x^{\prime} & & \\ .50000 & .00000 & ' p ' \\ 1.0000 & .00000 & ' x^{\prime} \\ 1.0000 & 1.0000 & ' x^{\prime} \\ .50000 & 1.0000 & \text { 'FDOM' } \\ \text { 'ENP' } & & \\ 1.00 & & \\ 4.00 & & \end{array}$

Figura 5.10: Fragmento do arquivo de entrada para a geometria da figura 5.9.

Cada linha destes arquivos apresenta, para o respectivo nó, as coordenadas X e Y seguidas de seu atributo, que carrega informação lógica para o algoritmo. O estabelecimento do atributo segue a convenção indicada na tabela 5.1.

TABELA 5.1 - ATRIBUTOS DE NÓS GEOMÉTRICOS USADOS NO ARQUIVO DE ENTRADA.

\begin{tabular}{|c|c|}
\hline ATRIBUTO & DESCRIÇÃO \\
\hline $\mathbf{X}$ & Nenhuma característica relevante; nó ordinário \\
\hline $\mathbf{F}$ & Voltará a ser empregado na geometria \\
\hline $\mathbf{P}$ & Foi referenciado anteriormente \\
\hline BAVS & Fechamento de contorno; continuação em um buraco, no mesmo domínio \\
\hline FDOM & Fechamento de domínio \\
\hline END & Último nó de toda a descrição, sem característica relevante \\
\hline ENP & O último nó de toda a descrição foi referenciado anteriormente \\
\hline
\end{tabular}

As últimas linhas do arquivo são reservadas aos valores de permissividade (eventualmente complexa) dos domínios. O problema da figura 5.9 tem, então, $\varepsilon_{\mathrm{r} 1}=1$ e $\varepsilon_{\mathrm{r} 2}=4$, referentes, 
respectivamente, ao primeiro e segundo domínios da esquerda para a direita. A influência da permissividade nas formulações será discutida mais adiante.

Uma análise da tabela acima permite concluir que se dois pares coordenados, adjacentes em suas indexações, apresentarem atributos que indiquem terem sido descritos anteriormente, então uma varredura em domínios já visitados poderá concluir que há um elemento de interface se os mesmos pares apresentarem indexação adjacente reversa à anterior. Não é necessário preocupar-se com nós que delimitam buracos, pois, por definição, nenhum elemento de buraco constitui elemento de interface.

\subsection{Aplicação de valores no contorno}

Tratamentos ligeiramente distintos precisam ser efetuados nos casos de formulação constante e formulação linear.

\subsubsection{Formulação constante}

Considere-se, por exemplo, a geometria indicada na figura 5.11, aplicada a problemas eletrodinâmicos (regidos pela equação de Laplace). Supondo que todos os elementos horizontais representem eletrodos ideais e, portanto, tenham potencial constante, sejam arbitrariamente fixadas as condições indicadas na tabela 5.2.

TABELA 5.2 - FIXAÇÃO DE CONDIÇÕES DE CONTORNO NOS ELETRODOS.

\begin{tabular}{|c|c|}
\hline Localização $(\boldsymbol{m})$ & Potencial $(\boldsymbol{V})$ \\
\hline $\mathrm{y}=0,-3 \leq \mathrm{x} \leq 3$ & 0 \\
\hline $\mathrm{y}=20,-6,5 \leq \mathrm{x} \leq 6,5$ & 300 \\
\hline
\end{tabular}




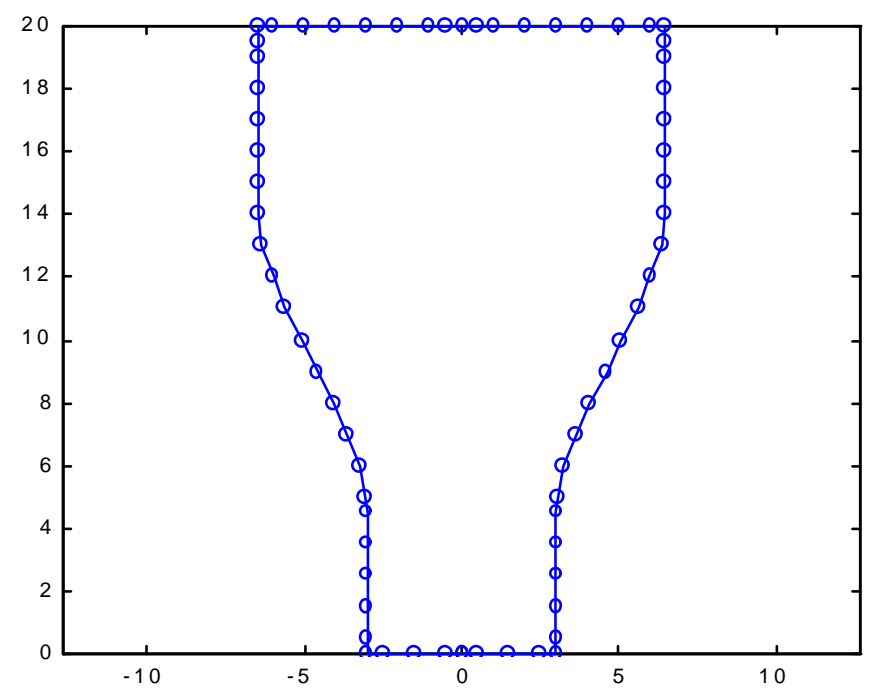

Figura 5.11: Problema de eletrodinâmica; valores no contorno.

Supondo que o domínio fechado seja uma região preenchida por material condutor $(\sigma \neq 0)$, então todos os elementos de contorno não-horizontais apresentam $\partial \mathrm{V} / \partial \mathrm{n}=\bar{q}=0$ e estão alinhados com linhas de campo elétrico. Estes elementos constituem a porção $\Gamma_{2}$ do contorno, onde se estabelecem as condições de Neumann. Nos eletrodos valem as condições de Dirichlet $(\bar{u}=0$ ou $\bar{u}=300)$ na porção $\Gamma_{1}$.

Como se trata de elementos subparamétricos, há apenas um nó de função para cada elemento de contorno. Supondo que a descrição geométrica comece a partir da origem dos eixos, as seis primeiras condições de contorno, aplicadas aos seis primeiros nós de função, podem ser fixadas pelo fragmento do arquivo mostrado na figura 5.12.

$$
\begin{array}{lllll}
.00000 & .00000 & \text { ' } x ' & 0 & 0.00 \\
.50000 & .00000 & \text { ' } \mathrm{x} \text { ' } & 0 & 0.00 \\
1.5000 & .00000 & \text { ' } \mathrm{x} \text { ' } & 0 & 0.00 \\
2.5000 & .00000 & \text { ' } \mathrm{x} \text { ' } & 0 & 0.00 \\
3.0000 & .00000 & \text { ' } \mathrm{x} \text { ' } & 1 & 0.00 \\
3.0000 & .50000 & \text { ' } \mathrm{x} \text { ' } & 1 & 0.00
\end{array}
$$

Figura 5.12: Descrição dos seis primeiros nós (e seis primeiros elementos) da figura 5.11 (geometria e condições de contorno). 
No arquivo citado, o quarto dado de uma certa linha j indica o código do tipo de condição de contorno (0 para Dirichlet; 1 para Neumann) do nó de função associado ao elemento compreendido pelos nós geométricos $\left(\mathrm{x}_{\mathrm{j}}, \mathrm{y}_{\mathrm{j}}\right)$ e $\left(\mathrm{x}_{\mathrm{j}+1}, \mathrm{y}_{\mathrm{j}+1}\right)$. Esta informação é seguida pelo valor numérico do nó de função. Abreviando-se "condição de contorno" por $C C$, tem-se a sequiência de entrada da figura 5.13. O código e o valor estabelecem a condição de contorno do elemento definido entre os nós geométricos $j$ e $j+1$.

$\begin{array}{lllll}\text { x1 } & \text { y1 } & \text { Atributo_1 } & \text { Código_da_CC1 } & \text { Valor_da_CC1 } \\ \text { x2 } & \text { y2 } & \text { Atributo_2 } & \text { Código_da_CC2 } & \text { Valor_da_CC2 } \\ \text { x3 } & \text { y3 } & \text { Atributo_3 } & \text { Código_da_CC3 } & \text { Valor_da_CC3 }\end{array}$

Figura 5.13: Designação genérica dos dados de entrada.

\subsubsection{Formulação linear}

Sendo utilizados, agora, elementos isoparamétricos, os nós de função coincidem em número com os nós geométricos. Cada elemento apresenta duas condições de contorno, fixadas uma em cada extremo, desde que não seja feito uso de elementos descontínuos. $\mathrm{O}$ arquivo de entrada precisa fornecer esta informação adicional. Um exemplo típico está ilustrado na figura 5.14; ao iniciar-se a descrição de um elemento, fornecem-se as condições de contorno de seus extremos (nós) inicial e final. O exemplo se refere à porção de descrição, no sentido anti-horário, que finaliza a cobertura da face direita e inicia a cobertura do eletrodo superior $(\mathrm{y}=20(\mathrm{~m}) ; \mathrm{V}=300(\mathrm{~V}))$ na figura 5.11. Ressalte-se a possibilidade de fixar valores diferentes para q em nós “anteriores” e "posteriores”, conforme mencionado na Seção 4.5. 
Figura 5.14: Fragmento de descrição para formulação linear.

Ocorrendo situação de interface, novos graus de liberdade são aplicados implicitamente ao sistema de equações. Cada nó de função pertencendo a elemento de interface não pode ter condições de contorno pré-fixadas; ao contrário, é imperativo que os valores de $u$ e $q$ a ele associados sejam calculados a partir dos demais. A fim de padronizar-se a entrada de dados para simplificar os procedimentos computacionais, foi determinado que à descrição de elementos de interface seguem-se valores arbitrários como se estivessem sendo impostos à ela. O algoritmo desenvolvido, após o reconhecimento que efetua na geometria, detecta o fato, desprezando a informação numérica, ou seja, reconhece não ser possível fixar condição de contorno em interface.

\subsection{Lógica da primeira subrotina}

Os procedimentos iniciais, relacionados à geometria e a seus valores de contorno, realizados por toda a família de programas desenvolvidos, foram agrupados em uma primeira subrotina. Estes procedimentos correspondem às tarefas: 
1. Caracterização da descrição dos vários domínios

2. Indexação dos elementos de fronteira

3. Montagem do vetor de código e vetor de valor nos elementos

4. Classificação dos elementos quanto ao seu número

- em um problema

- em cada domínio, identificando-o

- em quaisquer interfaces, identificando-as

- fora de interfaces

Pode-se intercambiar a ordem da terceira e quarta tarefas sem prejuízo algum nos objetivos do algoritmo.

Os pontos importantes da primeira tarefa são a leitura das coordenadas e a construção de um vetor de identificação de fim de domínio \{lst_fdom\}, de uma matriz de identificação de buracos [mtz_bur] e de um vetor de indexação de nós \{indx $\}$.

A obtenção dos três elementos (dois vetores e uma matriz), acima mencionados, por parte da subrotina desenvolvida, está esquematizada, de forma simplificada, no diagrama lógico de Nassi-Schneiderman (NS) nas figuras 5.15 e 5.16.

Por causa da estrutura de entrada de dados, alguns nós podem apresentar-se mais de uma vez. Uma das variáveis, não explicitadas nos diagramas lógicos que se seguirão, conta os nós de entrada sem preocupação sobre sua repetição; trata-se portanto de um contador não seletivo. Terminada a leitura da geometria, esta variável (nt_ptdescr) indicará o limite superior de outra variável a ser utilizada para contagem (e varredura) seqüencial e seletiva dos vários domínios. A seletividade mencionada representa a correta identificação de buracos e/ou 
mudanças de domínio; é aqui que o vetor \{lst_fdom $\}$ e a matriz [mtz_bur] ajudam a cumprir esta finalidade. O conteúdo do vetor é o valor do contador seqüencial não seletivo que indica o último nó de cada domínio. De modo equivalente, [mtz_bur], além de conter a informação de $\{1$ st_fdom $\}$, indica também o valor do contador seqüencial não seletivo a apontar o último nó antes do início de cada buraco. Estas informações são dispostas em colunas adjacentes da matriz; a primeira coluna indica o número de buracos em cada domínio. Todos os dados relacionados a um certo domínio $k$ encontram-se agrupados na k-ésima linha da matriz. A duplicidade de parte de informação no vetor e na matriz deve-se apenas à conveniência de programação, não havendo aqui qualquer preocupação por otimização.

O vetor $\{$ indx $\}$ contém a indexação dos nós geométricos.

\begin{tabular}{|c|c|c|c|c|c|}
\hline \multicolumn{6}{|c|}{ Início da primeira tarefa } \\
\hline \multicolumn{6}{|c|}{ Inicializar variáveis } \\
\hline \multicolumn{6}{|c|}{ Abrir arquivo para leitura } \\
\hline \multicolumn{6}{|c|}{ LEITURA DE LINHA:ler uma linha inteira } \\
\hline \multicolumn{6}{|c|}{ ESCOLHA: verificar atributo } \\
\hline 1 & 2 & 3 & 4 & 5 & 6 \\
\hline $\begin{array}{l}\text { atributo é } \\
\text { 'BAVS' }\end{array}$ & $\begin{array}{l}\text { atributo é } \\
\text { 'FDOM' }\end{array}$ & $\begin{array}{l}\text { atributo é } \\
\text { 'END' }\end{array}$ & $\begin{array}{l}\text { atributo é } \\
\text { ENP' }\end{array}$ & $\begin{array}{l}\text { atributo é } \\
\text { 'X' ou 'F' }\end{array}$ & $\begin{array}{l}\text { atributo é } \\
\text { 'P' }\end{array}$ \\
\hline \multicolumn{6}{|c|}{ atualizar variáveis } \\
\hline \multicolumn{6}{|c|}{ terminar montagem de [mtz_bur] } \\
\hline & da primeira & arefa & & & \\
\hline
\end{tabular}

Figura 5.15: Caracterização da descrição dos vários domínios. 
As ações tomadas em cada um dos seis casos previstos (seis atributos) estão resumidas na figura 5.16.

\begin{tabular}{|l|}
\hline CASO atributo seja 'BAVS' \\
\hline $\begin{array}{l}\text { atualizar variáveis e número de buracos em } \\
\text { domínio }\end{array}$ \\
\hline escrever em [mtz_bur] \\
\hline ler novo atributo \\
\hline vá para ESCOLHA \\
\hline
\end{tabular}

\begin{tabular}{|l|}
\hline CASO atributo seja 'FDOM' \\
\hline atualizar variáveis \\
\hline escrever em $\{$ Ist_fdom $\}$ \\
\hline ler novo atributo \\
\hline vá para ESCOLHA \\
\hline
\end{tabular}

\begin{tabular}{|l|}
\hline CASO atributo seja 'END' \\
\hline $\begin{array}{l}\text { carregar dados nos vetores de coordenada\$ } \\
\text { geométricas }\end{array}$ \\
\hline escrever no vetor $\{$ Ist_fdom $\}$ \\
\hline fechar arquivo de entrada \\
\hline
\end{tabular}

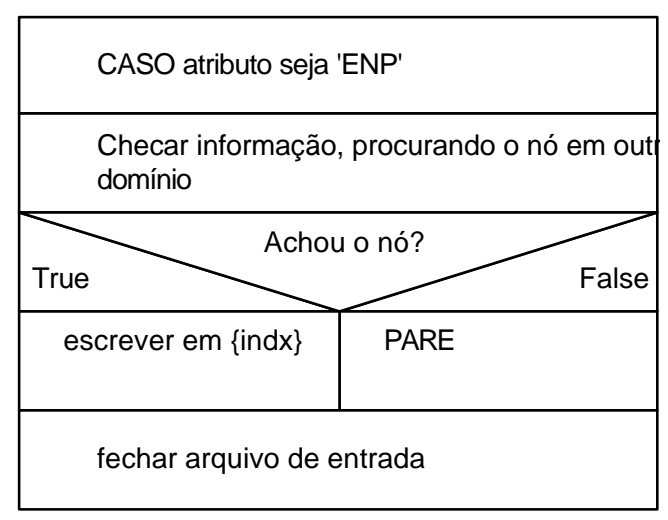

\begin{tabular}{|l|}
\hline CASO atributo seja 'X' ou 'F' \\
\hline $\begin{array}{l}\text { carregar dados nos vetores de coordenadas } \\
\text { geométricas }\end{array}$ \\
\hline escrever em $\{$ indx $\}$ \\
\hline atualizar variáveis \\
\hline vá para LEITURA DE LINHA \\
\hline
\end{tabular}

\begin{tabular}{|l|l|}
\hline \multicolumn{2}{|c|}{ CASO atributo seja 'P' } \\
\hline \multicolumn{2}{|l|}{$\begin{array}{l}\text { Checar informação, procurando o nó em out } \\
\text { domín }\end{array}$} \\
\hline True & Achou o nó? \\
\hline escrever em \{indx $\}$ & PARE \\
\hline atualizar variáveis \\
\hline vá para LEITURA DE LINHA \\
\hline
\end{tabular}

Figura 5.16: Detalhamento das ações referidas na figura 5.15. 
O tópico mais importante da segunda tarefa é a montagem de um vetor de indexação dos elementos, \{i_ele $\}$. Assim é possível realizar-se varreduras adequadas referenciando-as pelos nós (melhor em formulação linear) ou pelos elementos (melhor em formulação constante), conforme a necessidade. O diagrama simplificado da segunda tarefa está mostrado na figura 5.17 .

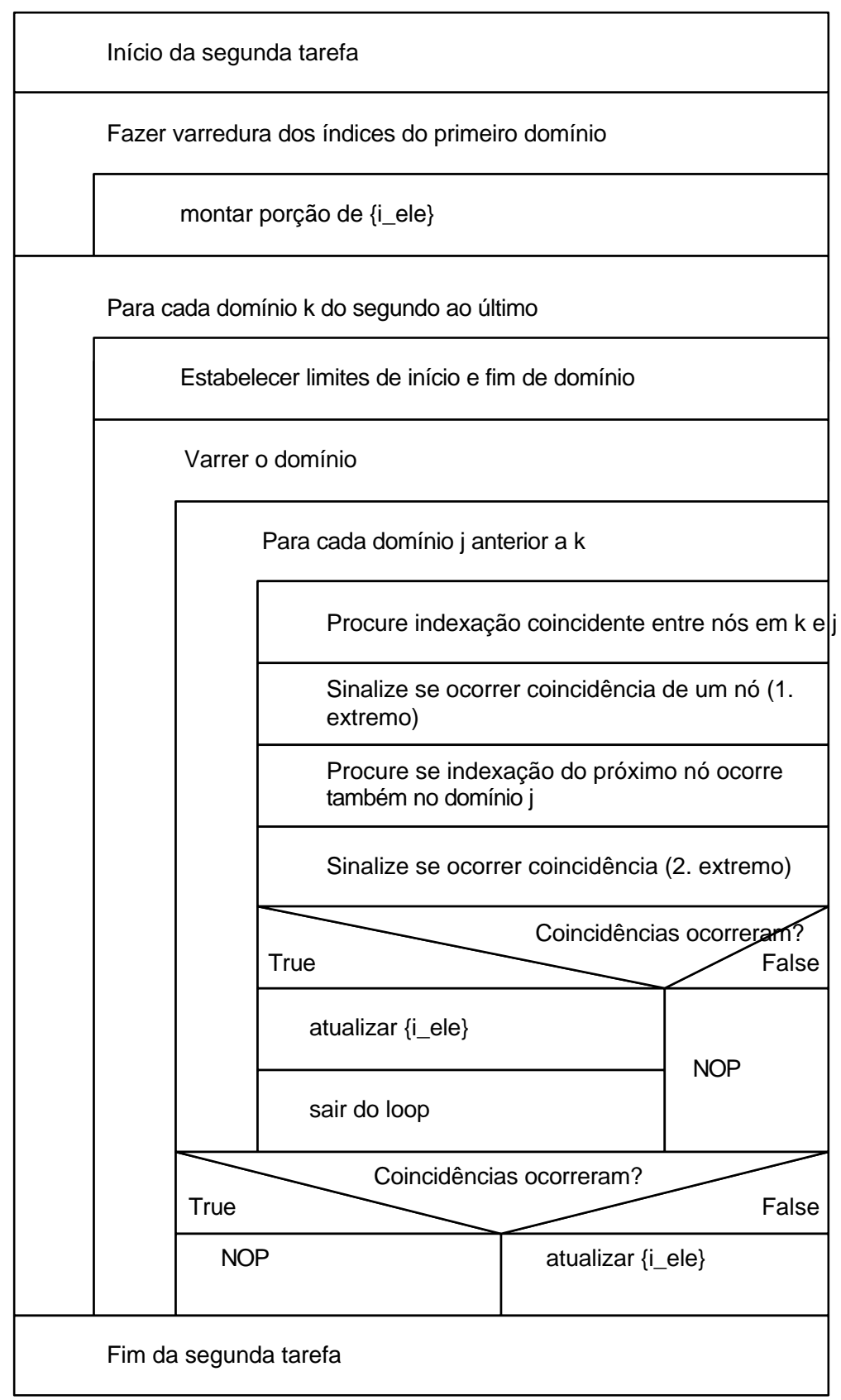

Figura 5.17: Indexação de elementos de fronteira. 
A terceira tarefa é a da montagem de um vetor de código, $\left\{\mathrm{kdg} \_\right.$ele $\}$, e um vetor de valor nos elementos, \{vl_ele $\}$. Conforme mencionado, o primeiro indica o tipo e o segundo contém o valor da condição de contorno fixada. Uma vez caracterizada a geometria e indexados seus nós e elementos, a tarefa de montagem destes vetores limita-se à leitura dos dados de entrada, colocando-os na posição correta destas variáveis. Para o caso de formulação constante, o diagrama NS simplificado está na figura 5.18.

A quarta tarefa, subdividida em outras quatro, é completada com o auxílio de simples loops que consideram variáveis já estabelecidas. Merece atenção a sub-tarefa ligada às interfaces. Nelas são montados três vetores (\{casado\}, \{dom_bxo $\}$ e $\{$ dom_alt $\})$ e uma matriz denominada [nele_intfc] (figura 5.19).

O vetor $\{$ casado $\}$ é de natureza lógica, está indexado ao vetor $\{1$ ele $\}$ já mencionado e identifica se cada elemento é ou não elemento de interface. Os vetores \{dom_bxo\} e \{dom_alt $\}$ estão também indexados ao vetor $\{$ i_ele $\}$ e contém, respectivamente, para o caso de elemento de interface, as indicações do primeiro domínio e do segundo (e último) domínio que referencia um dado elemento. Elementos fora de interface contém a mesma informação em ambos os vetores. Estes dados são muito importantes durante a montagem das matrizes [G] e $[\mathrm{H}]$ e também na etapa final de cálculo do valor da variável da equação em estudo, dentro dos domínios. $\mathrm{O}$ elemento $\mathrm{a}_{\mathrm{ij}}$ da matriz [nele_intf] contém o número de elementos de contorno na interface entre os domínios $i$ e $j$; os elementos $\mathrm{a}_{\mathrm{ii}}$, na diagonal principal desta matriz, informam o número de elementos de contorno fora de interface, para cada domínio $i$. 


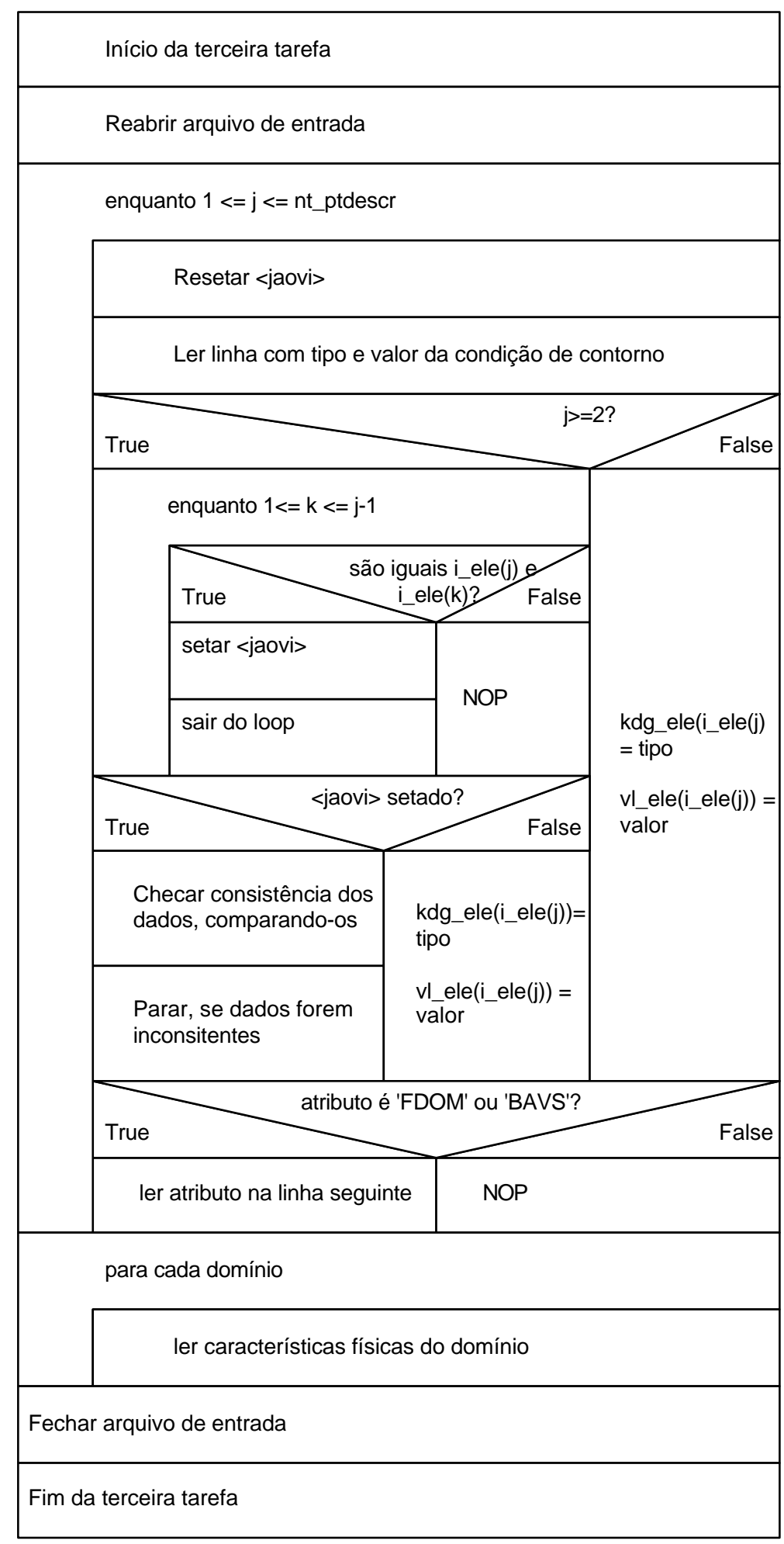

Figura 5.18: Montagem de vetores de código e de valor.

O diagrama lógico NS da sub-tarefa mencionada está na figura 5.19. 


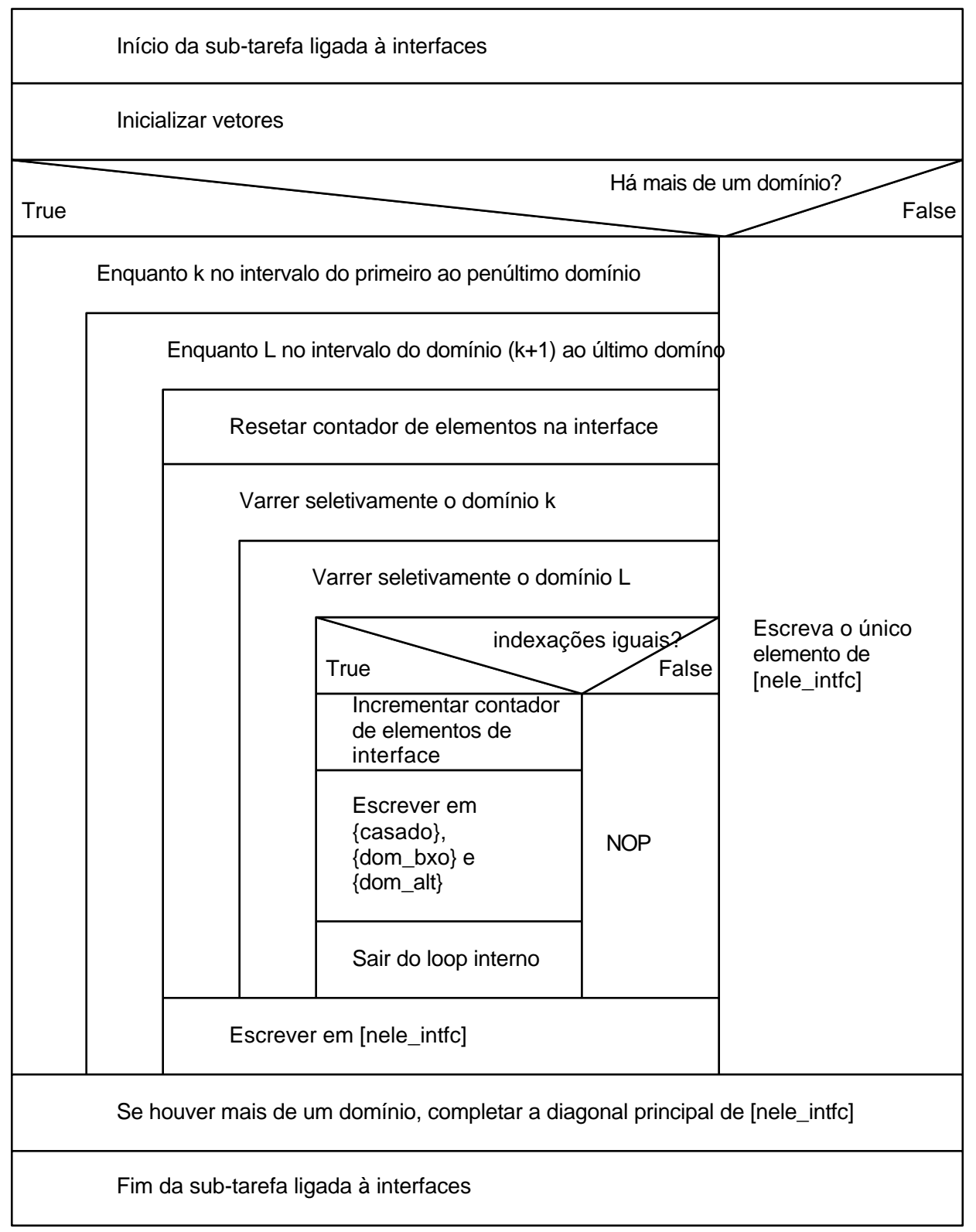

Figura 5.19: Sub-tarefas ligadas à interfaces.

No caso de formulação constante há ainda uma tarefa adicional, muito simples, que é a de obter as coordenadas dos nós de função pela média aritmética das coordenadas dos nós geométricos, realizada a partir de uma varredura seletiva. 


\subsection{Interfaceamento de domínios}

A presença de interfaces precisa ser considerada desde a montagem das matrizes [G] e $[\mathrm{H}]$. Em relação à equação de Helmholtz as considerações numéricas dependerão não apenas das características físicas dos meios materiais envolvidos, mas também do componente de campo escolhido como "potencial” na equação escalar. Evidentemente, esta escolha considerará uma adequada orientação dos eixos coordenados. Por esta razão, a apresentação da formulação será feita admitindo-se a equação de Laplace.

Seja a geometria da figura 5.20.

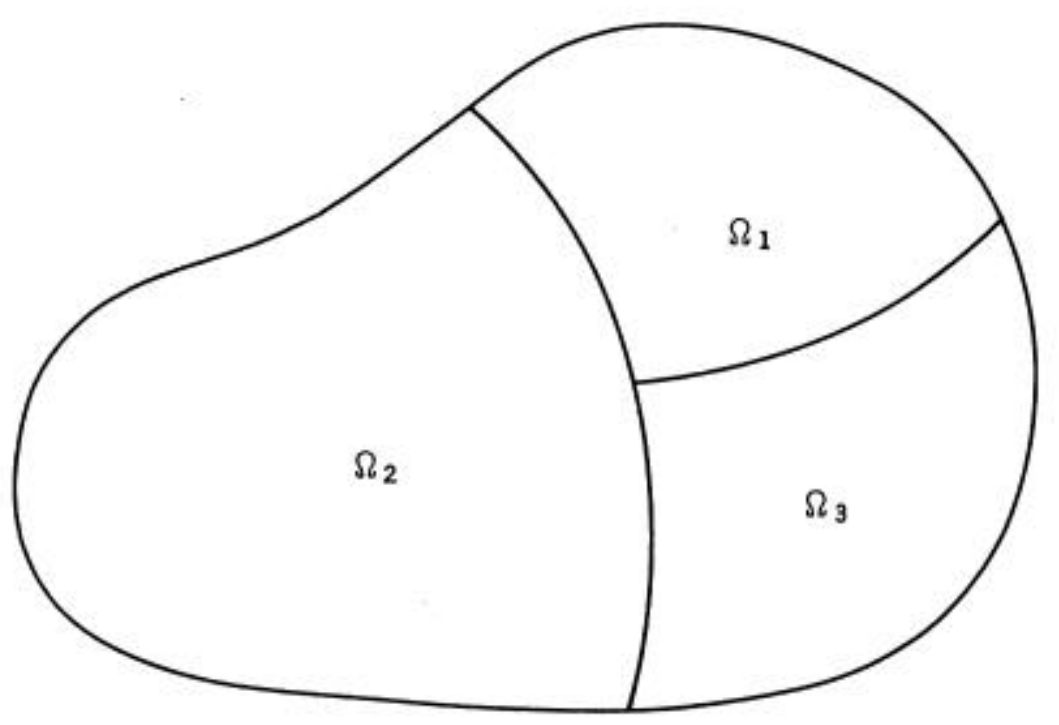

Figura 5.20: Geometria com três meios materiais distintos.

Primeiramente, a formulação é aplicada a cada meio material e, em seguida, as condições de contorno adequadas aplicadas aos elementos de interface. Escreve-se: 
no meio 1:

$$
\left[\begin{array}{lll}
H_{1} & H_{12}^{(1)} & H_{13}^{(1)}
\end{array}\right]\left\{\begin{array}{c}
u_{1} \\
u_{12}^{(1)} \\
u_{13}^{(1)}
\end{array}\right\}=\left[\begin{array}{lll}
G_{1} & G_{12}^{(1)} & G_{13}^{(1)}
\end{array}\right]\left\{\begin{array}{c}
q_{1} \\
q_{12}^{(1)} \\
q_{13}^{(1)}
\end{array}\right\}
$$

no meio 2:

$$
\left[\begin{array}{lll}
H_{2} & H_{12}^{(2)} & H_{13}^{(2)}
\end{array}\right]\left\{\begin{array}{c}
u_{2} \\
u_{12}^{(2)} \\
u_{13}^{(2)}
\end{array}\right\}=\left[\begin{array}{lll}
G_{2} & G_{12}^{(2)} & G_{13}^{(2)}
\end{array}\right]\left\{\begin{array}{c}
q_{2} \\
q_{12}^{(2)} \\
q_{13}^{(2)}
\end{array}\right\}
$$

no meio 3:

$$
\left[\begin{array}{lll}
H_{3} & H_{13}^{(3)} & H_{23}^{(3)}
\end{array}\right]\left\{\begin{array}{c}
u_{3} \\
u_{13}^{(3)} \\
u_{23}^{(3)}
\end{array}\right\}=\left[\begin{array}{lll}
G_{3} & G_{13}^{(3)} & G_{23}^{(3)}
\end{array}\right]\left\{\begin{array}{c}
q_{3} \\
q_{13}^{(3)} \\
q_{23}^{(3)}
\end{array}\right\}
$$

Nas equações acima, subscritos únicos referem-se às porções das matrizes fora das interfaces e aos valores de potencial e de $\partial \mathrm{u} / \partial \mathrm{n}$ nos elementos fora de interfaces.

$\mathrm{G}_{\mathrm{ij}}{ }^{(\mathrm{k})}$ e $\mathrm{H}_{\mathrm{ij}}{ }^{(\mathrm{k})}$ estão relacionados às porções das respectivas matrizes, calculadas apenas com os elementos na interface entre os domínios $i$ e $j$, porém referenciados a partir do domínio $k$, igual a $i$ ou a $j$. O mesmo acontece com os elementos $\mathrm{u}_{\mathrm{ij}}^{(\mathrm{k})} \mathrm{e}_{\mathrm{ij}}^{(\mathrm{k})}$.

No caso da equação de Laplace e meios isolantes, as condições de contorno aplicadas a cada elemento impõem a) continuidade do potencial $u$ ao cruzar uma interface; b) continuidade da componente normal do vetor deslocamento elétrico $D_{n}$. Com o auxílio da relação constitutiva $\vec{D}=\varepsilon \vec{E}$, escreve-se para a interface entre os meios $i$ e $j$

$$
\varepsilon_{\mathrm{i}} \mathrm{E}_{\mathrm{ni}}=\varepsilon_{\mathrm{j}} \mathrm{E}_{\mathrm{nj}}
$$

em que $\mathrm{E}_{\mathrm{n}}$ representa a componente normal de campo elétrico.

Chamando de $u$ o potencial escalar elétrico, a equação (5.7) é reescrita como 


$$
\varepsilon_{i} \frac{\partial u_{i}}{\partial n}=\varepsilon_{j} \frac{\partial u_{j}}{\partial n}
$$

ou, na notação utilizada desde o capítulo três,

$$
\varepsilon_{\mathrm{i}} \mathrm{q}^{(\mathrm{i})}=-\varepsilon_{\mathrm{j}} \mathrm{q}^{(\mathrm{j})}
$$

O aparecimento do sinal negativo deve-se às definições da normal ao elemento apresentaremse opostas quando o percurso for efetuado em $\Omega_{\mathrm{i}}$ e $\Omega_{\mathrm{j}}$.

Escreve-se, então, para a geometria da figura 5.20, as equações

$$
\begin{aligned}
& u_{12}^{(1)}=u_{12}^{(2)}=u_{12} \\
& u_{13}^{(1)}=u_{13}^{(3)}=u_{13} \\
& u_{23}^{(2)}=u_{23}^{(3)}=u_{23} \\
& \varepsilon_{1} q_{12}^{(1)}=-\varepsilon_{2} q_{12}^{(2)} \\
& \varepsilon_{1} q_{13}^{(1)}=-\varepsilon_{3} q_{13}^{(3)} \\
& \varepsilon_{2} q_{23}^{(2)}=-\varepsilon_{3} q_{23}^{(3)} .
\end{aligned}
$$

Tomando por referência o valor de $\partial \mathrm{u} / \partial \mathrm{n}$ na interface do domínio de ordem mais baixa (relacionado no vetor $\{$ dom_bxo $\}$ estabelecido na primeira subrotina), as equações (5.4) a (5.6), reunidas num único sistema, resultam:

$$
\left[\begin{array}{ccccccccc}
H_{1} & 0 & 0 & H_{12}^{(1)} & -G_{12}^{(1)} & H_{13}^{(1)} & -G_{13}^{(1)} & 0 & 0 \\
0 & H_{2} & 0 & H_{12}^{(2)} & \frac{\varepsilon_{1}}{\varepsilon_{2}} G_{12}^{(2)} & 0 & 0 & H_{23}^{(2)} & -G_{23}^{(2)} \\
0 & 0 & H_{3} & 0 & 0 & H_{13}^{(3)} & \frac{\varepsilon_{1}}{\varepsilon_{3}} G_{13}^{(3)} & H_{23}^{(3)} & \frac{\varepsilon_{2}}{\varepsilon_{3}} G_{23}^{(3)}
\end{array}\right]\left\{\begin{array}{l}
u_{1} \\
u_{2} \\
u_{3} \\
u_{12} \\
q_{12} \\
u_{13} \\
q_{13} \\
u_{23} \\
q_{23}
\end{array}\right\}=
$$




$$
\left[\begin{array}{ccc}
G_{1} & 0 & 0 \\
0 & G_{2} & 0 \\
0 & 0 & G_{3}
\end{array}\right]\left\{\begin{array}{l}
q_{1} \\
q_{2} \\
q_{3}
\end{array}\right\}
$$

As submatrizes na equação anterior particionam a matriz do membro esquerdo, mantendo-a quadrada; a matriz do membro direito passa a ser retangular. A solução do sistema de equações determina, também, os valores de $u$ e $q$ nos elementos de interface.

Um aspecto sutil, porém importante, aplica-se no caso da equação de Helmholtz: as características dos domínios não aparecem tão somente como multiplicadores de algumas das submatrizes [G]; elas permeiam cada elemento de todas as submatrizes pois o número de onda $k$ está implícito no argumento das funções de Hankel, sendo distinto entre os vários meios materiais, valendo, para cada um, a equação

$$
k_{i}=\omega \sqrt{\mu_{i} \varepsilon_{i}}
$$

Conforme mencionado no início desta seção, ainda no caso da equação de Helmholtz, as condições de contorno aplicáveis dependerão do componente de campo escolhido para a função "potencial” escalar.

Nota-se que a aplicação do MEC à geometria com interface(s) implica em matrizes algo esparsas (não no mesmo grau encontrado na formulação com Elementos Finitos), que antes, em situação de domínio único, apresentavam-se densas.

Mesmo em geometrias com um único domínio pode ser conveniente proceder-se a uma divisão artificial de $\Omega$; isto pode ocorrer se houver, por necessidade de discretização, uma proximidade muito grande entre nós de elementos não adjacentes. O tratamento normalmente dado às integrações não consideraria a quase singularidade (causada por tal proximidade), 
podendo causar erros significativos; a fonte deste problema cessará desde que aqueles elementos sejam alocados em domínios distintos, respeitadas as condições de contorno na interface. 


\subsubsection{Montagem das matrizes}

Por causa das submatrizes, a equação (5.16) pode ser compactada, reescrevendo-a como

$$
\left[\begin{array}{lll}
H_{\text {auto }} & \vdots & H_{\text {int erf }}
\end{array}\right]\left\{\begin{array}{c}
u_{\text {auto }} \\
\cdots \\
x_{\text {int erf }}
\end{array}\right\}=\left[G_{\text {auto }}\right]\left\{q_{\text {auto }}\right\}
$$

O subscrito "auto" está relacionado somente aos auto-elementos, ou seja, aos elementos de contorno fora de quaisquer interfaces; "interf” representa, portanto, os elementos localizados em interface. $\left\{\mathrm{x}_{\text {interf }}\right\}$ pode representar tanto valores de $u$ e/ou de $q$. Chamando de

- $\mathrm{m}_{\mathrm{d}} \mathrm{o}$ número de elementos num certo domínio $d$

- $\mathrm{n}_{\mathrm{d}}$ o número de auto-elementos no domínio $d$,

então cada submatriz $\left[\mathrm{G}_{\mathrm{d}}\right]$ e $\left[\mathrm{H}_{\mathrm{d}}\right]$, em $\left[\mathrm{G}_{\text {auto }}\right]$ e $\left[\mathrm{H}_{\text {auto }}\right]$, respectivamente, terá dimensão $m x n$, isto é

$$
\left[\mathrm{G}_{\mathrm{d}}\right]_{\mathrm{m} \times \mathrm{n}}
$$

e

$$
\left[\mathrm{H}_{\mathrm{d}}\right]_{\mathrm{m} \times \mathrm{n}}
$$

No caso da figura 5.20 as dimensões de $\left[\mathrm{H}_{\text {auto }}\right]$ e $\left[\mathrm{G}_{\text {auto }}\right]$ serão $M x N$, definidos por

$$
M=\sum_{d=1}^{N D} m_{d}
$$

$\mathrm{e}$

$$
N=\sum_{d=1}^{N D} n_{d}
$$


$\mathrm{ND}$ (no caso, $\mathrm{ND}=3$ ) representa o número de domínios na geometria. Fica constatado que a matriz $\left[\mathrm{G}_{\text {auto }}\right]$ não é quadrada. Computacionalmente, $\mathrm{N}$ é obtido pela soma dos elementos na diagonal principal da matriz [nele_intfc] descrita em seções anteriores; $M$ é também obtido totalizando os valores de um vetor \{nele_dom\}, estabelecido na quarta tarefa mencionada na seção 5.4 .

Chamando de

- $\mathrm{p}_{\mathrm{ij}}$ o número de elementos na interface entre domínios $i$ e $j$,

a submatriz $\left[\mathrm{H}_{\text {interf }}\right]$ pode ser esquematizada abaixo.

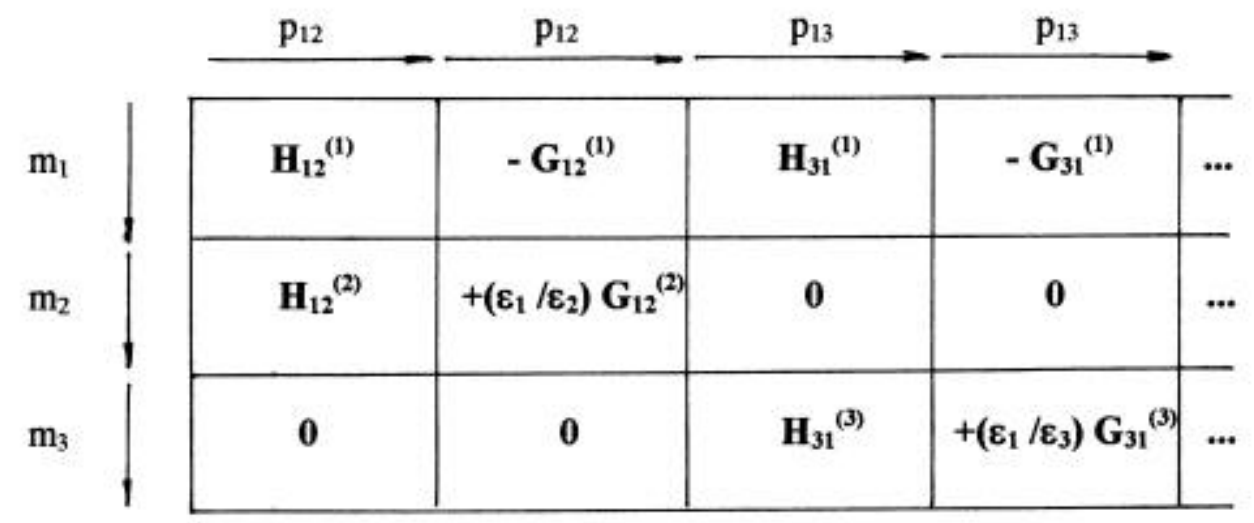

A submatriz acima terá dimensão $M x(M-N)$; alternativamente, $M-N$ pode ser obtido somando as parcelas $\mathrm{p}_{\mathrm{ij}}$ obtidas pela combinação de todos os $N D$ domínios tomados dois a dois.

Para cada dois domínios $i$ e $j$ que se interfaceiam há quatro submatrizes a ser construídas. Supondo $i<j$, ou seja, o domínio $i$ de ordem mais baixa que o domínio $j$ (o que equivale também a dizer que, em uma varredura seletiva dos nós de toda a geometria, o domínio $i$ é visitado antes de $j$ ), vale a representação genérica da figura 5.21. 


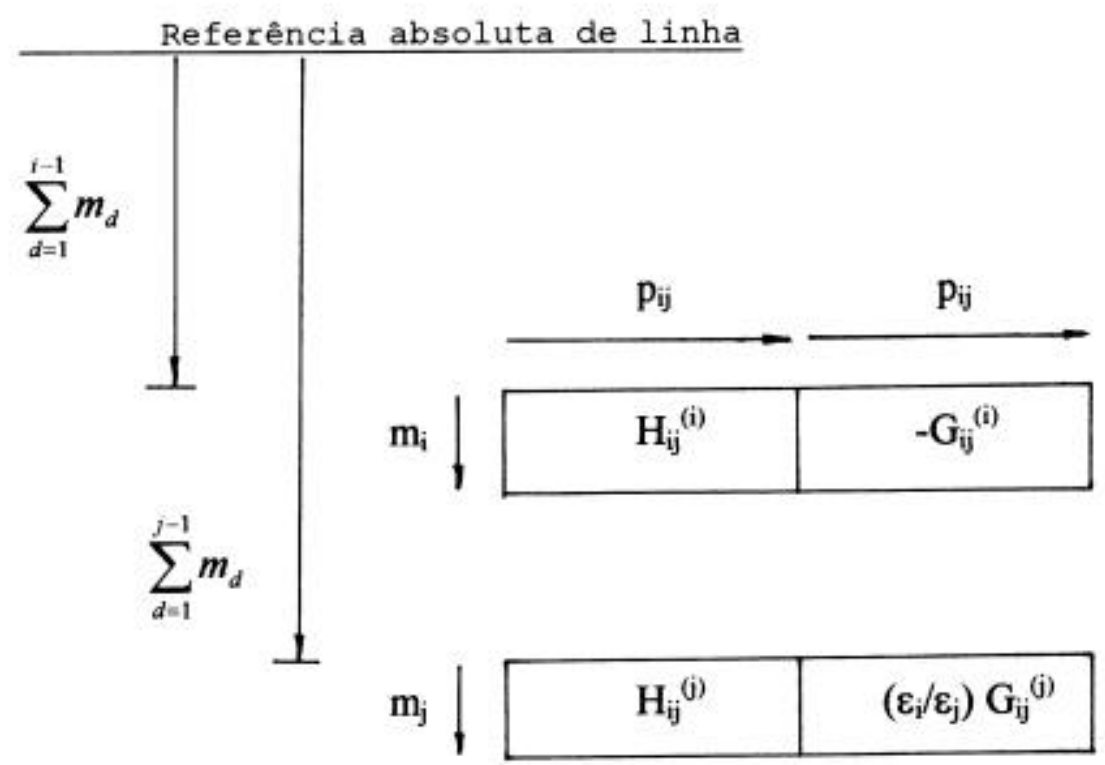

Figura 5.21: Representação genérica de quatro submatrizes relacionadas à interfaces.

O diagrama lógico NS para a montagem de $\left[\mathrm{H}_{\text {auto }}\right]$ e $\left[\mathrm{G}_{\text {auto }}\right]$ está na figura 5.22; o da montagem de $\left[\mathrm{H}_{\text {interf }}\right]$ está resumido na figura 5.23. 


\begin{tabular}{|c|c|c|}
\hline \multicolumn{3}{|c|}{ Início da montagem de [H_auto] e [G_auto] } \\
\hline \multicolumn{3}{|l|}{ Calcular M e N } \\
\hline \multicolumn{3}{|l|}{ Inicializar matrizes } \\
\hline \multicolumn{3}{|c|}{ Estabelecer referências globais de linha e coluna } \\
\hline \multicolumn{3}{|c|}{ faça k_dom varrer todos os domínios } \\
\hline \multicolumn{3}{|c|}{ calcular limites inferior e superior no domínio k_dom } \\
\hline \multicolumn{3}{|c|}{ estabelecer referência local de coluna } \\
\hline \multicolumn{3}{|c|}{ faça j varrer os elementos do domínio k_dom } \\
\hline \multicolumn{3}{|c|}{ estabelecer referência local de linha } \\
\hline \multicolumn{3}{|l|}{ True } \\
\hline \multicolumn{2}{|c|}{$\begin{array}{l}\text { faça k varrer os elementos do domínio } \\
\text { k_dom }\end{array}$} & \multirow{4}{*}{ NOP } \\
\hline True ${ }^{\text {elemen }}$ & lexados são & \\
\hline $\begin{array}{l}\text { proceder } \\
\text { integrações } \\
\text { singulares }\end{array}$ & $\begin{array}{l}\text { proceder } \\
\text { integrações } \\
\text { regulares }\end{array}$ & \\
\hline \multicolumn{2}{|c|}{ atualizar referência local de linha } & \\
\hline \multicolumn{3}{|c|}{ atualizar referência local de coluna } \\
\hline \multicolumn{3}{|c|}{ atualizar referências globais de linha e coluna } \\
\hline Fim da montagem de [H_auto] & auto] & \\
\hline
\end{tabular}

Figura 5.22: Diagrama para montagem de $\left[\mathrm{H}_{\text {auto }}\right]$ e $\left[\mathrm{G}_{\text {auto }}\right]$. 


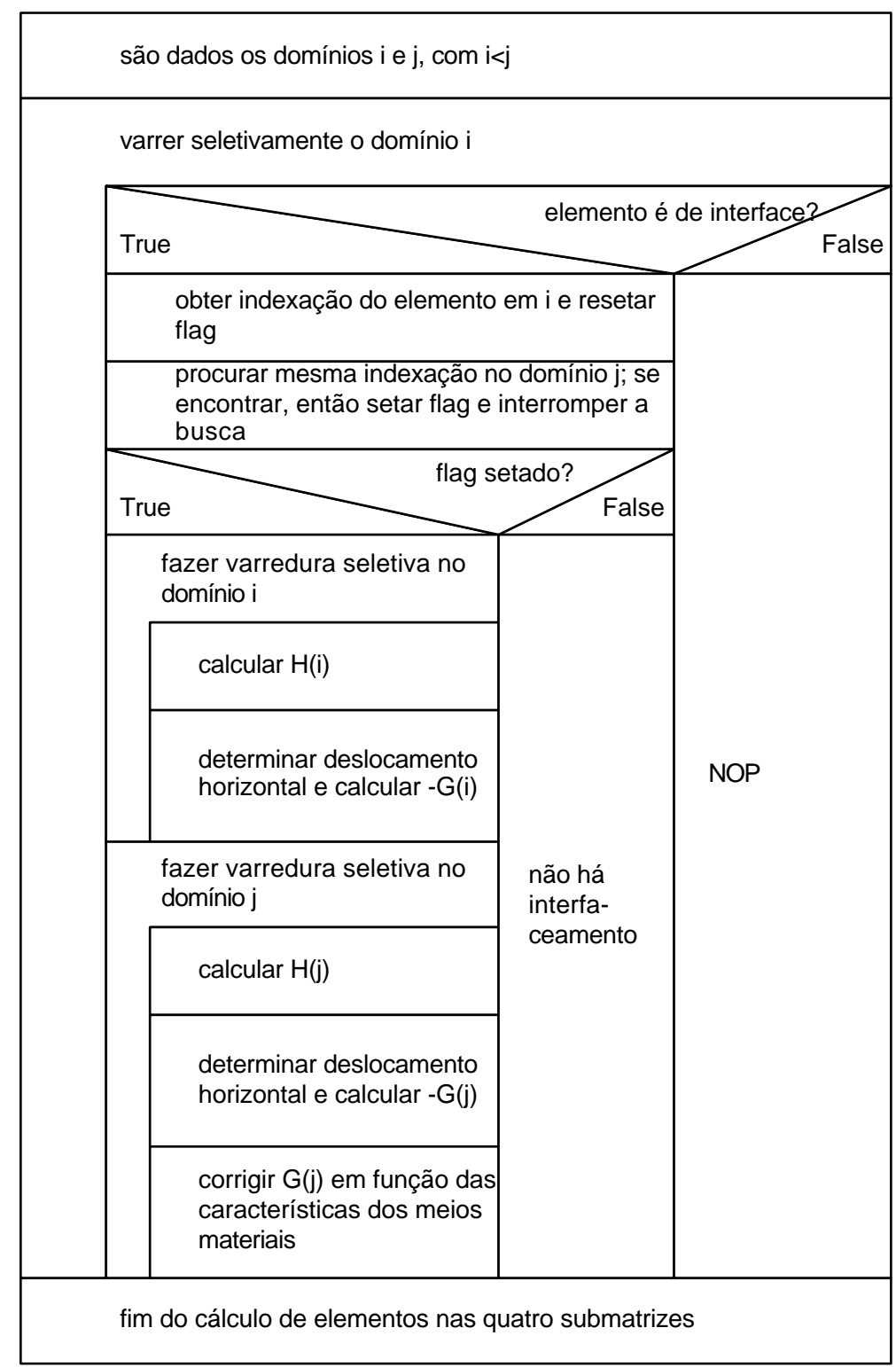

Figura 5.23: Diagrama para montagem de $\left[\mathrm{H}_{\mathrm{interf}}\right]$.

\subsection{Montagem e solução do sistema de equações}

A montagem do sistema de equações se restringe à manipulação algébrica necessária para reescrever a equação

$$
[\mathrm{H}]\{\mathrm{u}\}=[\mathrm{G}]\{\mathrm{q}\}
$$


como

$$
[\mathrm{A}]\{\mathrm{x}\}=\{\mathrm{b}\}
$$

Trata-se simplesmente de troca apropriada de colunas entre $[\mathrm{G}]$ e $[\mathrm{H}]$, balizada pelas informações do tipo de condição de contorno fornecida no início do problema. O vetor $\{b\}$ é calculado pelo produto de uma matriz (rearranjada) pelo vetor do valor das condições de contorno pré-estabelecidas, \{vl_ele $\}$.

A solução do sistema também não apresenta maiores dificuldades. Foi implementada com o auxílio de subrotinas de domínio público que efetuam as operações de decomposição LU da matriz [A], seguida de retro-substituição (PRESS, 1992).

A última etapa antes de prosseguir ao cálculo do valor da variável em pontos internos, solicita a redistribuição apropriada dos valores calculados de $u$ e $q$ e dos valores fornecidos para $\bar{u} \mathrm{e}$ $\bar{q}$ em conjuntos distintos, ou seja, separando-os quanto à natureza/tipo da condição de contorno.

\subsection{Cálculos finais}

Uma vez resolvido o problema e rearranjada a solução do sistema de equações da seção anterior, todos os valores no contorno são agora conhecidos. Tem-se, então, a possibilidade de voltar a aplicar a formulação integral de contorno a fim de calcular os valores da variável (potencial escalar) em pontos internos ao domínio através da equação (3.61), aqui repetida sem a parcela associada a fontes:

$$
u_{i}+\int_{\Gamma} u q^{*} d \Gamma=\int_{\Gamma} u^{*} q d \Gamma
$$


É evidente que na aplicação desta equação as integrações ocorrerão em $\Gamma=\Gamma_{\mathrm{D}}$, ou seja, no contorno do domínio que contém o ponto $i$. Faz-se, então, necessário localizar este ponto na geometria do problema.

\subsubsection{Localização geométrica do ponto $i$}

Conforme mencionado, uma vez resolvido o problema, a formulação integral de contorno pode ser aplicada novamente para calcular-se valores da função a partir do conhecimento de $u$ e $q$ nos nós de função. Torna-se, então, necessário identificar a localização do ponto $i$ de interesse no qual se aplica a excitação impulsiva. A questão de detectar em qual domínio se localiza $\mathrm{P}_{\text {aplic }}$ associado ao ponto $i$ pode ser encaminhada a partir das considerações de natureza geométrica, a seguir, e que foram utilizadas no algoritmo desenvolvido:

- Seja a região fechada $\Omega$, identificada com um domínio simplesmente conexo (figura 5.3);

- dado o ponto $\mathrm{P}_{\text {aplic, }}$, escolhe-se arbitrariamente uma reta que o contenha;

- a partir de qualquer uma das duas semi-retas, definidas implicitamente no item anterior, conta-se o número de intersecções entre ela e o contorno $\Gamma$ do domínio;

- se a ocorrência de intersecções for um número ímpar, então $\mathrm{P}_{\text {aplic }}$ é interno a $\Omega$; caso contrário $\mathrm{P}_{\text {aplic }}$ é externo (figura 5.24). 


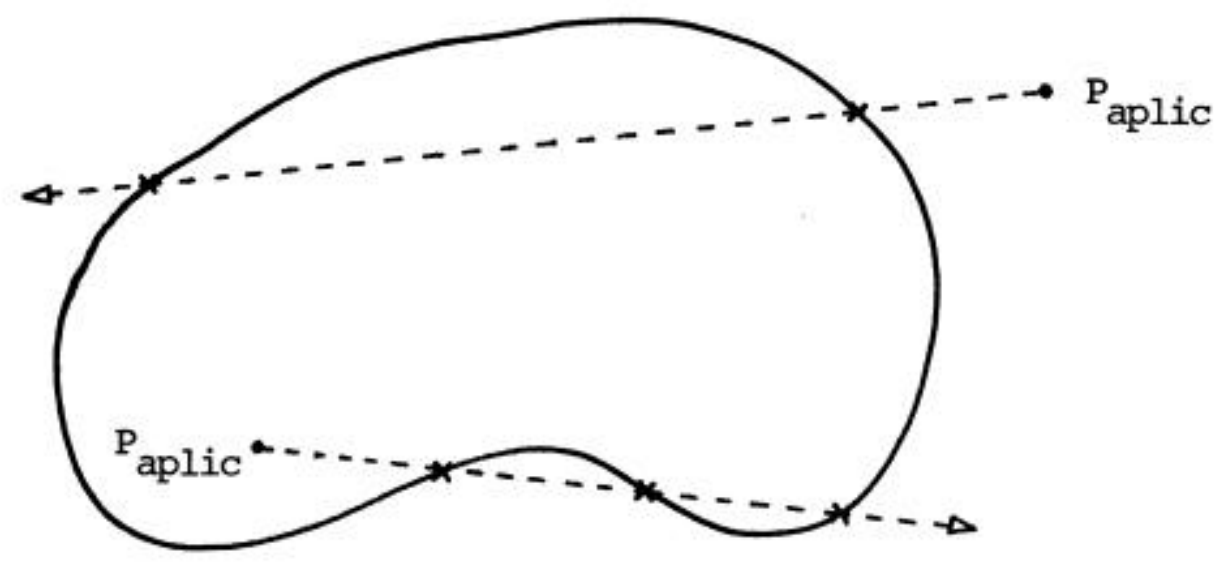

Figura 5.24: Contagem do número de intersecções para localizar $\mathrm{P}_{\text {aplic. }}$

Para a aplicação destes conceitos às geometrias poligonais tratadas neste trabalho, há que se considerar uma limitação importante que é a de nenhuma intersecção coincidir com algum vértice do domínio (figura 5.25).

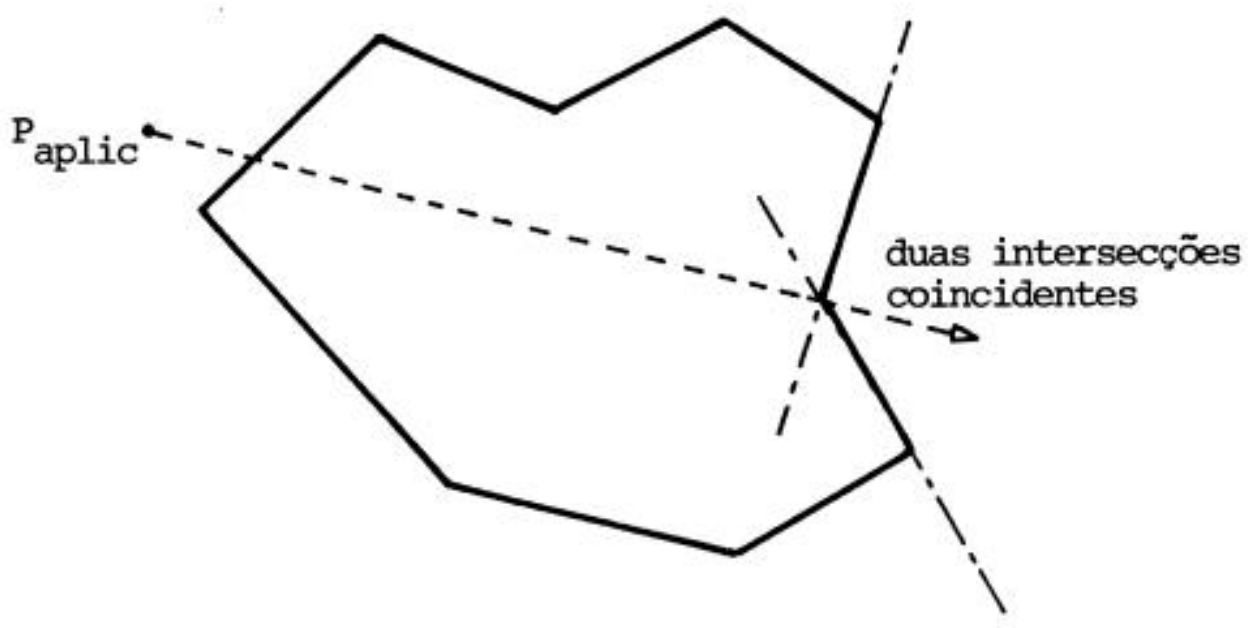

Figura 5.25: Situação patológica a ser evitada. 
Em um caso destes haveria duas intersecções coincidentes; o procedimento correto pode ser retomado bastando escolher-se outra reta de teste que não invalide o algoritmo.

Situações de paralelismo entre elemento(s) e semi-reta de teste também são contemplados, não gerando ocorrência de intersecção; a única exceção apresenta-se quando a semi-reta de teste suporta algum elemento. A detecção desta patologia implica necessariamente em trocarse a reta de teste.

É evidente que para a validação da semi-reta de teste $r$ e de cada uma das retas que suportam os elementos de contorno, é necessário que ela (a intersecção) ocorra no segmento de reta que define o elemento, excluídos seus extremos.

Os procedimentos descritos até aqui estão resumidos no fluxograma da figura 5.26. 


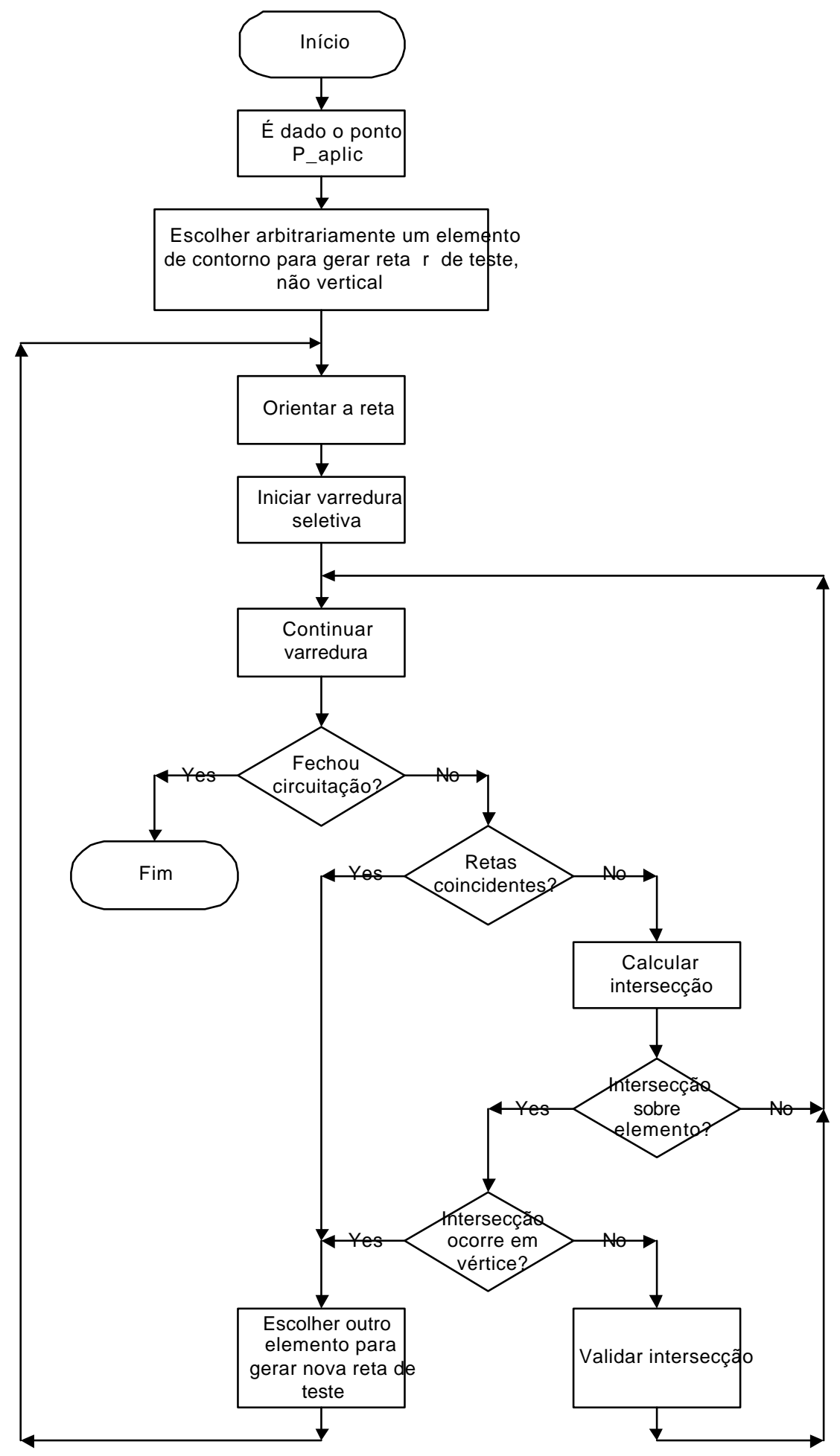

Figura 5.26: Detecção de ocorrências de intersecções válidas.

Como o contorno está descrito (armazenado) na forma de elementos, a intersecção procurada é definida na intersecção da semi-reta considerada e a reta que suporta o 
elemento. Os testes a ser efetuados para a validação de cada intersecção utilizam-se do cálculo do módulo de vetores e de seus produtos escalares; estes vetores são definidos abaixo:

- $\overline{P_{\text {aplic }} P_{\text {ref }}}$ : define a semi-reta de teste; $\mathrm{P}_{\text {ref }}$ é inicialmente estabelecido no nó de função do primeiro elemento da descrição. Se necessário, estabelece-se outro $\mathrm{P}_{\text {ref }}$ no segundo elemento, e assim por diante;

- $\overline{P_{\text {aplic }} P_{I}}$ : vetor orientado ligando o ponto de aplicação da função impulsiva e o ponto de intersecção com a reta de teste

- $\overline{P_{1} P_{2}}$ : vetor orientado associado a qualquer elemento de contorno (respeitado seu sentido de percurso)

Os testes que devem resultar verdadeiros para cada elemento de contorno em um certo domínio são:

1. $\left(\overline{P_{\text {aplic }} P_{\text {ref }}}\right) \cdot\left(\overline{P_{\text {aplic }} P_{I}}\right)>0$

2. $\left(\overline{P_{1} P_{2}}\right) \cdot\left(\overline{P_{1} P_{I}}\right)>0$

3. $\left|\overline{P_{1} P_{2}}\right|>\left|\overline{P_{1} P_{I}}\right|$

$\mathrm{O}$ primeiro teste atende à orientação da semi-reta. $\mathrm{O}$ segundo teste garante que, havendo intersecção, ela respeita o sentido de percurso no domínio. O último teste exclui as intersecções fora do elemento. Ainda, nos dois últimos testes, a desigualdade serve também para excluir as coincidências $\mathrm{P}_{1}=\mathrm{P}_{\mathrm{I}}$ (o que resultaria em zero no segundo teste) e $\mathrm{P}_{2}=\mathrm{P}_{\mathrm{I}}$ (o que resultaria em igualdade nos dois membros do terceiro teste). 


\subsubsection{O ponto $i$ sobre o contorno}

Apresentando de modo formal, a aplicação do ponto $i$ sobre o contorno não constitui problema algum porque os valores nos nós do contorno tornaram-se já conhecidos, bastando efetuar uma interpolação entre eles. Por outro lado, caso seja conveniente proceder-se a um mapeamento do valor da variável em locais próximos ao contorno, as aproximações numéricas realizadas para as integrações poderão gerar erros grandes nesta avaliação.

Por estas razões é também comum o emprego da equação (3.67) para calcular (de forma teoricamente redundante, mas computacionalmente não) o valor de $u$ em pontos sobre o contorno. Por causa da discretização da geometria em formas poligonais, dois casos podem ocorrer:

- $\mathrm{P}_{\text {aplic }}$ sobre o elemento, excluídos os extremos

- $\mathrm{P}_{\text {aplic }}$ sobre algum dos dois extremos do elemento

No primeiro caso, pela própria construção, tem-se

$$
c_{i}=1 / 2
$$

no segundo caso é necessário o cálculo do ângulo interno, $\theta_{\text {int }}$ referido na figura 3.5.

A detecção de $\mathrm{P}_{\text {aplic }}$ sobre algum elemento é realizada a partir de testes com o módulo de vetores (razão de segmentos) e seus produtos vetoriais. Chamando

- $\overline{P_{1} P_{\text {aplic }}}$ o vetor orientado que liga o nó inicial de um elemento ao ponto de aplicação da função impulsiva,

então os testes resumem-se a checar, para todos os elementos de um domínio, que: 


$$
\begin{aligned}
& \text { 1. }\left(\overline{P_{1} P_{2}}\right) \times\left(\overline{P_{1} P_{\text {aplic }}}\right)=0 \\
& \text { 2. }\left|\overline{P_{1} P_{2}}\right|>\left|\overline{P_{1} P_{\text {aplic }}}\right|
\end{aligned}
$$

sejam verdadeiros.

Ocorrendo a situação de $\mathrm{P}_{\text {aplic }}$ sobre um canto do contorno, o ângulo $\theta_{\text {int }}$ é calculado com auxílio do algoritmo representado no diagrama NS da figura 5.27, com símbolos definidos nas equações (5.27) a (5.29).

\begin{tabular}{|l|l|}
\hline $\begin{array}{l}\text { Calcular vetor A associado ao elemento } \\
\text { anterior }\end{array}$ \\
\hline $\begin{array}{l}\text { Calcular vetor B associado ao elemento } \\
\text { posterior }\end{array}$ \\
\hline Calcular PE, PV e alfa \\
\hline True False \\
\hline teta_int $=$ pi - alfa & teta_int $=\mathrm{pi}+$ alfa \\
\hline & Fim \\
\hline
\end{tabular}

Figura 5.27: Cálculo do ângulo interno.

$$
\begin{aligned}
& P E=\vec{A} \cdot \vec{B} \\
& P V=\vec{A} x \vec{B}
\end{aligned}
$$

$\mathrm{e}$

$$
\alpha=\arccos \left(\frac{\vec{A} \cdot \vec{B}}{|\vec{A}||\vec{B}|}\right)
$$

$\mathrm{O}$ fator $\mathrm{c}_{\mathrm{i}}$ é calculado pela equação (3.69). 


\subsubsection{Procedimento computacional}

Os tópicos abordados nas duas seções anteriores foram implementados de forma a poder operar em geometrias de vários domínios, não simplesmente conexos. A programação é significativamente complexa e segue os procedimentos gerais da figura 5.28. As variáveis <achei_csca> e <achei_dntr> são de natureza lógica e, se verdadeiras, indicam, respectivamente, a localização de $\mathrm{P}_{\text {aplic }}$ sobre o contorno ou no interior de um domínio, referenciado por uma outra variável que o aponta, 〈apt_dom>.

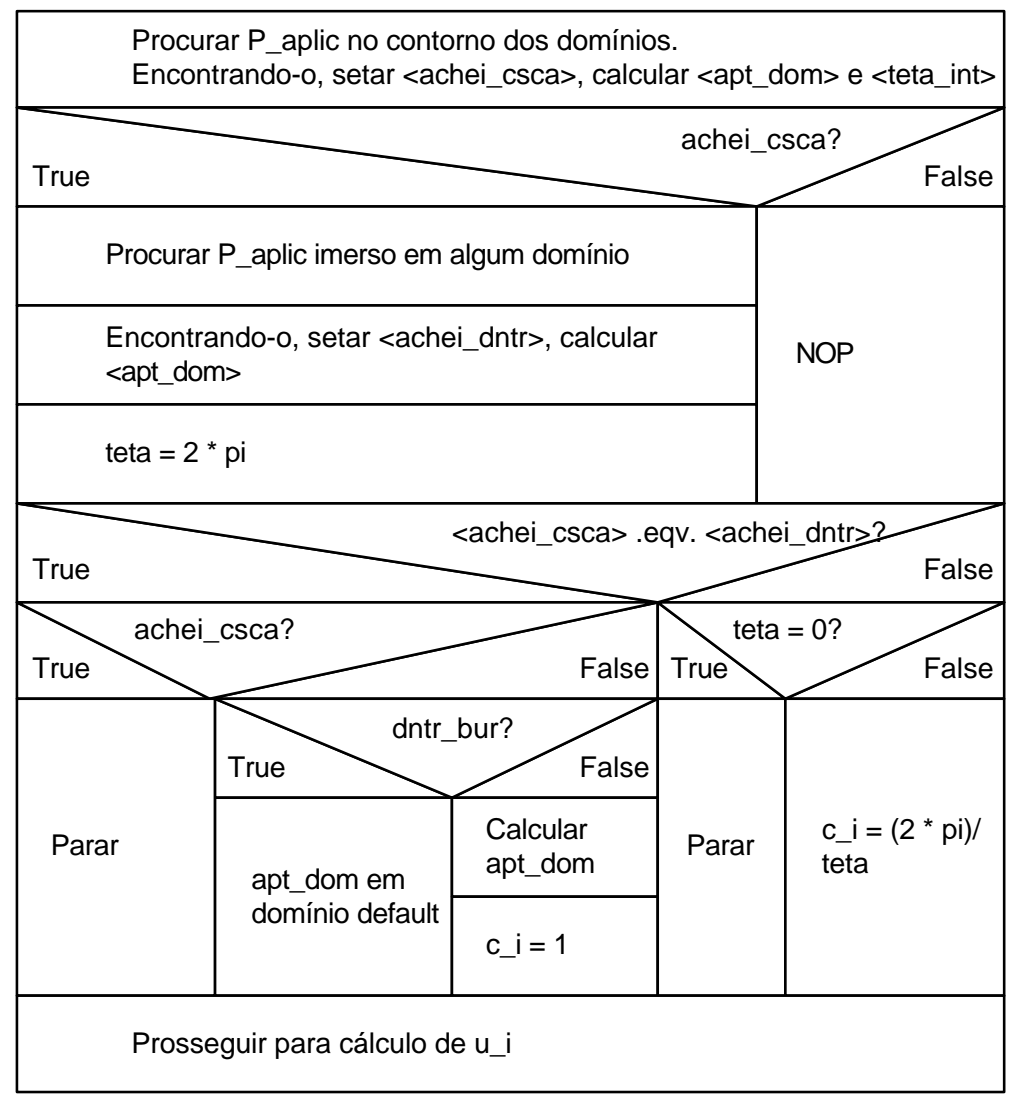

Figura 5.28: Localização de $\mathrm{P}_{\text {aplic. }}$ 
Devido aos procedimentos estabelecidos para a avaliação da geometria, os elementos de interface são referenciados ao domínio no qual foram identificados pela primeira vez; este domínio é chamado de domínio de ordem inferior, pois tem a ele associado um número seqüencial mais baixo. No cálculo do potencial escalar pode ser necessário trocar-se o sinal de $\partial \mathrm{u} / \partial \mathrm{n}$, já calculado nos elementos de interface, se o domínio que contiver $\mathrm{P}_{\text {aplic }}$ for de ordem superior em relação ao do outro domínio. A troca do sinal é necessária porque o vetor normal ao elemento foi definido quando de sua primeira identificação, portanto, não no domínio considerado.

Havendo reconhecimento da localização de $\mathrm{P}_{\text {aplic }}$ em um buraco, pode-se simplesmente fixar arbitrariamente $c_{i}=0$ por não ser região de interesse. Ocorrendo a situação de $P_{\text {aplic }}$ localizado fora de todos os domínios de interesse, o algoritmo implementado fornecerá um resultado numérico decorrente da integração em todos os elementos de contorno. Este resultado não apresenta significado físico, pela própria formulação do método.

Situação semelhante ocorre em relação aos valores resultantes como condições de contorno nos elementos de interface, ou seja, dependendo da natureza do problema, é imperativa a utilização, mais uma vez, da equação (5.9) para corrigir o valor de $\partial \mathrm{u} / \partial \mathrm{n}$ nos percursos efetuados em domínio superior ao que definiu o vetor normal nestes elementos. Por exemplo, considere a equação de Laplace regendo um problema de natureza eletrostática. $\mathrm{O}$ valor de $\partial u / \partial n$ calculado no elemento de interface em foco, está referenciado ao domínio de ordem mais baixa; é evidente que o valor de $\partial \mathrm{u} / \partial \mathrm{n}$, agora referenciado ao domínio superior, precisa ser calculado pela equação (5.9). Concluindo: pode ser necessária a troca do sinal e a aplicação de condição de contorno em resultados obtidos da solução do sistema de equações. 


\subsection{Estudo de propagação}

Para a aplicação em equação de Helmholtz, um aspecto importante é o da caracterização dos modos de ressonância nas estruturas de guiamento. Foram então desenvolvidos, também, procedimentos considerados como variantes das técnicas descritas nas seções anteriores. Estas variantes são:

- Cálculo de autovalores e autovetores associados

- Varredura em frequiência

- Excitação localizada

\subsubsection{Autovalores}

Considerando-se, por exemplo, a geometria vista na figura 5.2, uniforme ao longo do eixo z (guia de ondas), o comportamento das ondas, supostas em regime permanente senoidal, atende à equação de Helmholtz

$$
\nabla^{2} \vec{E}+k^{2} \vec{E}=0
$$

sujeita às condições de contorno. Equação semelhante vale para o vetor campo magnético $\vec{H}$. Admitindo $\gamma$ ser a constante de propagação no sentido de $z$ crescente, pode-se combinála com o número de onda $k$ e escrever

$$
\nabla_{x y}^{2} \vec{E}+\left(\gamma^{2}+k^{2}\right) \vec{E}=0
$$

ou

$$
\nabla_{x y}^{2} \vec{E}+k_{c}^{2} \vec{E}=0
$$


Equações semelhantes valem para $\vec{H}$. Utilizando-se coordenadas retangulares, as equações acima são desmembradas, cada uma, em três equações escalares.

No caso de modos transversais magnéticos (TM), resolve-se a equação escalar

$$
\nabla_{x y}^{2} e_{z}+k_{c}^{2} e_{z}=0
$$

$\mathrm{e}_{\mathrm{z}}(\mathrm{x}, \mathrm{y})$ representa o componente longitudinal do campo elétrico, excluída a dependência em $z$. A solução de $e_{z}$ deve atender condições de contorno de Dirichlet $\left(e_{z}(x, y)=0\right.$ em x $=0$ e $x=$ $a ; e_{z}(x, y)=0$ em $y=0$ e $\left.y=b\right)$.

Para os modos transversais elétricos (TE), a equação escalar a ser resolvida é

$$
\nabla_{x y}^{2} h_{z}+k_{c}^{2} h_{z}=0
$$

sujeita às condições de contorno de Neumann $\left(\partial \mathrm{h}_{\mathrm{z}} / \partial \mathrm{x}=0 \mathrm{em} \mathrm{x}=0 \mathrm{e} \mathrm{x}=\mathrm{a} ; \partial \mathrm{h}_{\mathrm{z}} / \partial \mathrm{y}=0 \mathrm{em} \mathrm{y}\right.$ $=0 \mathrm{e} \mathrm{y}=\mathrm{b}$ ) que equivalem a forçar a zero os valores do campo elétrico tangencial às paredes. Os valores de $k_{c}$ que atendem soluções de (5.32) ou (5.33) são os autovalores associados à equação.

Na formulação do MEC pode-se proceder à uma análise de autovalores a partir da equação

$$
[\mathrm{H}]\{\mathrm{u}\}-[\mathrm{G}]\{\mathrm{q}\}=0
$$

Deve-se lembrar que os elementos das matrizes $[\mathrm{H}]$ e $[\mathrm{G}]$ dependem dos valores de $\mathrm{k}_{\mathrm{c}}$. Nos problemas de propagação, interessa aplicar-se condições de contorno homogêneas do tipo Dirichlet ou Neumann. Neste caso, da equação (5.34) resultarão duas situações descritas por

$$
[\mathrm{H}]\{\mathrm{u}\}=0 \quad \text { (condição de Neumann) }
$$

ou

$$
[\mathrm{G}]\{\mathrm{q}\}=0 \quad \text { (condição de Dirichlet) }
$$


Para determinar soluções não triviais, os autovalores da matriz resultante no membro esquerdo de (5.35) ou (5.36) precisam ser obtidos.

Observe-se, também, que eventuais problemas definidos por condições de contorno homogêneas mistas podem ser considerados com a mesma abordagem da equação (5.34), que rearranjada conduz à forma

$$
[\mathrm{A}]\{\mathrm{x}\}=0
$$

A determinação dos autovalores referentes às equações (5.35) ou (5.36), permite a obtenção dos valores de $k_{\varepsilon}$ definidos em (5.32) e (5.33). Para esta determinação é proposto um procedimento de varredura em freqüência, visando minimizar problemas numéricos decorrentes da própria discretização.

\subsubsection{Varredura em freqüência}

A precisão destes resultados depende da maior ou menor discretização da geometria, pois estruturas contínuas não podem ser perfeitamente descritas se aproximadas por discretizações. Autovalores (modos) de ordem mais elevada podem resultar em valores complexos, quando são de fato reais.

A abordagem proposta considera que, na impossibilidade de determinar diretamente os valores de $\mathrm{k}_{\mathrm{c}}$, pode-se efetuar uma varredura e registrar o comportamento do determinante de $[H]$ ou $[G]$, visando determinar a freqüência em que seu valor é nulo.

Por razões de precisão numérica pode ser vantajoso obter a variação de $|\operatorname{det}[\mathrm{A}]|$, procurando, neste caso, pelos pontos de mínimo ao invés de raízes de $\operatorname{det}[\mathrm{A}]$. Estes pontos de mínimo estarão, então, associados às frequiências de ressonância. 
O fluxograma deste procedimento é mostrado na figura 5.29. 


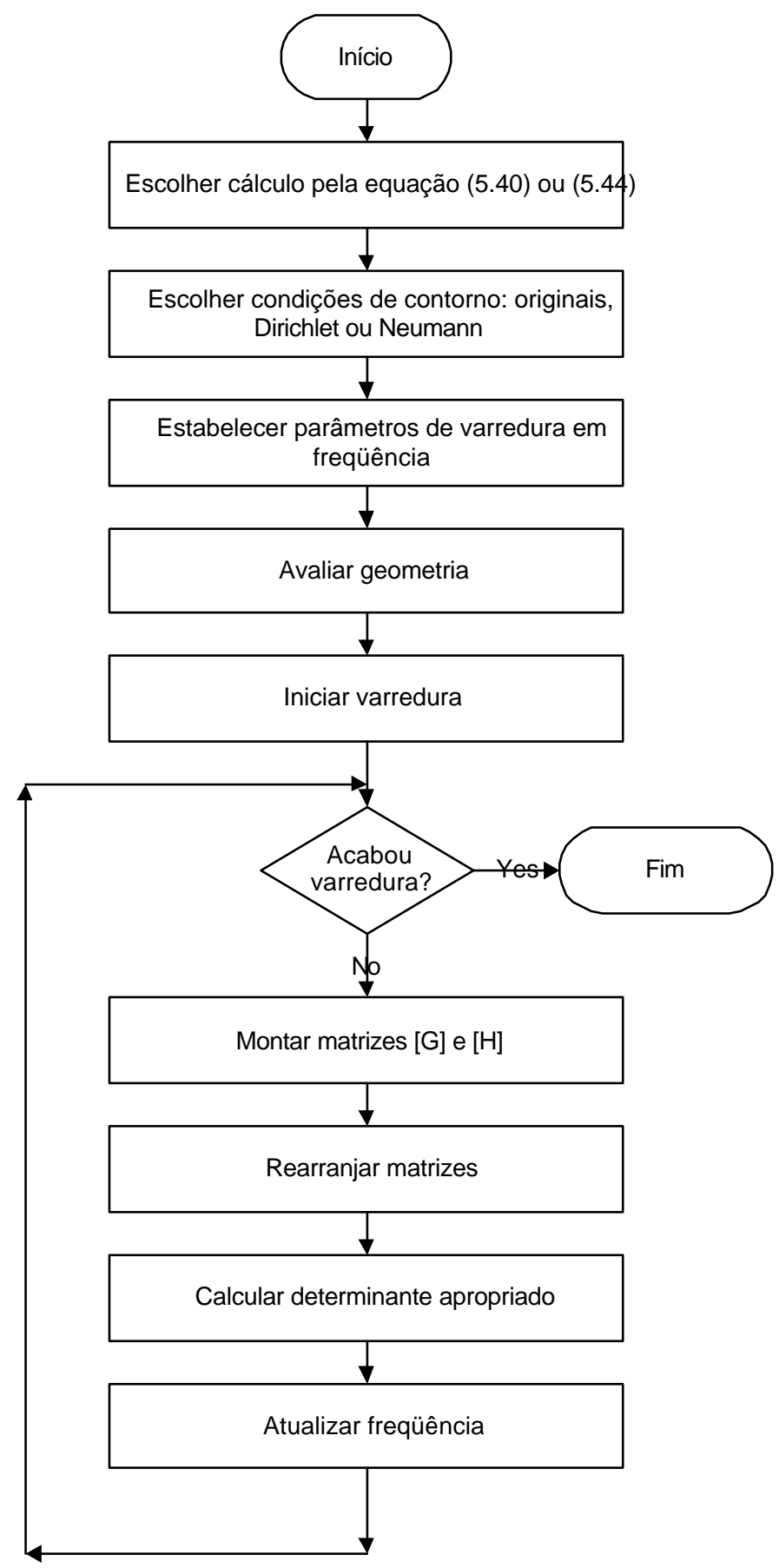

Figura 5.29: Varredura em frequiência

\subsubsection{Excitação localizada}

Apesar da técnica de varredura em freqüência da seção anterior obter as 
frequiências em que ocorrem ressonâncias na estrutura, ela é incapaz de fornecer os autovetores associados.

Suponha-se que, fixado um valor de frequiência coincidente com um modo de ressonância, sejam estabelecidas as condições $\mathrm{u}=0 \mathrm{em} \Gamma_{1}$ e $\mathrm{q}=0$ em $\Gamma_{2}$; procedendo-se a uma análise pelo método direto, apenas a solução trivial seria obtida (figura 5.1). Como se trata de um modo de ressonância, pode-se supor que, se algum nó de função na geometria tiver seu valor alterado de zero (condição homogênea) para outro valor, ainda que arbitrário, então a formulação integral de contorno modelará a influência deste nó sobre os demais; o comportamento resultante desta influência deverá atender à distribuição de campo relacionada ao modo excitado.

Isto corresponde a fixar, no contorno, algum valor diferente de zero para o componente tangencial de E (ou H, dependendo do tipo de condição de contorno imposta). Ter-se-á, então, numa pequena parte do contorno, $\mathrm{E}(\mathrm{ou} \mathrm{H}$ ) tangencial dado, sendo $\mathrm{H}$ (ou E) tangencial nulo no restante. Desta forma, obtém-se uma solução não trivial do problema, correspondente ao autovalor (freqüência de corte) desejado.

A implementação computacional realizada (figura 5.31) precisou apenas alterar as condições de contorno estabelecidas na descrição do problema (arquivo de entrada); exceto por esta tarefa, os procedimentos são semelhantes ao fluxograma da figura 5.1. 


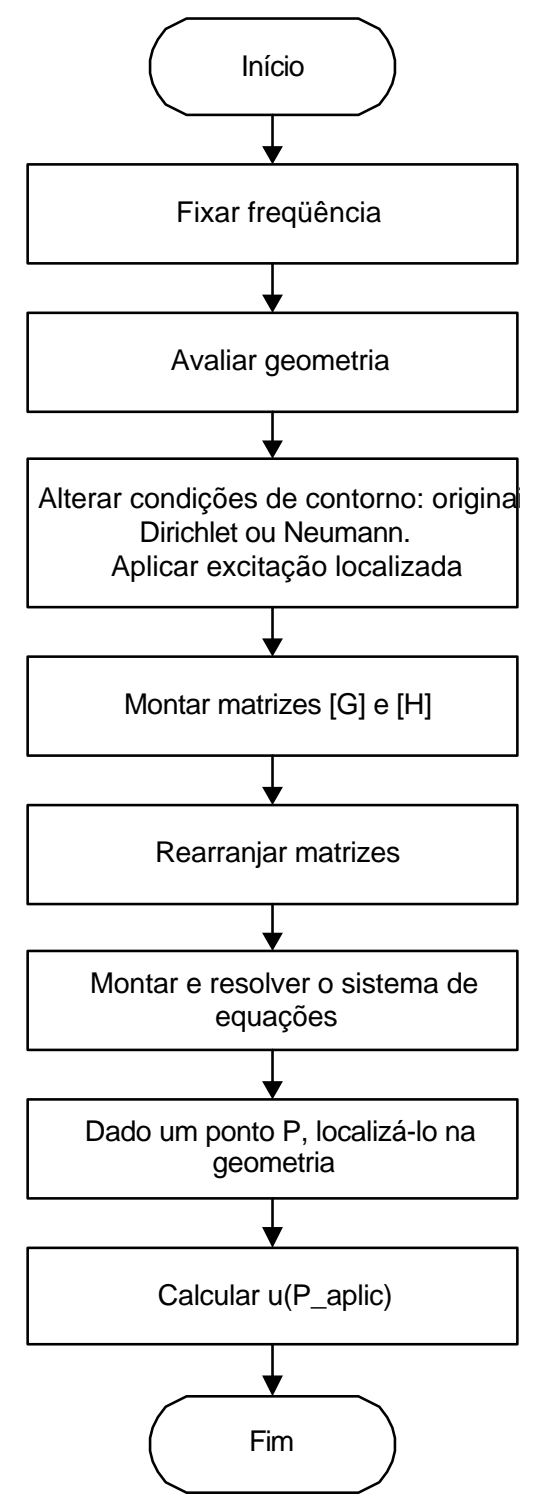

Figura 5.31: Cálculo do potencial devido ao modo de ressonância excitado.

O valor da amplitude da excitação localizada não é importante; pode, então, ser fixada arbitrariamente em um valor unitário. Os resultados obtidos permitem a visualização do comportamento do potencial em função de ponto. Como a excitação deu-se de forma localizada, ao contrário do problema citado no fim da seção 5.1 (o contorno já apresentava a distribuição do modo estudado), ocorrerão "perturbações" nos valores de potencial na região próxima à aplicação unitária. 


\section{Aplicação}

Conforme mencionado nas seções anteriores, este capítulo trata de alguns problemas nos quais se aplicam as ferramentas computacionais desenvolvidas para sua análise pelo Método dos Elementos de Contorno.

\subsection{Linha de transmissão bifilar}

O MEC necessita apenas da discretização do contorno do domínio ou dos domínios estudados. Isto representa uma grande vantagem em relação a outros métodos numéricos muito utilizados, como, por exemplo, o Método das Diferenças Finitas ou o Método dos Elementos Finitos. Em problemas nos quais há interesse em se estudar uma região aberta, isto é, que se estende ao infinito, o MEC é uma ferramenta que deve ser considerada. A fim de que ele seja adequadamente aplicado a problemas desta natureza é necessário que a solução fundamental tenda a zero no infinito. Este é o caso da equação de Laplace em que se utilizou a equação

$$
u^{*}=\frac{1}{2 \pi} \ln (1 / r)
$$

como função de Green no espaço livre; como de costume, $r$ representa a distância entre o ponto de aplicação da excitação impulsiva e o ponto em que se calcula o potencial de interesse. Neste exemplo, o potencial mencionado é o potencial escalar elétrico. Em geometrias mais complexas pode ser interessante considerar-se a substituição da equação (6.1) por uma outra função que atenda especificamente o problema. Neste caso, algumas condições de contorno seriam satisfeitas já por esta nova função. Num caso assim perde-se a 
generalidade da ferramenta, pois ela atende apenas a um tipo de geometria, mas tem-se a vantagem de necessitar discretizar apenas as porções do contorno não atendidas pela solução fundamental.

Seja a geometria de uma linha bifilar infinita, formada por dois fios circulares e paralelos, envolvidos pelo meio homogêneo de permissividade $\varepsilon$ (figura 6.1). A equação de Laplace rege o problema.

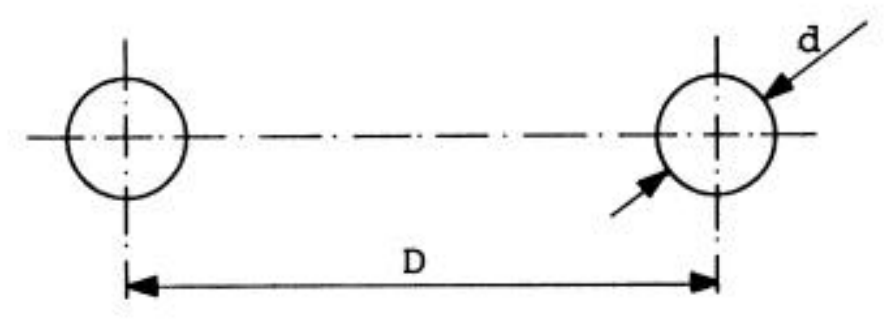

Figura 6.1: Linha bifilar infinita, mergulhada num meio homogêneo.

No exemplo numérico, as dimensões da linha foram ajustadas para resultar numa impedância característica $\mathrm{Z}_{0}=300 \Omega$. Os eixos dos fios condutores distam $\mathrm{D}=2 \mathrm{~h}=10 \mathrm{~mm}$; o diâmetro de cada condutor vale $\mathrm{d}=2 \mathrm{r}=1,6308 \mathrm{~mm}$. Para facilitar a comparação com a solução analítica do problema, impõe-se os potenciais $\mathrm{V}_{+}=0,398 \mathrm{~V}$ no condutor direito e $\mathrm{V}_{-}=-\mathrm{V}_{+}$ no esquerdo; estes valores de tensão decorrem do problema equivalente da determinação de superfícies equipotenciais geradas pela presença de duas linhas carregadas, respectivamente, com densidade linear de carga $\rho_{\mathrm{L}}= \pm 1 \mathrm{C} / \mathrm{m}$.

A geometria estudada pode ser entendida como inversa de uma situação de domínio único com um buraco (figura 5.4, que é de domínio fechado). Não interessam as porções internas dos condutores; então a descrição é feita percorrendo-os no sentido horário. Terminada a do 
primeiro condutor, a descrição do segundo (não simplesmente conexo ao primeiro) é efetuada pela definição de um "buraco" de domínio. Observe-se que não existem interfaces no problema.

Duas discretizações foram efetuadas:

- 8 elementos por condutor e

- 16 elementos por condutor.

Os resultados seguintes foram obtidos com formulação constante. A idéia é mostrar que, mesmo com poucos elementos, os resultados, neste caso, convergem rapidamente para os valores da solução analítica conhecida.

Dada a geometria aberta, a circulação do contorno foi efetuada no sentido horário, a partir das coordenadas $\mathrm{x}=5,8154$ (equivalente a $D / 2+r$, com o eixo x passando pelo centro dos condutores e o eixo y eqüidistante deles) e y $=0$, medidas em milímetros. A figura 6.2 mostra a primeira discretização.

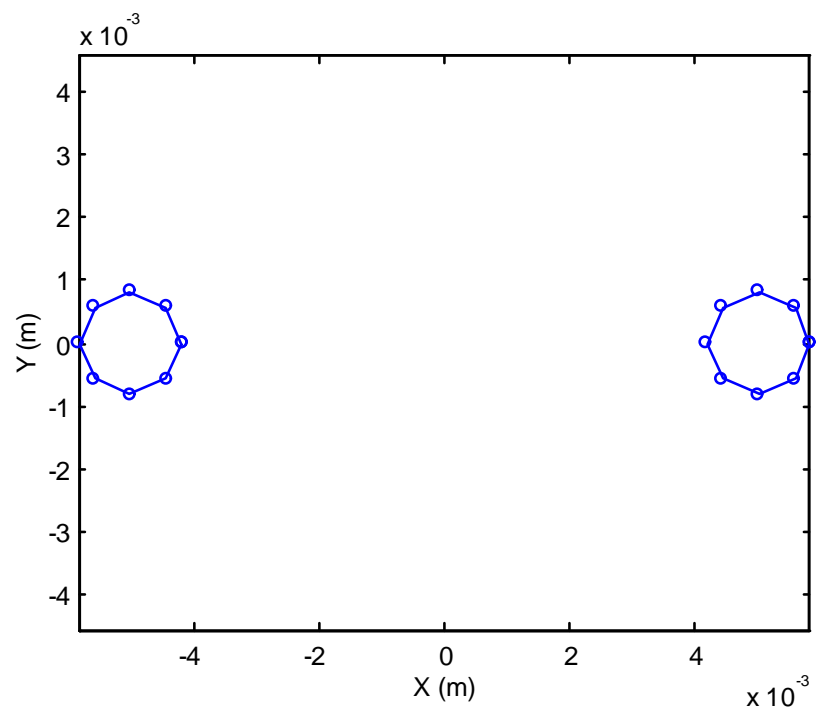

Figura 6.2: Discretização da linha bifilar. $D=2 h=10 \mathrm{~mm} ; \mathrm{d}=2 \mathrm{r}=1,6308 \mathrm{~mm}$. 
Os resultados obtidos estão mostrados na Tabela 6.1, que apresenta os valores das coordenadas $(\mathrm{x}, \mathrm{y})$ dos nós de função, os valores de $u$ (no caso, todos impostos aos elementos) e os valores resultantes de $\partial \mathrm{u} / \partial \mathrm{n}$.

Tabela 6.1: Resultados nos elementos da geometria da figura 6.2.

\begin{tabular}{|c|c|c|c|}
\hline $\mathrm{x}(\mathrm{mm})$ & $\mathrm{y}(\mathrm{mm})$ & Potencial & $\partial \mathrm{u} / \partial \mathrm{n}$ \\
\hline $.56960 \mathrm{E}-02$ & $-.28830 E-03$ & .39800 & 168.98 \\
\hline $.52885 E-02$ & $-.69600 \mathrm{E}-03$ & .39800 & 182.34 \\
\hline $.47115 \mathrm{E}-02$ & $-.69600 \mathrm{E}-03$ & .39800 & 205.39 \\
\hline $.43040 \mathrm{E}-02$ & $-.28830 \mathrm{E}-03$ & .39800 & 225.52 \\
\hline $.43040 \mathrm{E}-02$ & $.28830 \mathrm{E}-03$ & .39800 & 225.52 \\
\hline $.47115 \mathrm{E}-02$ & $.69600 \mathrm{E}-03$ & .39800 & 205.39 \\
\hline $.52885 E-02$ & $.69600 \mathrm{E}-03$ & .39800 & 182.34 \\
\hline $.56960 \mathrm{E}-02$ & $.28830 E-03$ & .39800 & 168.98 \\
\hline$-.43040 \mathrm{E}-02$ & $-.28830 E-03$ & -.39800 & -225.52 \\
\hline$-.47115 \mathrm{E}-02$ & $-.69600 \mathrm{E}-03$ & -.39800 & -205.39 \\
\hline$-.52885 \mathrm{E}-02$ & $-.69600 \mathrm{E}-03$ & -.39800 & $-182 \cdot 34$ \\
\hline$-.56960 \mathrm{E}-02$ & $-.28830 \mathrm{E}-03$ & -.39800 & $-168 \cdot 98$ \\
\hline$-.56960 \mathrm{E}-02$ & $.28830 \mathrm{E}-03$ & -.39800 & $-168 \cdot 98$ \\
\hline$-.52885 \mathrm{E}-02$ & $.69600 \mathrm{E}-03$ & -.39800 & $-182 \cdot 34$ \\
\hline$-.47115 \mathrm{E}-02$ & $.69600 \mathrm{E}-03$ & -.39800 & -205.39 \\
\hline$-.43040 E-02$ & $.28830 \mathrm{E}-03$ & -.39800 & -225.52 \\
\hline
\end{tabular}

A partir do conhecimento do potencial e do $\partial \mathrm{u} / \partial \mathrm{n}$ em todos os elementos, é possível a determinação do potencial e, se necessário, suas derivadas parciais em relação a x e y em qualquer ponto do domínio. O potencial é calculado por

$$
u=\int_{\Gamma} q u^{*} d \Gamma-\int_{\Gamma} u q^{*} d \Gamma
$$

equação cujo membro direito, agora, não apresenta mais incógnitas e, quando discretizada, é reescrita como

$$
u=\sum_{j=1}^{N} g_{i j} q_{j}-\sum_{j=1}^{N} h_{i j} u_{j}
$$

Os valores de u e $^{*}$ são os decorrentes da aplicação da função impulsiva no ponto de coordenadas $\left(x_{P}, y_{P}\right)$ em que se procura o valor $u\left(x_{P}, y_{P}\right)$. Os elementos $g_{i j}$ e $h_{i j}$ da equação acima não correspondem mais a nenhuma coluna das matrizes $[\mathrm{G}]$ e $[\mathrm{H}]$ porque a localização 
do ponto de aplicação da função impulsiva, agora interno ao domínio, não equivale mais a nenhum dos nós de função utilizados para a montagem do sistema de equações.

Caso desejado, as derivadas de $u$ nas direções $\mathrm{x}$ e $\mathrm{y}$, em pontos internos, poderão ser obtidas por

$$
\frac{\partial u}{\partial x}=\left.\int_{\Gamma} q \frac{\partial u^{*}}{\partial x}\right|_{P} d \Gamma-\left.\int_{\Gamma} u \frac{\partial q^{*}}{\partial x}\right|_{P} d \Gamma
$$

e

$$
\frac{\partial u}{\partial y}=\left.\int_{\Gamma} q \frac{\partial u^{*}}{\partial y}\right|_{P} d \Gamma-\left.\int_{\Gamma} u \frac{\partial q^{*}}{\partial y}\right|_{P} d \Gamma .
$$

As expressões das derivadas parciais no membro direito são calculadas analiticamente. Vale observar que estas equações podem ser utilizadas em problemas magnéticos, formulados com o auxílio do potencial vetorial magnético $\vec{A}$; em problemas bidimensionais, este potencial tem apenas uma componente (por exemplo, $\vec{A}=A_{z} \hat{z}$ ), o que resulta, a partir de $\vec{B}=\nabla x \vec{A}$, em

$$
\vec{B}=B_{X} \hat{x}+B_{y} \hat{y}=\frac{\partial A_{z}}{\partial y} \hat{x}-\frac{\partial A_{z}}{\partial x} \hat{y}
$$

Equacionando-se o problema com A como potencial escalar na formulação do MEC, o cálculo do vetor densidade de campo magnético é feito pela equação (6.6) com auxílio de (6.4) e (6.5).

Voltando ao problema analisado, a figura 6.3 mostra o resultado do potencial ao longo de um segmento paralelo ao eixo $\mathrm{x}$, a saber: $\mathrm{y}=1,5 \mathrm{~mm}$ e $-8 \mathrm{~mm} \leq \mathrm{x} \leq 8 \mathrm{~mm}$. O resultado analítico também está registrado para efeito de comparação.

A situação de discretização com dezesseis elementos por condutor apresenta resultados ainda melhores e está mostrada na figura 6.4. 


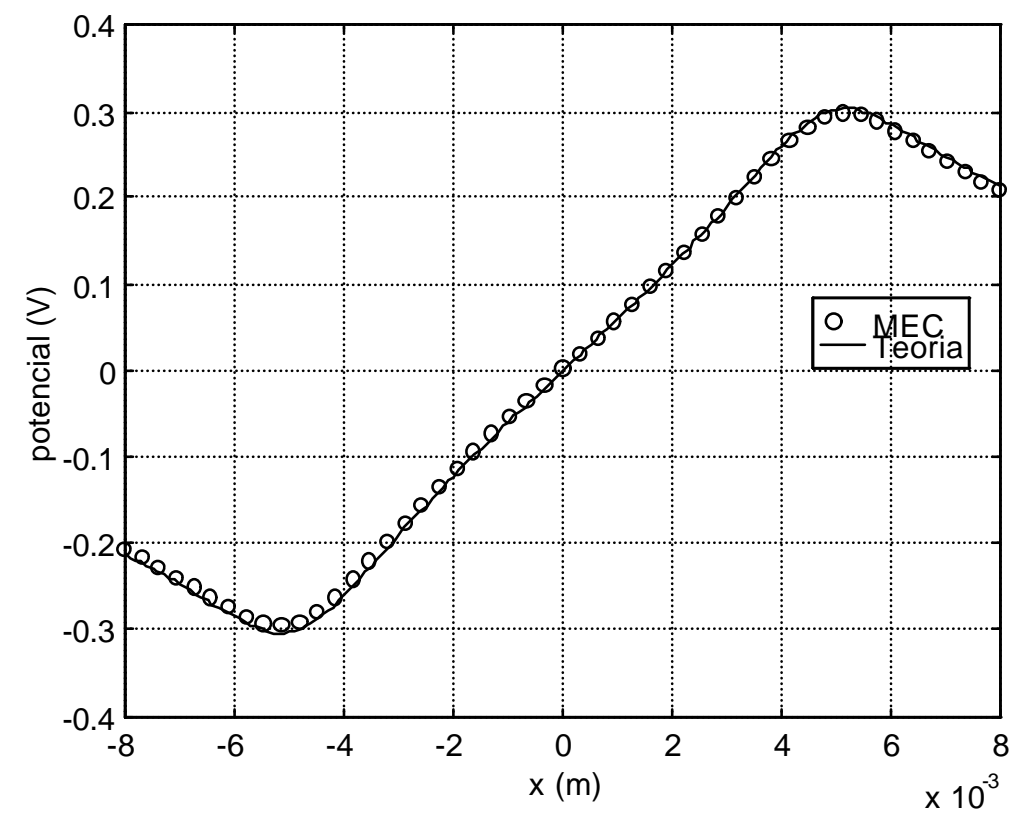

Figura 6.3: Variação do potencial ao longo de segmento paralelo ao eixo $\mathrm{x}(\mathrm{y}=1,5 \mathrm{~mm})$ para a geometria da figura 6.2; oito elementos por condutor.

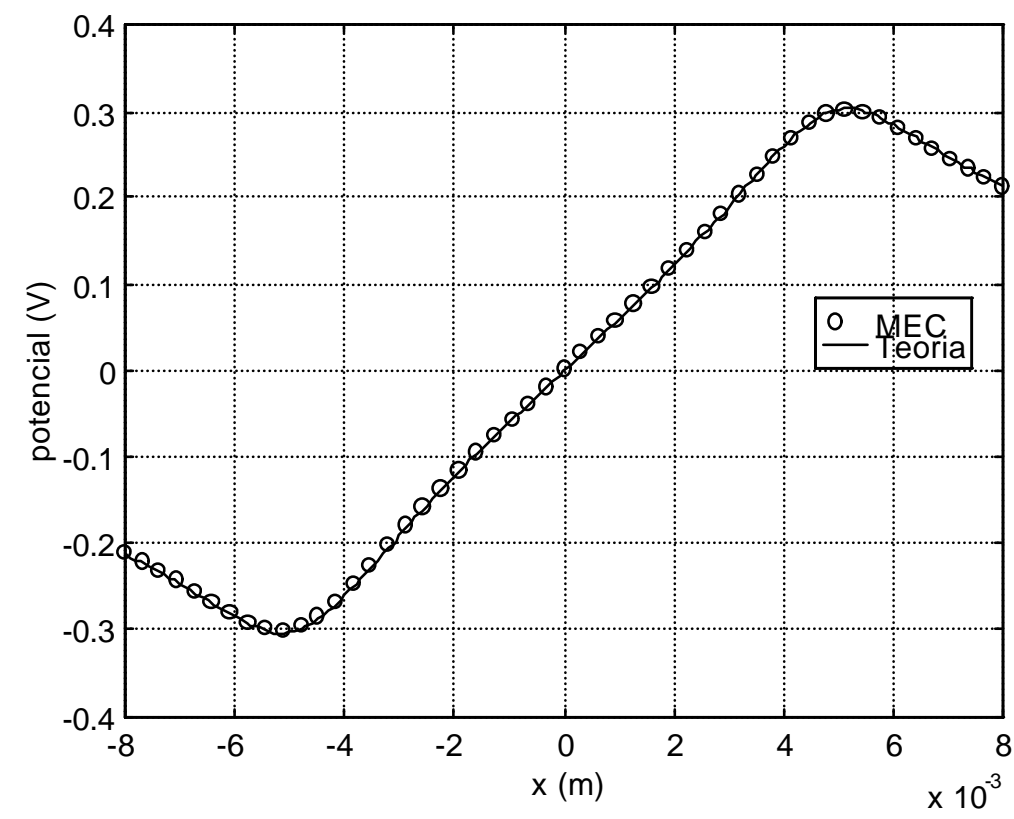

Figura 6.4: Variação do potencial ao longo de segmento paralelo ao eixo $\mathrm{x}(\mathrm{y}=1,5 \mathrm{~mm})$ para a geometria da figura 6.2; dezesseis elementos por condutor.

Os casos em que o ponto $\mathrm{P}$, no qual se deseja o valor do potencial, estiver sobre uma porção do contorno precisam ser tratados de modo especial: formalmente este ponto pertence ao 
contorno e, como tal, pode ter o valor do potencial e de $\partial \mathrm{u} / \partial \mathrm{n}$ calculado por interpolação dos valores dos nós do elemento. Uma outra abordagem é a de aplicar um fator multiplicativo $\mathrm{c}_{\mathrm{i}}$ ao resultado do potencial, calculado como se este ponto $\mathrm{P}$ fosse interno ao domínio. Este fator é de dependência geométrica, tal como visto em capítulos anteriores; do ponto de vista numérico há o aparecimento de singularidade no integrando. Esta dubiedade de abordagem é consequiência da implementação numérica, portanto aproximada, e não da formulação do método propriamente dita. Mesmo com discretizações bem "finas" os resultados das equações (6.2) a (6.4) deterioram com a aproximação do ponto $\mathrm{P}$ ao contorno. A figura 6.5 mostra esta característica; nela o potencial foi obtido em pontos distribuídos uniformemente em um quadrilátero envolvendo o condutor direito ( $3 \mathrm{~mm} \leq \mathrm{x} \leq 7 \mathrm{~mm} ;-2 \mathrm{~mm} \leq \mathrm{y} \leq 2 \mathrm{~mm})$. Na cobertura desta área, notam-se as perturbações em alguns pontos localizados próximos a elementos que definem o contorno do condutor. Estas perturbações atrapalham a construção de linhas equipotenciais, apresentando um compromisso entre a densidade de pontos escolhidos para o mapeamento de campo e a visualização do contorno.

Os pontos internos ao condutor são externos ao domínio e, por isto, não tem maior importância; neste caso a formulação indica $c_{i}=0 \Rightarrow u\left(x_{P}, y_{P}\right)=0$. No entanto, o código fonte propositalmente não implementou o reconhecimento desta situação; percebe-se, mesmo assim, que os resultados do valor do potencial tendem a zero para pontos externos ao domínio quanto mais afastados eles estiverem do contorno. 


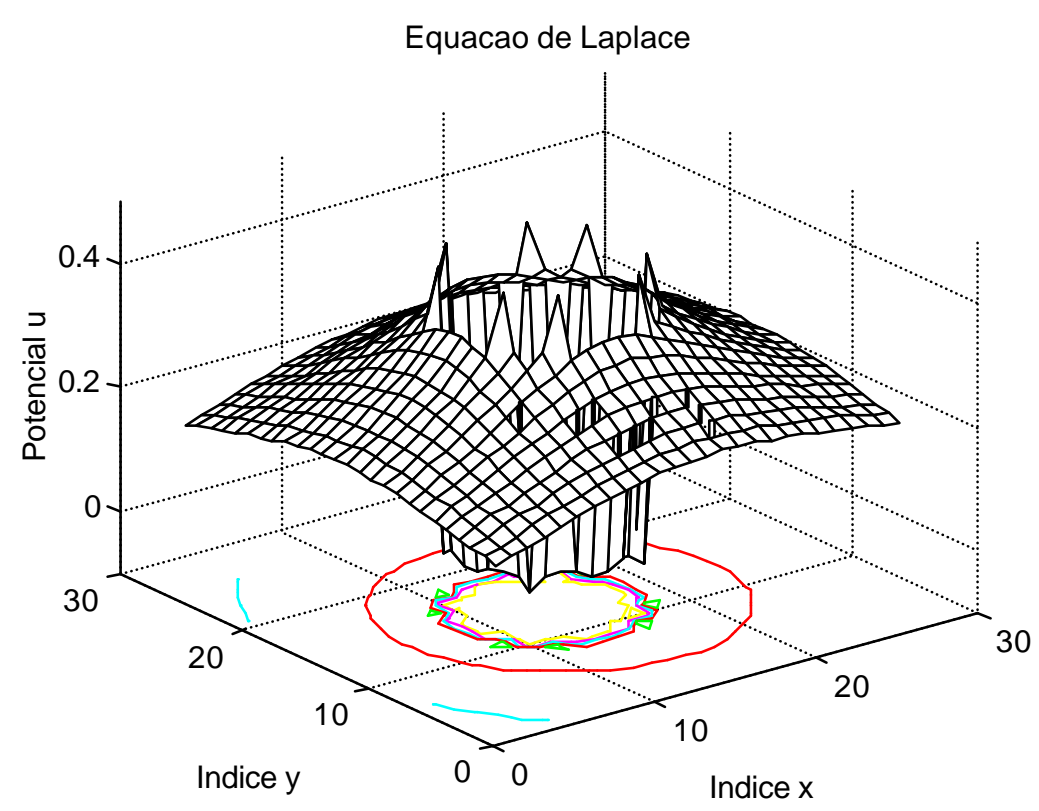

Figura 6.5: Distribuição do potencial próximo ao condutor (3 $\mathrm{mm} \leq \mathrm{x} \leq 7 \mathrm{~mm} ;-2 \mathrm{~mm} \leq \mathrm{y} \leq 2$ $\mathrm{mm})$.

A figura 6.6 mostra a situação para pontos afastados do contorno, com o quadrilátero do mapeamento cobrindo a área representada por $(0 \leq \mathrm{x} \leq 4 \mathrm{~mm} ;-4 \mathrm{~mm} \leq \mathrm{y} \leq 4 \mathrm{~mm})$.

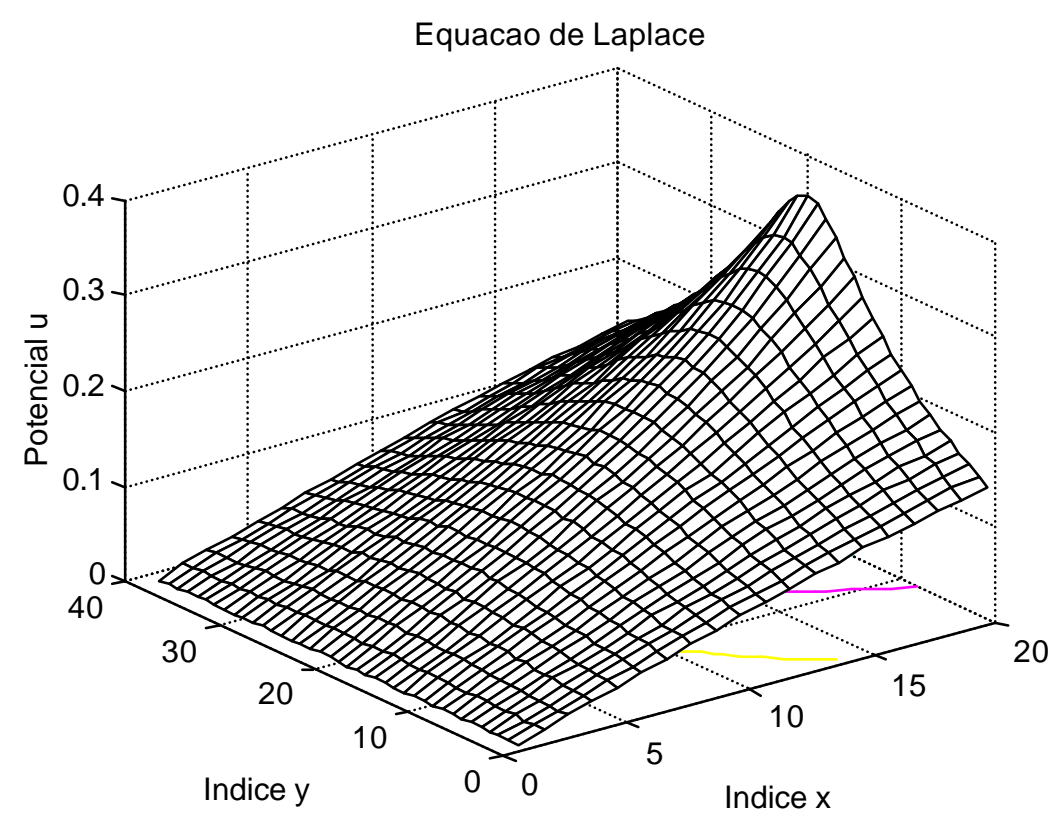

Figura 6.6: Distribuição do potencial $(0 \leq \mathrm{x} \leq 4 \mathrm{~mm} ;-4 \mathrm{~mm} \leq \mathrm{y} \leq 4 \mathrm{~mm})$. 
As linhas equipotenciais, mostradas na figura 6.7, salientam as deformações impostas pela discretização do contorno; a cobertura de área deu-se no intervalo $-7 \mathrm{~mm} \leq \mathrm{x} \leq 7 \mathrm{~mm}$ e -3 $\mathrm{mm} \leq \mathrm{y} \leq 3 \mathrm{~mm})$

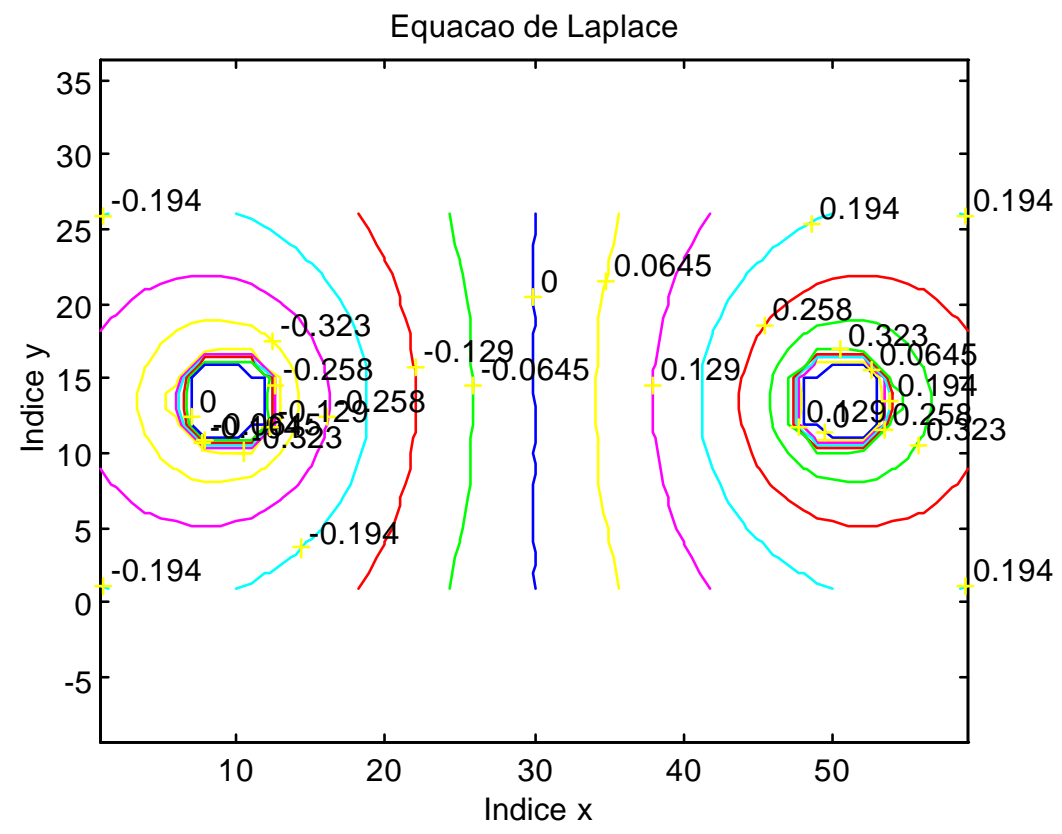

Figura 6.7: Linhas equipotenciais $(-7 \mathrm{~mm} \leq \mathrm{x} \leq 7 \mathrm{~mm} ;-3 \mathrm{~mm} \leq \mathrm{y} \leq 3 \mathrm{~mm})$.

A capacitância distribuída uniformemente ao longo do eixo z (perpendicular ao papel) também pode ser avaliada numericamente. Tem-se

$$
C=\frac{Q}{V}
$$

em que a diferença de potencial $\mathrm{V}$ é conhecida e $\mathrm{Q}$ é a carga armazenada em um dos condutores. Considerando-se uma profundidade $z=1 \mathrm{~m}$, o valor da carga na superfície é calculado por

$$
Q=\int_{\Gamma} \rho_{\ell} d \Gamma
$$

em que $\rho_{1}$ é a densidade linear de carga no contorno. Por causa da discretização escreve-se 


$$
Q \cong \sum_{i} \rho_{i} \Gamma_{i}
$$

Supondo-se condutor perfeito, o valor da componente normal do vetor deslocamento elétrico é numericamente igual à densidade superficial de carga. Então a relação constitutiva $\vec{D}=\varepsilon \vec{E}$ aplicada na equação (6.9) resulta

$$
Q \cong \sum_{i} \varepsilon \frac{\partial V_{i}}{\partial n} \Gamma_{i}
$$

com i varrendo todos os elementos associados a um dos condutores.

Os resultados da tabela 6.1 aplicados em (6.10) e (6.7) com V = 2 . 0,398 (V) fornecem o valor da capacitância distribuída por unidade de comprimento ao longo da linha,

$$
\mathrm{C} \cong 1,2266 \varepsilon \quad(\mathrm{F} / \mathrm{m})
$$

Este valor é comparável ao fornecido pela teoria de linhas de transmissão,

$$
C=\frac{\pi \varepsilon}{\cosh ^{-1}(D / d)} \cong 1,2567 \varepsilon \quad(\mathrm{F} / \mathrm{m})
$$

resultante das dimensões estabelecidas. $\mathrm{O}$ erro foi de $-2,4 \%$ com apenas oito elementos por condutor. Repetindo o cálculo da capacitância para a geometria de 16 elementos por condutor o resultado é

$$
\mathrm{C} \cong 1,2489 \varepsilon \quad(\mathrm{F} / \mathrm{m})
$$

com erro de $-0,62 \%$.

\subsection{Stripline}

A estrutura conhecidas por stripline, ou linha em fita, juntamente com a microfita (microstrip), constituem importantes linhas de transmissão planares usadas em circuitos integrados de microondas (GUPTA, 1996). Sua configuração é mostrada na figura 6.8. 


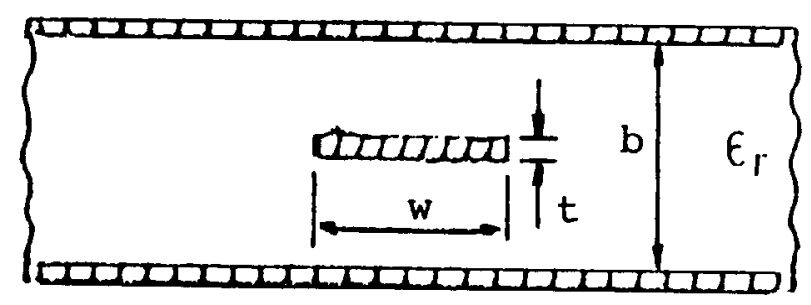

Figura 6.8: Configuração de linha stripline.

Como sua secção transversal é totalmente preenchida com um único meio material (dielétrico), então seu modo dominante é transverso eletromagnético (TEM). A análise matemática destas estruturas é razoavelmente complexa, principalmente quando se considera modos superiores ao TEM. Por outro lado, a técnica de mapeamento conforme permite iniciar-se a análise, admitidas hipóteses simplificadoras como fita condutora central com espessura nula. Por causa do modo TEM, a análise pode ser feita pela equação de Laplace (domínio fechado) e a impedância característica da linha pode ser calculada facilmente, uma vez conhecida sua capacitância distribuída. Vale a equação

$$
Z_{c}=\sqrt{L / C}=\sqrt{\mu \varepsilon} / C
$$

$\mathrm{Z}_{\mathrm{c}}$ é a impedância característica, $\mu$ e $\varepsilon$ caracterizam o meio e $\mathrm{L}$ e $\mathrm{C}$ representam, respectivamente, a indutância e a capacitância distribuídas ao longo da linha. Quando se considera o efeito de espessura do condutor, a análise registrada pela literatura apresenta equações com fatores de correção ou, então, fórmulas empíricas. Alguns destes resultados são encontrados em (BALANIS, 1989) e são aqui utilizados para comparação.

Considere-se, então, a estrutura stripline, discretizada, mostrada na figura 6.9. Trata-se de estrutura com um único domínio não simplesmente conexo (há um buraco). As dimensões são 
fornecidas, arbitrariamente, em metros, podendo ser considerados outros valores pela aplicação de fator de escala.

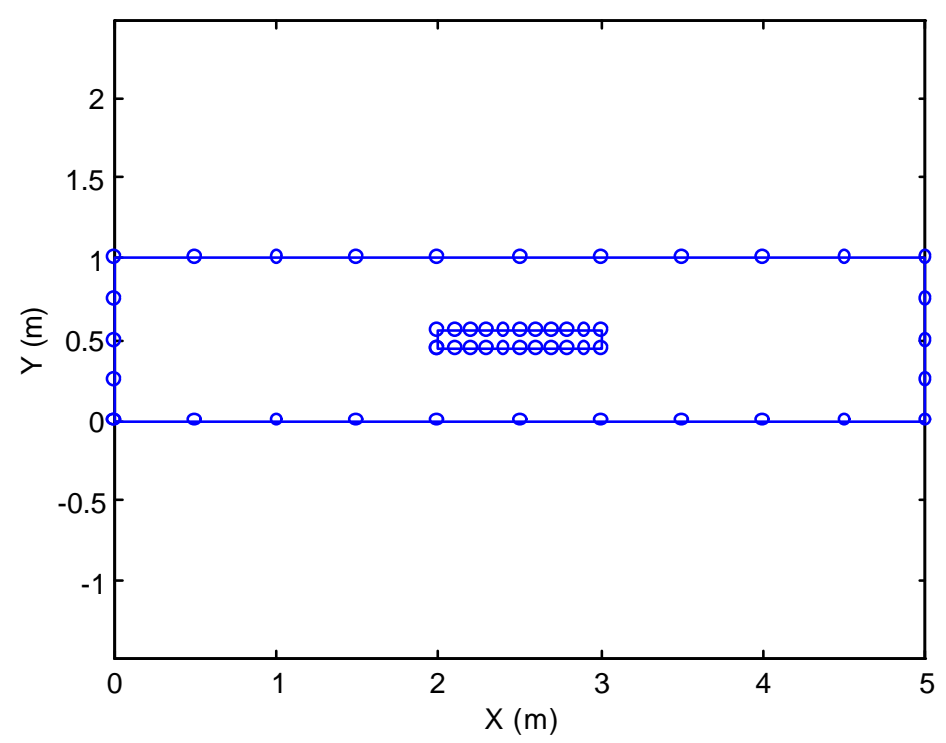

Figura 6.9: Stripline discretizada.

Note-se que a largura de toda a estrutura foi limitada em um valor significativamente maior que a largura $w$ do condutor central, conforme as aplicações práticas. Admitindo-se condutores perfeitos nos planos de terra e na fita central, agora com espessura $t$ não nula, pode-se fazer $\bar{u}=0 \mathrm{~V}$ nos elementos de contorno horizontais externos, $\bar{u}=1 \mathrm{~V}$ em todos os elementos internos e $\bar{q}=0$ nos elementos verticais externos. O cálculo de $Z_{c}$ em (BALANIS, 1989) apresenta equações que contemplam também a capacitância de borda $C_{f}$. Manipulação algébrica mostra valer a equação da capacitância total distribuída,

$$
C_{t}=4 \varepsilon\left(\frac{w / b}{1-t / b}\right)+\frac{C_{f}}{\varepsilon}
$$

com

$$
\frac{C_{f}}{\varepsilon}=\frac{1}{\pi}\left\{\frac{2}{1-t / b} \ln \left(1+\frac{1}{1-t / b}\right)-\left(\frac{1}{1-t / b}-1\right) \ln \left(\frac{1}{(1-t / b)^{2}}-1\right)\right\}
$$


O MEC foi utilizado para avaliar a capacitância total da estrutura. Inicialmente foram feitas três análises variando-se apenas a largura $w$ da fita (tabela 6.2). A geometria foi discretizada com 22 elementos na fita central e 28 elementos no contorno externo; usou-se a formulação constante.

TABELA 6.2: RESULTADO EM ESTRUTURA STRIPLINE COM VARIAÇÃO DA LARGURA DA FITA.

\begin{tabular}{|c|c|c|c|c|c|c|}
\hline ANÁLISE & $\mathbf{w}(\mathbf{m})$ & $\mathbf{t}(\mathbf{m})$ & b (m) & $\begin{array}{c}\mathbf{C}_{t} / \varepsilon \\
\text { (BALANIS) }\end{array}$ & $\begin{array}{c}\mathrm{C}_{\mathrm{t}} / \boldsymbol{\varepsilon} \\
(\mathrm{MEC})\end{array}$ & $\begin{array}{c}\text { Desvio } \\
\text { relativo }(\%)\end{array}$ \\
\hline 1 & 2,0 & 0,1 & 1,0 & 11,208 & 11,113 & $-0,85$ \\
\hline 2 & 1,0 & 0,1 & 1,0 & 6,764 & 6,696 & $-1,01$ \\
\hline 3 & 0,5 & 0,1 & 1,0 & 4,542 & 4,489 & $-1,17$ \\
\hline
\end{tabular}

A figura 6.10 mostra ambos os resultados, estando representados pelo traço contínuo os valores obtidos por (BALANIS, 1989).

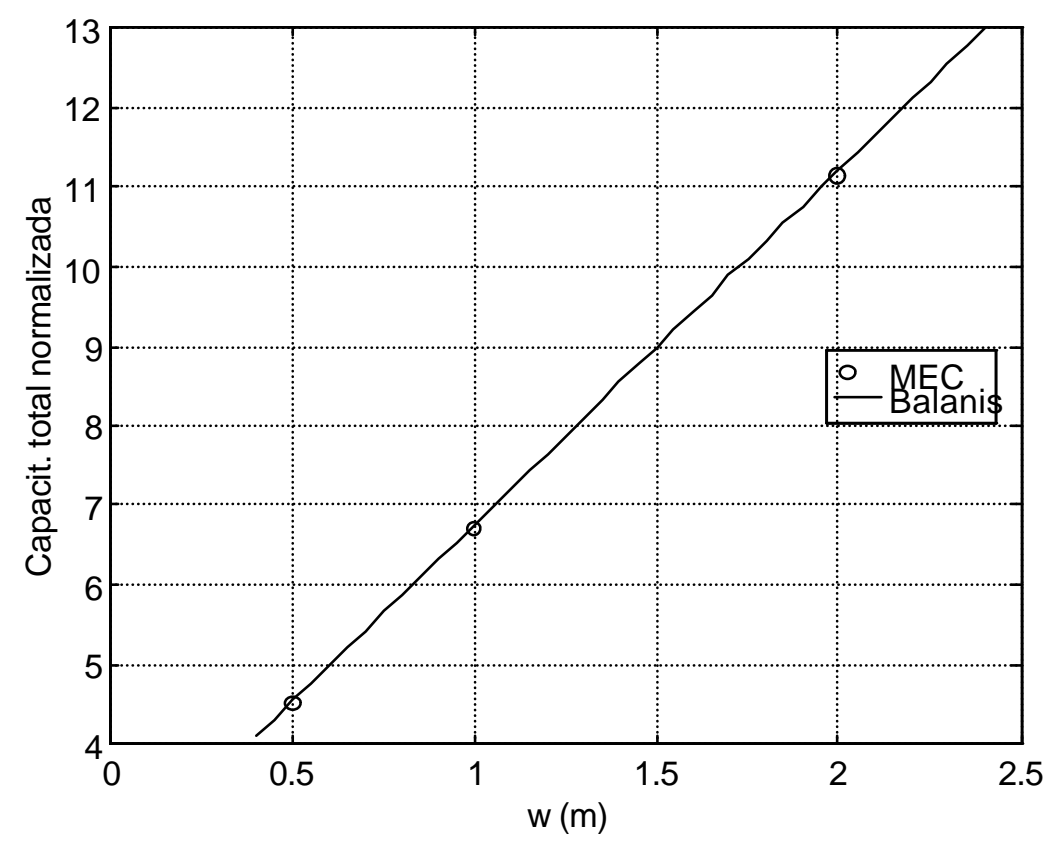

Figura 6.10: Capacitância total normalizada $\left(\mathrm{C}_{\mathrm{t}} / \varepsilon\right) ; t / b=0,1 ; b=1 \mathrm{~m}$. 
Constata-se que o desvio é pequeno, apesar do número pequeno de elementos. Por outro lado, a constatação de que o desvio aumenta com a diminuição da largura da fita está relacionado ao fato de que, mantendo-se o mesmo número de elementos na descrição da fita, haverá uma diferença maior entre o comprimento destes elementos e os que descrevem o contorno externo, mantido inalterado, ou seja, haverá um conjunto de elementos com comprimento médio muito diferente de outro conjunto de elementos no mesmo domínio. Este procedimento foi proposital a fim de se manter constante o número de elementos no problema.

A seguir investiga-se o comportamento resultante da variação na espessura do condutor central. Os resultados estão mostrados na tabela 6.3.

TABELA 6.3: RESULTADO EM ESTRUTURA STRIPLINE COM VARIAÇÃO DA ESPESSURA DA FITA.

\begin{tabular}{ccccccc}
\hline ANÁLISE & $\mathbf{w}(\mathbf{m})$ & $\mathbf{t}(\mathbf{m})$ & $\mathbf{b}(\mathbf{m})$ & $\begin{array}{c}\mathbf{C}_{\mathbf{t}} / \boldsymbol{\varepsilon} \\
(\text { BALANIS) }\end{array}$ & $\begin{array}{c}\mathbf{C}_{\mathbf{t}} / \boldsymbol{\varepsilon} \\
(\mathbf{M E C})\end{array}$ & $\begin{array}{c}\text { Desvio } \\
\text { relativo (\%) }\end{array}$ \\
\hline 4 & 1,0 & 0,025 & 1,0 & 6,043 & 5,953 & $-1,49$ \\
5 & 1,0 & 0,05 & 1,0 & 6,287 & 6,235 & $-0,83$ \\
2 & 1,0 & 0,1 & 1,0 & 6,764 & 6,696 & $-1,01$ \\
6 & 1,0 & 0,2 & 1,0 & 7,764 & 7,666 & $-1,26$ \\
\hline
\end{tabular}

O desvio aumenta com fitas muito finas ou muito grossas. Na primeira situação tem-se a proximidade muito acentuada dos elementos superiores e inferiores que descrevem a fita central e o erro nas integrações numéricas se acentuará. Uma possibilidade de amenizá-lo é "quebrar" o condutor, descrevendo metade dele como "buraco" do domínio $\Omega_{1}$ e a outra metade como um segundo domínio, artificial, $\Omega_{2}$, porém mantendo-se $\varepsilon_{2}=\varepsilon_{1}$. 
A condição de espessura muito grande não representa situação real; além disto, neste caso, não é assegurada a validade da aproximação da capacitância pela equação (6.16). Os resultados gráficos estão na figura 6.11 .

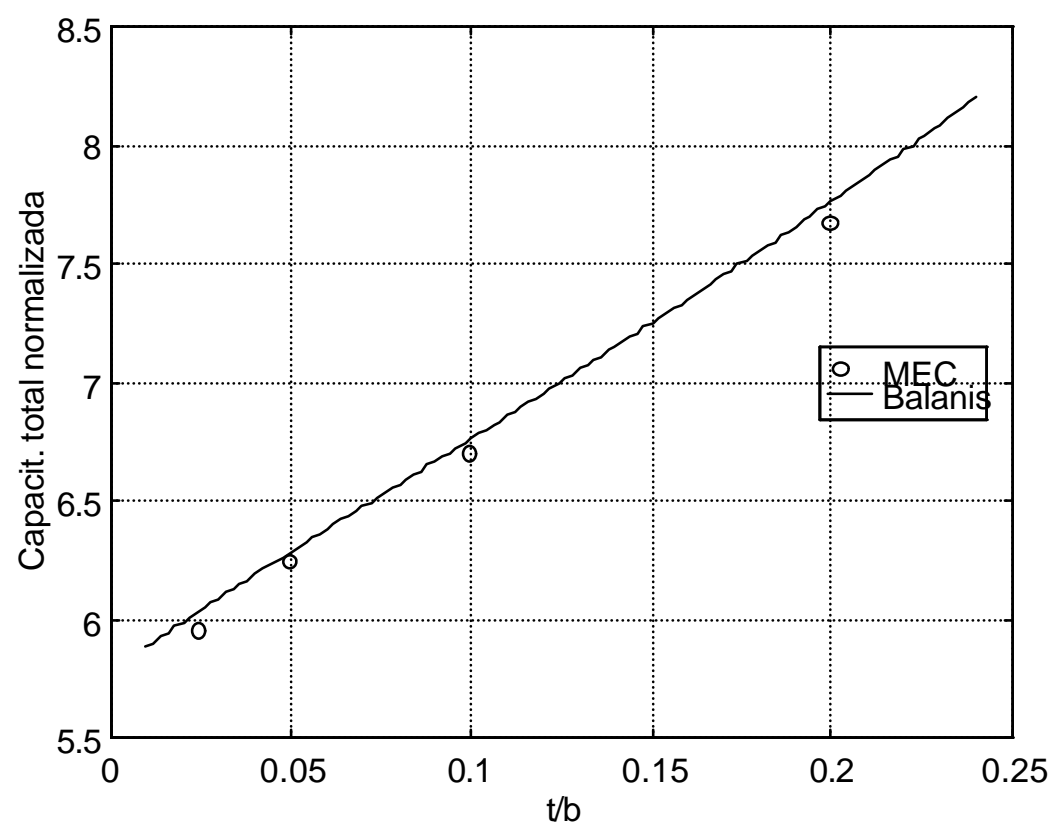

Figura 6.11: Capacitância total normalizada $\left(\mathrm{C}_{\mathrm{t}} / \varepsilon\right) ; w=1 \mathrm{~m} ; b=1 \mathrm{~m}$.

Por fim, a situação da análise número 2 foi reavaliada, dobrando-se o número de elementos a descrever a fita central (44 elementos no contorno interno e 28 no externo). A capacitância obtida foi

$$
\mathrm{C}_{\mathrm{t}} / \varepsilon=6,724
$$

que representa um desvio relativo de $-0,59 \%$. Esta nova análise diminui 1,7 vezes o valor do erro.

A figura 6.12 mostra os valores de $\partial u / \partial n$ nos nós de função. Uma comparação das equações (6.9) e (6.10) indica que $\partial u / \partial n$ é proporcional à densidade superficial de cargas; a figura permite também uma visão espacial desta densidade superficial de cargas. 


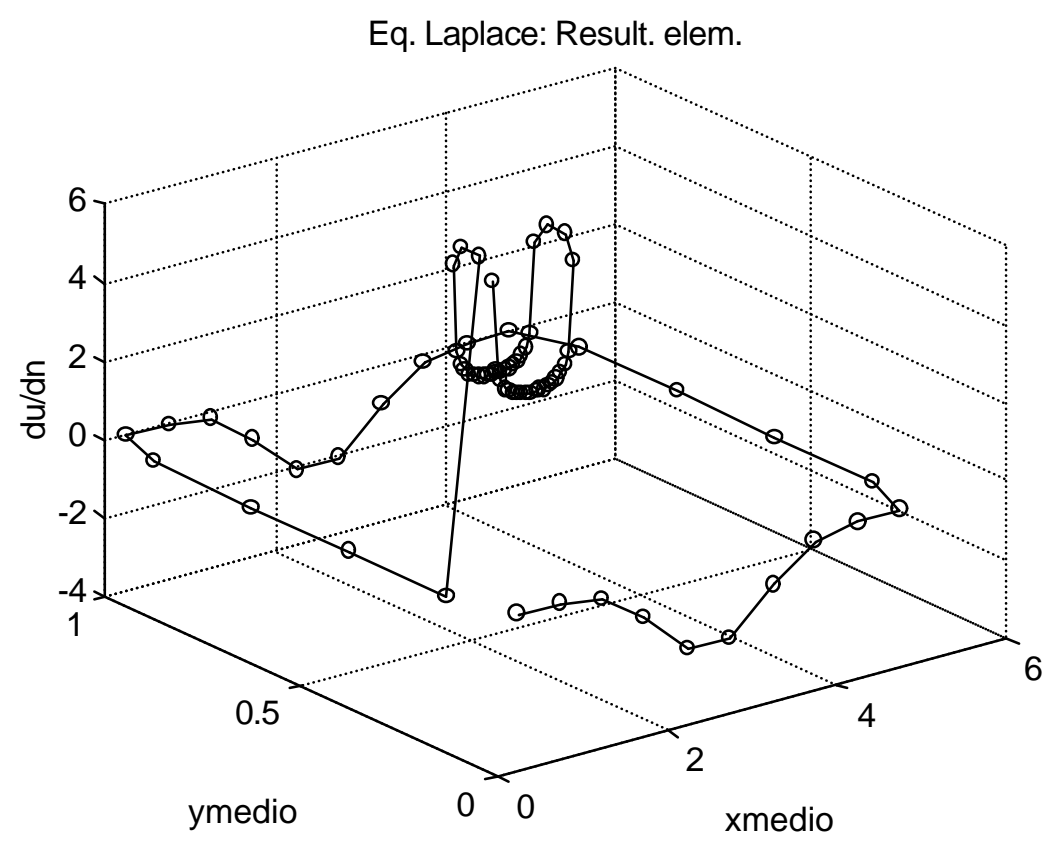

Figura 6.12: Valores de $q$ nos nós de função.

\subsection{Guia de onda homogêneo}

Nesta seção serão utilizados os procedimentos descritos na parte final do capítulo anterior, aplicados aqui ao estudo de guias de onda retangulares e circulares, totalmente preenchidos. Será avaliado o comportamento dos resultados em função da discretização da geometria e da formulação implementada (constante e linear).

\subsubsection{Guia retangular}

Considere-se a geometria do guia de onda retangular de secção transversal indicada na figura 6.13 . 


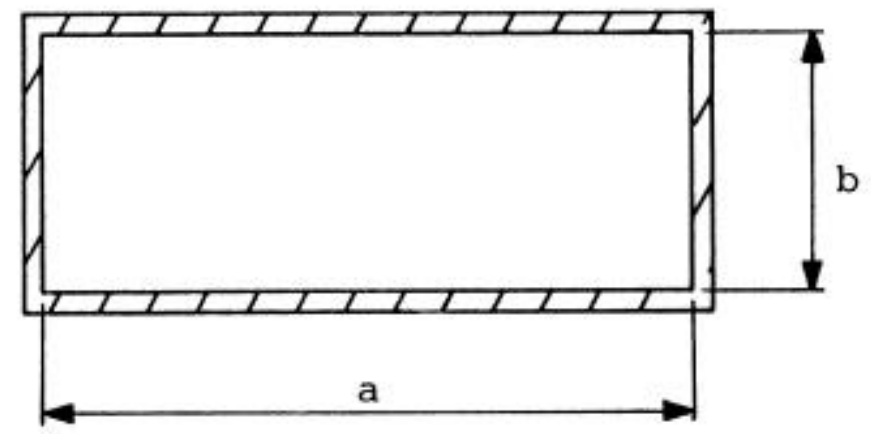

Figura 6.13: Secção transversal de guia retangular.

Supondo-se dimensões $\mathrm{a}=30 \mathrm{~mm}$ e $\mathrm{b}=10 \mathrm{~mm}$, a solução analítica para a freqüência de corte de alguns modos deste guia, com dielétrico ar, está indicada na tabela 6.4.

TABELA 6.4: FREQÜÊNCIAS DE CORTE DE GUIA RETANGULAR $(\mathrm{a}=30 \mathrm{~mm}$; $\mathrm{b}=$ $10 \mathrm{~mm})$.

\begin{tabular}{ll}
\hline $\mathbf{f}_{\mathbf{c}}(\mathbf{G H z})$ & Modo $\mathbf{T E}$ \\
\hline 4,9977 & $\mathrm{TE}_{10}$ \\
9,9954 & $\mathrm{TE}_{20}$ \\
14,993 & $\mathrm{TE}_{30}$ e $\mathrm{TE}_{01}$ \\
15,804 & $\mathrm{TE}_{11}$ \\
18,020 & $\mathrm{TE}_{21}$ \\
19,991 & $\mathrm{TE}_{40}$ \\
24,989 & $\mathrm{TE}_{50}$ e $\mathrm{TE}_{41}$ \\
\hline
\end{tabular}

Foram realizadas três discretizações para representar o guia; seus valores estão indicados na tabela 6.5 . 
TABELA 6.5: DISCRETIZAÇÕES REALIZADAS

\begin{tabular}{ccc}
\hline DISCRETIZAÇÃO & $\begin{array}{c}\text { NO. ELEMENTOS POR FACE } \\
\text { HORIZONTAL }\end{array}$ & $\begin{array}{c}\text { NO. ELEMENTOS POR FACE } \\
\text { VERTICAL }\end{array}$ \\
\hline 1 & 9 & 3 \\
2 & 18 & 6 \\
3 & 36 & 12 \\
\hline
\end{tabular}

O processo de varredura em frequiência foi aplicado às três discretizações, impondo-se condições de contorno homogêneas, do tipo Neumann. Os limites inicial e final foram estabelecidos, respectivamente, em $3 \mathrm{GHz}$ e $28 \mathrm{GHz}$. O comportamento do determinante (em módulo e fase) é mostrado na figura 6.14, para a discretização 1 . Nota-se a presença de modos nas freqüências em que o módulo do determinante tende a um mínimo. Observe-se também os valores em que ocorrem trocas de sinal no argumento (fase) do determinante.
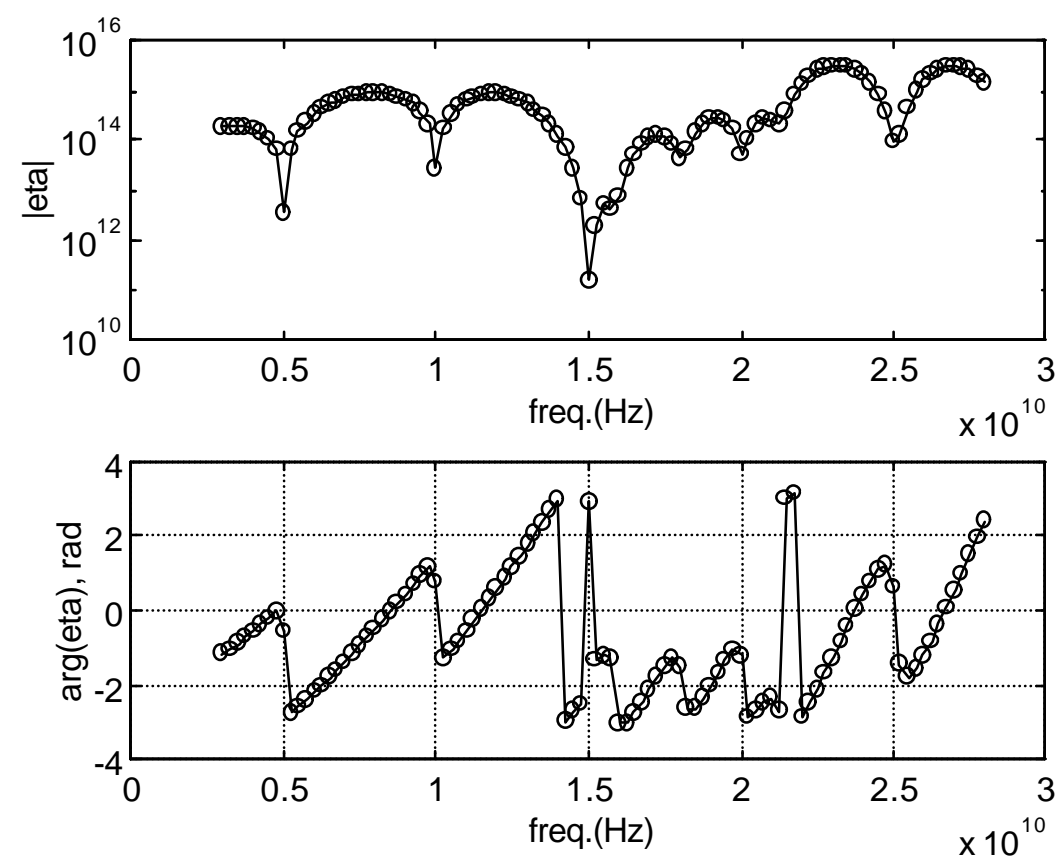

Figura 6.14: Comportamento do determinante na discretização 1. 
Os resultados para as discretizações 2 e 3 estão mostrados nas figuras 6.15 e 6.16. Não é conveniente superpor-se os resultados em gráficos únicos por causa da variação significativa na ordem de grandeza do módulo do determinante.
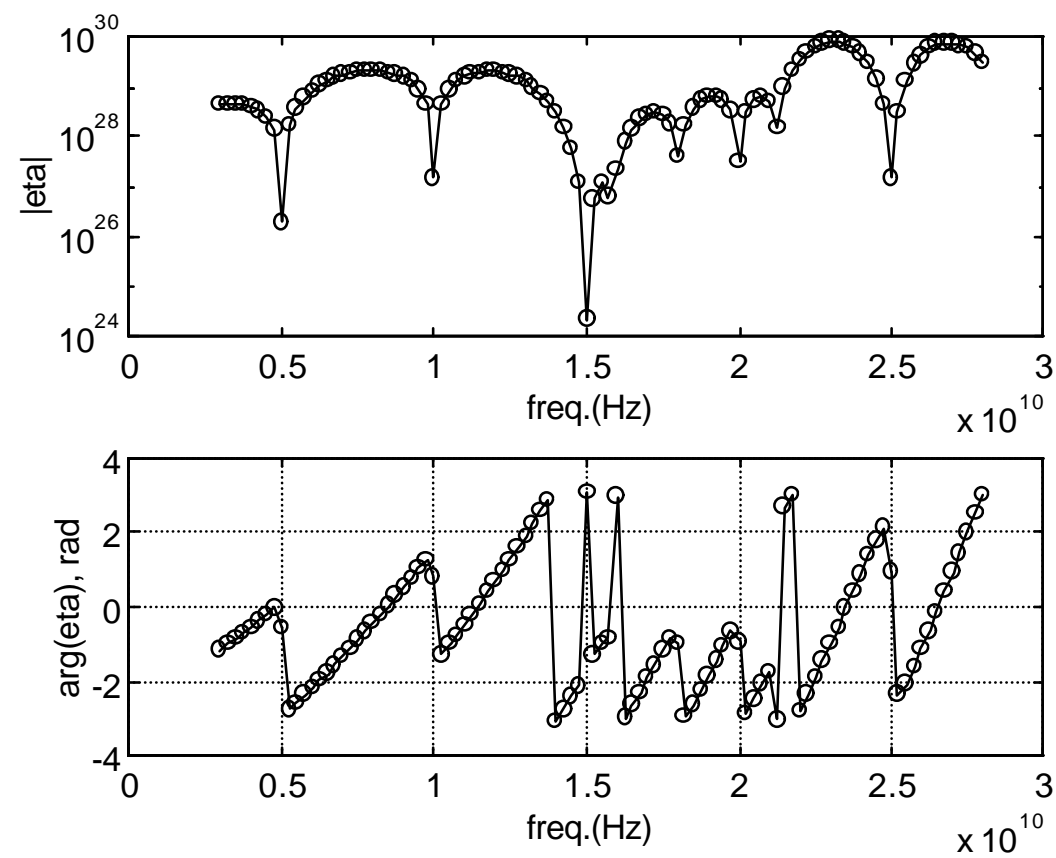

Figura 6.15: Comportamento do determinante na discretização 2.
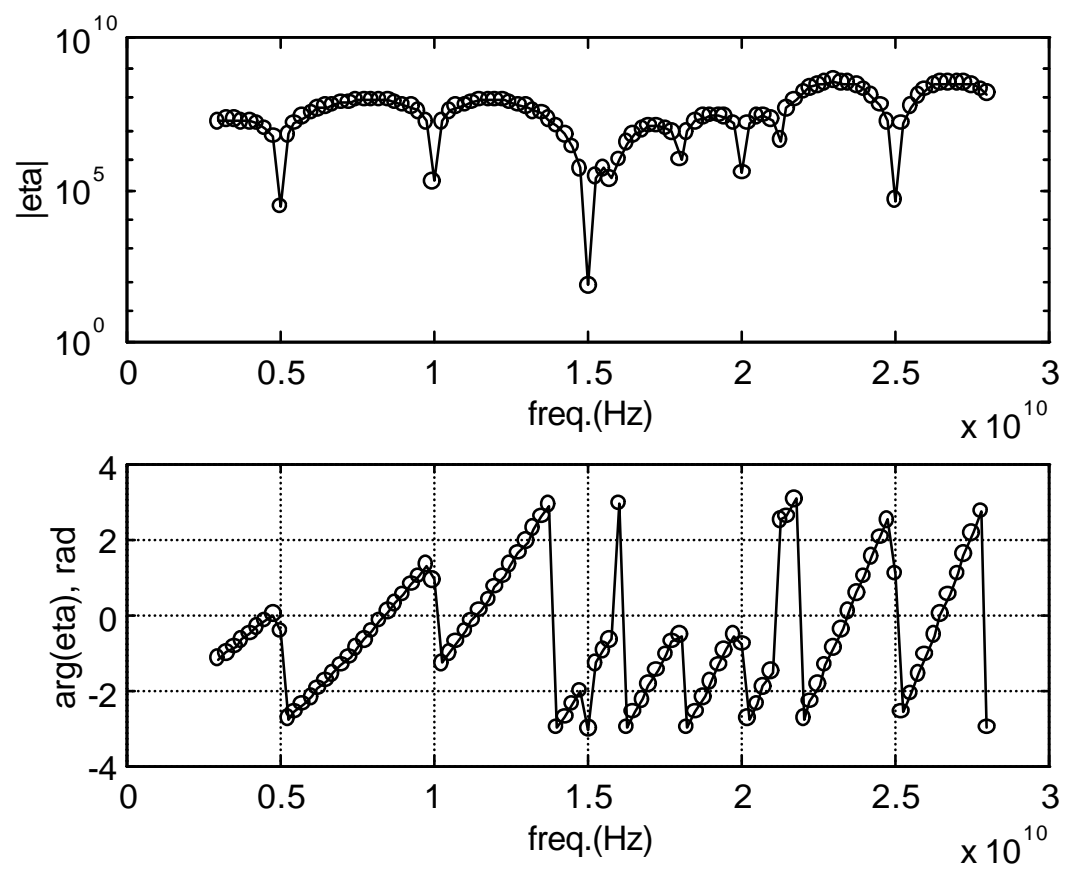

Figura 6.16: Comportamento do determinante na discretização 3. 
Das três últimas figuras pode-se observar a indicação das frequiências de todos os modos referenciados na tabela 6.4 .

A seguir foram investigadas as duas primeiras frequiências de ressonância encontradas em cada varredura. Os resultados estão mostrados na tabela 6.6.

TABELA 6.6: RESULTADOS DE $\mathrm{f}_{\mathrm{c}}$ COM TRÊS DISCRETIZAÇÕES.

\begin{tabular}{ccccc}
\hline Discretização & $\mathrm{f}_{\mathrm{c}} \mathrm{TE}_{10}(\mathrm{GHz})$ & Erro relativo $(\%)$ & $\mathrm{f}_{\mathrm{c}} \mathrm{TE}_{20}(\mathrm{GHz})$ & Erro relativo (\%) \\
\hline 1 & 5,006 & 0,17 & 10,027 & 0,73 \\
2 & 5,004 & 0,13 & 10,006 & 0,11 \\
3 & 5,000 & 0,05 & 10,002 & 0,07 \\
\hline
\end{tabular}

Observe-se que resultados melhores são obtidos com discretizações mais finas e que a discretização normalizada (em relação ao comprimento de onda) é tanto mais grosseira quanto maior for a freqüência.

Finalmente, todo o processo foi repetido com formulação linear. A detecção dos modos deuse de maneira semelhante ao caso anterior (figuras 6.14 a 6.16). Os resultados da busca refinada das frequiências de corte dos dois primeiros modos está mostrada na tabela 6.7.

TABELA 6.7: RESULTADOS COM TRÊS DISCRETIZAÇÕES (FORMULAÇÃO LINEAR).

\begin{tabular}{ccccc}
\hline Discretização & $\mathrm{f}_{\mathrm{c}} \mathrm{TE}_{10}(\mathrm{GHz})$ & Erro relativo $(\%)$ & $\mathrm{f}_{\mathrm{c}} \mathrm{TE}_{20}(\mathrm{GHz})$ & Erro relativo (\%) \\
\hline 1 & 5,002 & 0,08 & 10,043 & 0,48 \\
2 & 4,991 & $-0,14$ & 10,003 & 0,08 \\
3 & 4,986 & $-0,24$ & 9,994 & $-0,02$ \\
\hline
\end{tabular}


Estranhamente, não houve tendência de se repetir o comportamento observado na formulação constante. Uma explicação para este fato está relacionada a fatores de ordem geométrica usados para o cálculo de $\mathrm{c}_{\mathrm{i}}$ em $\mathrm{h}_{\mathrm{ii}}$ (equação (4.41), com valor obtido por equação semelhante à (5.29)), ou seja, o ângulo é calculado a partir de um produto escalar e de um produto de módulo de vetores. A aritmética de precisão simples, em certas situações, invalidava a aplicação de (5.29) porque o argumento do arco-cosseno resultava (muito levemente) superior a +1 ou inferior a -1 . Correções automáticas foram previstas à custa da introdução de pequenas tolerâncias. É evidente que isto afeta o cálculo da matriz [G]. Estas observações são de caráter geral e a situação descrita não se repetirá se a geometria deixar de apresentar um grande número de elementos de contorno paralelos entre si, o que ocorre, por exemplo, no estudo de guias circulares. Outra situação em que isto não ocorre é na imposição de condicões de contorno homogêneas do tipo Dirichlet, pois o determinante calculado é o da matriz [G].

A aplicação de excitação localizada permite a observação de distribuição do módulo do campo magnético. A figura 6.17 mostra o resultado obtido para o modo $\mathrm{TE}_{10}$ tendo sido excitado o ponto $\mathrm{x}=0 \mathrm{e} \mathrm{y}=5,416 \mathrm{~cm}$ (na parede vertical esquerda). $\mathrm{O}$ modo $\mathrm{TE}_{20}$ pode ser visualizado na figura 6.18. Observam-se em ambas as figuras os erros no valor do campo magnético em pontos próximos ao contorno, fato já discutido no Capítulo 4. 


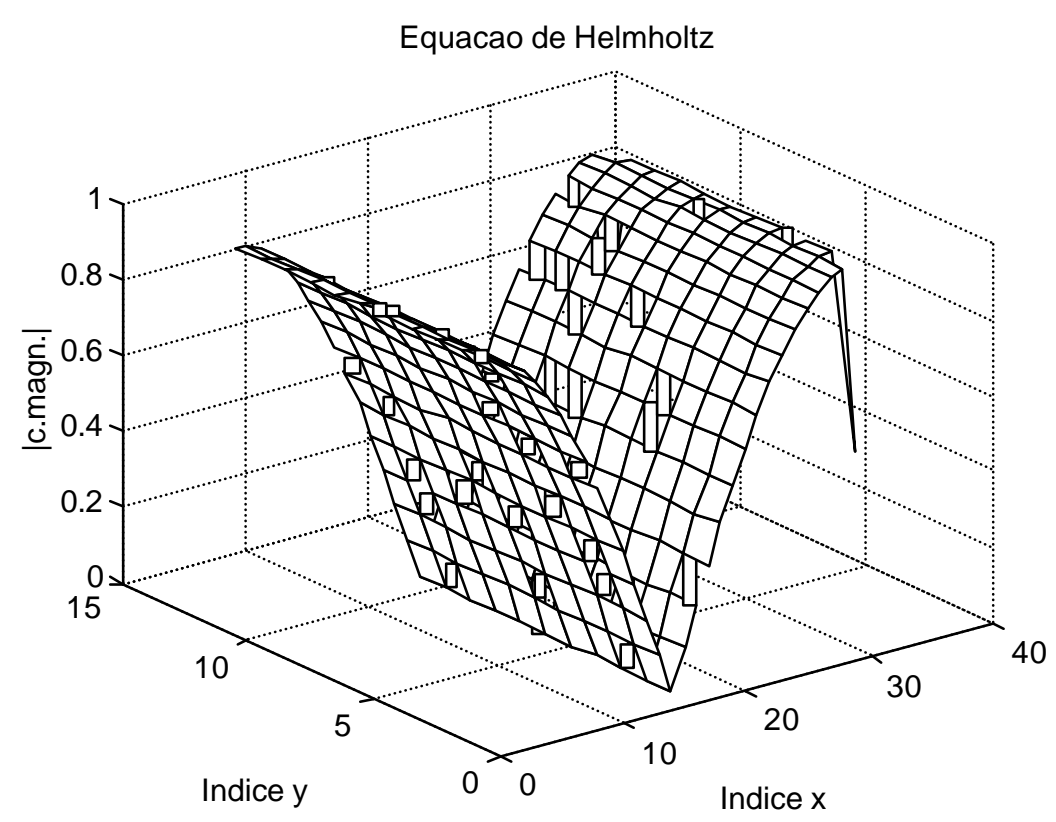

Figura 6.17: Configuração de campo magnético para o modo $\mathrm{TE}_{10}$.

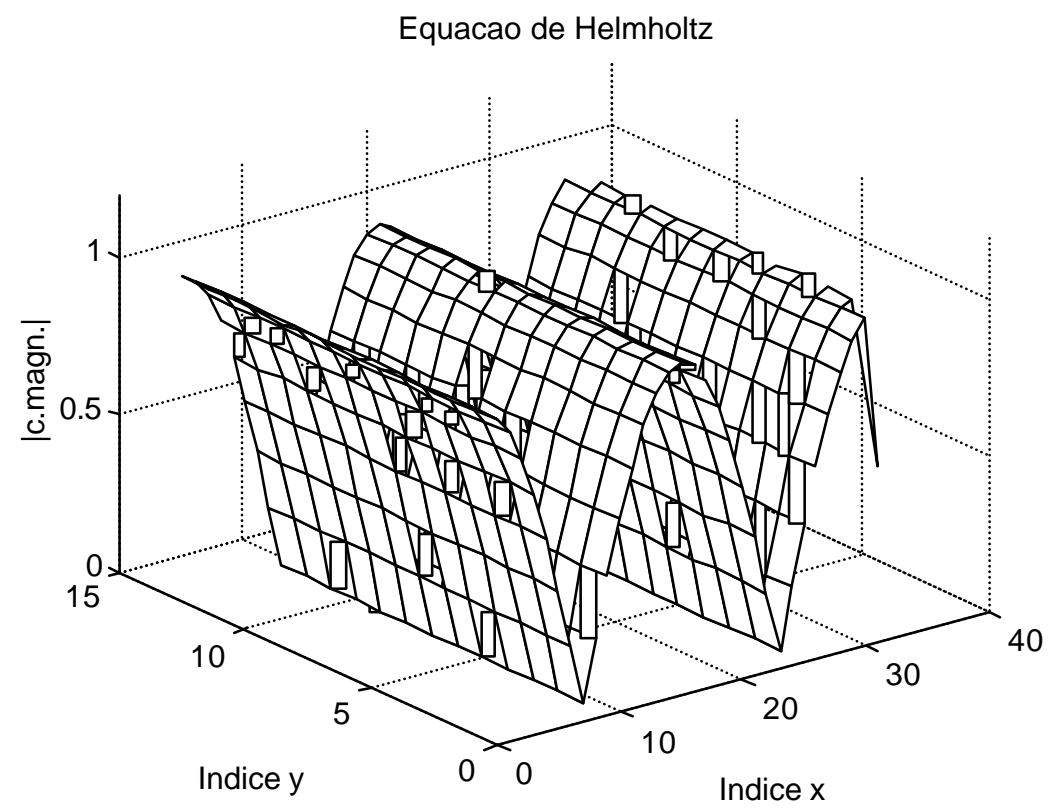

Figura 6.18: Configuração de campo magnético para o modo $\mathrm{TE}_{20}$.

Mudando-se para os modos transversais magnéticos, determinados a partir de condições de contorno de Dirichlet, foi calculada para cada discretização e formulação, a frequiência de corte do modo $\mathrm{TM}_{21}$, de valor teórico $18,020 \mathrm{GHz}$. Os resultados estão na tabela 6.8 , donde 
se verifica que a discretização 3 não apresentou ganho sobre a discretização de refinamento "médio".

TABELA 6.8: FREQÜÊNCIA DE CORTE DO MODO TM TM $_{21}$

\begin{tabular}{c|cc|cc}
\multicolumn{2}{c}{ CONSTANTE } & \multicolumn{2}{c}{ LINEAR } \\
\hline Discretização & $\mathrm{f}_{\mathrm{c}} \mathrm{TM}_{21}$ & Erro relativo (\%) & $\mathrm{f}_{\mathrm{c}} \mathrm{TM}_{21}$ & Erro relativo (\%) \\
\hline 1 & 17,995 & $-0,13$ & 18,062 & 0,26 \\
2 & 18,037 & 0,10 & 18,028 & 0,05 \\
3 & 18,038 & 0,10 & 18,028 & 0,05 \\
\hline
\end{tabular}

\subsubsection{Guia circular}

De maneira semelhante aos guias retangulares da seção anterior, são agora considerados guias de seção circular. Seus raios foram arbitrados em a $=2 \mathrm{~cm}$. Os dois primeiros modos de ressonância $\left(\mathrm{TE}_{11} \mathrm{e} \mathrm{TE}_{21}\right)$ têm frequiência de corte, para dielétrico ar, mostrada na tabela 6.9.

TABELA 6.9: FREQÜÊNCIAS DE CORTE DE GUIA CIRCULAR $(\mathrm{a}=2 \mathrm{~cm})$

\begin{tabular}{cc}
\hline $\mathbf{f}_{\mathbf{c}}(\mathbf{G H z})$ & Modos TE \\
\hline 4,3955 & $\mathrm{TE}_{11}$ \\
7,2914 & $\mathrm{TE}_{21}$ \\
\hline
\end{tabular}

Foram realizadas três discretizações, todas uniformes, com passo angular
1) $30^{\circ}$, totalizando 12 elementos;
2) $20^{\circ}$, totalizando 18 elementos; 
3) $10^{0}$, totalizando 36 elementos.

Os resultados para formulação constante estão na tabela 6.10 e os de formulação linear na tabela 6.11 .

TABELA 6.10: FREQÜÊNCIAS DE CORTE OBTIDAS COM FORMULAÇÃO CONSTANTE

\begin{tabular}{ccccc}
\hline Discretização & $\mathrm{f}_{\mathrm{c}} \mathrm{TE}_{11}$ & Erro relativo (\%) & $\mathrm{f}_{\mathrm{c}} \mathrm{TE}_{21}$ & Erro relativo (\%) \\
\hline 1 & 4,546 & 3,43 & 7,624 & 4,56 \\
2 & 4,462 & 1,52 & 7,436 & 1,98 \\
3 & 4,410 & 0,32 & 7,328 & 0,51 \\
\hline
\end{tabular}

TABELA 6.11: FREQÜÊNCIAS DE CORTE OBTIDAS COM FORMULAÇÃO LINEAR

\begin{tabular}{ccccc}
\hline Discretização & $\mathrm{f}_{\mathrm{c}} \mathrm{TE}_{11}$ & Erro relativo (\%) & $\mathrm{f}_{\mathrm{c}} \mathrm{TE}_{21}$ & Erro relativo (\%) \\
\hline 1 & 4,503 & 0,45 & 7,500 & 2,85 \\
2 & 4,443 & 1,09 & 7,385 & 1,28 \\
3 & 4,408 & 0,27 & 7,315 & 0,32 \\
\hline
\end{tabular}

O comportamento destes resultados segue toda previsão anterior, apresentando menos erros como decorrência do refinamento das discretizações e da formulação.

O procedimento de excitação localizada fornece para o modo $\mathrm{TE}_{21}$ a configuração de módulo de campo magnético vista na figura 6.19 . 


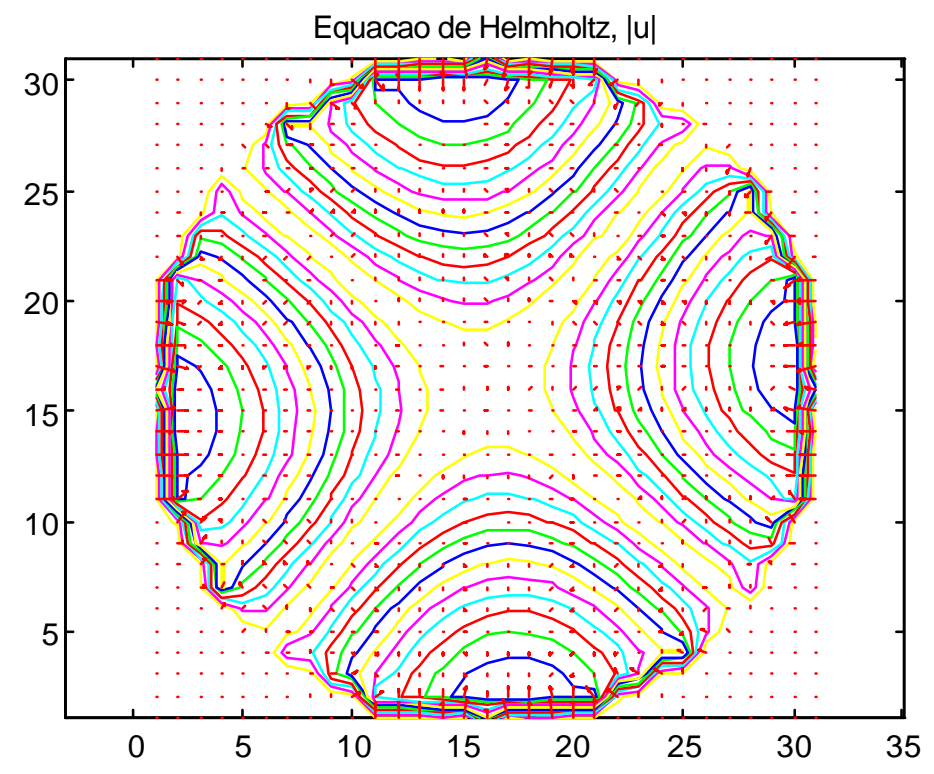

Figura 6.19: Configuração de campo magnético para o modo $\mathrm{TE}_{21}$.

\subsection{Perdas}

O método desenvolvido permite também considerar efeitos de perdas no meio de propagação. Constata-se que elas não provocam efeitos significativos na configuração de campos, desde que se situem na faixa de valores existentes para dielétricos reais. A fim de observar com maior sensibilidade o efeito destas perdas foi considerado o problema de incidência normal de uma onda plana em meio condutor não perfeito. A onda propaga-se no sentido de $\mathrm{x}$ crescente (figura 6.20).

Trata-se de um problema unidimensional em que o comportamento do campo dentro da região condutora atende à equação

$$
E(x)=E_{0} \exp (-x / \delta) \exp \left(-j \frac{x}{\delta}\right)
$$

$\mathrm{E}_{\mathrm{o}}$ representa o campo na interface e $\delta$ a profundidade de penetração, que é função da frequiência e de parâmetros constitutivos do meio. 


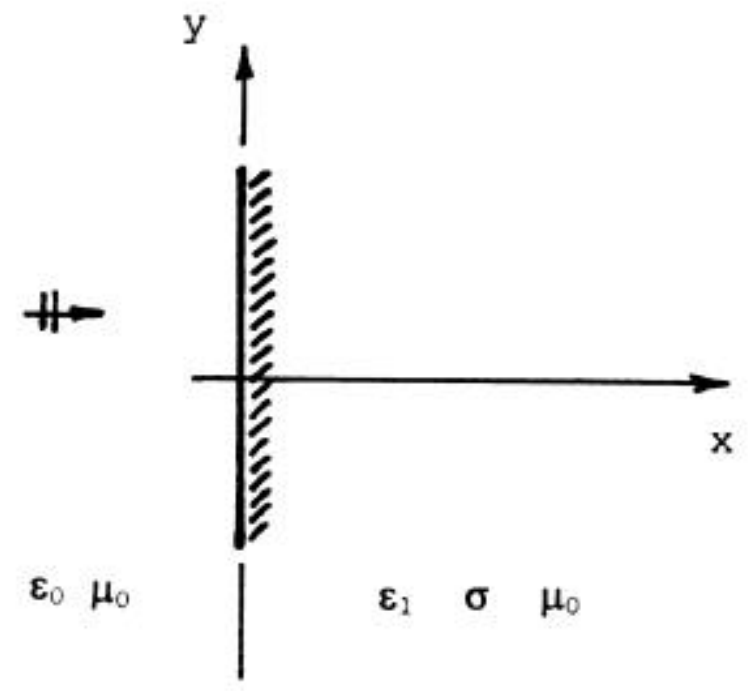

Figura 6.20: Incidência de campo em região com perdas ( $x \geq 0)$.

Este problema pode ser facilmente abordado pelo MEC, considerando-se a geometria discretizada da figura 6.21, onde se fixam as condições

- $\bar{q}=0$ em todos os elementos horizontais;

- $\bar{u}=1$ nos elementos da face esquerda;

- $\bar{u}=0$ nos elementos da face direita.

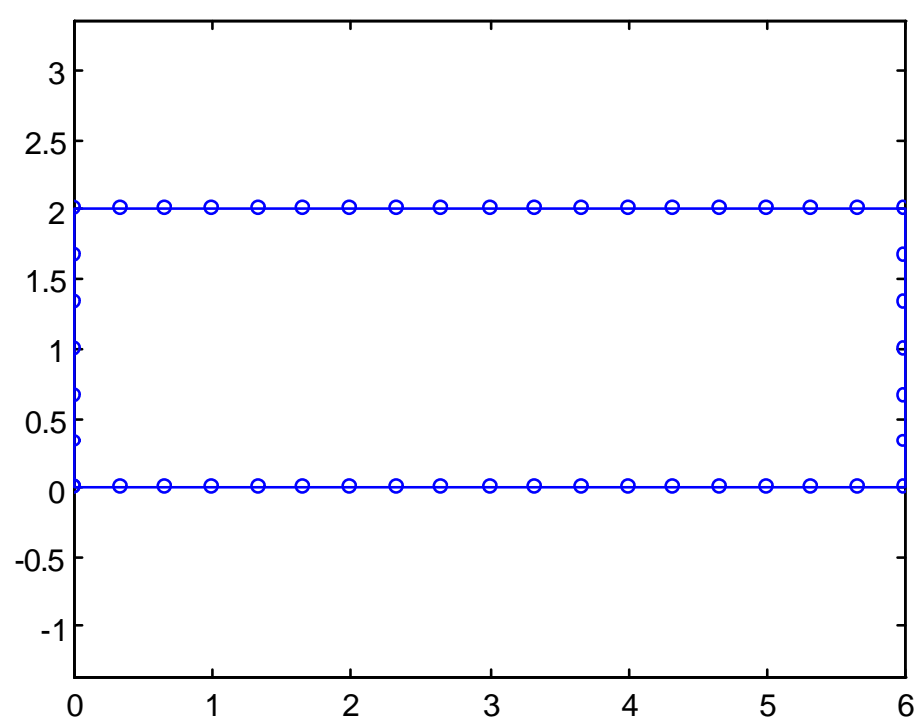

Figura 6.21: Geometria do meio dissipativo. 
A segunda imposição representa o campo na interface, arbitrado em valor unitário. A terceira imposição força campo nulo em região muito afastada da interface $(x \rightarrow \infty)$. Ambas as imposições, juntamente com a primeira forçam o modelamento unidimensional do problema.

Os parâmetros usados na simulação foram $\varepsilon_{\mathrm{r} 1}=72, \sigma=4(\mathrm{~S} / \mathrm{m})$ e frequiência igual a $50 \mathrm{kHz}$. A profundidade de penetração $\delta$ resulta $1,125(\mathrm{~m})$; portanto, a imposição de $\bar{u}=0$ em x $=6$ (m) representa uma condição de contorno fixada em região muito afastada da interface. Os resultados obtidos estão na figura 6.22, comparados com os teóricos.
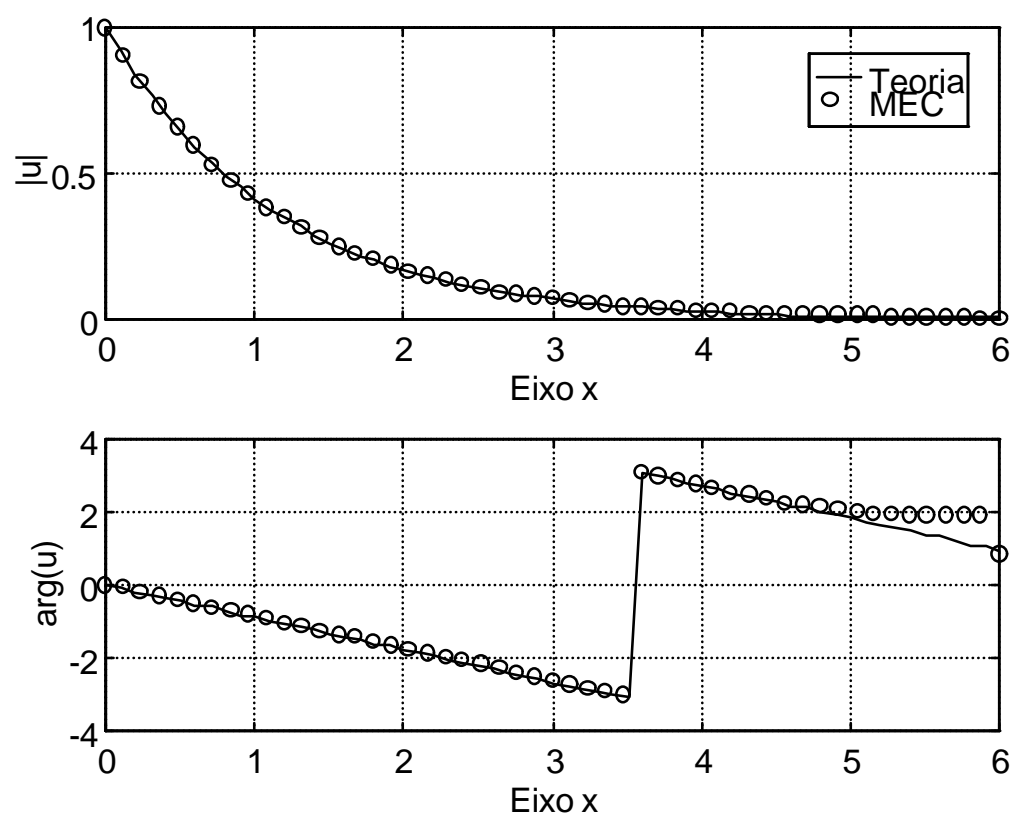

Figura 6.22: Valores do fasor de campo em meio dissipativo.

Nas proximidades de $\mathrm{x}=6(\mathrm{~m})$ ocorre maior erro na fase devido à imposição artificial da condição de contorno $u=0$ com fase nula em $x=6(\mathrm{~m})$. 


\subsection{Guia de onda com ressalto (Ridged Waveguide)}

Os guias de onda com ressalto são estruturas que oferecem a possibilidade de aumentar a largura de faixa de operação quando comparados aos guias convencionais. A banda de operação é tomada como a faixa que separa a frequiência de corte do modo fundamental e a freqüência de corte do segundo modo que é excitado na estrutura. Guias retangulares com $b=2 a$ apresentam largura de faixa 2:1. Este valor pode ser melhorado diminuindo-se a altura do guia em parte de sua secção transversal (COLLIN, 1992).

Neste exemplo o MEC será aplicado para a determinação da freqüência de corte dos dois primeiros modos que se propagam num guia de estrutura semelhante ao da figura 6.23. Algumas situações serão analisadas pela variação dos parâmetros $w / a$ e $s / b$, mantendo fixos $a$ e $b$.

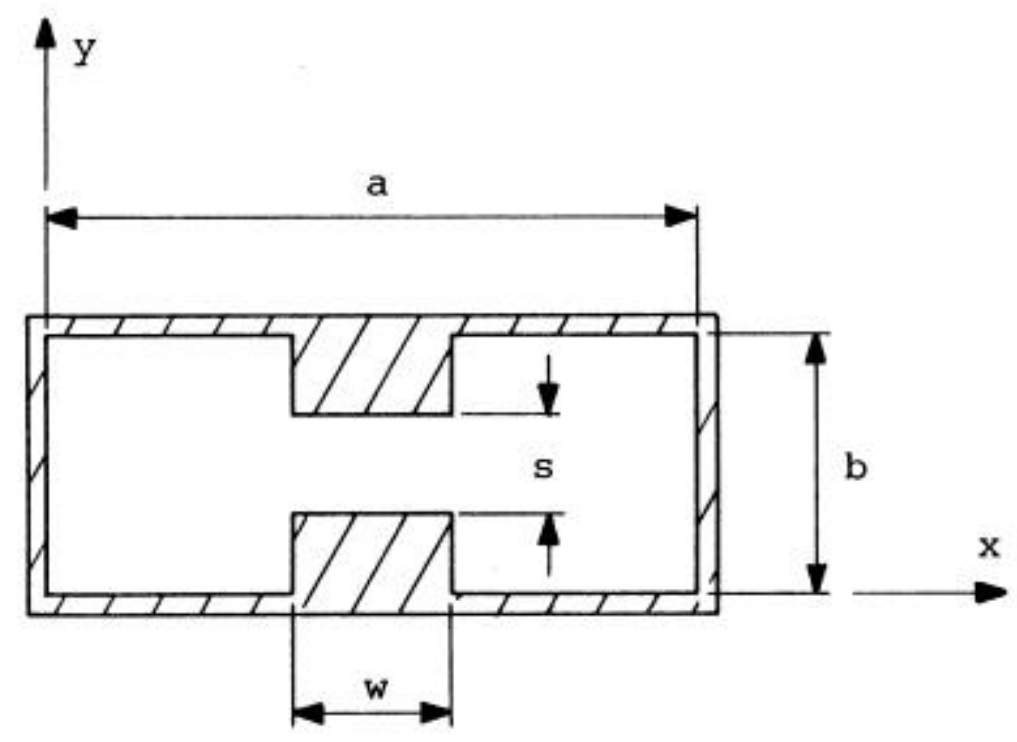

Figura 6.23: Geometria de um guia com ressalto duplo. 
Uma discretização típica está mostrada na figura 6.24 .

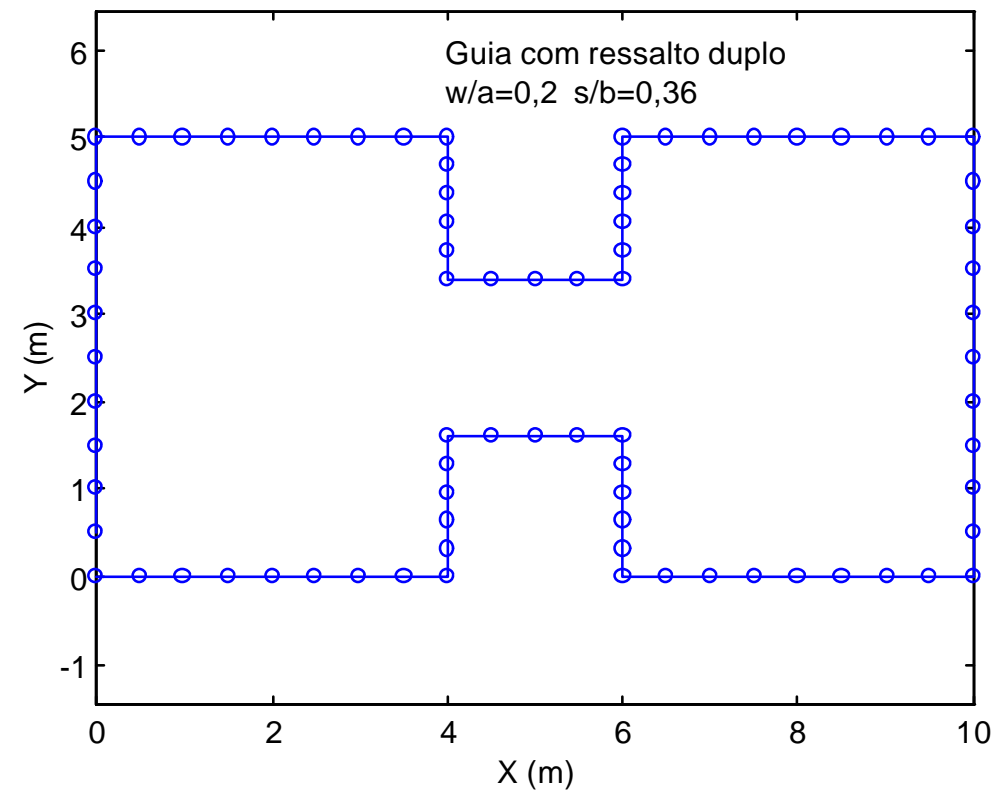

Figura 6.24: Geometria discretizada típica.

A obtenção dos valores dos comprimentos de onda de corte é feita de forma semelhante ao exemplo anterior. Indica-se que, em todos os elementos a condição de contorno é do tipo $\partial \mathrm{u} / \partial \mathrm{n}$ dado, não importando, por ora, seu valor. O objetivo é o de avaliar o determinante da matriz [A], indicativo dos modos de propagação. Duas situações estão mostradas na figura 6.25 com resultados reunidos na tabela 6.12.

TABELA 6.12: ALGUNS VALORES OBTIDOS DO GRÁFICO DA FIGURA 6.25

\begin{tabular}{cccc}
\hline GUIA & $\begin{array}{c}\boldsymbol{\lambda}_{\mathbf{c}} / \mathbf{a} \\
\text { Primeiro modo }\end{array}$ & $\begin{array}{c}\mathbf{k}_{\mathbf{c}}\left(\mathbf{m}^{-\mathbf{1}}\right) \\
\text { Primeiro modo }\end{array}$ & $\begin{array}{c}\mathbf{k}_{\mathbf{c}}\left(\mathbf{m}^{-\mathbf{1}}\right) \\
\text { Segundo modo }\end{array}$ \\
\hline $\mathrm{w} / \mathrm{a}=0,2 \mathrm{~s} / \mathrm{b}=0,36$ & 2,94 & 0,214 & 0,641 \\
$\mathrm{w} / \mathrm{a}=0,8 \mathrm{~s} / \mathrm{b}=0,1$ & 4,43 & 0,142 & 0,406 \\
\hline
\end{tabular}




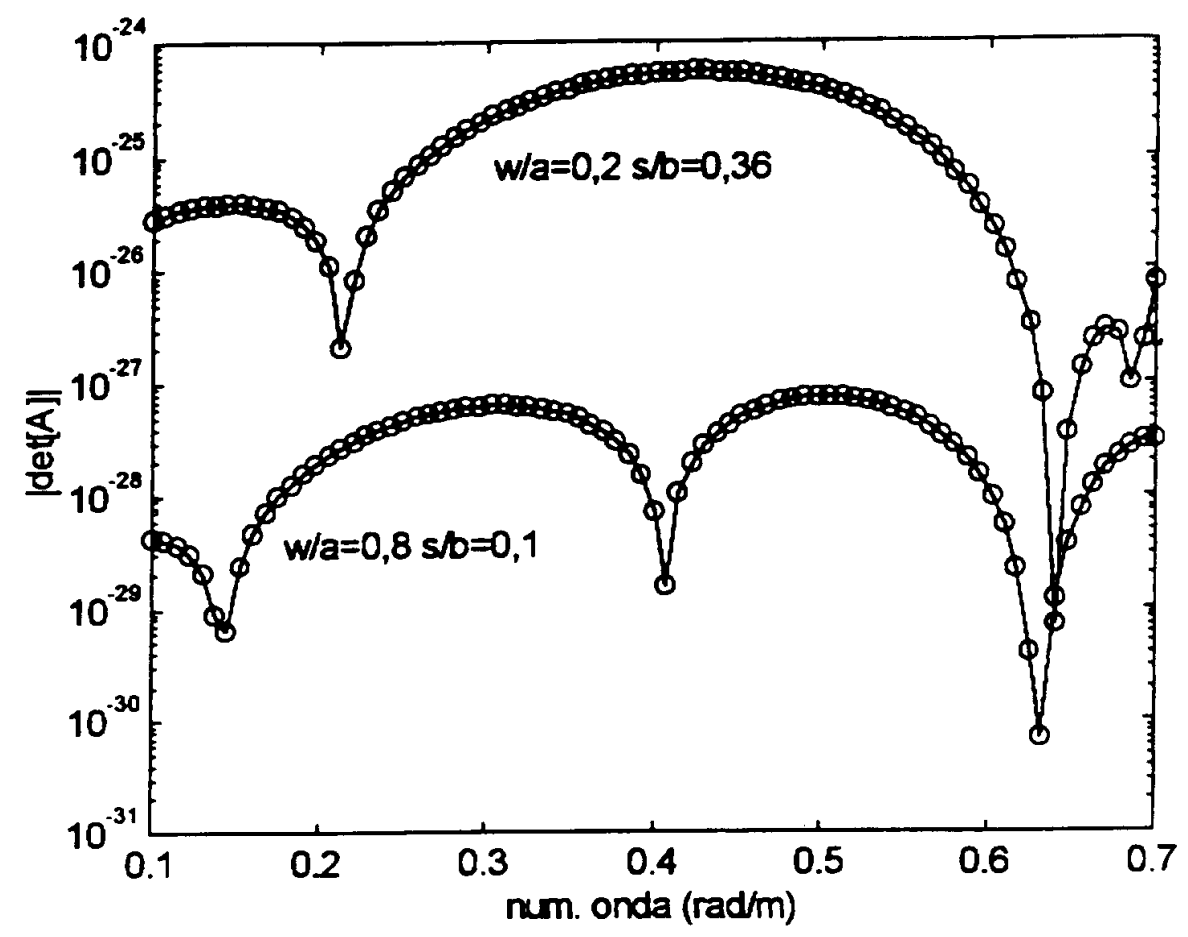

Figura 6.25: Guias de onda com ressalto duplo; $a=2 b$.

A literatura apresenta resultados para este tipo de guia (COLLIN, 1992), reproduzidos na figura 6.26. O procedimento numérico obteve resultados semelhantes, sumarizados no gráfico da figura 6.27 .

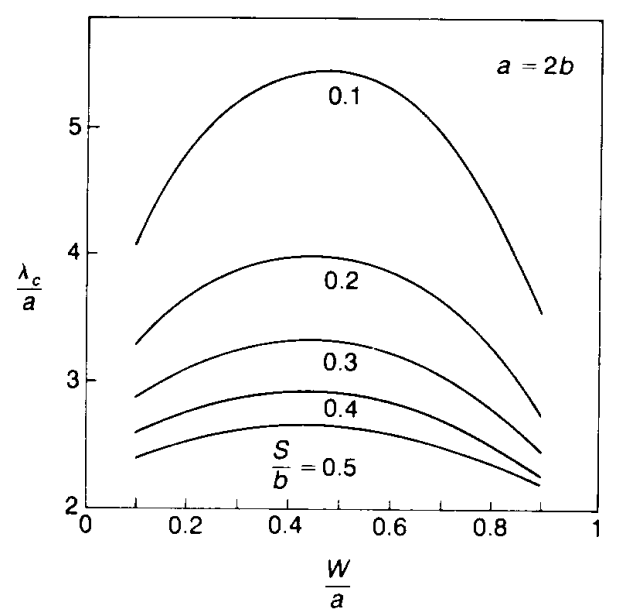

Figura 6.26: Comprimento de onda de corte para guias com ressalto duplo; $a=2 b$. (COLLIN, 1992). 


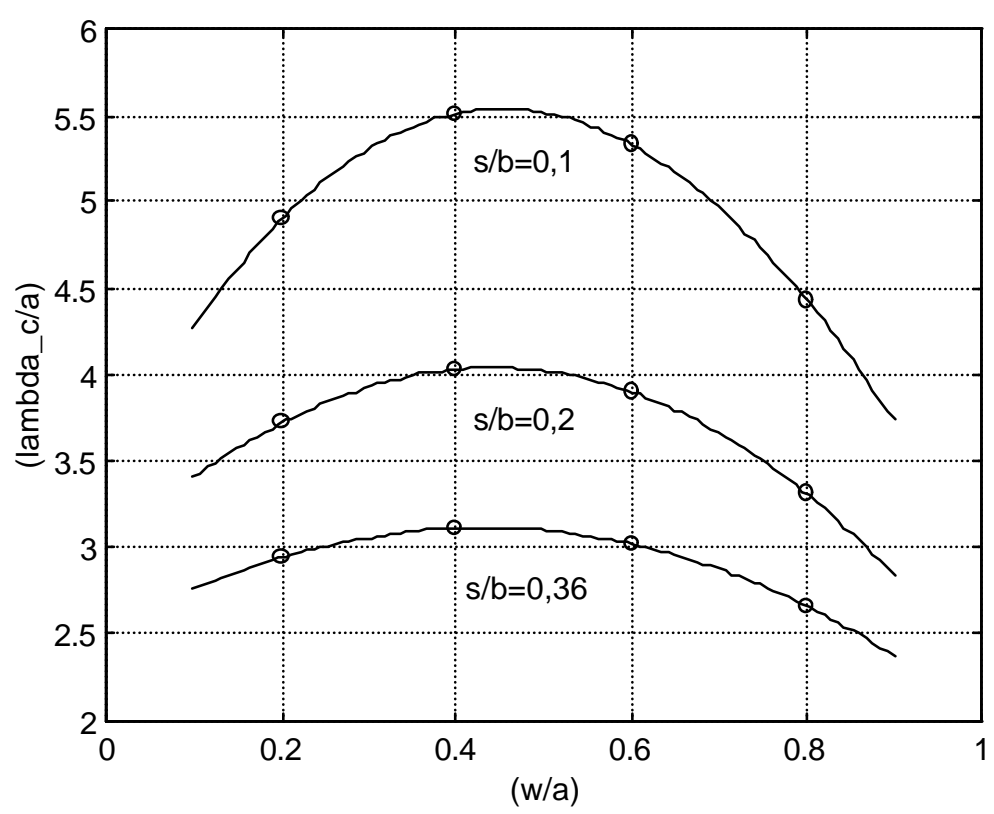

Figura 6.27: Comprimento de onda de corte do primeiro modo para guias com ressalto duplo, obtido pelo MEC; $a=2 b$.

O resultado da largura de faixa destes guias é visto na figura 6.28, sendo comparável aos já apresentados na literatura (BALANIS, 1989) e reproduzido na figura 6.29.

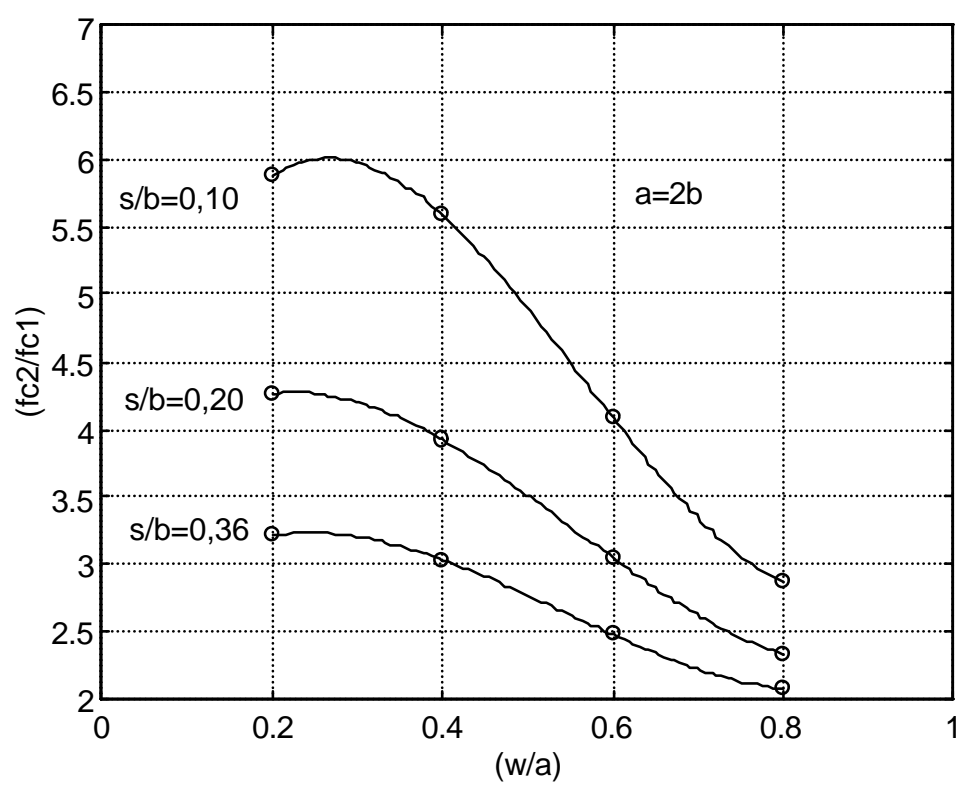

Figura 6.28: Largura de faixa de guias de onda com ressalto duplo. 


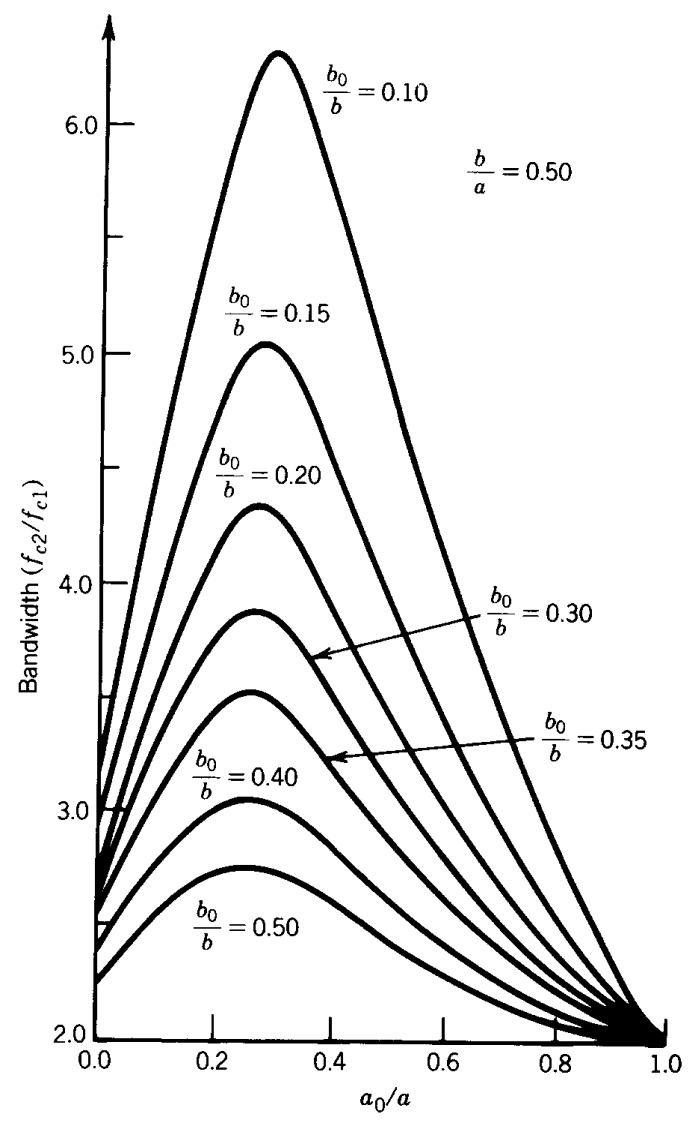

Figura 6.29: Largura de faixa de guias com ressalto duplo, referenciado em (BALANIS, 1989).

\subsection{Guia de onda parcialmente carregado}

Considere-se um guia de onda retangular parcialmente carregado por um dielétrico sem perdas $\left(\varepsilon_{\mathrm{d}} \neq 1, \mu_{\mathrm{d}}=1\right)$ e cuja interface é paralela ao plano xz (figura 6.30). Por causa da secção transversal não homogênea, esta estrutura não suporta mais modos TE ou TM puros, mas sim combinações de ambos, chamadas de modos híbridos. No caso da figura os modos híbridos possíveis são designados por $\mathrm{TE}^{\mathrm{y}}$ ou $\mathrm{TM}^{\mathrm{y}}$, sendo portanto, longitudinais à direção de propagação (BALANIS, 1989). A secção transversal do guia já discretizada é mostrada na figura 6.31 . 


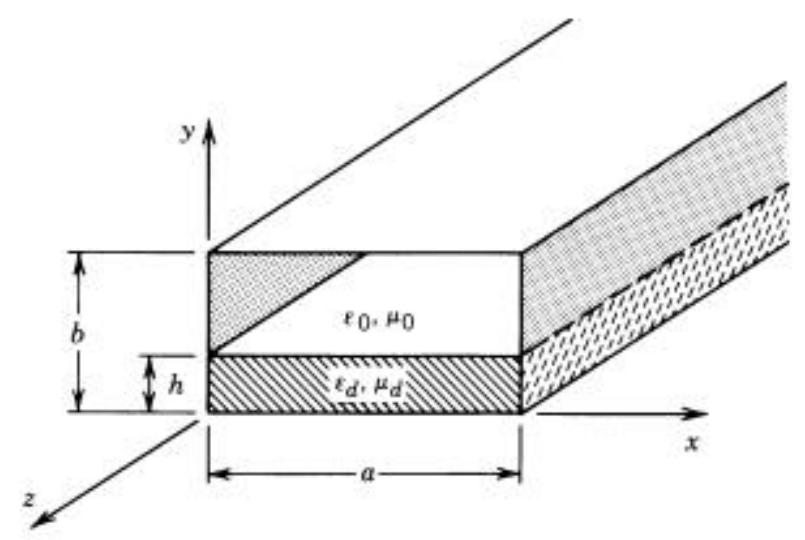

Figura 6.30: Guia parcialmente preenchido.

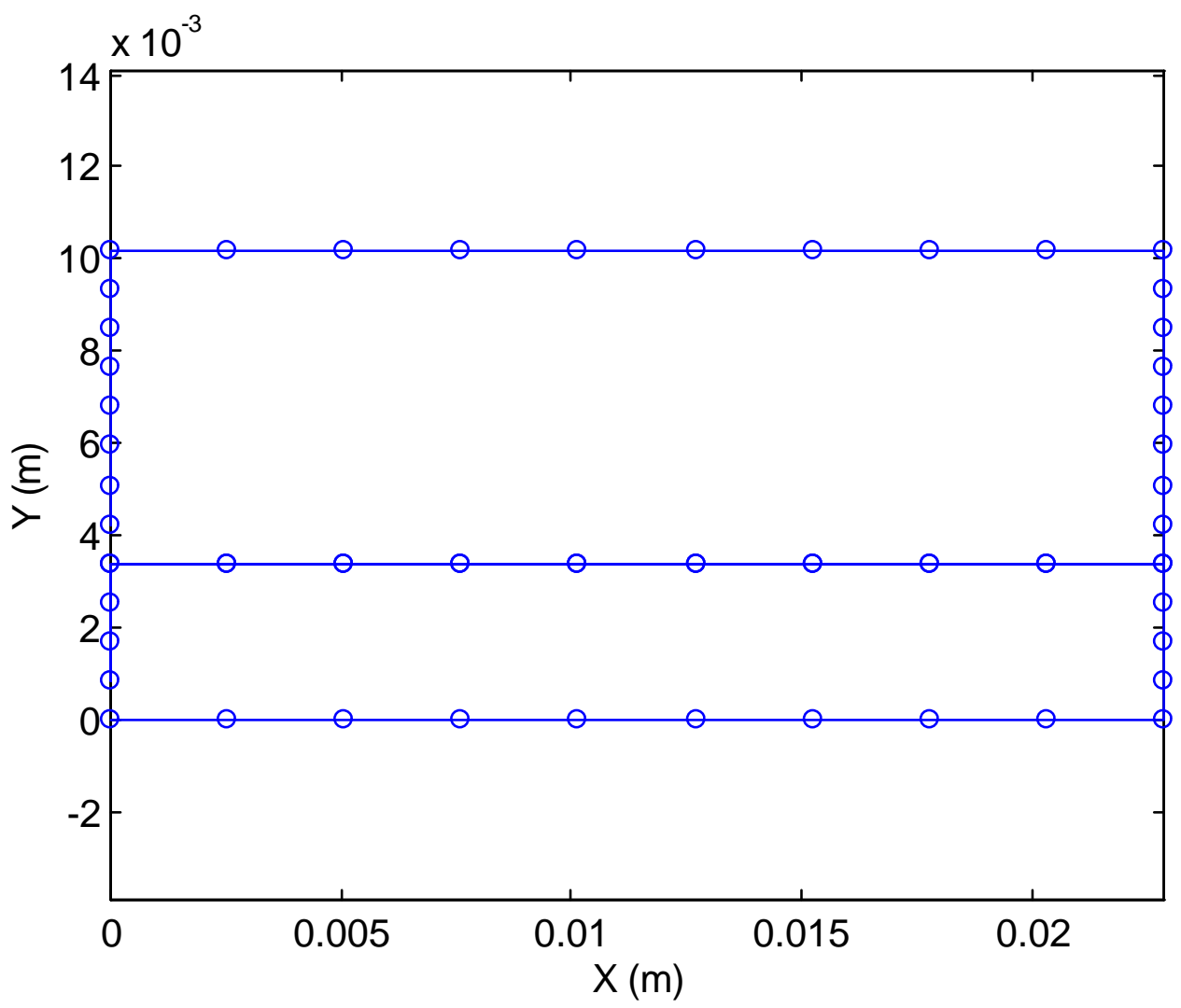

Figura 6.31: Discretização do guia

Ainda é possível escrever-se a equação de onda nos componentes x e y, referenciados ao componente longitudinal do campo, para cada meio material. $\mathrm{Na}$ interface dielétrico-ar os componentes longitudinais do campo precisam ter sua continuidade garantida. 
Este problema também pode ser avaliado pelo MEC. Para as dimensões a = 0,9" = 2,286 cm e $\mathrm{b}=0,4 "=1,016 \mathrm{~cm}$ do guia discretizado (figura 6.31), preenchido com material dielétrico de constante dielétrica $\varepsilon_{\mathrm{d}}=2,56$, altura $\mathrm{h}=\mathrm{b} / 3$, (BALANIS, 1989) calcula-se analiticamente a freqüência de corte do modo $\mathrm{TE}_{01}^{\mathrm{y}}$ em $12,62 \mathrm{GHz}$.

Da mesma forma estabelecida nas seções anteriores, o procedimento computacional pode aplicar condições de contorno homogêneas do tipo mistas (Dirichlet nas paredes horizontais e Neumann nas verticais) e proceder à varredura em freqüência. Neste caso não há imposição de valores na interface e a condição de continuidade é atendida na montagem da submatriz $\left[\mathrm{H}_{\text {interf }}\right.$ (Capítulo 4). O resultado da varredura está mostrado na figura 6.32 que indica frequiência de corte estimada em 12,63 GHz.
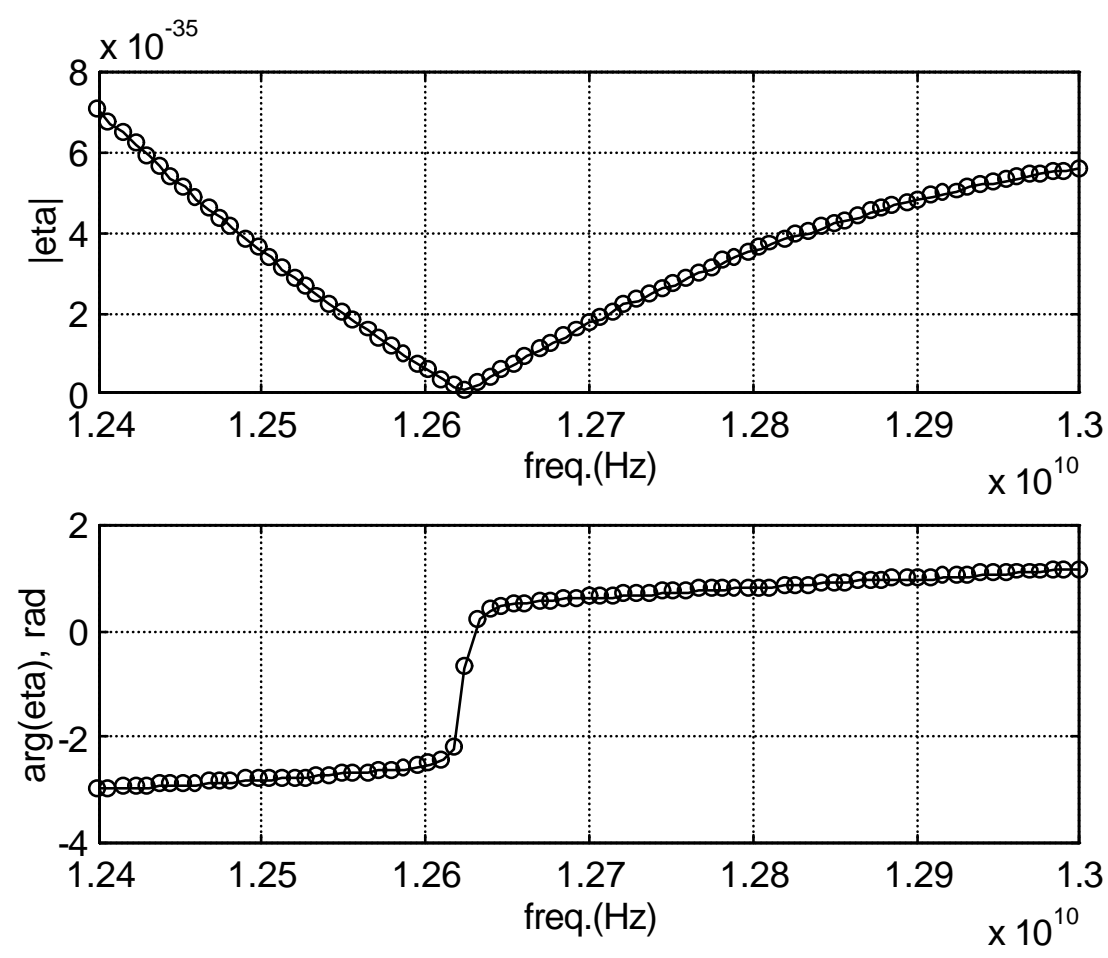

Figura 6.32: Varredura no guia parcialmente preenchido. 
Para se avaliar a sensibilidade desta frequiência de corte em relação ao valor da constante dielétrica, submeteu-se a mesma geometria discretizada à análise pelo MEC, variando-se $\varepsilon_{\mathrm{d}}$. Os resultados estão mostrados na figura 6.33 .

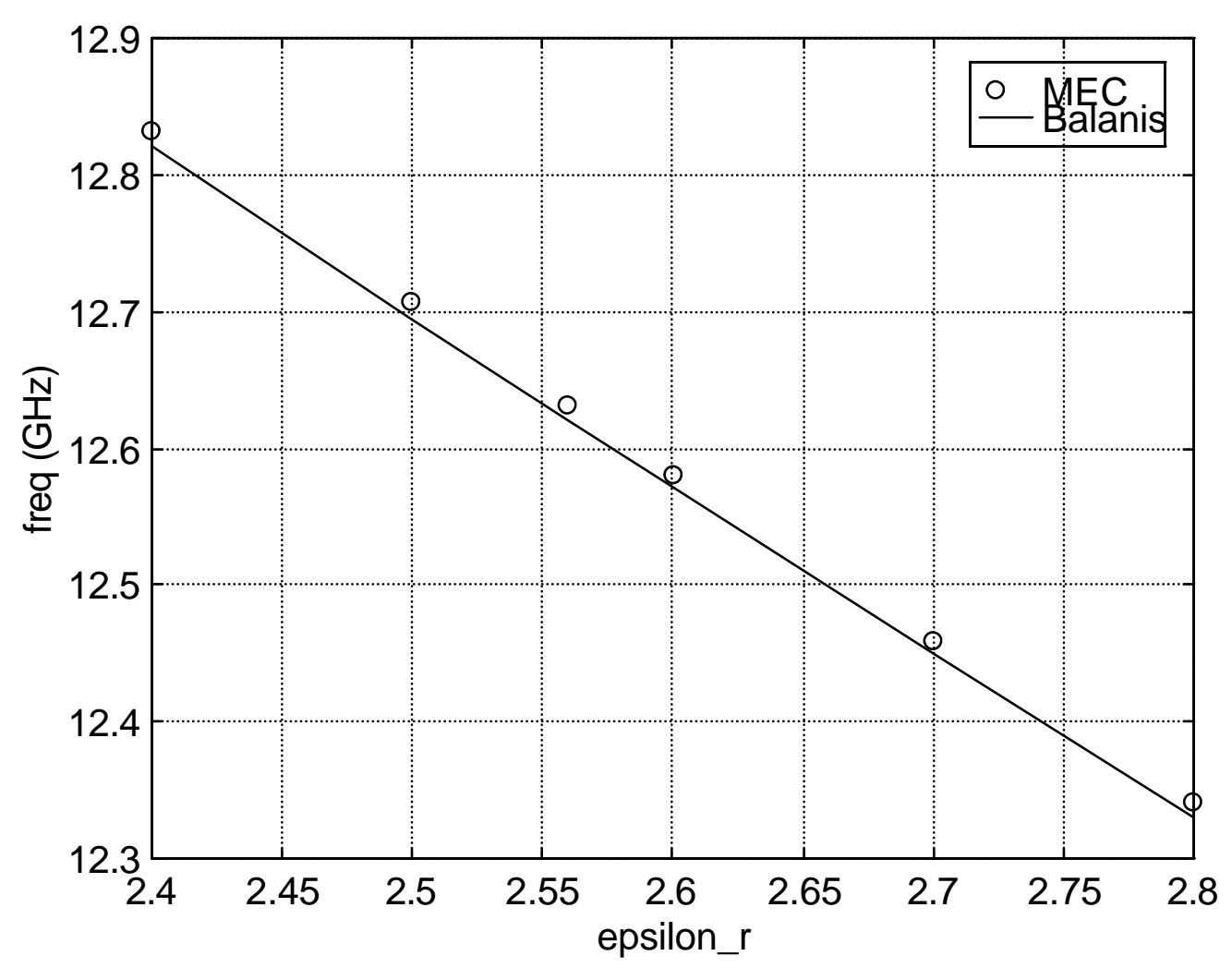

Figura 6.33: Frequiência de corte em função da constante dielétrica. 


\section{Conclusões}

Este trabalho realizou um estudo de aplicação do Método dos Elementos de Contorno à análise de propagação em estruturas guiadas, tendo sido desenvolvidas ferramentas computacionais nele baseadas.

As ferramentas foram validadas por comparação a casos conhecidos. A variação de parâmetros que as caracterizam ajudou a avaliar o desempenho do método. Seu principal atrativo é o de não precisar efetuar integrações de domínio nas estruturas estudadas. Isto permite uma economia muito grande em recursos computacionais, tendo por conseqüência aspectos positivos como: rapidez de processamento (apenas alguns segundos, em varreduras típicas com algumas dezenas de valores de freqüência); arquivos de entrada muito pequenos (somente alguns kilobytes em geometrias semelhantes às aqui estudadas) de fácil elaboração, até mesmo manualmente; possibilidade de estudo de geometrias mais complexas.

O método auxilia bastante na análise de estruturas guiadas porque permite o cálculo e a visualização da distribuição de campo no interior do domínio. A formulação escalar da equação de Helmholtz, como ponto de partida para a aplicação do método restringe a solução à sua componente longitudinal, enquanto as demais podem ser calculadas a partir da solução encontrada.

Impondo-se condições de contorno apropriadas, o MEC permite, ainda, atender situações de mais de um meio material.

No início do desenvolvimento do trabalho, optou-se por desenvolver ferramentas semelhantes às pretendidas, porém atendendo antes à equação de Laplace, o que teve por vantagem futura poder comparar os resultados através de um processo de limite. 
Foram atendidas as formulações constante e linear, tendo esta última apresentado sempre resultados superiores à primeira, quando o problema era regido pela equação de Laplace. Por outro lado, constatou-se que isto nem sempre ocorria no caso de Helmholtz, onde as implicações de natureza geométrica atuam de forma muito severa no cerne das integrações (e, portanto, na precisão numérica resultante, quando de sua implementação) nas quais o método se apóia.

Além do desenvolvimento das ferramentas computacionais e discussão dos resultados, este trabalho apresenta contribuições ao procurar avaliar de forma sistemática os passos necessários para a aplicação do MEC à equação de Helmholtz. Menciona-se, também, a obtenção da distribuição de campos a partir de excitação localizada e uma proposta de continuidade é a de obter esta distribuição a partir de excitação interna ao domínio, porém mantendo toda a formulação ainda no contorno.

Cita-se também o algoritmo desenvolvido para a localização de pontos em qualquer lugar do contorno. No decorrer do trabalho foram impostas algumas restrições adicionais, que podem ser levantadas futuramente, como, por exemplo, a suposição de que elementos em "buracos" não podem interfacear com outros domínios.

Considerações de natureza geométrica são muito importantes para sua aplicação, ocorrendo uma forte dependência entre distâncias geométricas e os resultados obtidos. Assim, dividindose em dois passos o seu processo de aplicação (ou seja, a) cálculo de variáveis no contorno e b) cálculo da função no domínio), os resultados numéricos têm de ser avaliados cuidadosamente em regiões muito próximas do contorno. Procedimentos de integração, distintos dos aqui tratados, podem ser investigados. 
Por estas razões, algumas propostas de continuidade de trabalho podem ser destacadas; a mais natural é a extensão da aplicação do método a problemas bidimensionais com algum tipo de simetria (cilíndrica, por exemplo), e, ainda, a problemas tridimensionais. Simetrias em valores de natureza elétrica ou física também poderão ser atendidos pelo uso de funções de Green adequadas; incluem-se aqui a situação de meios anisotrópicos e a possibilidade de poder discretizar apenas parte do contorno e não o seu todo.

O MEC representa uma alternativa vantajosa a outros métodos, desde que a equação estudada não tenha termos relacionados a fontes ou excitações independentes. Uma formulação mais recente, conhecida como Método de Dupla Reciprocidade (MDR), procura diminuir este inconveniente aproximando a função de excitação com funções de forma que tenham a mesma natureza do problema original (homogêneo). Neste caso a equação de Helmholtz poderia ser considerada uma extensão da equação de Poisson, mas por causa da natureza real (e não complexa) desta última, acredita-se que o MDR possa apenas auxiliar, porém com vantagem, a detecção de modos de ressonância nas estruturas de guiamento. 


\section{REFERÊNCIAS BIBLIOGRÁFICAS}

ABDULNOUR, J.; MARCHILDON, L. Boundary Elements and Analytic Expansions Applied to H-Plane Waveguide Junctions. IEEE Transactions on Microwave Theory and Techniques, v.42, n.6, p.1038-45, 1994.

ABRAMOWITZ, M.; STEGUN, I.A. Handbook of Mathematical Functions. New York, Dover Publications, 1965. p.358-60.

ARCIONI, P.; BRESSAN, M; PERREGRINI, L. On the Evaluation of the Double Surface Integrals Arising in the Application of the Boundary Integral Method to 3-d Problems. IEEE Transactions on Microwave Theory and Techniques, v.45, n. 3, p.436-9, 1997.

ATSUKI, K.; LI, K. Partial-Boundary Element Method for Analysis of Striplines with Arbitrary Cross-Sectional Dielectric in Multi-layered Media. IEEE Transactions on Microwave Theory and Techniques, v.43, n.5, p.1153-61, 1995.

BALAGANGADHAR, M.; SARKAR, T.K.; REJEB, J; BOIX, R. Solution of the General Helmholtz Equation in Homogeneously Filled Waveguides Using a Static Green's Function. IEEE Transactions on Microwave Theory and Techniques, v.46, n.3, p.302-7, 1998.

BALANIS, C.A. Advanced Engineering Electromagnetics. New York, John Wiley, 1989. p.457-61.

BREBBIA, C.A. The Boundary Element Method for Engineers. London, Pentech Press, 1978.

BREBBIA, C.A.; TELLES, J.C.F.; WROBEL, L.C. Boundary Element Techniques: Theory and Applications in Engineering. Berlin, Springer-Verlag, 1984.

BREBBIA, C.A.; DOMINGUEZ, J. Boundary Elements: An Introductory Course, 2nd. Edition. Southampton, Computational Mechanics Publications, 1992.

CHANG, T.; SZE, Y.C. Flexibility in the choice of Green's Function for the Boundary Element Method. IEEE Transactions on Microwave Theory and Techniques, v.42, n.10, p.1973-7, 1994.

CHANG, T.; LIN, Y. Quasi-Static Analysis of Shielded Microstripline by a Modified Boundary Element Method. IEEE Transactions on Microwave Theory and Techniques, v.41, n.4, p.729-31, 1993. 
CHANG, T.; TAN, C. Analysis of a Shielded Microstrip Line with Finite Metallization Thickness by the Boundary Element Method. IEEE Transactions on Microwave Theory and Techniques, v.38, n.8, p.1130-2, 1990. 
CHAO, J.C.; LIU, Y.J.; RIZZO, F.J.; MARTIN, P.A.; UDPA, L. Regularized Integral Equations and Curvilinear Boundary Elements for Electromagnetic Wave Scattering in Three Dimensions. IEEE Transactions on Antennas and Propagation, v.43, n.12, p.1416-22, 1995.

COLLIN, R.E. Foundations for Microwave Engineering, 2nd. Edition. New York, McGraw-Hill, 1992. p.205-7.

COLLIN, R.E. Field Theory of Guided Waves, 2nd. Edition. New York, IEEE Press, 1991. p.446-8.

DI NALLO, C.; FREZZA, F.; GALLI, A. Full-Wave Modal Analysis of Arbitrarily-Shaped Dielectric Waveguides Through an Efficient Boundary Element Method Formulation. IEEE Transactions on Microwave Theory and Techniques, v.43, n.12, p.2982-90, 1995.

DUDLEY, D.G. Mathematical Foundations for Electromagnetic Theory. New York, IEEE Press, 1994. p.45-9.

EIBERT, T.; HANSEN, V. 3-D FEM/BEM-Hybrid Approach Based on a General Formulation of Huygens' Priciple for Planar Layered Media. IEEE Transactions on Microwave Theory and Techniques, v.45, n.7, p.1105-12, 1997.

FONTGALLAND, G.; NAJID, A.; BAUDRAND, H.; GUGLIELMI, M. Application of Boundary Element Method to the Analysis of Cutoff Wavenumbers of Ridged Rectangular Waveguides and Ridged Circular Waveguides. In: 1997 SBMO/IEEE MTT-S INTERNATIONAL MICROWAVE AND OPTOELECTRONICS CONFERENCE, Natal, 1997. Proceedings. Natal, SBMO, 1997. p.171-5.

FRANCO, S.C.C.S. O Método dos Elementos de Contorno aplicado a problemas de campo regidos pela equação de Laplace. São Paulo, 1993. 162p. Dissertação (Mestrado) - Escola Politécnica, Universidade de São Paulo.

GIPSON, G.S. Boundary Element Fundamentals: Basic Concepts and Recent Developments in the Poisson Equation. Southampton, Computational Mechanics Publications, 1987. p.15-8.

GUPTA, K.; GARG, R.; BAHL, I.; BHARTIA, P. Microstrip Lines and Slotlines. Boston, Artech House, 1996. p. 1-6.

KAGAMI, S.; KUKAI, I. Application of the Boundary-Element Method to Electromagnetic Field Problems. IEEE Transactions on Microwave Theory and Techniques, v.32, n.4, p.455-61, 1984. 
KAGAWA, Y.; SUN, Y.; MAHMOOD, Z. Regular Boundary Integral Formulation for the Analysis of Open Dielectric/Optical Waveguides. IEEE Transactions on Microwave Theory and Techniques, v.44, n.8, p.1441-50, 1996.

KRAUS, J.D. Electromagnetics, 4th. Edition. New York, McGraw-Hill, 1992. p.155-8.

LIN, S.; LEE, C. A Full Wave Analysis of Microstrips by the Boundary Element Method. IEEE Transactions on Microwave Theory and Techniques, v.44, n.11, p.1977-83, 1996.

NOWAK, A.J.; NEVES, A.C. The Multiple Reciprocity Boundary Element Method. Southampton, Computational Mechanics Publications, 1994.

PARTRIDGE, P.W.; BREBBIA, C.A.; WROBEL, L.C. The Dual Reciprocity Boundary Element Method. Southampton, Computational Mechanics Publications, 1992.

PRESS, W.H.; TEUKOLSKY, S.A.; VETTERLING, W.T.; FLANNERY, B.P.

Numerical Recipes in FORTRAN: The Art of Scientific Computing, 2nd. Edition. Cambridge, Cambridge University Press, 1992.

ROZZI, T.; PIERANTONI, L; FARINA, M. Eigenvalue Approach to the Efficient Determination of the Hybrid and Complex Spectrum of Inhomogeneous, Closed Waveguide. IEEE Transactions on Microwave Theory and Techniques, v.45, n.3, p.345-53, 1997.

SAUVIAC, B.; GUILLOT, P.; BAUDRAND, H. Rigorous Analysis of Shielded Cylindrical Dielectric Resonators by Diadic Green's Functions. IEEE Transactions on Microwave Theory and Techniques, v.42, n.8, p.1484-93, 1994.

SHEN, J. Computational Electromagnetics using Boundary Elemets: Advances in Modelling Eddy Currents. Southampton, Computational Mechanics Publications, 1995.

SHEN, J.; STERZ, O. A Mixed Galerkin and Collocation Approach for Treating Edge and Corner Problems in the BEM. IEEE Transactions on Magnetics, v.34, n.5, p.3296-9, 1998.

SILVESTER, P.P.; FERRARI, R.L. Finite Elements for Electrical Engineers, 3rd. Edition. Cambridge, Cambridge University Press, 1996. p.459-60.

SMIRNOV, V. Cours de Mathématiques Supérieures. Moscou, Éditions Mir, 1970. v.2. p.216-9.

SWAMINATHAN, M.; ARVAS, E.; SARKAR, T.K.; DJORDJEVIC, A.R. Computation of Cutoff Wavenumbers of TE and TM Modes in Waveguides of Arbitrary Cross Sections 
Using a Surface Integral Formulation. IEEE Transactions on Microwave Theory and Techniques, v.38, n.2, p.154-9, 1990.

WANG, H.; WU, K.; LITVA, J. The Higher Order modal Characteristics of CircularRectangular Coaxial Waveguides. IEEE Transactions on Microwave Theory and Techniques, v.45, n.3, p.414-9, 1997.

WANG, G.; PAN, G; GILBERT, B.K. A Hybrid Wavelet Expansion and Boundary Element Analysis for Multiconductor Transmission Lines in Multilayered Dielectric Media. IEEE Transactions on Microwave Theory and Techniques, v.43, n.3, p.664-75, 1995.

WYLIE, C.R.; BARRETT, L.C. Advanced Engineering Mathematics, 5th. Edition.

Singapore, McGraw-Hill International Editions, 1982. p.589-91. 